
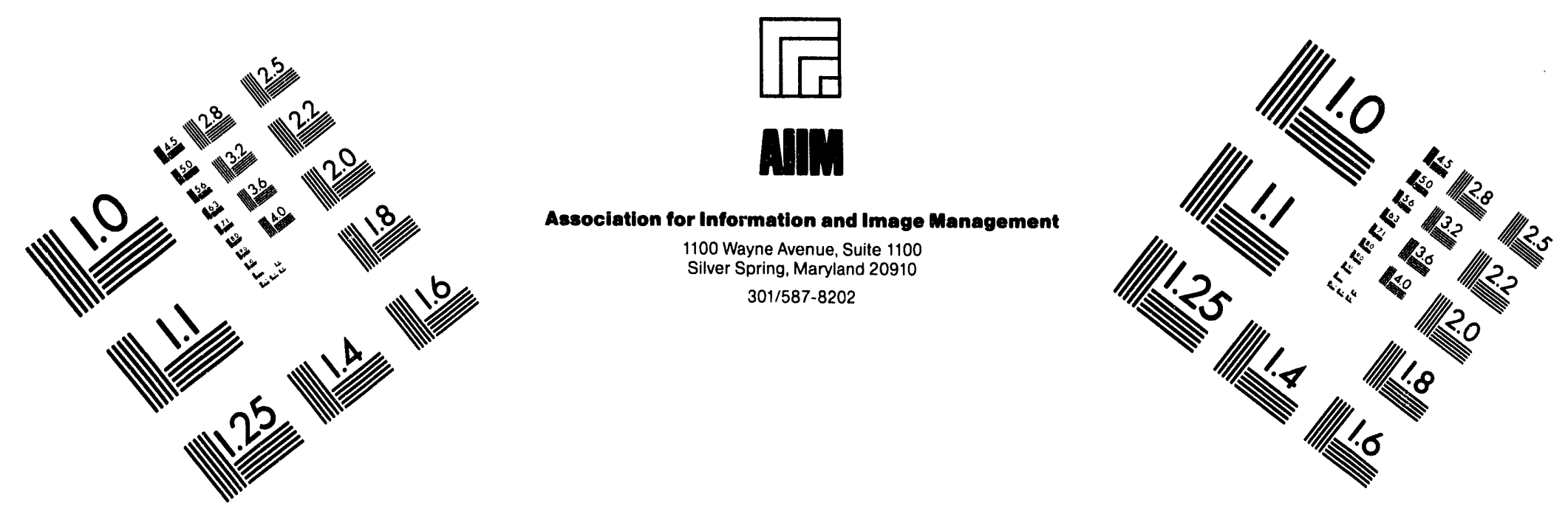

Centimeter

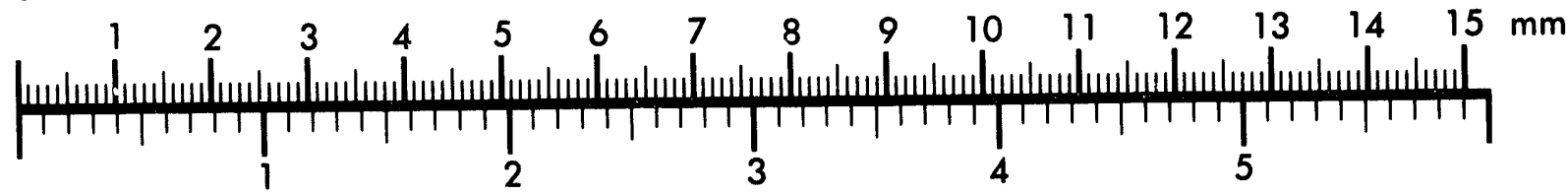

Inches
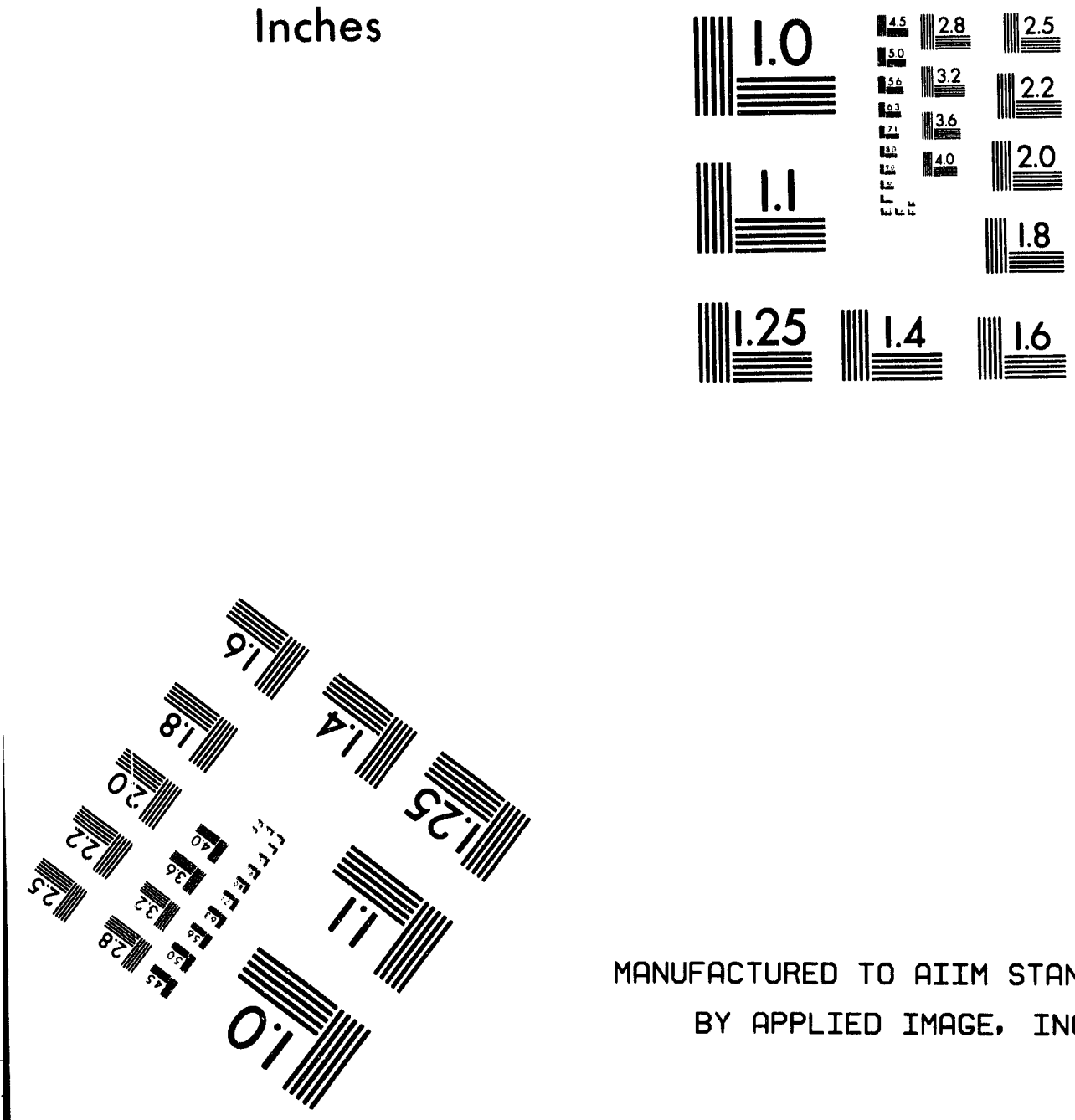

MANUFACTURED TO AIIM STANDARDS

BY APPLIED IMAGE, INC.

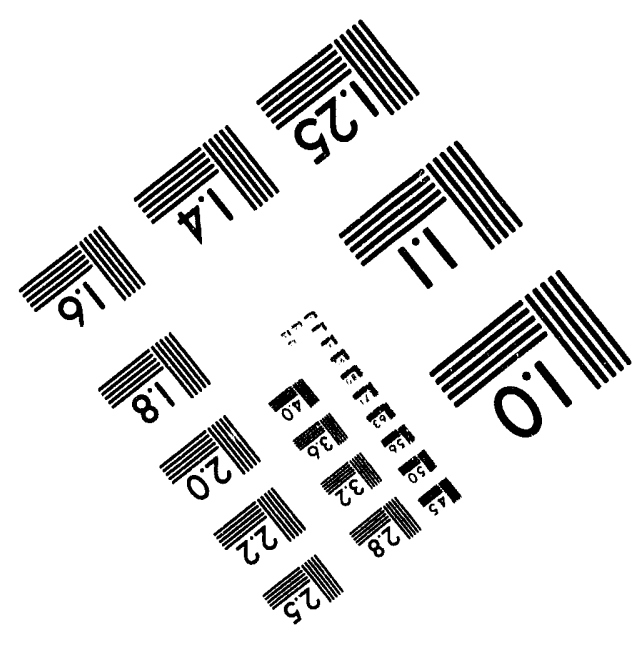



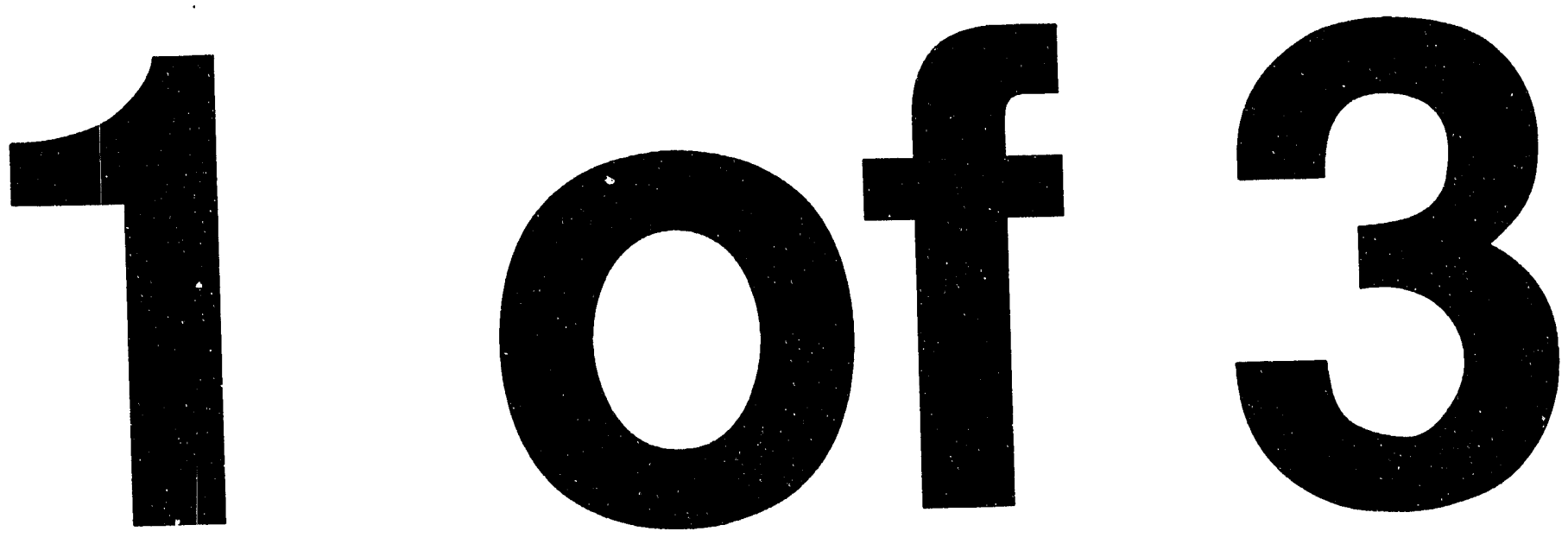


\title{
The Production of Chemicals from Food Processing \\ Wastes Using a Novel Fermenter Separator
}

\author{
Annual Progress Report \\ March 15, 1994
}

for Period January 1993 through March 1994

\section{C. Dale, K.V. Venkatesh, H. Choi, L. Salicetti-Piazza N. Borgos-Rubio, M. R. Okos, P. C. Wankat Purdue University West Lafayette, Indiana}

March 15, 1994

Prepared for

The U.S. Department of Energy

Agreement No. DE-FG02-85-CE40772

Notice: This report was prepared as an account of work sponsored by the United States Government. Neither the United States nor the Department of Energy, nor any of their employees, makes any warranty, express or implied, or assumes any legal liability or responsibility for the accuracy, completeness, or usefulness of any information, apparatus, product or process disclosed or represents that its use would not infringe privately-owned rights. 


\section{Table of Contents}

\section{Project Abstract}

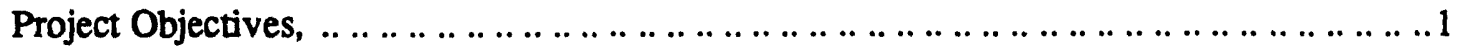

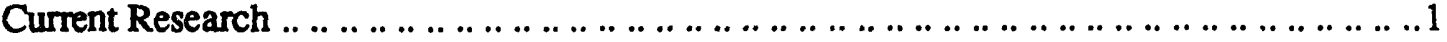

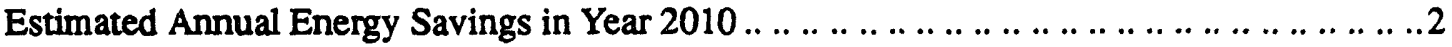

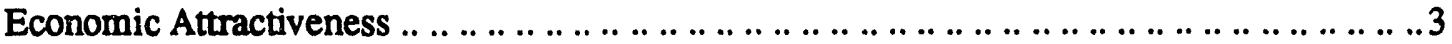

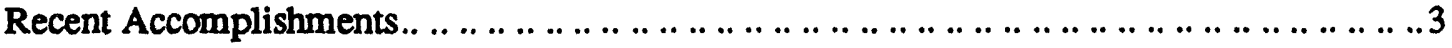

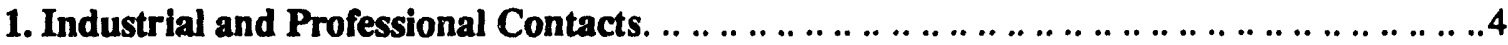

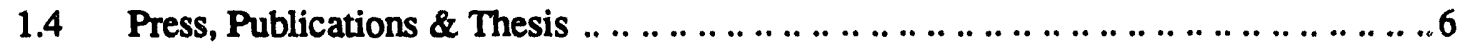

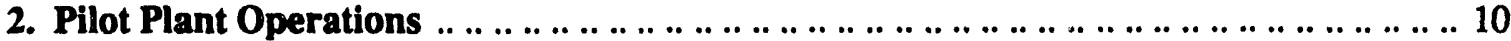

$2.17,500$ Liter Immobilized Cell Reactor Separator (ICRS) at

Permeate Refining Inc., Hopkinton, IA .. .. ... . . . . . . . . . . . . . . . . . . . . . . . . . . . . . . 10

a) Design \& Construction ICRS/Absorber unit ... .................... ... 10

b) Installation and Operation.................................... 11

2.3 Effluent Handling at PRI site ........................................... 11

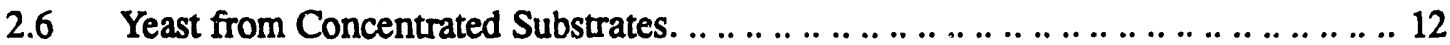

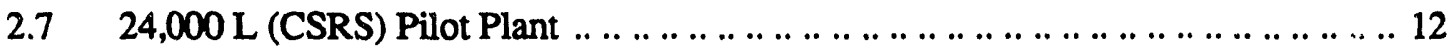

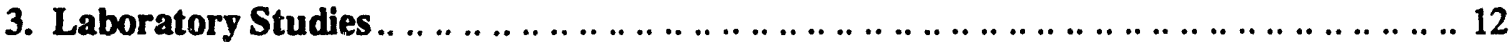

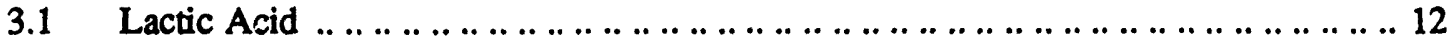

3.3 Anti-fungal compounds from Immobilized Plant tissue culture ... ............... 13

3.4 Production of Yeast from High BOD waste water .......................... . . 13

3.5 Production of Gluconic Acid from Waste Glucose . . . .......................... 14

3.6 Simultaneous Saccharification and Fermentation (SSF)

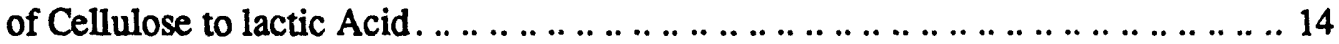

3.7 Simultaneous Saccharification and Fermentation (SSF) of Starch to ethanol ..................................................... 14

3.8 Production of yeast streams from concentrated syrup streams .. ... ... ........... 15

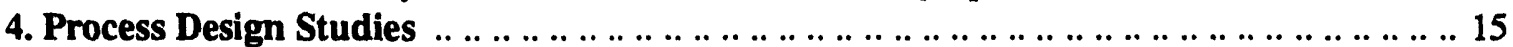

4.1 FOODS Development and Starch. ........................................... 15 Appendices

1.2 Papers Lennoned

1 Osmotic Inhibition of Free and Immobilized K. marxianus Anaerobic Growth and Ethanol Productivity in Whey Permeate Concentrate. M.C. Dale, A. Eager \& M.R. Okos.

2. Ethanol Production from Whey via an Immobilized Cell Reactor-Separator. M.Clark Dale.

3. Ethanol from Concentrated Sucrose and Molasses Solutions using S. Pombe in an Immobilized Cell Reactor-Separator. M.C. Dale, N. Perrin and M. Okos.

4. Kinetic Model of Growth and Lactic Acid Production from Lactose by Lactobacillus bulgaricus. K.V. Venkatesh, M.R. Okos and P.C. Wankat.

2.1 DOE/Permeate Refining - 7,500L Pilot Plant

2.1C Design of SAED - resmared

2.3 Effluent Handling at PRI

2.6C 200L Yeast Pilot Plant at Purdue

2.7 CSRS Pilot Plant

3.1 Lactic Acid Production

3.3 Production of High Value Products from Immobilized Plant Cell Tissue Cultures

3.5a Acetic Acid

3.5b Gluconic Acid

3.7 Evaluation of Simultaneous Saccharification and Fermentation of Com or Potato Starch Streams Using the CSRS

3.8 Production of Yeast from Concentrated Syrup Streams

4.1 FOODS 


\section{Project Objectives:}

The basic objective of this project is to convert waste screams from the food processing industry (and eventually agricultural and municipal wastes) to usable fuels and chemicals using novel bioreactors. These bioreactors should allow economical utilization of waste streams (whey, waste sugars, waste starch, bottling wastes, candy wastes, molasses, and cellulosic wastes) by the production of ethanol, acetone/butanol, organic acids (acetic, lactic, and gluconic), yeast (from both high and low level substrates), diacetyl flavor, and antifungal compounds. Continuous processes incorporating various processing improvements such as simultaneous product separation and immobilized cells are being developed to allow commercial scale utilization of waste streams. The production of ethanol by a continuous reactor-separator is the process closest to commercialization, with a 7,500 liter pilot plant presently sited at an Iowa site to convert whey lactose to ethanol.

\section{Current Research:}

1. Pilot (7,500 liter) scale conversion of whey lactose to ethanol in an Immobilized Cell Reactor Separator. This reactor was constructed during 1992 , installed by $6 / 93$, and is currently undergoing production trials. Feed handling, reactor seeding, start-up, shutdown, clean-up, and sterilization procedures are being developed at the plant site.

2. Mathematical, lab and pilot studies of an Solvent Absorption-Extractive Distillation (SAED) process for the low energy recovery of anhydrous ethanol from ICRS type reactors.

3. Lab and pilot (200 liter) studies on production of yeast from highly concentrated whey and syrup streams. It is hoped this process will allow the elimination of centrifugal harvesting of the yeast crop as well as reducing the capital and energy costs associated with yeast production.

4. Lab scale studies on BOD reduction of distillery wastes and other high BOD waste water streams using a dual culture of yeasts in a new bioreactor are underway. It is hoped that this reactor will allow the conversion of BOD into a salable feed yeast stream. One graduate student (L. Saliceti - PHD in Chemical Engineering) is doing fundamental studies on cell growth kinetics on multiple substrates, while lab scale trials on actual and simulated wastes is being performed by Dale and Moehlman

5. Lab scale studies on lactic acid production from whey lactose. One graduate student (Nelson Borges - PhD Chemical Eng) is following up on a previous student's (K. Venkatesh - $\mathrm{PhD}$ Chemical Eng) work on design and modeling of lactic acid production. Membrane extraction is being evaluated as a method of purifying the LA from the fermentation broth.

6. No-cook conversion of waste starch/corn grits to ethanol in a continuous stirred reactor separator. Eliminating the cooking process from the starch conversion process can save a significant fraction of the energy used in ethanol production. We have established the feasibility of a 'no-cook' process on the lab scale using two different systematic techniques.

7. Lab scale conversion of high brix candy wastes to ethanol in a stirred reactor separator.

8. Lab scale conversion of xylose to ethanol with various strains of yeast.

9. Lab scale conversion of cellulosic materials to fermentable sugars. A reactor involving simultaneous enzymatic conversion of cellulose to glucose to ethanol will be operated. We are beginning a cooperation with Xylan Inc. who have developed a pretreatment process for wood 
chips/corn stalks/straw/waste paper.

10. Lab scale conversion of waste glucose to gluconic acid in a continuous immobilized cell reactor.

11. Plant cell culture conversion of waste glucose to antifungal agents. Enhanced production of the desired product is being attained by immobilizing, permealizing, and eliciting the generation of the antifungal compound from immobilized plant cells.

12. Development of a food processing unit operations computer modeling package for the design and economic comparisons of various food, fermentation, and waste stream utilization processes. This package, termed FOODS, has been worked on for the last several years and is used in teaching food process engineering at Purdue.

\section{Estimated Annual Energy Savings in Year 2010.}

Energy savings will accrue from

1. CRS for ethanol production from food wastes - If we assume that $40 \%$ of the high sugar/ starch food wastes produced in 2010 are converted to ethanol - with the total fermentable food processing waste volume estimated at $2.85 \mathrm{e} 10 \# / \mathrm{yr}, 0.88 \mathrm{e} 9$ gallons of ethanol could be produced.

a) Fuel energy created @ 84,000 BTU/gal -----> 7.4e13 BTU/yr

b) Energy saved over conventional ethanol tech. ----->1.9e13 BTU/yr

c) Energy saved from not treating these sugars as waste @ $1 \mathrm{KW}-\mathrm{h} / 1$ \# BOD -----> 4.0e13 BTU/yr

2. utilization of the CRS lower energy technology for conversion of corn/starch to ethanol - if $20 \%$ of ethanol producers switch or upgrade from current energy usage of 40-60,000 BTU/ gal to the Purdue technology with an estimated energy usage of $28,500 \mathrm{BTU} / \mathrm{gal}$., and $50 \%$ of the new add-on ethanol capacity expected by the year 2010 (Current ethanol production is out 0.95 billion gal/yr, while Year 2010 is conservatively estimated at 1.96 billion gal/yr (Eth. Alert, Neb. Energy Office, Aug, 1992), so .19 billion gal due to upgrade, .51 billion gal due to new capacity using CRS technology leads to $0.7 \mathrm{e} 9 \mathrm{gal}$. ethanol from corn/starch in year 2010 .

a) Fuel energy created @ 84,000 BTU/gal --.--> 5.8e13 BTU/yr

b) Energy savings over conventional technology -.--> 1.5e13 BTU/yr

3. utilization of the CRS lower energy technology for the conversion of waste paper to ethanol Assuming $20 \%$ of waste paper is used as a feed stock at .35\# ethanol/\# paper, and 1.5e11\# paper per year is produced (Opportunities for Energy form MSW, Goodman and Walter, 1990) $1.6 \mathrm{e} 9$ gallons of ethanol will be produced.

a) Fuel energy crated @ $84 \mathrm{MBTU} / \mathrm{gal}$-..-->1.3e14 BTU/yr

b) Energy savings over conv. tech. ----->3.52e13BTU/yr

c) Landfill volume reduced @ 15\#/ft3 -..--> 2e9 ft3/yr

4. Utilization of biomass crops/municipal yard wastes for ethanol w/CRS technology - Assuming 18 billion \#/yr are used in ethanol production with .3\# ethanol per pound biomass -..--> $0.5 \mathrm{e} 9 \mathrm{billion} \mathrm{gal} / \mathrm{yr}$.

a) Fuel energy created @ 84 MBTU/gal -...-> 4.2e13 BTU/yr

b) Energy savings over conv. tech. -..-->1.1e13 BTU/yr

c) landfill space for $50 \%$ which are MYW @ $5 \# / \mathrm{ft} 3 \ldots . . .->1.8 \mathrm{e} 9 \mathrm{ft} 3$ 
5. utilization of our low energy technology for yeast production from high level waste sugar streams and other sugar sources- assuming 30\% of yeast produced in 2010 (10 million\#/yr.) is produced by Purdue-DOE technology. This results in the production of $4.5 \mathrm{e}$ \# yr of yeast product.

a) Energy savings over conventional technology (0.3 from $1.6 \mathrm{KW}-\mathrm{h} / \#)----->2.0 \mathrm{e} 8 \mathrm{BTU} /$ yr

b) Energy saved from not treating these sugars as waste @ $1 \mathrm{KW}-\mathrm{h} / 1$ \# BOD ...--> 3.5e11 BTU/yr

6. Utilization of Purdue-DOE technology for yeast production form low level BOD waste water from food processing plants -- assuming a waste water discharge of 100,000 gal/day @ 20,000 ppm BOD reduced to $5,00 \mathrm{ppm}$ from 500 plants nationwide leads to the elimination of 4.6e9 \# of BOD per year in the year 2010.

a) Energy savings over treating these wastes @ $1 \mathrm{KW}-\mathrm{h} / \# \mathrm{BOD}----->1.6 \mathrm{e} 13 \mathrm{BTU} / \mathrm{yr}$

b) Production of $1.15 \mathrm{e} 9$ \# of fodder yeast worth $\$ 0.05 / \#$ or $\$ 54,750$ income per plant.

7. Utilization of Purdue-DOE extractive fermentation for lactic acid from waste sugars. Energy use in lactic acid is largely due to purification costs. We are attempting to reduce these costs with an extractive system, however, we are not far enough along to begin to quantify the energy savings.

\section{Economic Attractiveness}

The Purdue ethanol process offers a lower capital method for ethanol production. Capital costs for an add-on type arrangement for a waste sugar generator to add an ethanol production unit to his facility are estimated at only $\$ 1.00$ per annual gallon at the 250,000 gal/yr. scale. Labor and operating costs are also substantially reduced. Thus we feel that the Purdue process may make it feasible to have many smaller ethanol facilities rather than be forced to the $10-40$ million gal/yr. scale by economic of scale which is the current condition for batch ethanol production from corn/starcli streams.

Preliminary design calculations on yeast production from both high and low level substrate streams are also encouraging. Again, the movement towards a continuous process, the reduction of energy needs, and the reductions in capital cost should make the Purdue yeast process very competitive for yeast production. We feel that there is a good possibility the use of centrifugal yeast harvesters can be eliminated for the production of yeast from high level substrates, resulting in a substantial reduction in plant complexity and cost. We determined an ROI of $90 \%$ for a process producing 1.5 tons/day of dried mineral yeast from concentrated whey permeate.

\section{Recent Accomplishments}

Accomplishments during 1993 include 1) installation and start-up of a 7,500 liter ICRS for ethanol production at an industrial site in Iowa, 2) Donation and installation of a 200 liter yeast pilot plant to the project from Kenyon Enterprises, 3) Modeling and testing of a low energy system for recovery of ethanol from vapor streams using a solvent absorption/extractive distillation system, 4) Simultaneous saccharification/fermentation of raw corn grits and starch in a in a stirred reactor/ separator, 6) Testing of the ability of a 'koji' process to ferment raw corn grits in a 'no-cook' process, 7) Modeling of lactic acid bacteria growth and productivity as a function of $\mathrm{pH}$ and LA concentra- 
tion, 8) Modeling and demonstration of an extractive fermentation for lactic acid production, 9)Determination of the effect of osmotic inhibition on aerobic yeast production, 10) Our group has reported our findings in a number of presentations and publications during 1993. These include:

1. Dale, M.C., A. Eagger and M. Okos. 1993. "Osmolality Inhibition of Aerobic K fragilis Growth and Productivity in Batch and Immobilized Cell Reactors." Process Biochemistry. In Press

2. Dale, M.C., 1993. A Low Effluent Ethanol Process For Corn, Starch and Biomass. Governor's Ethanol Coalition, Peoria, IL, November.

3. Salicetti, L., M. Okos \& P.C. Wankat. 1993. "Modeling of Lactose Assimilation by the Yeast, K. marxianus". Conf. on Environment, Purdue Univ., August.

4. Dale, M. Clark. 1993. Ethanol Production from Whey. AIChE ChAPTER One. 7:2,22-28.

5. Dale, M.C., N. Perrin, and M. Okos. 1993. "Production of Ethanol from Concentrated Sucrose and Molasses Solution Using S. Pombe in an Immobilized Cell Reactor Separator." In Press. Proceeding of Conference on Food Engineering.

6. Dale, M.C. 1993. Production of Yeast from Concentrated Whey Permeate using a Immobilized Cell Reactor. Final Report to Kenyon/WMMB. February.

7. Dale, M.C. 1993. "The Solvent Absorption/Extractive Distillation (SAED) Process for Ethanol Recovery from Gas Streams" AICHE COFE meetings, February, Chicago

8. Dale, M.C., S. Michel, and M. Okos. 1993. "A No-Cook Process for the conversion of Starch to Sugars for Ethanol Production" AICHE COFE meetings, February, Chicago,IL

9. Dale, M.C. 1992. "Design and Construction of a 7,500 Liter Immobilized Cell Reactor Separator for Ethanol Production from Whey Permeate". AICHE paper 161a Miami. November.

10. Saliceti, L., M.C. Dale, M. Moelhman, M. Okos, and P. Wankat. 1992. "Free and Immobilized Yeast for BOD Reduction in Dairy Waste Streams". AICHE Annual Meeting, Paper 105k, Miami. November.

11. Dale, M.C. 1992. "Production of Ethanol, Lactic Acid or SCP from Biomass". Biobased Products Expo '92. St. Louis. October.

12. Lee, W.S., M. Okos, and M. Dale. 1992. "Production of a Butter Flavor Compound (Diacetyl) with Simultaneous Product Separation". AICHE paper 8d. Minneapolis, MN. August.

13. Venkatesh, K.V., M.R. Okos and P.C. Wankat. 1992. "Kinetic Model for Lactic Acid Production from Cellulose by Simultaneous Fermentation and Saccharification." AIChE summer meeting, Minneapolis, MN, August,.

\section{Industrial and Professional Contacts}

Industrial sponsors for our project include:

Permeate Refining Inc. (PRI) PRI is a small comnany in the business of converting food waste streams such as waste starch, whey permeate, candy wastes, and the like to ethanol. Permeate Refining's operational vice-president, Bob Lehman, is also the president of Captain Clean, a company involved with industrial cleaning of food plants such as Cargill, ADM, starch plants, and others. Thus Mr. Lehman is often asked to clean out tanks and silos full of out of specification starch, 
flour, or sugars. With his new ethanol plant in Hopkinton, PRI is able to take these waste sugars and convert them to ethanol. The plant consists of a batch ethanol plant which was purchased used from a bankrupt ethanol operation. There are over fifteen 15,000 gallon fermenters in the plant along with a distillation and dehydration system. The plant was completed in late 1992, with a plant expansion currently in progress to approximately double the floor-space of the plant. Mr. Lehman has donated considerable time, effort, floor space, utilities, plant labor, and raw materials to our ICRS pilot plant project. His in-kind contributions during 1992-3 are valued at approximately $\$ 200,000$.

Merrill Iron and Steel- Merrill I\&S president is Roger Henner. Mr. Henner designed and built the ICRS/Absorber from rough prints supplied by Dr. Dale of Purdue. He designed the doors, door fasteners, spraying lid, and the structural integrity of the unified ICRS/ABS. Mr. Henner agreed to build the ICRS/ABS on a 'at-cost' basis. Mr. Henner also cooperated with Kenyon Enterprises in the construction of a spacerless packing matrix for the ICRS unit. This matrix is proprietary to Kenyon/M I\&S. Total contributions to the project by M I\&S during 1992-93 are valued at \$xx,000.

Kenyon Enterprises (KE)- KE is a small company which was in the ethanol consulting industry. Its past president, Wendall Harris built and operated an ethanol plant during 1982-1985, and then went into the starch conversion industry. $\mathrm{KE}$ cooperated during the design and fabrication of the ICRS, and developed a spacerless packing matrix which is currently being tested. KE also became interested in the application of the ICR to yeast production from concentrated sugar streams. KE and M I\&S built a 200 liter pilot unit to test for yeast production. $K E$ contributed $\$ 10,000$. to the Purdue/DOE project in cash, and made a further contribution of about $\$ 85,000$ in time, effort towards the ethanol and yeast portions of the project and operation of the 200 liter pilot plant in Plainfield, WI.

Xylan Inc.- Xylan/Xymax are companies operated by George Tyson. Xylan owns two patents for cellulose pretreatment technology based on extrusion of biomass. This pretreatment allows the enzymatic attack on the cellulose polymer to break the polymer to its monomer glucose units. Xymax Inc. is involved in the conversion of waste cellulose/plastics to structural plastic composite board or beams. The production of railroad ties and sign posts is envisioned. Xylan hopes to com. bine its pretreatment technology with the ICRS or CSRS fermentation system. Xylan has invested approximately $\$ 10,000$ to date in time and in-kind contributions to the project, and plans to contribute between $\$ 10$ and $\$ 30,000$ cash to the Purdue project during 1994 , along with $\$ 100$ to $\$ 200,000$ in further combined developmental work.

Other industrial contacts/project contributors include:

1) Wisconsin Dairies, who have contributed 2,000\# of dried permeate,

2) Kraft Inc. who remain interested in applying the CRS technology in several of their plants,

3) Ethanol Resources, of FL who want to make ethanol from yard wastes, palm fronds, and napier grass.

4) Enviroenergy Inc. who currently have anaerobic conversion technology 
5) Great Lakes Governor's Biomass Council, who have contributed $\$ 50,000$ to the CSRS starch/biomass project

6) NIST/DOE ERIP who plan to support the CSRS starch/biomass project

A project review was held on May 30-31, 1993 with Dr. Dale and Okos describing recent project accomplishments to Allan Shroeder and Dan Kung at Argonne, $\mathbb{Z}$. An industrial review meeting was then held at Hopkinton, IA Permeate Refining Inc. plant site. Attending were Kenyon Enterprises (Cheryl Plitt, Wendall Harris), Permeate Refining (Bob Lehman, Carol Lehman, Keith Korr), Merill I\&S (Roger Henner), Xylan/Xymax (George Tyson, Ruth Tyson, Gene Anderson). A tour of the PRI facility was accompanied by a description of the ICRS and a look at the ICRS in operation.

\subsection{Press, Presentations, Publications, and Theses}

\section{Press Notices:}

Novel Fermentation Process Converts Whey Permeate to Fuels, Chemicals. The Cheese Reporter. October 2, 1987.

Immobilized Yeast Process converts whey permeate to ethanol. Food Engineering. 2:88 page 77.

\section{Presentations:}

1. Havlik, S., P. Moyer, and M.R. Okos. Computer-Aided Food Process Design. ASAE, December, 1987.

2. Dale, M.C., Y. Koo, S. Havlik, and M.R. Okos. Comparison of Recovery Processes for Ethanol from an Immobilized Cell Reactor-Separator. AIChE, August, 1988.

3. Lin, J., M.C. Dale, M.R. Okos. Environmental Effects on Ethanol Production by Immobilized Z. mobilis. SIM, August 1988.

4. Dale, M.C. and M.R. Okos. Scale Up and Performance of an ICRS for the Production of Ethanol from Whey Lactose. SIM, August, 1988.

5. Lin, J.J., M.C. Dale, and M.R. Okos. 1988. Improvement of Bioreactor Performance: Ethanol Production by Zymomonas mobilis in an Immobilized Cell Reactor-Separator. IFT, June, 1988.

6. Park, C.H., M.R. Okos, and P.C. Wankat. Effects of pH and Temperature on the Ethanol Fermentation by Free and Immobilized Yeast. AIChE, August, 1988.

7. Park, C.H., M.R. Okos, and P.C. Wankat. Butanol (ABE) Fermentation with Product Separation in an Immobilized Cell Reactor-Separator (ICRS) (Mathematical Modeing and Analysis). AIChE, August, 1988.

8. Park, C.H., M. Okos, and P. Wankat. Continuous Production of Butanol-Acetone in an Immobilized Cell Trickle bed Reactor. AIChE, November, 1988.

9. Dale, M.C., S. Havlik, and M.R. Okos. 1989. The Production of Ethanol from Whey Permeate 
using an Immobilized Cell Reactor-Separator. Wisconsin Center for Dairy Research, January 1989.

10. Dale, M.C. and M.R. Okos. Design and Performance of an Immobilized Cell Reactor and Separator for the Production of Ethanol and Other Solvents. Presented at the 5th Intl. Congress on Engineering and Food. Cologne, Germany, May 28 - June 3, 1989.

11. Havlik, S.E., M.R. Okos, and G.V. Reklaitis. Design and Simulation Methodology for Food Processing Modeling. Presented at the 5th Intl. Congress on Engineering and Food. Cologne, Germany, May 28 - June 3, 1989.

12. Lee, W.S. and M.R. Okos. Production of Flavor Compounds from Cheese Whey. Presented at the 1989 AIChE Meeting, Philadelphia, PA, August 1989.

13. Havlik, S. A. Balint, and M. Okos. Food Operations Oriented Design System: A Steady State Food Process Design and Analysis Program. Presented at the 1989 ASAE Winter Meeting, New Orleans, LA, December 1989.

14. Dale, M.C. and M.R. Okos. Design and Analysis of a Structured Packing for Trickle Flow Type Bioreactors Incorporating Simultaneous Production and Gas Stripping of Volatile Fermentation Products. Presented at the ACS 200th Annual Meeting, Aug. 26-31, 1990

15. Dale, M.C., A. Eagger, B. Truax, and M.R. Okos. Osmolality Effects on K. fragilis Growth and Productivity in Batch and Immobilized Cell Reactor. Presented at the AIChE 1990 Annual Meeting, Paper 286-b, November 15, 1990.

16. Dale, M.C., J. Smith, and M.R. Okos. Whey Lactose Conversion to Ethanol in a 50 Liter Immobilized Cell Reactor Separator (aka pilot). Presented at the AIChE 1990 Annual Meeting, Paper 286-f, November 15, 1990.

17. Lee, W. and M.R. Okos. Production of Diacetyl by Continuous Fermentation and Simultaneous Product Separation. Presented at the AIChE 1990 Annual Meeting, November 15, 1990.

18. Dale, M. C., A Novel Fermenter-Separator to Produce Ethanol from Waste Sugar Streams. Presented at the DOE Technology Fair, Washington, D.C., April 1991.

19. Dale, M. C. and M. R. Okos. A Low Effluent Process to Produce Ethanol for Corn Sugar. Corn Ethanol Conference, Peoria, Il, May 25, 1991.

20. Venkatesh, K.V., M.R. Okos and P. Wankat. Production of Lactic Acid in Membrane Recycle Bioreactor Utilizing lactose. AIChE meeting, November, 1991, Los Angeles, CA.

21. Dale, M.C., D. Guntrip, M. Moelhman, and M. Okos. 1992. Production of Ethanol in an Immobilized Cell Reactor-Separator. China-USA Bio-Reaction \& Bioseparation Conference, Hangzhou, P.R.C., June.

22. Dale, M.C. 1992. Design and Analysis of Continuous Bio-reactors Utilizing Immobilized Living Cells. China-USA Bio-Reaction \& Bioseparation Conference, Hanghou, P.R.C., June.

23. Dale, M.C. 1992. Food and Non-Food Uses for Whey. Ohio Dairy Producers Conference, Columbus, $\mathrm{OH}$, March.

24. Venkatesh, K. V., Okos, M. R., Wankat, P. C., Modelling of Simultaneous Saccharification and Fermentation of cellulose to lactic acid. AIChE summer meeting, Minneapolis, August 1992.

25. Lee, W.S., M. Okos and M.Dale. 1992. Production of a Butter Flavor Compound (Diacetyl) 
with simultaneous Product Separation. AIChE paper 8d., Minneapolis, MN, August.

26. Dale, M.C. 1992. Production of Ethanol, Lactic Acid or SCP from Biomass. Biobased Products Expo '92. St. Louis. October.

27. Salicetti, L., M.C. Dale, M. Moelhman, M. Okos, and P. Wankat. 1992. Free and Immobilized Yeast for BOD Reduction in Dairy Waste Streams. AICHE Annual Meeting, Paper 16k, Miami, November.

28. Dale, M.C. 1992. Design and Construction of a 7,500 Liter Immobilized Cell Rector Separator for Ethanol Production from Whey Permeate. AICHE paper 16la Miami. November.

29. Dale, M.C., S. Michel, and M. Okos. 1993. A No-Cook Process for the Conversion of Starch to Sugars for Ethanol Production. AICHE COFE meetings, February, Chicago, $\mathbb{I L}$.

30. Dale, M.C. 1993. The Solvent Absorption/Extractive Distillation (SAED) Process for Ethanol Recovery from Gas Streams. AICHE COFE meetings, February, Chicago.

31. Dale, M.C., 1993. A Low Effluent Ethanol Process For Corn, Starch and Biomass. Governor's Ethanol Coalition, Peoria, $\mathbb{L}$, November.

32. Salicetti, L., M. Okos \& P.C. Wankat. 1993. "Modeling of Lactose Assimilation by the Yeast, K. marxianus". Conf. on Environment, Purdue Univ., August.

\section{Publications:}

1. Park, C., M.R. Okos, and P.C. Wankat. 1989. Acetone-Butanol-Ethanol (ABE) Fermentation in an Immobilized Cell Trickle Bed Reactor. Biotechnology and Bioengineering, 34:18-29.

2. Park, C.H., M.R. Okos, and P.C. Wankat. 1989. Ethanol Fermentation using Immobilized and Free Saccharomyces cerevisiae: Effect of $\mathrm{pH}$ and Temperature. Submitted to Enzyme and Microbiology Technology.

3. Lin, J.J., M.C. Dale, and M.R. Okos. 1991. Osmotic (A w) Effects on Growth and Ethanol Production of Free and Immobilized Zymomonas Mobilis. Journal of Process Biochemistry, 26 143-151.

4. Park, C.H., M.R. Okos, and P.C. Wankat. 1989. Characterization of an Immobilized Cell, Trickle Bed Reactor during Long Term Butanol (ABE) Fermentation. Submitted to Biotechnology and Bioengineering.

5. Lin, J.J., M.C. Dale, and M.R. Okos. 1990. Ethanol Production by Zymomonas Mobilis in an Immobilized Cell Reactor Separator. Journal of Process Biochemistry 25:61-66.

6. Chen, C., M.C. Dale, and M.R. Okos. 1990. The Long-Term Effects of Ethanol on Immobilized Cell Reactor Performance Using K. fragilis. Biotechnology and Bioengineering 36:975982.

7. Chen, C., M.C. Dale, and M.R. Okos. 1990. Minimal Nutritional Requirements for Immobilized Yeast. Biotechnology and Bioengineering 36:993-1001.

8. Dale, M.C., C. Chen, and M.R. Okos. 1990. Cell Growth and Death Rates as Factors in the Long-Term Performance, Modeling, and Design of Immobilized Cell Reactors. Biotechnology and Bioengineering 36:983-992.

9. Park, C-H., M.R. Okos, and P.C. Wankat. 1990. Acetone-Butanol-Ethanol (ABE) Fermentation and Simultaneous Separation in a Trickle Bed Reactor. Accepted for publication in Bio- 
technology Progress.

10. Venkatesh, K. V., Okos, M. R., Wankat, P. C., 1992. Kinetic model of growth and lactic acid production from Lactose by Lactobacillus bulgaricus. Accepted for publication in Process Biochemistry, (in print).

11. Venkatesh, K.V., M.R. Okos and P.C. Wankat. 1993 Immobilized Cell Réactor (ICR) to Produce Lactic Acid from Lactose. Submitted to Biotechnology Progress.

12. Venkatesh, K.V., M.R. Okos and P.C. Wankat. 1993. Continuous Production of Lactic Acid by Bioprocess with Cell Recycle and Hollow Fiber Extractor. Submitted to Biotechnology Progress.

13. Venkatesh, K.V., M.R. Okos and P.C. Wankat. 1993 A Hollow Fiber, Immobilized Cell Reactor Separator (ICRS) to Produce Lactic Acid by Extractive Fermentation. Submitted to Biotechnology Progress.

14. Dale, M.C. 1993. Ethanol Production from Whey in an Immobilized Cell Reactor. AICHE Chpt One 7:2 22-28.

15. Lin, J., M.C. Dale, and M. Okos. 1991. Osmotic (aw) Effects on growth and Productivity of Free and Immobilized $Z$ mobilis. Process Biochem. 26:143.

16. Dale, M.C., A. Eagger, and M.R. Okos. 1994.Osmotic Inhibition of Free and Immobilized $K$. marxianus Anaerobic G.'owth and Ethanol Productivity in Whey Permeate Concentrate. Process Biochemistry. 29 000-000.

17. Dale, M.C., N. Perrin, and M. Okos. 1994. Production of Ethanol from Concentrated Sucrose and Molasses Solution Using S. Pombe in an Immobilized Cell Reactor Separator. In Press. AICHE Proceedings of Conference on Food Engineering.

\section{Publications in Progress}

1. Dale, M.C., D. Guntrip, and M. Okos. A Structured Packing for Trickle Flow Type Bioreactors Incorporating Simultaneous Production and Gas Stripping of Volatile Fermentation Products. I. Design and Analysis. In Progress...to be submitted to Chem. Eng. Progress

2. Dale, M.C., D. Guntrip, and M. Okos. A Structured Packing for Trickle Flow Type Bioreactors Incorporating Simultaneous Production and Gas Stripping of Volatile Fermentation Products. II. Experimental Performance. In Progress...to be submitted to Chem. Eng. Progress

3. Dale, M.C., M. Moelhman, and M. Okos. Whey Lactose Conversion to Ethanol in a 50 Liter Pilot Plant Immobilized Cell Reactor-Separator. In Progress...to be submitted to Biotech. Bioeng.

4. Dale, M.C., S. Havlik, and M. Okos. Acid Whey Utilization by Production of Whey Protein Concentrate and Ethanol. In Progress...to be submitted to J. Food Sci.

5. Patterson, J.T., M.C. Dale and M.R. Okos. RTD Studies of a Trickle-Bed Column with an Absorbent Packing. In progress.

6. Venkatesh, K. V., Okos, M. R., Wankat, P. C., 1992. Kinetic modelling of simultaneous saccharification and fermentation of cellulose to lactic acid. Communicating with Biotech. Bioeng. 


\section{Theses:}

1. Chen, C. 1988. Environmental Effects on Growth and Ethanol Fermentation of Immobilized Kluyveromyces Fragilis.

2. Lin, J.J. 1988. Environmental Effects on Ethanol Production by Immobilized Zymomonas mobilis in a Trickle-Flow Fermenter.

3. Park, Chang Ho. 1989. Simultaneous Fermentation and Separation in an Immobilized Cell Trickle Bed Reactor: Acetone-Butanol Ethanol (ABE) and Ethanol Fermentation. Ph.D. Thesis, Agricultural Engineering Department, Purdue University.

4. Havlik, Steven E. 1989. Computer Aided Design and Modeling of Food and Food By Product Processes with Case Studies in Whey Processing alternatives. M.S. Thesis, Agricultural Engineering Department, Purdue University.

5. Lineback, D.S. 1989. Thermophilic Ethanol Production from Lactose. M.S. Thesis, Food Science Department, Purdue University.

6. Lee, W. S. 1991. Diacetyl Production using Free and Immobilized Cells. Ph.D. Thesis, Agricultural Engineering Department, Purdue University.

7. Venkatesh, K.V. 1993. Lactic Acid Production using Extractive Fermentation. Ph.D. Thesis, Chemical Engineering Department, Purdue University.

\subsection{Pilot Plant Operations}

\subsection{7,500 liter ICRS Pilot Plant @ Hopkinton, IA.}

\section{Design and Construction}

The ICRS system was designed during mid-1992, and constructed between 6/92 and 1/93 in Merrill, WI by Merrill I\&S. Roger Henner, president, designed and built the doors, windows, and interacted with Dr. Dale on the detailed design prints for the reactor. The ICRS is combined with an absorber in a single unit, with duct work all internally routed within a $8^{\prime} \times 9^{\prime}$ unit. This allows a very small simple apparatus. The unified design has the following advantages

1) Reduced construction costs and lower material costs

2) Reduced floor space

3) reduced complexity of ducts and construction

4) elimination of external ducting, gasketing, and blower connections

5) reduced chance for leakage and contamination from external sources. A multicolumn ICRS system was designed and found to have a floor space requirement of 13'x 20' as shown in Figure 2.1 A sketch of the unit with the solvent desorption/extractive distillation system is shown in Figure 2.2 Appendix 2.1 shows the basic design and construction of the unit along with specifications for the blower. The unit is designed to have a solvent run on the absorber side to pick-up the ethanol from the vapors leaving the ICRS unit. The solvent is then taken to a desorber where the ethanol is recovered.

The important design principles for construction and operation of the ICRS apparatus are given in Table 2.1. The reactor is designed to be sterilized by an initial steam cycle, inoculated with yeast, and the have a sugar stream continuously introduced to the reactor system. 


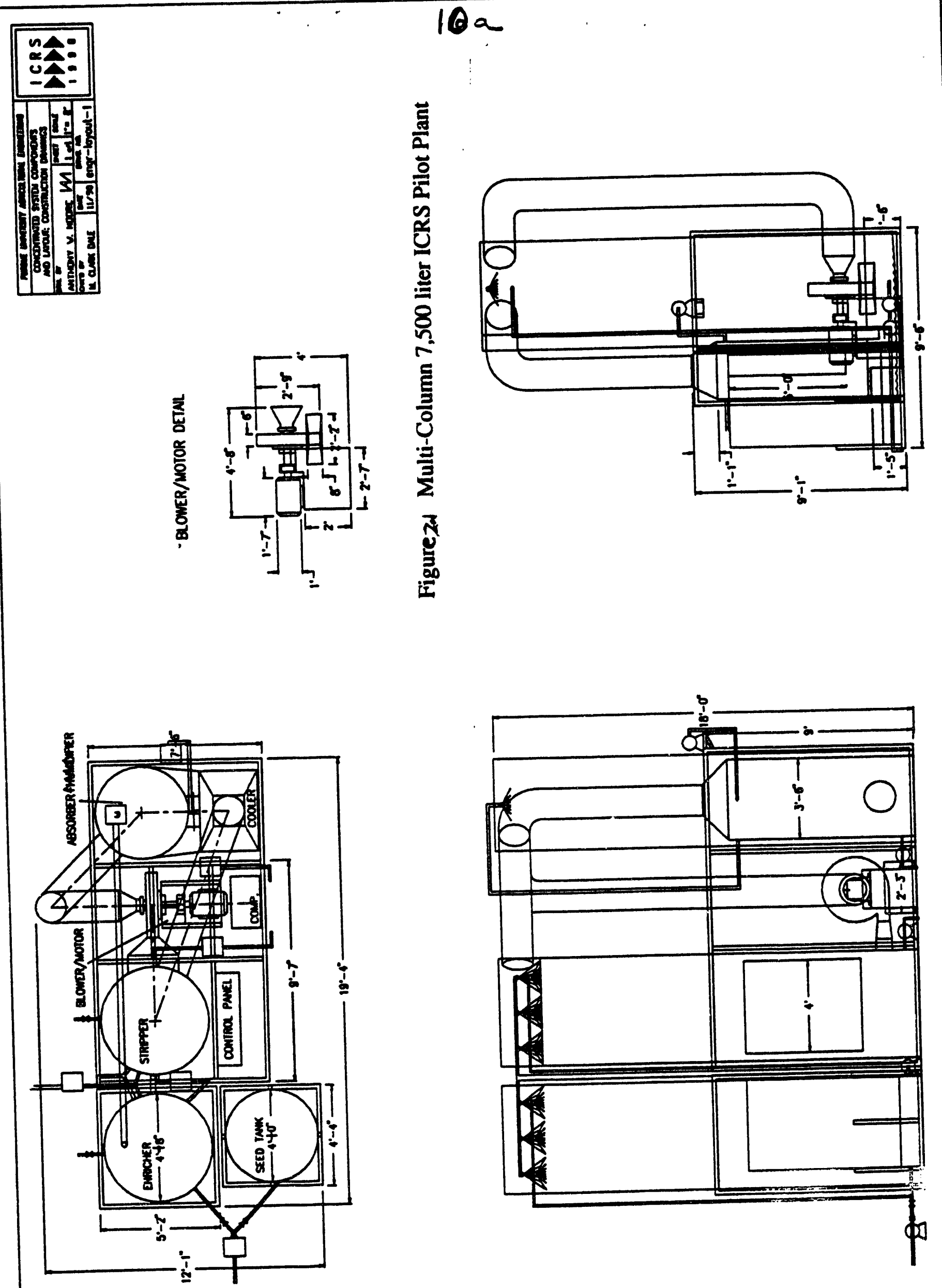




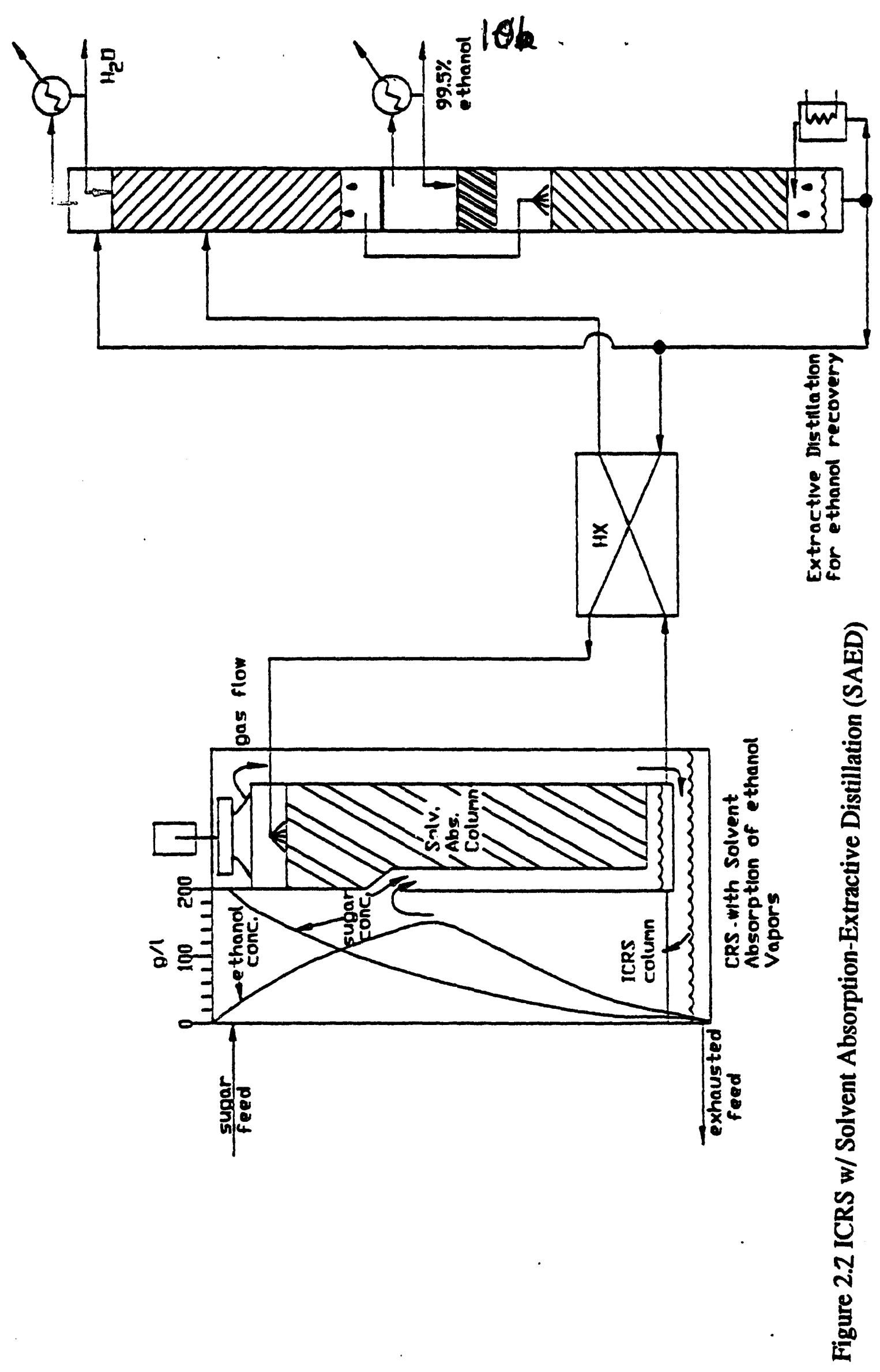


The basic design specifications for the fermenter are shown in Table 2.2 for the pilot unit. A spacerless design for the immobilization matrix was designed and built by Kenyon and Merrill I\&S. Table 2.3 gives the advantages and disadvantages for the spacerless matrix. Based on conversations between Purdue, KE, and Merrill I\&S, PRI decided to test the spacerless packing matrix.

\section{Installation}

The unit was moved from Merrill, WI and installed in late February, 1993 on site in Hopkinton, IA. Electrical, air, water, and feed lines, pumps, and controls were installed between $2 / 15$ and 4/15 by PRI workers. Four spacerless packing matrix bales were installed in both the enricher and the stripper.

The unit was started on 4/28 with yeast inoculated from a 2,000 gallon seed tank grown aerobically. Table 2.4 gives the initial start-up and operational data. The system was shut down on $5 / 15$ to allow a number of improvements to be make in the system including: 1) installation of smaller spray heads to allow operation in the range of 3 to $10 \mathrm{GPM}, 2$ ) addition of a feed filter to reduce clogging of the spray heads, 4) use of dry sterile air for pressure gauges and rotometers- the preliminary use of air from the compressor was found to entrain a large amount of water, 5) the addition of temperature gauges and thermocouples on various points at the reactor, 6) testing of spacerless matrix with and without spacer 'twisties', 7) improvement in the feed holding/batch pasteurization, 8) addition of SO2 to the feed stream or feed tank to help kill and inhibit bacteria in the feed. These changes and additions were accomplished between 7/93 and 12/93. It was determined that there was a leak between the cooling jacket and the internals of the seed tank used for yeast propagation. This leak caused repeated contamination of seeds being prepared for the ICRS unit start-ups.

In the repeated start-ups, high fermentation rates have not been attained. We have tried several clean-in-place matrix cleaning cycles. As per table 2.1, easy rapid clean-up and restart of the reactor is an important design feature. Unfortunately, we have yet to effectively regain the ability of the matrix to hold cells with the cleaning procedures used to date. Our next efforts will be concentrating on cleaning or replacing of the matrix. [Design of the Solvent Absorption/Extractive Distillation (SAED) System.]

The use of a solvent to absorb ethanol from the solvent is being suggested for use on the ICRS pilot plant. The solvent will selectively adsorb ethanol vapors over water vapors. This allows a concentrated (50-80\%) ethanol product to be recovered during desorption. Solvents with high selectivity for ethanol tend to give dissolved water a high activity coefficient, allowing extractive distillation of the water. This is described in Appendix 2.1.e

\subsection{Effluent Handling}

The conversion of high BOD distillery or food wastes to yeast is being extensively studied. Preliminary studies have shown that a gas continuous system can reduced the BOD from distiller's bottom water from 12,000 to 3,000 with a residence time of under 10 hours. The basic idea is to convert the residual lactic acid, glycerol, and unconverted sugars to yeast. The ability of various strains to convert these substrates, and the kinetics of multiple substrate utilization are being studied in a basic fashion by L. Salicetti for a Ph.D. project. Dale and Moelhman are approaching the 
Table 2.1 Critical Design Features for Continuous Reactors

1) Initial sterilization of reactor/separator

2) Maintain sterile feed

3) Continuous feed to the reactor

4) No ambient gas leakage into the reactor

5) Sterile sampling of reactor while operating

6) Design for easy, rapid clean-up and restart of reactor

Table 2.2 Design Specifications of 7,500 Liter Pilot Plant

Feed Flow Rate......4-8 GPM of 14\% Whey Permeate Concentrate (11\% lactose)

Design Ethanol Production Rate........150-200 \#/hr (250,000 gal/yr)

Gas Flow Rate......4,800 CFM CO2 through ICRS Stripper

ICRS reactor volume.......7,500 liters

4'x8' by 4' deep enricher section

4'x 8 ' by 4' deep stripper section

High Efficiency Structured Packing Volume .....3,600 liters

4'x8' by 4' deep below bottom of stripper/reactor)

Superficial Gas Velocity in ICRS Stripper.....150 fpm

Superficial Gas Velocity in Solvent Absorber......200 fpm

Flow rate of Solvent........75-95 GPM

Total Dimensions of unified ICRS/Absorber.....8'X $9.5^{\prime}$ base by $24^{\prime}$ high 


\section{6}

Table 2.3 Design and Construction of Spacer-Free Immobiliziation Matrix

Advantages

1) rectangular-fits well in unified design

2) elimination of cost for spacer mesh

3) reduction of gas phase pressure drop

4) more easily cleaned

Disadvantages

1) technology must be developed for contruction

2) unproven in practice

Proprietary matrix developed by Kenyon Enterprises and Merrill I\&S Designed and built by Merrill I\&S for 7,500 liter ICRS unit.

Table 2.4 Operation of ICRS unit during May @ PRI site

1) Plexiglass top cover bowed \& cracked during steaming Replaced by high temperature polymer by PRI-

2) Innoculate 2000 gal propogator $4 / 28$

3) Begin feed at 8 GPM- emptied 2,000 gal feed tank overnight.

4) Put in recycle mode- hook in 12,000 gal feed tank

5) On 5/4- 8 GPM Feed Inlet feed $11.7 \%$ solids- outlet $7.5 \%$ solids $50 \%$ utilization of sugars- alcohol conc. in absorber water $2.95 \%$ ethanol

6) 10,000 gal. tank cooled, bacteria level became high- fed bacteria laden feed to reactor$5 / 5$

7) dehydrating system @ PRI not functioning correctly-decided to shut down. 
problem in a more applied way, testing various reactor configurations with actual bottoms water from Iowa and artificial bottoms water made-up in the lab. These studies, and a design for a waste water plant for the PRI site are given in Appendix 2.3

\subsection{Yeast from concentrated substrates}

The ability to create a concentrated stream of yeast from a concentrated sugar stream was demonstrated by Shay and Wagner $(1987,1988)$ using a reactor with a highly efficient oxygen transfer and cooling system. This system offers the possibility of using a concentrated whey input to produce a yeast/salt product with no waste water generation and no centrifuges. Our efforts in conjunction with Kenyon Enterprises, have been to build, test, and operate a low pressure drop immobilized cell yeast reactor (ICYR). A 200 liter ICYR was build by Merrill I\&S, tested in Plainfield WI by Kenyon, and then tested at Purdue in late ' 93 and early ' 94 . A report on the 200 liter pilot plant is appended with this report as Appendix 2.6

\subsection{4,000 L CSRS Pilot Plant}

The extension of the ICRS technology to a stirred tank in series $w /$ gas phase separation of the ethanol has been under design and investigation by Dr. Dale for the last few years. The basic reactor design consists of stirred tanks in series, with the overflow contacted with a stripping gas to reduce the ethanol levels. A 24,000 liter pilot unit is currently under construction for testing at the same PRI site that the ICRS is being tested. The costs for this project are not being covered by the DOE Division of Industrial Technologies. A description of this project is included as Appendix 2.7

\subsection{Laboratory Studies}

\subsection{Lactic Acid}

Lactic acid is a higher value chemical (priced at $\$ 0.75-1.00 / \mathrm{lb}$.) that can be produced by homofermentative bacteria from the genera Lactobacillus and Streptococcus by the fermentation of sugars. Currently, is produced commercially form corn sugar, molasses and whey. It has many uses in connection with foods, fermentations, pharmaceutical, and the chemical industries. The increasing problem of waste whey disposal in the dairy industry, the improving market for feed supplements in cattle industry, and the potential of lactic acid as a raw material for biodegradable plastics might further the demand for lactic acid.

Argonne National Laboratory has been working in the area of lactic acid research for several years. In the is phase of the project we propose to cooperate with them. We are investigating the kinetics of lactic acid production using lactose as a substrate. High lactic acid concentrations have been obtained. In addition, diacetyl, a valuable flavoring compound, has been obtained as a secondary product. Solvent extractions along with membrane partitioning of solvent and fermentation broth to achieve a purified product in a more economic manner have been investigated. 


\subsection{Anti-Fungal Compounds from Immobilized Plant Cell Tissue Culture}

In this project we are attempting to convert waste sucrose from molasses or glucose from waste potato starch, to a higher value product, an antifungal chemical called gossypol. This chemical is produced in plant cells. Large scale cultivation of plant cells is hampered by poor understanding of biochemical pathways. Major problems associated with secondary metabolite formation by plant cells are the slow metabolic rate and the low yield of cells. Another factor that presents problems in using plant cells on a large scale is their sensitivity to shear. To solve these problems, immobilization of plant cell is being considered.

The major goal of this study is the immobilization of plant cell in order to enhance the productivity. Gossypium arboreum which can produce antifungal reagent, gossypol, has been selected as a preliminary model system. We have characterized that species and analyze for gossypol content both inter and extra. However, due to its slow growth rate (doubling time is 3-4 days), we have designed a method which allows fast experiments such as differential reactor. We have: a) designed a small reactor to examine the growth kinetics for the cell; b) chosen suitable parameter levels for batch and continuous operation of reactor (nutrient concentration, $\mathrm{pH}$, aeration, and temperature must be determined for continuous operation); c) tested application of an elicitor to enhance the productivity; d) tested application of a permeat,ilizing agent such as DMSO (dimethyl sulfoxide) to increase the secretion of secondary metabolites from the plant cell; e) determined a method for determination of cell viability; and f) attempted to optimize productivity. This work is largely completed, with a modeling effort being undertaken by Mr. Choi, who expects to receive his Ph.D in May, 1994.

\subsection{Production of Yeast from High BOD Waste Water}

The ability of yeast to metabolize the various organic compounds remaining in distillery wastes is being evaluated. The three major components in 'bottoms water' have been determined to be a) suggar: (lactose or glucose), lactic acid, and glycerol. The use of the different substrates by the yeast Klvyveromyces marxianus was found to be sequential. Furthermore, growth rates and rates of substrate utilization on lactic acid We have looked at various strains of yeast to determine those strains best able to metabolize these substrates. The use of multiple yeast strains is being studied, a $\mathrm{K}$. marxianus strain and a Candida utilis strain. The use of substrates by the and glycerol were found to be very slow with this yeast. Experiments were conducted in order to identify other yeast species that would be capable of utilizing lactic acid and glycerol much faster. A series of different types of yeast obtained from the culture collection of the Department of Agriculture were cultured in a multiple substrate medium and evaluated for faster growth and utilization kinetics. It was found that Candida utilis NRRL Y-1082 has a better growth rate on glycerol than K. marxianus.

Another series of experiments was performed using a mixed culture of $\mathrm{C}$. utilis and $\mathrm{K}$. marxian mixed population it was found that $C$. utilis would start utilizing the glycerol while $\mathrm{K}$. marxianus would first utilize the lactose. After these two substrates were taken up, both yeasts would switch to utilize the lactic acid. The total amount of time to completely utilize the multiple carbon source available was reduced considerably by being able to utilize lactose and glycerol simultaneously in the first growth phase and by having a faster utilization rate of lactic acid in the second phase of growth. No interaction between the two yeast species was noticeable. Based on these results, the 
next efforts will focus in the individual growth kinetics and substrate utilization of the yeasts $K$. marxianus NRRL Y-2415 and C. utilis NRRL Y-1082.

Experiments are under way to determine the kinetics of individual substrate utilization by each of the selected yeasts. A series of batch experiments are being conducted to determine the Monod parameters and yield coefficients. These parameters will be incorporated into a mathematical model that will enable the prediction of the growth behavior and substrate utilization rates of the mixed culture yeast culture. The mathematical model will be based in the cybernetic modelling approach developed by professor Ramkrishna from Purdue University (Kompala, et al., Biotech. Bioeng. Vol. 28, 1044-1055, 1986). With this model, performance of batch and continuous stirred tank bioreactor can be predicted and suitable process design conditions can be estimated. Simulation results will be corroborated in laboratory experiments to ascertain the validity of the model.

\subsection{Production of Gluconic Acid from waste glucose}

Gluconic Acid is a higher valued product that can be produced from ethanol or sugars. In 1983, a research program about Immobilized Cell Reactors was set up at Purdue University with the aim of taking advantage of waste food products such as cheese whey, molasses and lactose whey; aiming to recover partially the large source of energy lying in these products. Actually, development through conversion of some agricultural by-products especially whey permeate and starch in Immobilized Cell Reactors, using different strains of yeasts, molds and bacteria. In some studies, simple sugars such as lactose, glucose or xylose are also used.

This project on oxidative bacteria (Gluconobacter oxydans ssp. suboxydans) is immobilized to produce gluconic acid from a glucose source. The effect of $\mathrm{pH}$ on the growth and productivity was studied and led to a $22 \%$ increase in the gluconic acid production.

\subsection{Simultaneous Saccharification and Fermentation of Cellulose to Lactic Acid}

Cellulose is perhaps the single largest biochemical polymer produced on earth. There has been considerable efforts by many researchers to establish methods of breaking down wood, paper, and crop debris to glucose. We will begin cooperating with Xylan Inc. during this next year of the project. They will provide us with pre-treated biomass products including waste paper, switch grass, municipal yard wastes, and corn stalks. Cellulose in natural wood and crop products, is bound with hemicellulose in a tough crystalline matrix. Breakdown of the cellulose products can be achieved via acid or enzymatic hydrolysis. In this phase of the project, we will be evaluating the ability of co-culturing cellulase producing organisms (or adding cellulase) and yeasts to produce ethanol or lactic bacteria to produce lactic acid.

\subsection{Simultaneous Saccharification and Fermentation of Starch to Ethanol}

Starch, like cellulose, is a polymer of glucose, however, starch is much more easily hydrolyzed to the simple sugars, and does not have any pentoses as does hemicellulose. Starch is generally broken down by two enzymatic processes; $\alpha$-amylase liquefies the gelatinized starch, breaking the starch into long chain dextrins (liquefaction), then gluco-amylase is used to convert the dextrins to glucose (saccharification). These enzymes are readily available and used in corn syrup and ethanol 
plants on a standard basis. These has been some work with yeasts that produce these hydrolytic enzymes, but enzymes do not represent a major cost in general. We propose a system involving simultaneous fermentation and saccharification, along with separation of ethanol from the broth. Some studies of this system are shown in Appendix 3.7

\subsection{Production of Yeast from Concentrated Syrup Streams}

The use of high concentrations of sugars to produce high concentrations of yeast is being evaluated both on the lab and pilot scale. A small $1.5 \mathrm{~L}$ gas continuous reactor has been operating in our lab for extended periods of time. The performance of this reactor is described in Appendix 3.8. It is hoped that the cost of producing yeast can be reduced by investigating low energy oxygen transfer into and out of the reactor.

\subsection{Process Design Studies}

\subsection{FOODS Development and Status}

The current status of the Food Oriented Optimization and Design Soybean (FOODS) is discussed in Appendix 4.1. We have one graduate student, Heidi Diefes, working on the updating and confirmation of this program. 
Preliminary Design of a Waste Water Treatment Facility

\author{
M. Clark Dale \\ Sr. Research Eng. \\ Biochemical and Food Process Eng. Div \\ AGEN, Purdue University
}

Design Parameters:

A. INLET WASTE WATER CHARACTERISTICS

1) Waste water production rate--50,000 gal/day

2) Inlet BOD/COD----35-50,000/70-100,000 ppm

3) Temp----85 F.

4) $\mathrm{Ph}------3.3-3.8$

B. DESIRED OUTLET WATER CHARACTERISTICS

1) Outlet BOD/COD----50/100 ppm

2) Temp ---70 F.

3) $\mathrm{pH}---6.5$

C. Treatment Design Strategy

The high BOD rates coming from the plant are much higher than normal waste water plants can handle. Typical BOD's coming into wastewater plants are between 100 and $500 \mathrm{ppm}$. Thus, a pretreatment to get the BOD down is required. We have been working on a bio-reactor for the production of yeast from low levels of sugars, lactic acid, and glycerol for the last several years (Dale et al, 1991, Salicetti et al, 1992). It is suggested here that this sort of bio-reactor be used to drop the BOD of the inlet from 50,000 to under $10,000 \mathrm{ppm}$ or to remove $80-90 \%$ of the substrates which can be easily metabolized by the yeasts. The effluent from the yeast/BOD burner will then be taken to a staged trickle flow type aeration water treatment towers. The high (4-10,000 BOD) feed is still much too strong for a typical one stage filter. Thus our strategy is:

1) Yeast conversion of lactic acid, glycerol, remaining sugars, some salts, phosporus, protein to cell mass.

INLET BOD/COD: $50,0000 / 100,000$ ppm (21,000 \#/day)

INLET FEED RATE: $2,000 \mathrm{gal} / \mathrm{hr}$

OUTLET BOD/COD: $7,000 / 15,000$ ppm (2,940 \#/day) 
Yeast Concentration in Reactor Outlet: $15-30 \mathrm{~g} / 1$

Yeast Produced per hour/day: 125-250 \# per hour / 3,000-6,000 \#/day)

Yeast Production rate: $2.5 \mathrm{~g} / \mathrm{h}-\mathrm{hr}$

BOD Reduction rate: $500 \mathrm{ppm} / 1-\mathrm{hr}(8,000$ \#/1000ft3-day)

Reáctor Packed Volume: 60,200 liters/ 16,000 gal./ $2200 \mathrm{ft} 3$

Reactor height: $15 \mathrm{ft}$

Reactor diameter: $14 \mathrm{ft}$

2) Three stage aerobic filter- $w /$ final clarifier for sludge removal

A. Stage 1.

INLET BOD/COD: $7,000 / 15,000$ (2,940\#/day)

OUTLET BOD/COD: $1,400 / 3,000$ (1,176 \#/day)

BOD LOAD - reaction rate: $300 \# / 1000 \mathrm{ft3}$-day

Reactor packed volume: $6,000 \mathrm{ft} 3$

Recirculation rate 3:1

Reactor height $18 \mathrm{ft}$

Reactor base dimensions: $20 \times 16$ '

(See Figure 1)

B. Stage 2.

INLET BOD/COD: $1,400 / 3,000$ (1,176 \#/day)

OUTLET BOD/COD: 560/1,100 (290 \#/day)

BOD LOAD - reaction rate: $130 \# / 1000 \mathrm{ft} 3$-day

Reactor packed volume: $6,000 \mathrm{ft} 3$

Recirculation rate 3:1

Reactor height $18 \mathrm{ft}$

Reactor base dimensions: 20 X 16'

B. Stage 3.

INLET BOD/COD: 560/1,100 (290 \#/day)

OUTLET BOD/COD: 50/100 (29 \#/day)

BOD LOAD - reaction rate: 75 \#/1000 ft3-day

Reactor packed volume: $4,000 \mathrm{ft} 3$

Recirculation rate 1:1

Reactor height $18 \mathrm{ft}$

Reactor base dimensions: $20 \times 11$

(See Figure 2) 
$11 / 5 / 93$

】

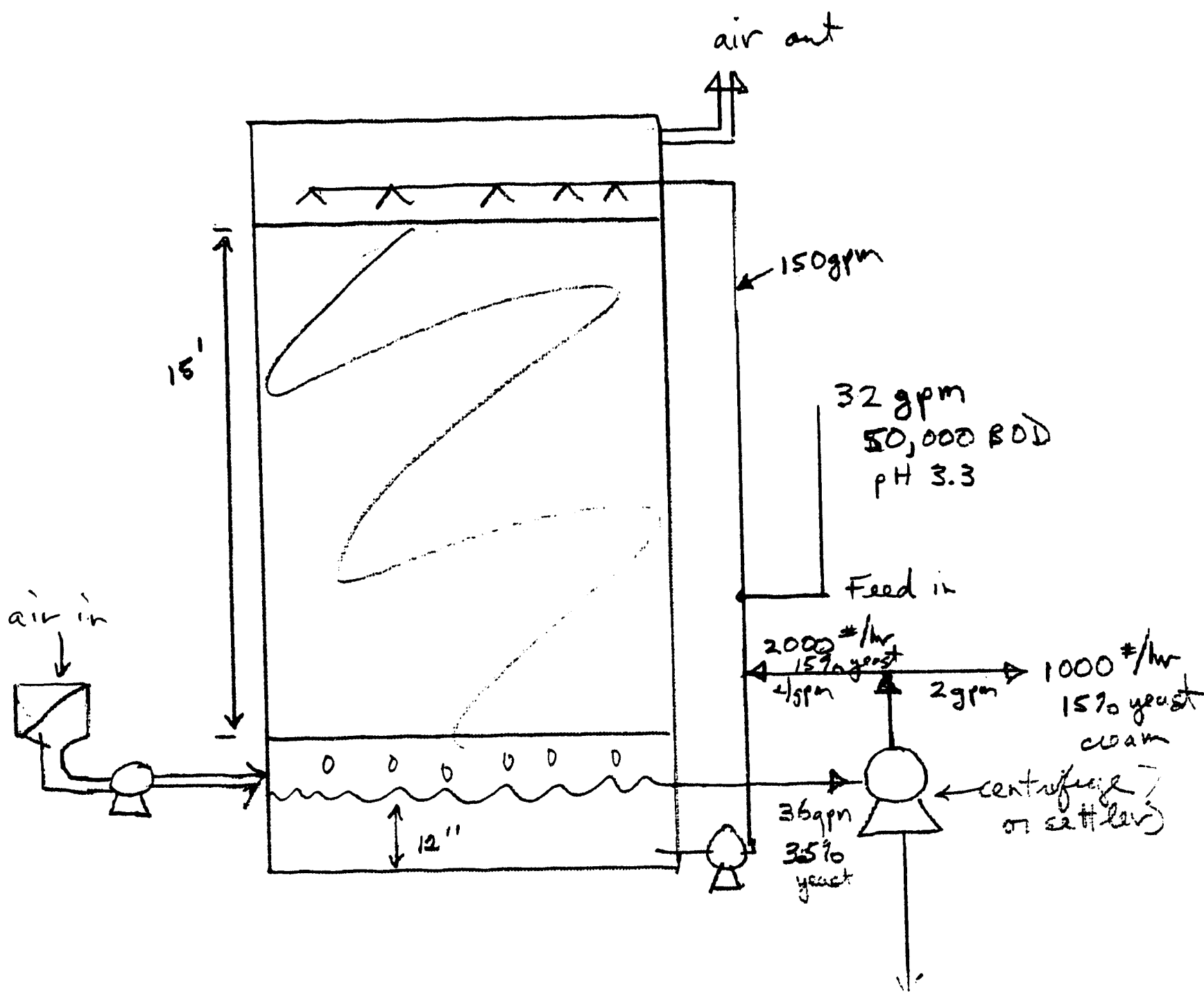

Yeust Pretratront Finter

30 gpm
$3 .-5,000$ BO

Figune 1 
3 stage Nerobir Felder

stoge 1

stage2 stoge 3

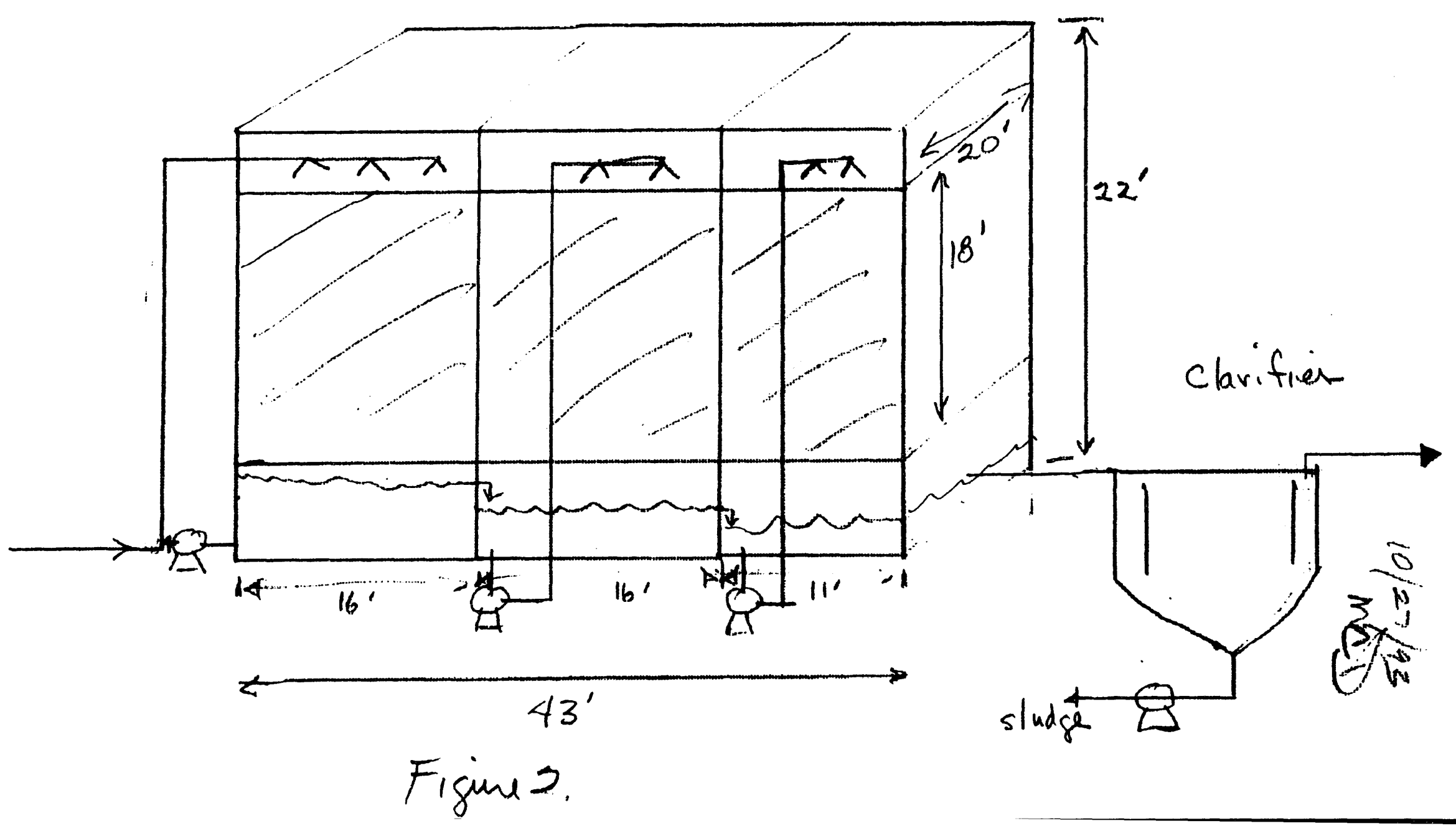




\section{Design of Trickle Bed Aerobic Filters for Waste Water Treatment}

Nomenclature:

F $=$ Feed flow rate- gal/day

$S_{f}=$ Feed substrate conc. ppm or $\mathrm{mg} / \mathrm{l}$ (BOD)

$\mathrm{F}_{\mathrm{O}}=$ Feed to reactor after mixing $\mathrm{w} /$ recirculation stream-ppm

$S^{0}=$ Feed substrate conc . to reactor after mixing $w /$ recirc-ppm.

$\mathrm{S}_{\mathrm{e}}=$ Effluent substrate concentration from the reactor- $\mathrm{ppm}$ BOD

\&alpha\& $=$ Feed recirculation rate as ratio of $F$ to recirc.

$F_{o} / A_{c}=H=$ Hydraulic loading rate-gal/day-ft2

$\mathrm{L}=$ packed height of filter $-\mathrm{ft}$

Waste water treatment facilities remove the various dissolved components in the feed stream water to produce a purified water which can be returned to rivers and streams. The concentration of biodegradable solids in the waste water is given as Biological Oxygen Demand (BOD) which is the amount of oxygen required to oxidize the substrate to $\mathrm{CO} 2$ and water. The basic reaction which occurs in waste water facilities is:

Carbohydrates/Nitrogen/Phosphorus + $\mathrm{O} 2$----> Biomass $+\mathrm{CO} 2+\mathrm{H} 2 \mathrm{O}$

For a substrate such as sugar (glucose) we have:

$$
\mathrm{C}_{6} \mathrm{H}_{12} \mathrm{O}_{6}+6 \mathrm{O}_{2} \longrightarrow 6 \mathrm{CO}_{2}+6 \mathrm{H}_{2} \mathrm{O}
$$

Which on a weight basis results in 1 pound of sugar requiring 1.07 pounds of oxygen to oxidize the sugar to $\mathrm{CO} 2$ and water. Thus the BOD (ppm oxygen) is about the same as the dissolved solids concentration (ppm soluble biodegradable solids) of the wastewater as a general rule.

In order to convert dissolved solids to biomass and $\mathrm{CO} 2$, the waste water must be contacted with biomass and oxygen in a waste water bioreactor. There are five basic types of aerobic bioreactors: 1) Aerated Lagoon, 2) Activated Sludge, 3) Aerobic Digester, 4) Trickle Filter, and 5) Rotating disc reactors.

According to Grady and Lim (1980) the trickle filter is the simplest and easiest waste water facility to operate. These type of reactors are robust and tolerate changes in flows and concentrations well. They also are useful where land area is limited. In trickling 
Figue 3. Singh stage derobic Fitten w) Clavision

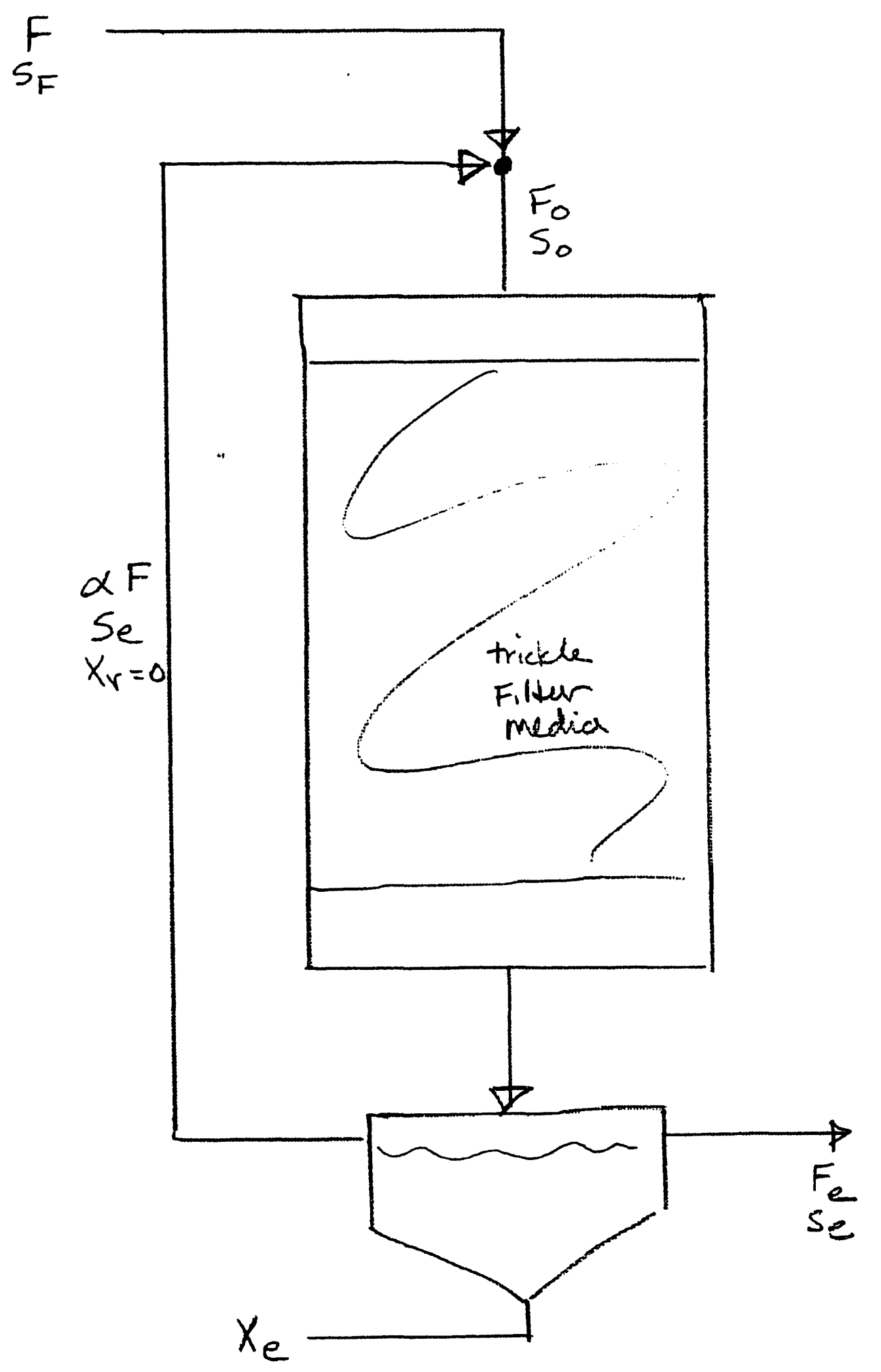


filters, a biomass film forms on the surface of the packing material. There is a complex microbial community which develops to metabolize the nutrients in the waste water stream. The trickling filter community is more diverse than found in activated sludge type reactors. "In addition to a rich mixture of eucaryotic and procaryotic organisms, trickling filters contain many higher life forms, notably nemotodes, rotifers, snails, sudge worms, and larvae of certain insects. This more complex food chain allows more complete oxidation of organic matter with the net result that fewer excess organisms are produced." (Grady \& Lim, pg. 223) The film builds up to a certain thickness, generally about 1 to $2 \mathrm{~mm}$, although clogging of bioreactors by very thick crusts of biomass is an operational hazard of trickle bed reactors. Orr and Lawty (1990) describe clogging of a plastic packed trickle bed reactor used for municiple sewage due to the overgrowth of a filamentous bacteria. This problem was treated by addition of hypochloite and increasing the irrigation rate. Zooglea type bacteria were more effective at BOD reduction and nonclogging of the bed than fungi/Psychoda species. Thicker films lead to anaerobic conditions within the film, and generally results in bad odors being created. Film thickness is generally controlled by the higher level "grazing" organisms. Low temperature (winter) operations can have a definite inhibitory effect on these higher organisms with a film build-up resulting (Sarner, 1980). However, hydraulic removal the film is generally successful (higher rate application of the waste water over the top of the bed).

The basic design and operational variables for a trickle bed filter is shown in Figure 3. Inlet feed is diluted with a recirculation stream at a ratio $\alpha$ and the inlet $B O D, S_{f}$, is reduced to the outlet level, $S_{e}$. As the BOD in the feed to the reactor increases, the rate of BOD consumption increases, but the degree of utilization of the BOD drops. Thus for high BOD streams, multiple beds are needed to allow the production of a low BOD effluent unless a very large bed is used with a high degree of recycle.

There are three basic types of packing used in trickle beds, 1) stone, 2) random plastic packing, and 3) structured plastic sheet packing. Stones are the cheapest media, but do not allow air to pass well, resulting in the use of wide, shallow beds of an average depth of 5 to 7 feet. Plastic packings allow the use of taller beds due to the easy flow of air through the beds. Maximum hydraulic loading rates of stones is in the range of $40 \mathrm{gal} / \mathrm{ft} 2$ $\mathrm{hr}$, while for random packed and modular media there is minimum application rate of $\mathbf{3 0}$ $\mathrm{gal} / \mathrm{hr} \mathrm{ft} 2$ to maintain wetting of the biomass film, with a recommended loading rate in the range of 35-100 gal/hr-ft2, with maximum application rates in the range of 250-350 gal/hr-ft2 (Grady \& Lim, 1980). Sarner (1980) shows hydraulic loads for structured plastic packings ranging from 2 to $5 \mathrm{~m} 3 / \mathrm{hr} \mathrm{m} 2(50-125 \mathrm{gal} / \mathrm{hr} \mathrm{ft} 2)$.

$B O D$ reduction rates depend upon the strength of the BOD fed to the reactor. Higher concentration of substrate results in higher rate BOD reduction, but less complete utilization of all of the substrate. An empirical model for substrate reduction is given by: 
$1 1 / 4 \longdiv { 9 3 }$
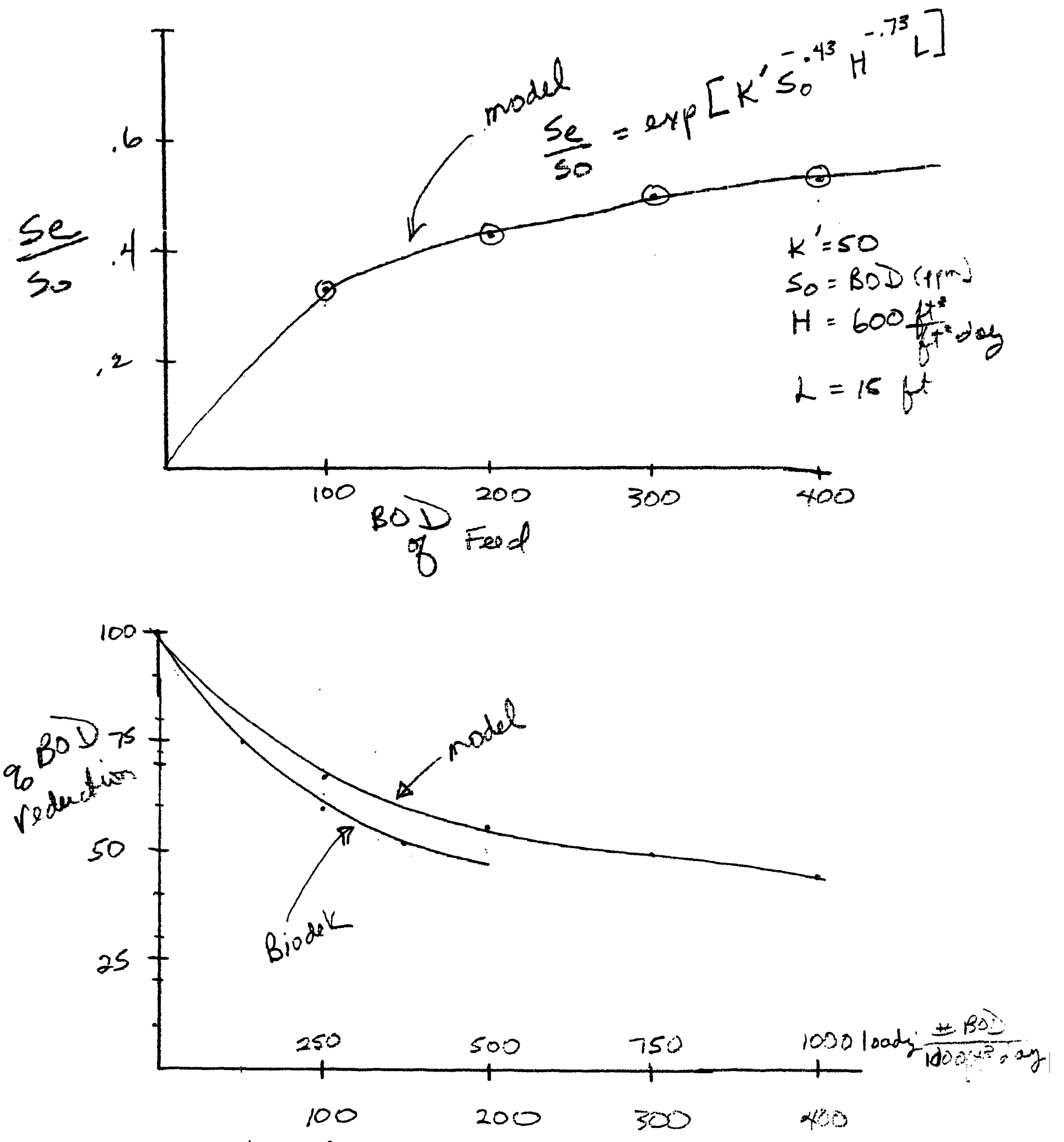

Figure 4. Paformane of Trill k as Towers as = fun of Feed BOD concentration 


\section{Dyunters}

Writiam A. Beckman

Sales \& Marketing Manager

Water Trealment Division

\section{BIOdek ${ }^{\circledR}$ Fixed Film Media General Description}

Munters Corporation 33907

P.O. Box 6428 Fort Myers, Florida 33911

B13/936-1555 1.800-116-6868

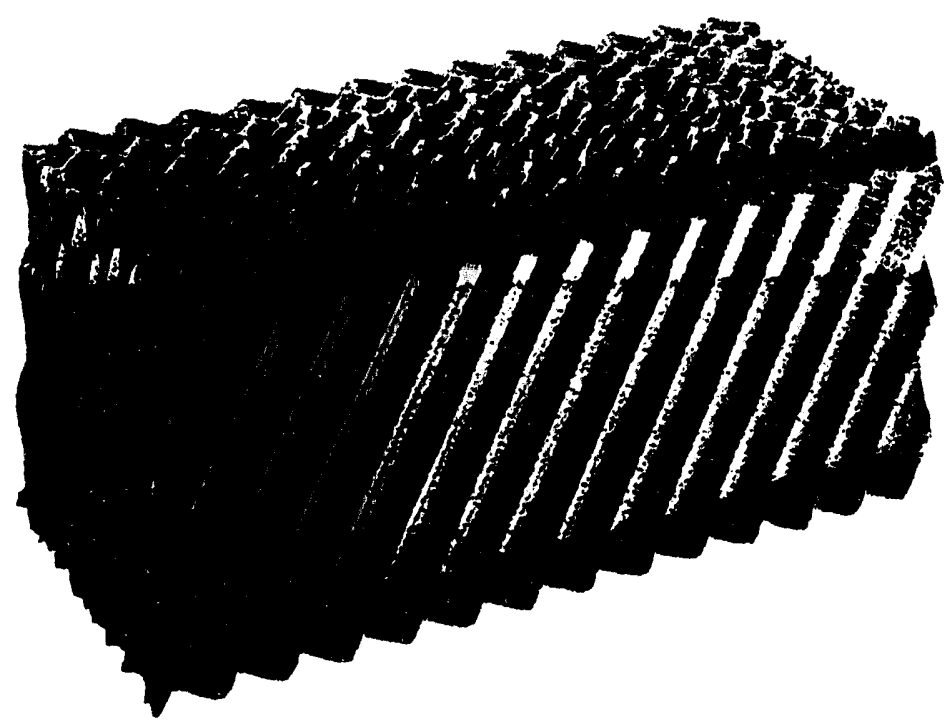

BIOdek is a modular sheet type media with a unique cross fluted design creating numerous interconnecting channels or redistribution points. The patented cross fluted design of BIOdek allows for uniform redistribution of air or liquid within the media.

BlOdek is manufactured from polyvinylchloride (PVC) sheets and assembled into rigid self supporting modules. All sheets within a BIOdek module are structurally reinforced by double folding the top and bottom edges a minimum of $1 / 2$ inch. The double fold edge construction provides extra strength and structural durability without obstructing flow.
BlOdek modules can be manufactured in a wide variety of sizes. BlOdek modules are available in heights from 12-24 inches high, widths from 12-24 inches and lengths up to 10 feet. Special cutting is also available for circular or irregular vessels.

BlOdek is available in lour different specific surface areas (see below) depending on the application. BIOdek is also available in chlorinated polyvinylchloride (CPVC), polypropylene and stainless steel where high temperature or compatability with PVC may be a problem.

For more information on BIOdek for a specific application, please contact Munters Corporation.

Specific

Surface Area

$\mathrm{ft}^{2} / \mathrm{ft}^{3}\left(\mathrm{~m}^{2} / \mathrm{m}^{3}\right)$

Spacing Applications

BIOdek 30060

$30(100)$

(inches)

BlOdek 19060

$42(140)$

1.07

Industrial/Municipal Waste

Roughing/polishing treatment

BlOdek 12060

$68(230)$

.750

BlOdek 7060

$115(383)$

.461

.250
Nitrification/Denitrification

Odor Control

Aquaculture

Bioremediation

Aquaculture Oil/Water Separation

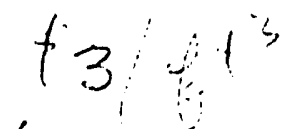

\%

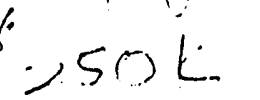

Water Sector $8 / 91$ 1-800-446-6868 
Pre-Biofilter conditions

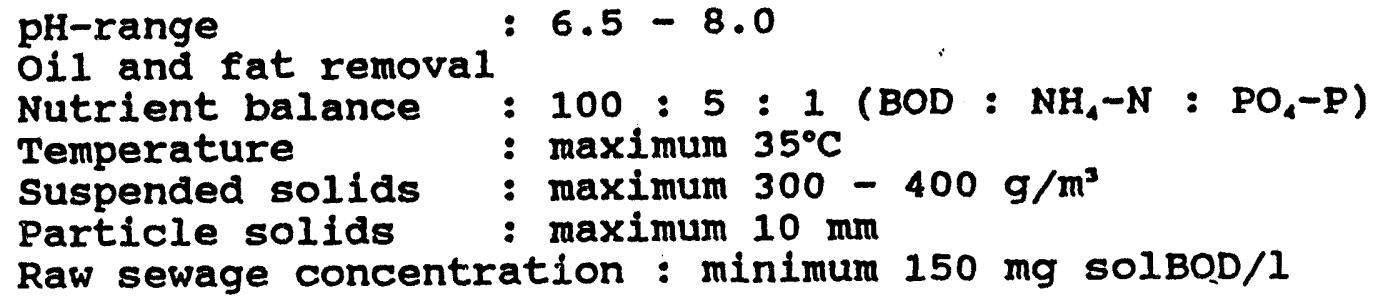

classification according to treatability

High curve

Fruit and vegetabile Distillery

Brewery

Dairy

\section{Median Curve}

Meat Processing

Poultry

Pulp and Paper

Municipal

Dye stuffs

Chemical

soft drink
Low Curve

Textile

Tannery

Landfill drainings

\section{REMARKS}

- In case there are doubts as to classification of the treatability, we recommend a pilot plant test.

- For full biological treatment and nitrification, please ask for special design recommendations.

- The design curves are based on Munters and independent research and the performance of full scale plants. However, it should not be construed as guaranteeing specific properties of the products or their suitability for a particular application. 


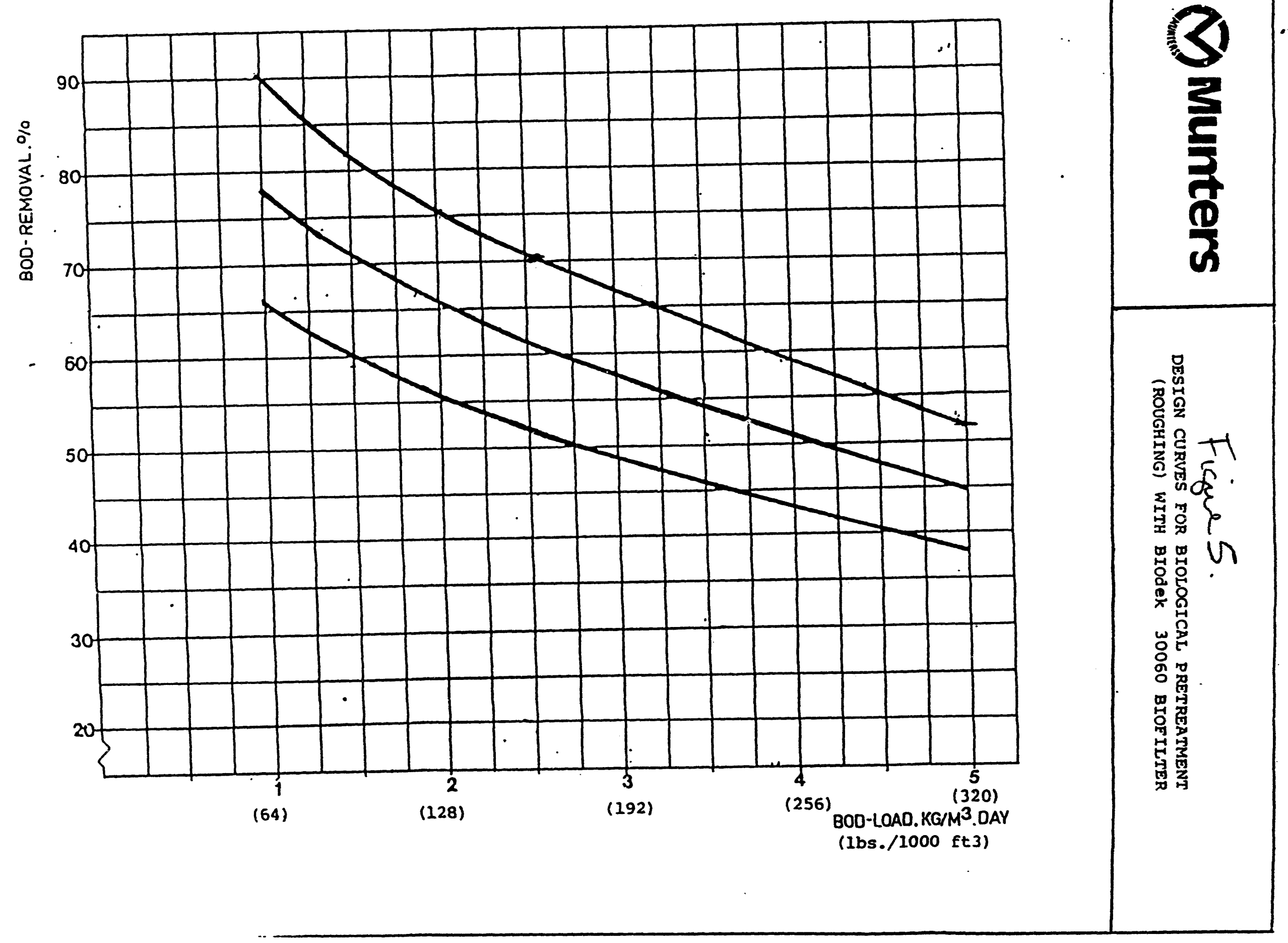


Biodeck decition ...

$m_{10 / 27 / 93}$

stage $1 \rightarrow$ BOD 1000

BOD enougl vate $57 \%$

Fud in $\rightarrow 5,000$ BOD @ 50,000 sal/day $\rightarrow 400,000=$ ppm $6,500 \mathrm{ft} / \mathrm{d} y \mathrm{y}$

$4,200 * /$ ay

$1,900 \mathrm{ks} / \mathrm{dag}$

Siage $1 \rightarrow 67 \%$ amoval $\rightarrow 1,414 * 10$ ay $/ \frac{320 *}{1000} \Rightarrow 4,40=1 t^{3}$

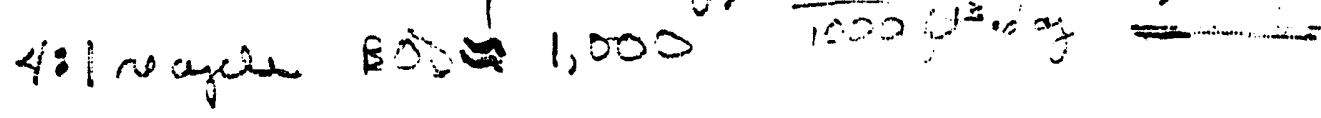

$$
h=15^{\prime}, A_{c}=300 t^{2}-16^{\prime} \leftrightarrow 20^{\prime}
$$

$\sin 2 \rightarrow 75 \%=128 \% 10 \%=00 \%$

$$
\begin{aligned}
& \text { BOD }=250 \\
& h=15^{\prime}
\end{aligned}
$$

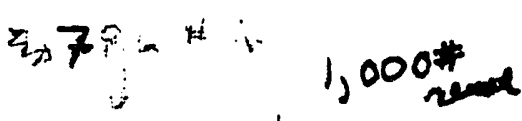

$$
\begin{aligned}
& 196 \text { * ont } \\
& \Rightarrow 4,12 y^{3}
\end{aligned}
$$

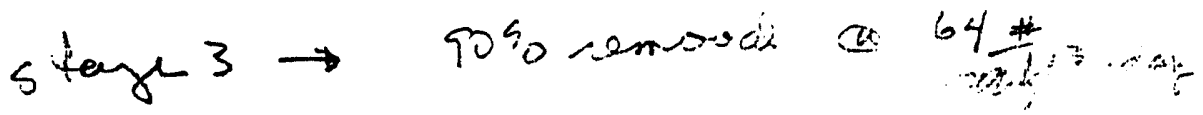

$$
\begin{aligned}
& 311=1,260 y^{\circ} \\
& \Rightarrow 2,061
\end{aligned}
$$

$$
1307=25
$$




$$
\frac{S_{e}}{S_{o}}=\exp \left(-K S_{o}^{m} H^{n} L\right)
$$

Where $\mathrm{H}$ is the hydraulic loading rate on the bed ( $\mathrm{ft} 3 / \mathrm{ft} 2$ day). A plot of this equation using $\mathrm{K}$ of 50, $\mathrm{m}$ of.- .43 , and $\mathrm{n}$ of -.70 is shown in Figure 4 for various inlet feed concentrations ( $\left(\mathrm{S}_{\mathrm{e}}\right)$, a hydraulic loading rate of $600 \mathrm{ft} 3 / \mathrm{ft} 2$ day $(180 \mathrm{gal} / \mathrm{ft} 2 \mathrm{hr}$ ) and a bed depth of 15 feet. A design plot for a structured plastic packing from Munters is shown in Figure 5, and replotted on Figure 4 showing the applicability of equation 2. Crine et al, (1990) suggest that the performance of trickle filters might be characterized by the amount and degree of wetting of the surface, and a minimal surface flow rate $\Gamma$ which both wets and scours the surface to allow the film to be contacted with the waste water and prevent $a$ build-up or clogging of the packing.

$$
\frac{S_{e}}{S_{o}}=\exp \left(-K A_{w} H^{-1} L\right)
$$

where $A_{\text {in }}$ is the wetted surface area of the bed. They show that $\Gamma$ varies between 0.5 and $3.5 \times 10^{-4} \mathrm{~m} 2 / \mathrm{hr}$ for a wide variety of packing types where $\Gamma$ is defined as:

$$
\Gamma=\frac{H}{A_{s}}
$$

where $A_{S}$ is the specific area of the packing $(\mathrm{m} 2 / \mathrm{m} 3)$, and $\mathrm{H}$ is the hydraulic loading of the packing $(\mathrm{m} 3 / \mathrm{hr})$. Crine et al. also determine that $\Gamma_{\min }$ is related to the biomass loading of the bed in a linear fashion:

$$
\Gamma=.0081 K S_{o}
$$

They determine an estimate of $\mathrm{K}$ as $.0034 \mathrm{~m} / \mathrm{h}$, and $\Gamma_{\min }$ of These estimates allow the design of trickle filters for a wide range of packing types as well as giving required minimum hydrauling loading rates.

\section{References}

1. Chippenfield, P, M Askew, and H Benton. 1972. "Multiple Stage Plastic Media Treatment Plants" J of WPCF 44:10 1955-1975.

2. Crine, M., M Schlitz and L Vandevenne. 1990. "Evaluation of the performances of random Plastic Media in Aerobic Trickling Fllters. Wat Sci Tech. 22:1 227-238

3. Dale, M.C., L. Salicetti, B. Truax, and M. Okos. 1991. "Conversion of Dilute Lactic Acid to Single Cell Protein". ASAE paper \#916585. 
4. Grady,CP, and H. Lim. 1980. "Biological Wastewater Treatment" Marcel Dekker Inc. $\mathbf{N Y}$.

5. Harrison, J.R. Ed. 1986. "Operation and Maintainance of Trickling Filters" Water Pollution Control Fed., VA

6. Mobius, C., I. Demel, and R. Huster. 1990. "Performance Increase of Papermill Waste Water Treatment Platns by a High Capacity Trickling Filter Inserted as First Stage" Water Sci and Tech. 22:7, 217-223.

7. Orr,P and R. Lawty. 1990. "Operating Experience with Large Random Packed Biofilm Reactors" Wat Sci Tech. 22:1 203-214

8. Parker, D. M. Lutz, and A Pratt. 1990. "New Trickling Filter Applications in the USA" Water Sci Tech. 22:1, 215-226.

9. Sarner,E. 1980. "Plastic-Packed Trickle Filters" Ann Arbor Sci. MI 


\title{
Appendix 2.6C
}

\author{
Operation at Purdue
}




\title{
Design and Operation of a 200 Liter Yeast Pilot Plant: A Gas Continuous Immobilized Cell Reactor
}

\author{
M. Clark Dale and M. Moelhman \\ Biochemical and Food Process Eng. Div. AGEN, Purdue University
}

Reacior Design

A reactor chamber for testing an immobilized yeast bed was built by Merrill Iron and Steel. The basic design of the unit consists of a epoxy painted mild steel frame covered with plexiglass sheets allowing observation of the reactor internals. The frame is covered in plexiglass sheets held to the frame by clamps. The cell immobilization matrix was installed in the reactor. Air and feed were recirculated to the top of the matrix to allow gas and liquid co-current flow. The liquid tends to flow down through the absorbant sheets while the gas passes between the sheets. There is a 2 " air inlet at the top of the reactor, and a 4 " outlet 12 " from the bottom of the reactor. The largest portion of the reactor is run gas continuous, with a liquid pool of a depth of 6 " in the bottom of the reactor to feed the recirculation pump. This pool has an approximate volume of 10 gallons. Liquid level is maintained by a overflow standpipe at 6 " which allows product to be delivered from the reactor. $\mathrm{A} \mathrm{pH}$ probe and oxygen probe were installed in the liquid recycle line from the bottom of the reactor to the recirc. pump.

\section{Air Feed to the Reactor}

A 1/3 HP low pressure blower is used to provide air to the reactor. The flow capacity curve for this blower is shown in Figure 2. Air coming into the blower is filtered through $22 \times 2$ ' high efficiency furnace filters. The outlet from the blower is taken to a series of two HEPA filters to sterilize the air. Thus the inlet air filters removed most of the dust and dirt, while the HEPA filters remove all particle of .2 microns or larger. After leaving the HEPA filters, the air is taken to a humidification column. This column is a 12" diameter expoxy painted mild steel column packed with a mesh packing matrix. Water is recirculated using a $1 / 8 \mathrm{HP}$ magnetic drive centrifugal pump. Steam is introduced into the air stream entering the humidifier. The steam flow is controlled by a self actuated temperature control valve with the temperature sensor placed in the air stream leaving the humidifier. This air system is shown diagramatically in Figure 3. Air flow to the reactor was measured at about 150 CFM with a pressure drop through the reactor of about 1.5 " H2O. 


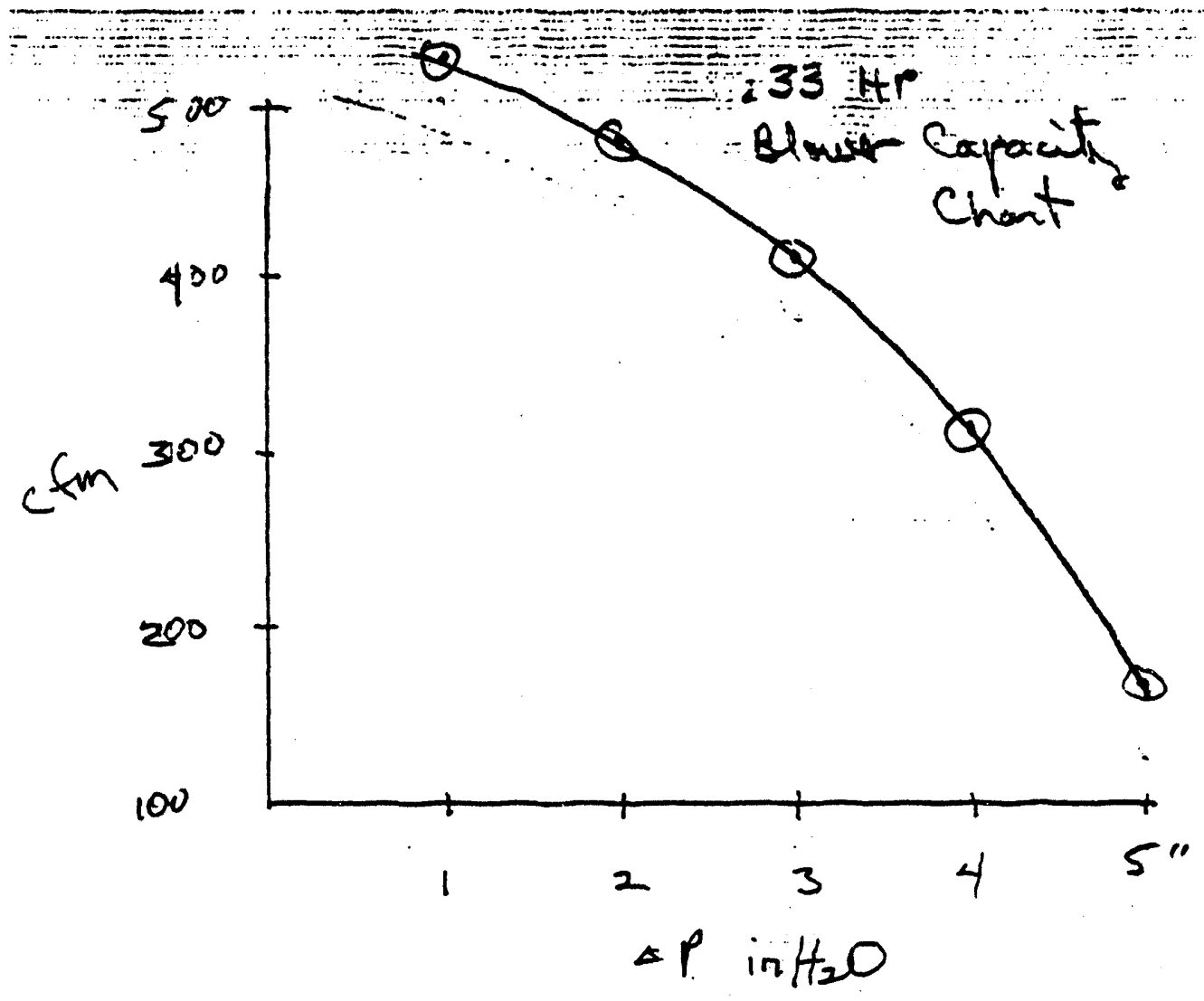

Figun 2. Blonser Capacity

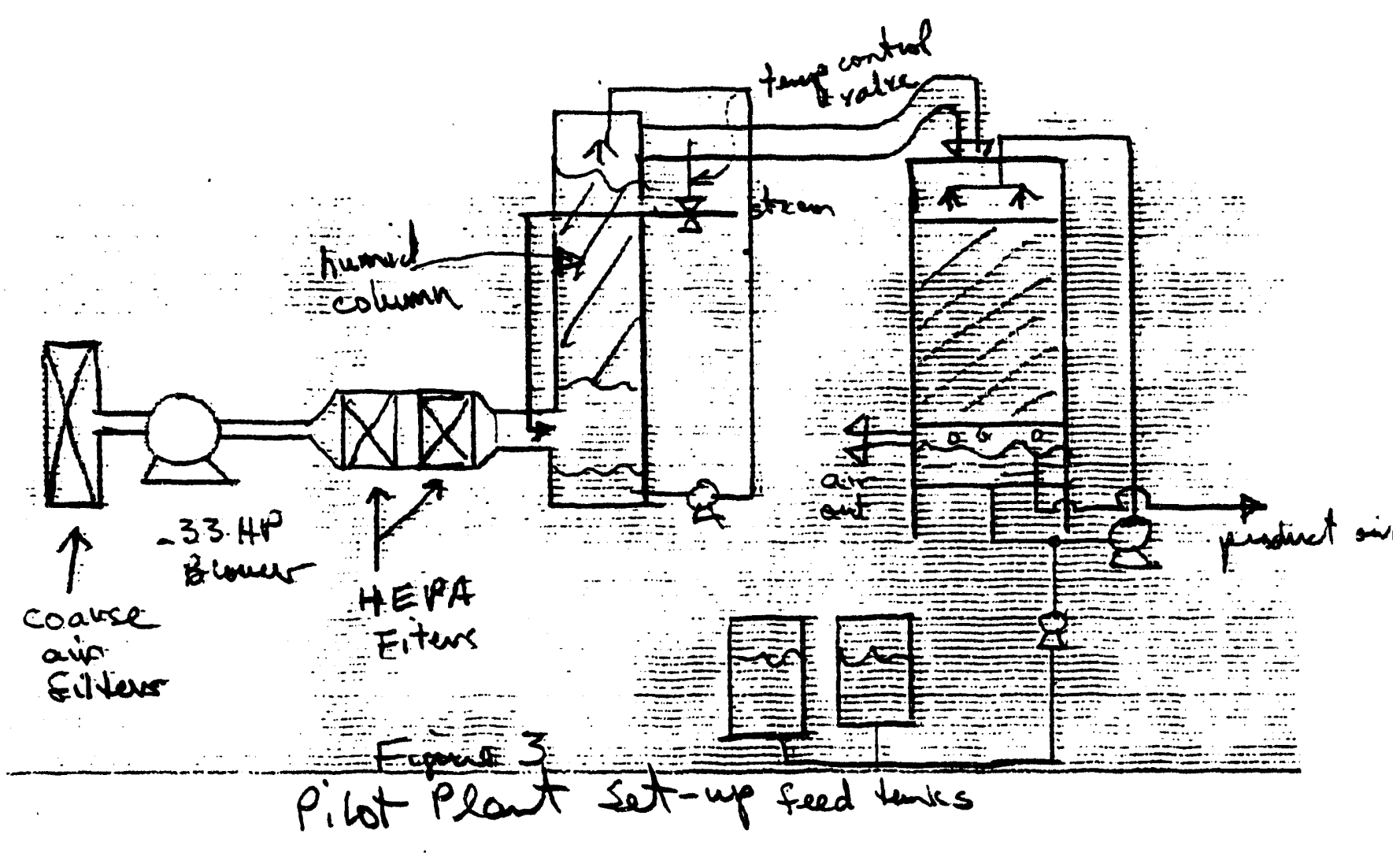




\section{Liquid Feed to the Reactor}

Liquid feed to the reactor is introduced to the inlet of the recirculation pump which distributes the feed and the recirculation stream over the top of the packing matrix. The feed is taken from 90 gallon stainless steel jacketed temperature controlled tanks using a masterflex type peristaltic pump. A 1/3 HP self priming centrifugal pump is used to recirculate the fermentation broth. Flow rates for the recirc. pump were measured at about 20 GPM using 'pig tail' type low pressure spray heads. The spray heads are designed to be able to be raised and lowered to allow adjustment of the spray impact region.

\section{Operation of the 200 L Yeast Reactor}

Feed was added to the reactor on a continuous basis, with lactose levels monitored at regular intervals. Feed rates were determined by gradually increasing the feed rate while monitoring residual lactose levels from the reactor. As long as residual lactose levels were under $1 \%(10 \mathrm{~g} / \mathrm{l})$ the feed rate was increased. The feed rate was then held at this higher feed rate for 4 to 24 hours after which lactose levels were again monitored. When outlet levels of lactose were over $10 \mathrm{~g} /$, the feed rate was held steady or decreased until lactose concentrations decreased. The reactor was started on 5\% whey permeate, then 10 , 15,20 and finally $30 \%$ whey permeate was fed.

The feed to the system consisted of dried permeate, donated to the project by Foremost Food Ingredients of Baraboo, WI. Dried permeate was weighed and mixed into 90 gallon jacketed feed tanks which were held at 150-170 F. The basic ingredients used are shown in Table 1

Table 1. Feed Make-up for Yeast Reactor

Per each 100 \# permeate at $80 \%$ lactose:

24\# NH4SO4

$920 \mathrm{ml} \mathrm{H} 3 \mathrm{PO} 4$ (75\%)

$250 \mathrm{ml} \mathrm{H} 2 \mathrm{SO} 4$

$1.5 \mathrm{~g}$. niacin

$0.45 \mathrm{~g}$. pantothenic acid

61 g. trace elements @ 64\% FeSO4

$5.2 \% \mathrm{CuSO} 4$

$27 \% \mathrm{ZnSO} 4$

$2.1 \% \mathrm{MnSO} 4$

$1.1 \% \mathrm{Na} 2 \mathrm{MoO} 4$

$0.2 \% \mathrm{CoCl} 2$

$400 \mathrm{ppm} \mathrm{Na2SO} 3$

4 L Com Steep Liquor (30\% TS) 
Total salts and nutrients to lactose ratio of feed $0.61 / 1.0$

\section{Experimental Performance of the Pilot AGCIY}

The Aerobic Gas Continuous Immobilized Yeast (AGCIY) reactor was initially seeded on 12/1/93 with 60 gallons of aerobically grown yeast. A 5\% whey solids stream with nutrients as shown in Table 1 was started at 3 Liter per hour (LPH). Effluent lactose level was monitored using HPLC and brix readings. (Brix reading were correlated by the HPLC allowing rapid determination of lactose levels.) Some foaming was noted, and silicon and vegetable oil antifoams were added to the liquid resevoir (aquarium) at the bottom of the reactor. Few yeasts were noted in the overflow $(0.1 \mathrm{~g} / /$ cells $)$ as most cells were attaching to the matrix. On $12 / 3$ it was noted that mold growth was beginning on the matrix, while the $\mathrm{pH}$ of the medium had dropped to 2.3-2.7. By 12/4 large mats of mold had formed, blocking much of the spacing between the matrix sheets. The reactor was turned off, cleaned in place by a pressurized water spray.

The reactor was sterilized by using a $0.5 \%$ formaldehyde solution recyling in the system, while inhibition studies with propionate were undertaken to be able to inhibit mold growth in future studies. It was found that $400 \mathrm{ppm}$ propionate would stop mold growth without hurting yeasts. Yeast growth was inhibited at $1000 \mathrm{ppm}$ propionate, with a $19 \%$ inhibition of 72 hour concentration with yeast strain 2415 , and a $40 \%$ inhibion of yeast density with strain 1109 . In our futher studies, $400 \mathrm{ppm}$ propionate was added to the feed.

The effectiveness of the washing procedure was determined by adding a yeast stream to two cloth samples (dimensions 2 by $10 \mathrm{~cm}$ ) \#1 from the reactor, and \#2 a fresh clean cloth sample. Yeast holding in the old matrix was determined to be about $50 \%$ reduced as compared to the new matrix ( $.31 \mathrm{~g}$ cells adsorbed onto the new matrix with $.16 \mathrm{~g}$ cells adsorbed onto the new matrix). Total weight of the dried matrix samples after adding of the cells was $29.95 \mathrm{~g}$ for the fresh matrix and $34.45 \mathrm{~g}$ for the sample from the reactor.

The seed tank was again innoculated with 60 gallons of yeast prepared. On 12/19, an innoculation of $2.8 \mathrm{~g} / \mathrm{l}$ cells was taken over to the reactor. A feed of $5 \%$ whey w/ nutrients was added at $2.4 \mathrm{LPH}$. On 12/20 5" of foam was noted in the LR, with a cell density of 16 million cells $/ \mathrm{ml}(0.5 \mathrm{~g}$ cell/L). Temperature was held at $92 \mathrm{~F}$. by steam addition to the humidifier. By $12 / 22$ yeast build up on the matrix could be noted visually with streaks of grey/white noted. The feed rate was increased to $7.2 \mathrm{LPH}$. By 12/25 a high concentation of yeast was beginning to be shed from the reactor- 50 million cells $/ \mathrm{ml}$ $(1.5 \mathrm{~g} / \mathrm{L})$. On $12 / 27$ the feed rate was increased to $10.5 \mathrm{LPH}$, with 1.05 billion cell $/ \mathrm{ml}$ noted $(32 \mathrm{~g} / \mathrm{L})$. The cell density dropped for the next few days to 0.4 billion cells $/ \mathrm{ml}$ (17 $\mathrm{g} / \mathrm{L}$ ). On $1 / 1 / 94$, the feed was adjusted to $10 \%$ permeate plus nutrients. Some mold was noted to be coating the outside portions of the matrix which were not being hit with the 
feed spray. On $1 / 2 / 94$, a cell density of 1.1 billion cells/ml ( $35 \mathrm{~g} / \mathrm{L}$ cells) was recorded at a feed rate of $5.3 \mathrm{LPH}$ with an outlet lactose level of $0.25 \%$. 1/3 data showed 0.3 billion cells $/ \mathrm{ml}, 9.3 \mathrm{~g} / \mathrm{L}$ cells, no outlet lactose, and no ethanol at a feed flow rate of $5.0 \mathrm{LPH}$. $1 / 8$ data showed 0.57 billion cell $/ \mathrm{ml}(17.6 \mathrm{~g} / \mathrm{L})$ yeast with some bacteria. Antibiotic (penicillin-streptomyocin) was added on a daily basis. $1 / 11$ data indicated 0.5 billion cells $(15.6 \mathrm{~g} / \mathrm{L})$ cells with fewer bacteria. Foaming continued to be a problem with the reactor. Occaionally the foam was quite stiff and hard to dissipate even with fairly large added doses $(10 \mathrm{ml})$ of antifoam.

On $1 / 12$ the feed strength was increased to $15 \%$ whey permeate plus nutrients for a total feed brix of 16.7. Feed rate was adjusted to about 3.2 LPH. A cell count of 0.4 billion cells $(12.5 \mathrm{~g} / \mathrm{L})$ was noted on $1 / 13$. $1 / 15$ showed 0.75 billion cells $(24 \mathrm{~g} / \mathrm{L})$, while on $1 / 160.95$ billion cells/ml were counted $(29.5 \mathrm{~g} / \mathrm{L})$.

On 1/21 the feed concentration was again raised to $20 \%$ inlet brix of 19.4 and the feed rate adusted to $2.1 \mathrm{LPH}$. A cell count of 1.2 billion cells $(35 \mathrm{~g} /$ ) was noted on 1/24. Foaming problems were reduced at the slower feed rates given to the reactor at 15 and $20 \%$ permeate probably due to the slower rate of antifoam washout. On 1/25 a cell count of 1.8 billion cells $/ \mathrm{ml}(55.8 \mathrm{~g} / \mathrm{L})$ was recorded.

On $1 / 27$ the feed concentration was increase to $30 \%$ whey permeate. A cell count on $1 / 31$ showed 0.85 billion cells ( $26 \mathrm{~g} / \mathrm{L}$ ) with an inlet brix of 32 and outlet brix of 21.4 . The cells seemed to be smaller than normal on a visual inspection. A crack in the side of the reactor developed at this time and was closed with a strip of duct tape. On 2/2, an outlet brix of 20.8 was noted with 0.48 billion cells/ml counted $(14 \mathrm{~g} / \mathrm{L})$.

Analysis of Results

Feed flows, inlet and outlet lactose levels over the 50 day experiment are shown in Figure 4. We see that outlet lactose levels were kept low throughout the experiment, with some higher levels $(2-3 \%)$ noted at the end of the trial where $30 \%$ whey permeate was fed. Figure 5 shows yeild, $\mathrm{Y} x / \mathrm{s}$, grams of yeast (dry basis) per gram of lactose disappearing from the reactor. We see that yields dropped from near theoretical $(.5 \mathrm{~g} / \mathrm{g})$ on $1 / 4$ when bacterial infection was noted in the reactor. Mold growth may have also contributed to lower yeast yields. Yields stabilized at $0.2-0.3$ as the feed concentration was raised from 10 to 15 to $20 \%$. However, at $30 \%$ feed, yields dropped considerably. Lactose utilization rates were relatively constant at about $2.0 \mathrm{~g} / \mathrm{L}$ for all the feed rates, with a slight loss in reaction rates as feed concentration increases.

Table 2 shows lactose utilization rates and yeilds obtained by various researchers producing yeast from whey in batch and continuous reactors.

Our calculations indicate that the liquid hold-up in the reactor is about $25 \%$, so that on a liquid hold-up basis, reaction rates in the AGCIY are about $10 \mathrm{~g} / \mathrm{l}$-hr. This compares well 


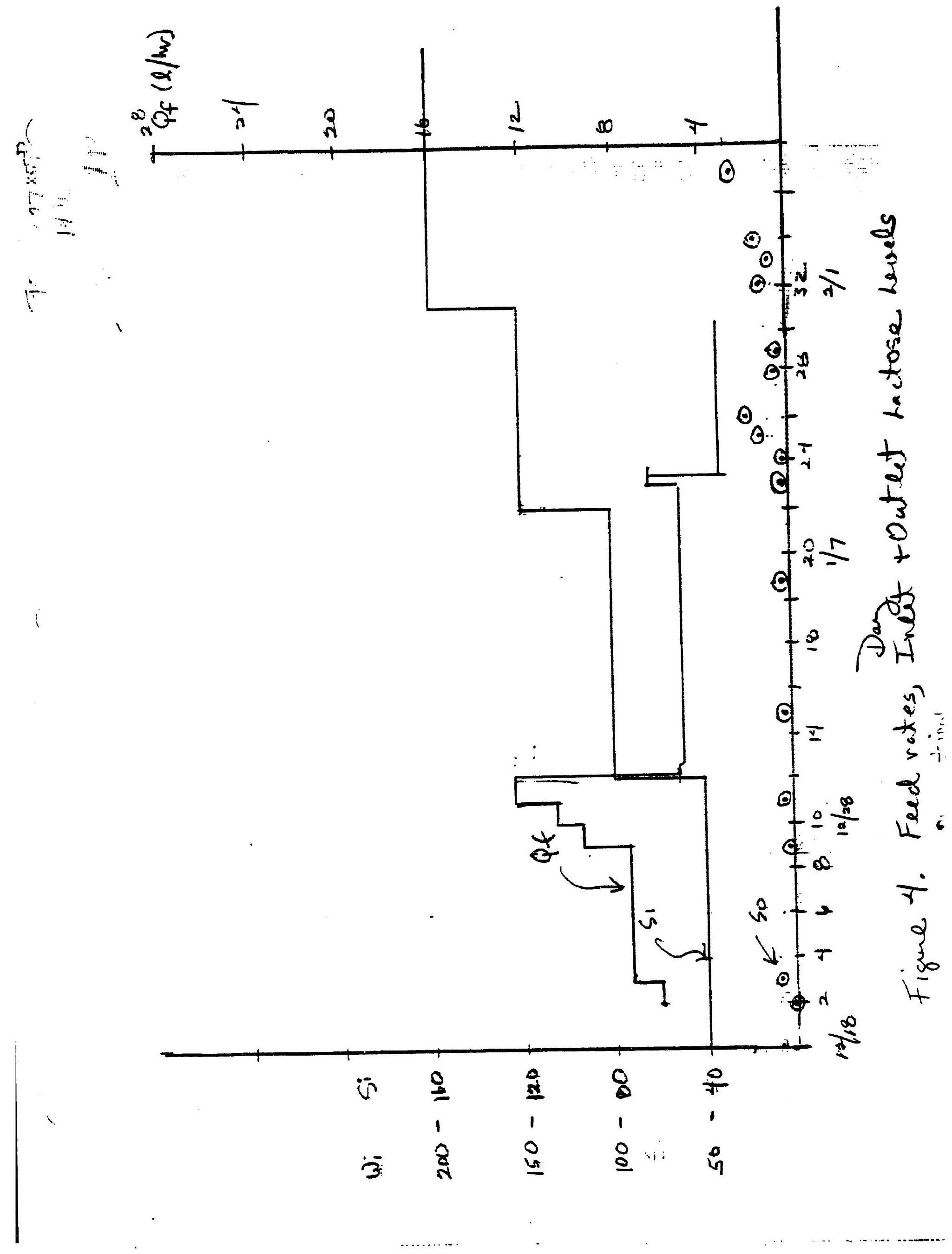




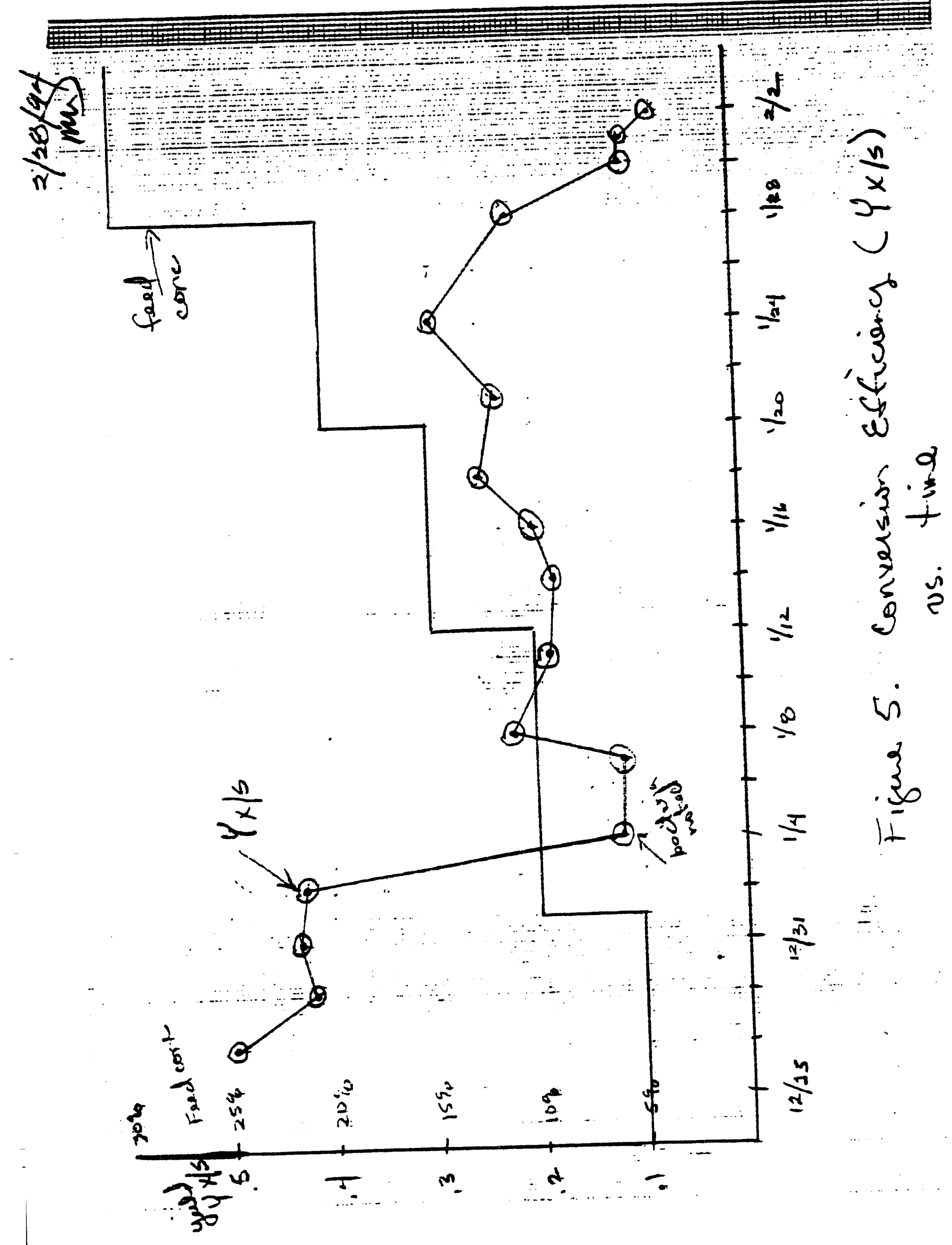


Table 2. $\begin{gathered}\text { Eactose Utiligation } \\ \text { Rates }\end{gathered}$

Researcher

Latese

utiligation Rte

yeast

$y$ reld

(a yeust/g Lartas)

.31

1) Monsour etal

4 g/L.hor

2) Bunstein + Everson

$6.3 \mathrm{~g} / \mathrm{L} \cdot \mathrm{hm}$

.45

3) Bechtle + Claytom

$3.1 \mathrm{~g} / \mathrm{L} \cdot \mathrm{hr}$

.50

4) Vanavat +Kinselk

$2.4 \mathrm{~g} / 2.4 \mathrm{r}$

.55 (1975)

5.) Maiovella + Custillo

$6.2 \mathrm{~g} / \mathrm{h} \cdot \mathrm{mr}$

.45

6) Movess at al C 1990

4.1
8.7
10.7

.47

.38

$-36$

7) Wasser man

$10.75 \mathrm{~g} / \mathrm{h} \cdot \mathrm{m}$

$-51$

8) Shay + Waguer

10 glLow

.43

20

.44

40

$-44$

$\mathrm{TO}$ (w/ rime $\mathrm{O}_{2}$ )

$-43$ 
to most of the results given in the literature.

\section{Conclusions}

From these results we can conclude:

1) the reactor can be operated on a continuous, low labor, low trouble manner for extended periods of time.

2) Lactose utilization rates are similar to batch yeast growth rates as reported in the literature on a volumetric basis, but higher on a liquid hold-up basis.

3) The reactor should be designed to have sterile operating conditions. Bacteria and mold both were determined to be able to co-exist in the reactor. Adding propionate can control molds, and low pH combined with antibiotics can control bacteria, but it is preferable to not add these compounds.

4) Yields in the reactor were lower than would be ideal, although near $100 \%$ efficient yields were noted for during week 2 of operation at 5 and $10 \%$ whey feeds. We feel that yields dropped due to competing organisms in the reactor. Yeilds of 0.2 to 0.3 (40 to $60 \%$ of theoretical) were noted for operation at 15 and $20 \%$ whey permeate feed concentrations.

5) A feed concentration of $30 \%$ caused yeild performance to drop considerably. We suspect that the salt concentration is inhibitory at this level of feed.

Process Economics for the AGCIY reactor.

A process.for the conversion of whey permeate to yeast is shown in Figure 6 . In this design, a 0.2 micron sterile filtration system is suggested for feed sterilization. The concentrate from this membrane process can be taken back to the UF system to improve yields. A flash heat sterilization could also be used, although it is important to keep flow turbulent when heating and cooling whey permeate as there is a tendancy for minerals from the whey to preciptate onto heat exchange surfaces. In Table 3, the economics of yeast production by a standard process as suggested my Maiorella (1984) is compared with the AGCIY reactor. Both processes are characterized by an input stream of 100,000 \#/day of $6.2 \%$ whey permeate. The conventional process converts the whey lactose to yeast, centrifugally collects the yeast, and discards 70,000 \# day of exhaused (de-lactosed) whey permeate with a BOD estimated at $10,000 \mathrm{ppm}$ to a waste water system. The AGCTY system concentrates the whey by a factor of 3 to $18 \%$ solids using RO, sterilizes the concentrate using a 0.2 micron membrane, and this concentrate is converted to a $12 \%$ solids mineral yeast product. As per Table 3, energy use by the AGCTY reactor is 
estimated at $16 \mathrm{HP}$ versus $105 \mathrm{HP}$ for the conventional fermenters, a reduction of about $85 \%$ in energy use. Drying costs are similar for the two processes. Costs for concentrating the whey with RO are comparable to the cost of treating the waste water in the conventional system. Capital costs for the AGCIY reactor are about $79 \%$ less than the conventional fermenters. Total capital cost for the AGCTY system is estimated at $\$ 365 \mathrm{~K}$ (bare module cost) versus $\$ 827 \mathrm{~K}$ for the conventional system. 


\section{Table 3.}

Preliminary Economic Comparison of the AGCTY Reactor for Yeast Production versus Conventional System.

Basis- 100,000 \#/day of incoming $6.2 \%$ whey permeate ( $5 \%$ lactose).

Conventional- Two stirred, aerated fermenters $(20,000$ gal each), a centrifuge, yeast cream storage, and drier

Capital Equipment

1) seed tank- 400 gallon- $\$ 8.5 *(980 / 560)$

2) fermenters- $2 @ 20,000$ gal- $2 *(20,000 / 10,000)^{\wedge} .6 * \$ 100.5$ $\mathrm{w} /$ agitators, cooling coils, aeration---.-> $\$ 528 \mathrm{~K}$

3) centrifuge- $110 \mathrm{HP}-\$ 18.9 *(10 \mathrm{HP} / 5 \mathrm{HP})^{\wedge} .8 *(980 / 560)$ $----->\$ 57 \mathrm{~K}$

4) fluidized bed drier- $26,000 \# /$ day water removed ----->\$90 K

5) 70,000 \# day waste water @ 10,000 ppm BOD .....-> $\$ 150 \mathrm{~K}$

$$
\text { TOTAL \$827 K }
$$

Energy Requirements

1) fermenter- air compressor -...-.. $75 \mathrm{HP}$

$$
\begin{aligned}
& \text { agitator--.---.--- } 30 \mathrm{HP} \\
& \text { cooling water--...-.-- } 30,000 \# / \mathrm{hr}
\end{aligned}
$$

2) centrifuge-

$10 \mathrm{HP}$

3) Fluid bed drier $60 \mathrm{MSCF} / \mathrm{day}$

4) Waste water (0.5 KW/\#BOD)--.-.-.- $300 \mathrm{KW}$-h/day

Energy Costs---(elect .05/KW-h, gas \$4/MSCF, $\$ .01 / 1000 \#$ CW)---> \$358/day

Product rate: $2,500 \# /$ day dried yeast at $85 \%$ yeast, $15 \%$ minerals 


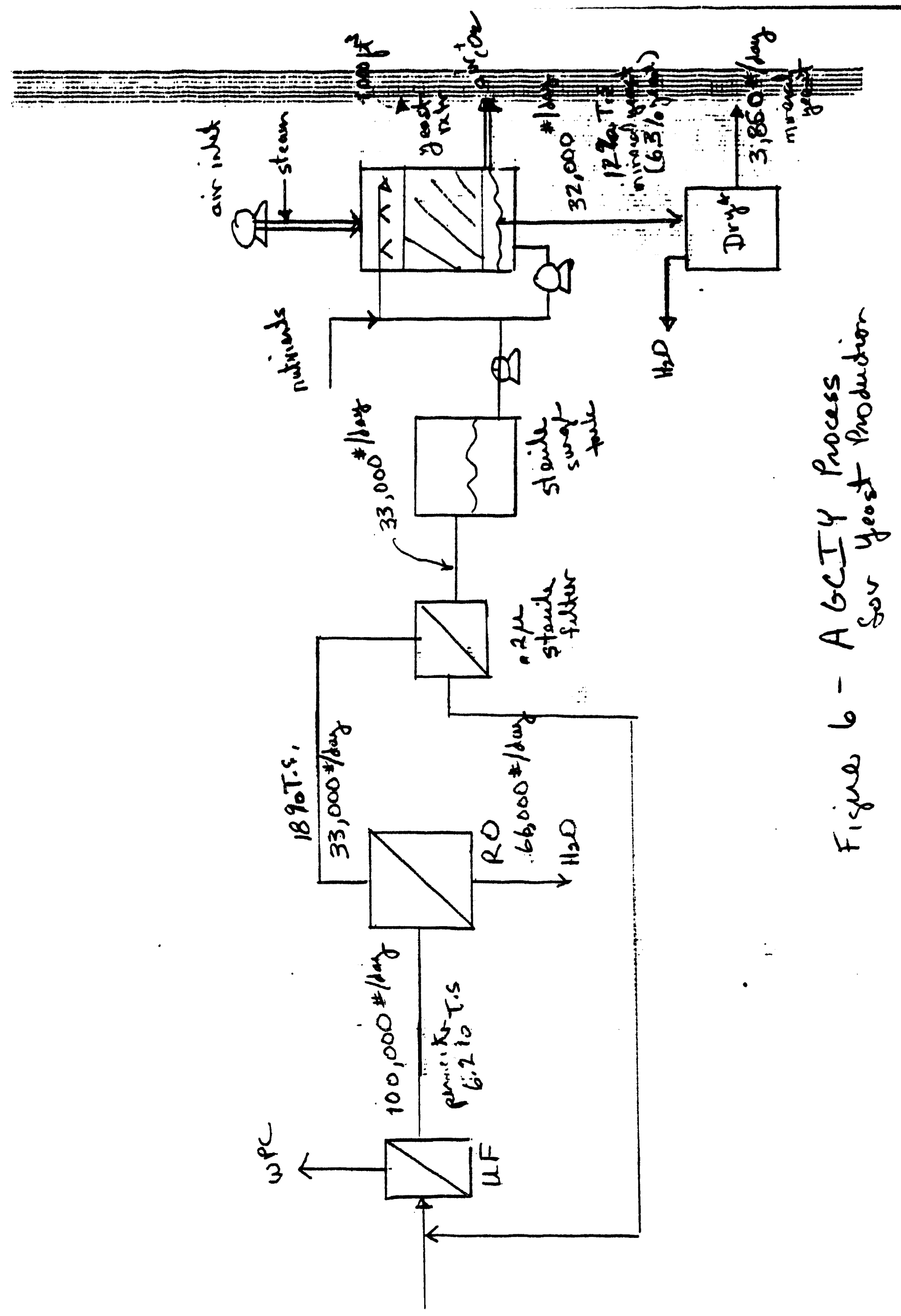




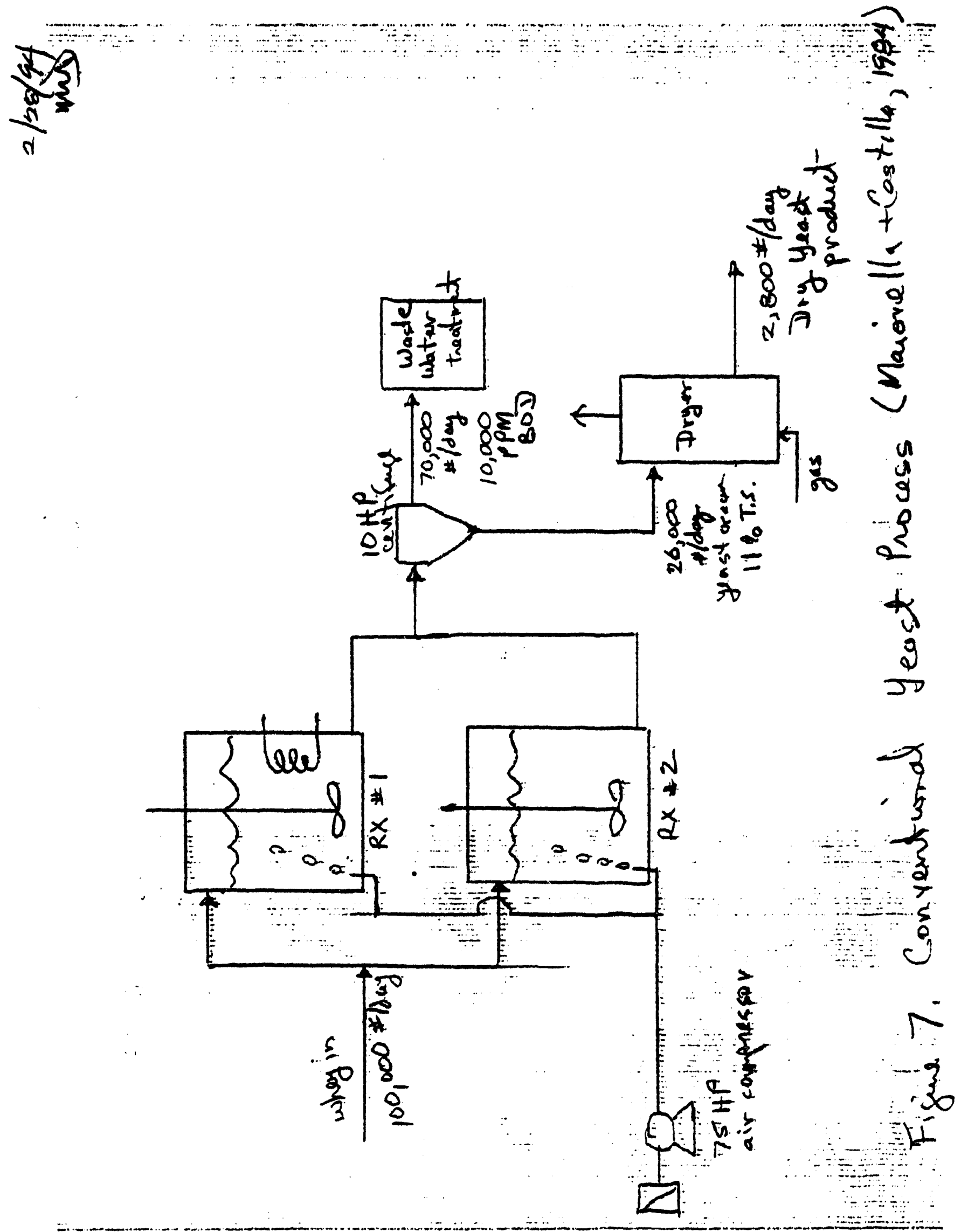


AGCIY Reactor Economics- RO conc./memb. steriliz, AGCIY Reactor, Fluidized Bed Dryer

Capital Equipment

1) seed tank- 400 gallon- $\$ 8.5 *(980 / 560)---->\$ 12.8 \mathrm{~K}$

2) RO/.2 micron membrane system ( $3 \mathrm{X}$ to $18 \%$ )

$\$ 120 \mathrm{~K} *(980 / 60)-\ldots-\ldots 153 \mathrm{~K}$

3) AGCIY fermenter- $1 @ 750 \mathrm{ft} 3 \mathrm{w} / 1 \mathrm{HP}$ blower---> $\$ 110 \mathrm{~K}$

4) fluidized bed drier- $28,800 \# /$ day water removed --.-->\$90 K

TOTAL \$365 K

Energy Requirments

1) $\mathrm{RO} / .2$ micron system $30 \mathrm{HP}$

2) AGCTY reactor -........-> $26 \mathrm{HP}$

3) fluidized bed drier- 67 MSCF/day

Energy Costs---(elect .05/KW-h, gas \$4/MSCF, \$.01/1000\# CW)---> \$315/day

Product yield -.------> 3,850 \#/day of mineral yeast (55-65\% yeast, 35-45\% minerals) 


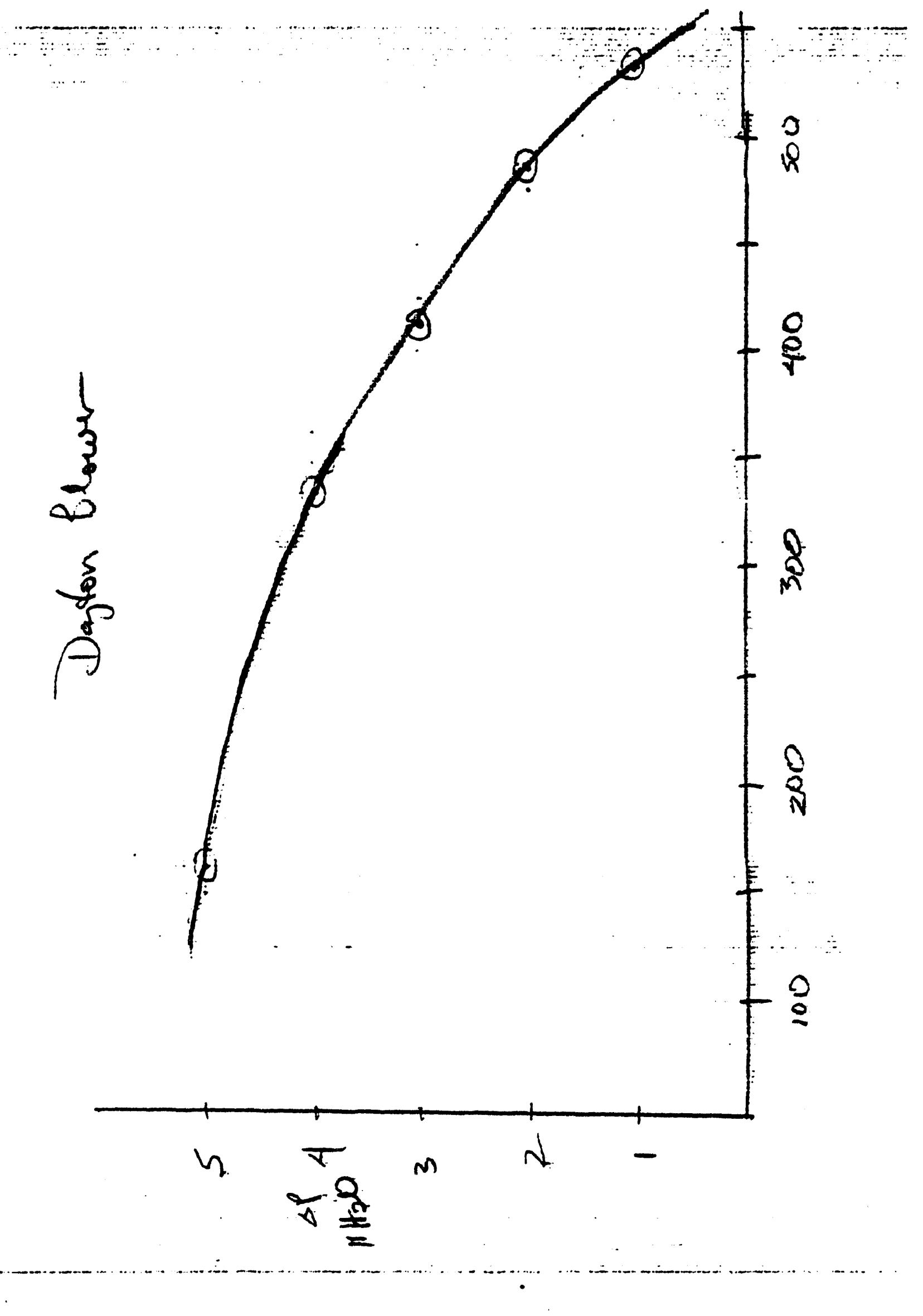




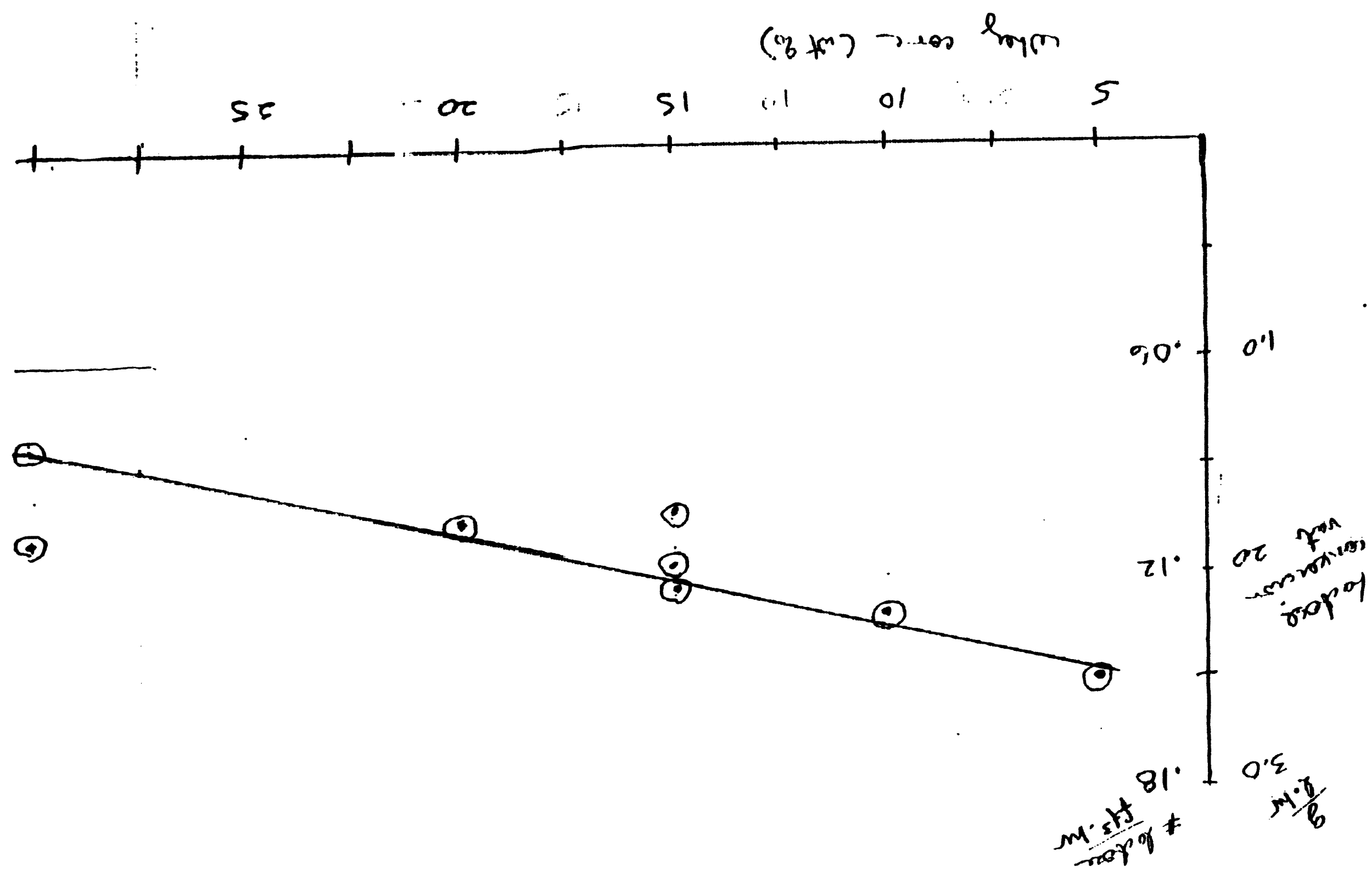

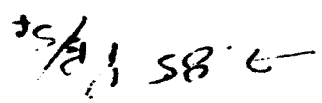




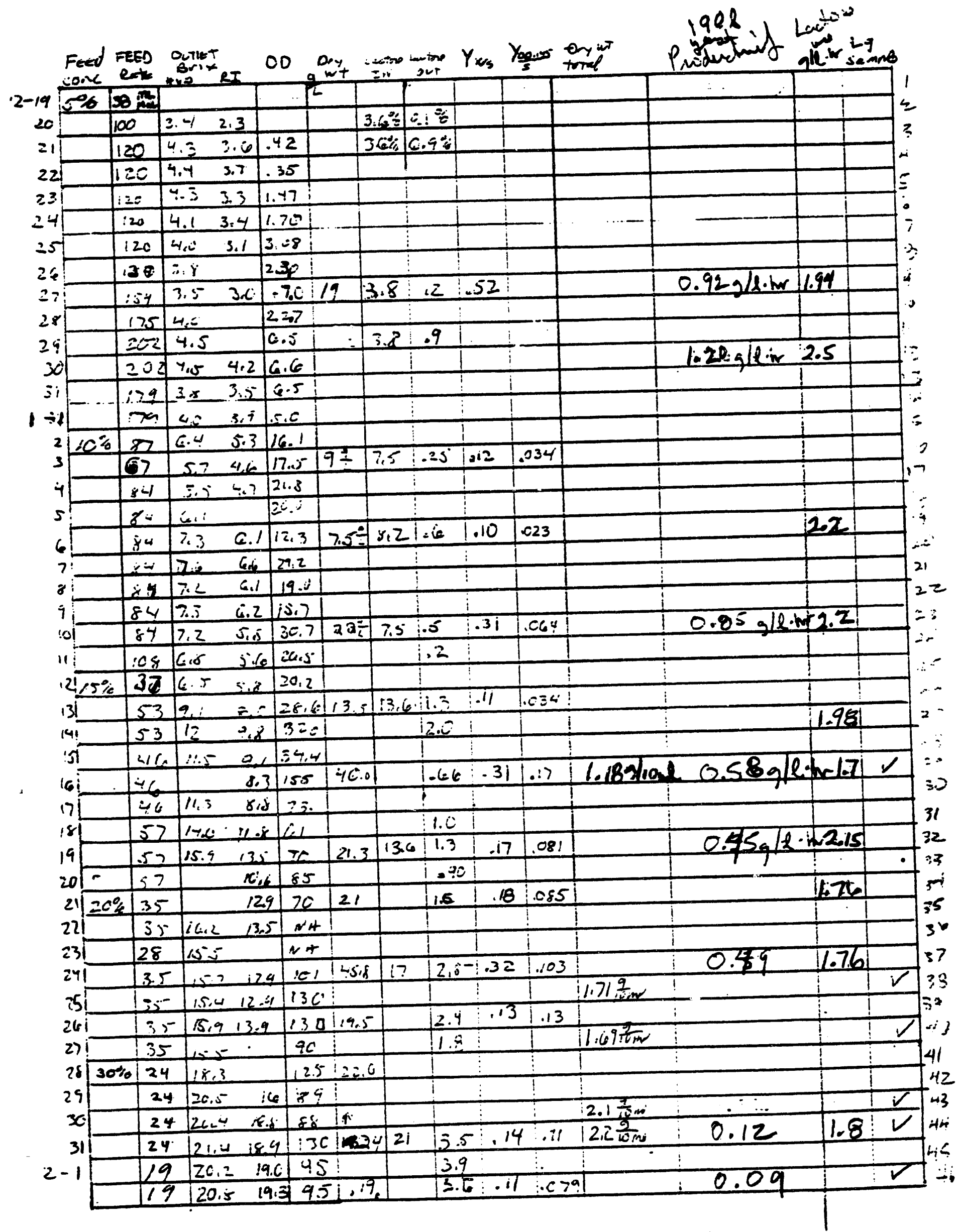




\title{
Appendix 2.7
}

\author{
CSRS Pilot Plant
}




\section{Development of an Low-Energy Reactor-Separator Process for the Production of Ethanol from Grain or Biomass}

\section{Executive Summary}

A novel reactor/separator is coupled with a solvent ethanol recovery system to give a low energy continuous process for the production of ethanol from starch or biomass. Combining reaction with separation allows the fermentation of highly concentrated streams of up to $50 \%$ solids. Simultaneous saccharification and fermentation of polysaccharides such as starch and cellulose can be quickly completed in the Continuous Reactor Separator (CRS). Preliminary calculations indicate that anhydrous ethanol ethanol may be obtained from feed concentrations as low as as 3 to 4\% sugar with an energy consumption of only 10,500 BTU/gal for ethanol recovery and dehydration when the CRS is coupled with solvent absorption recovery of the ethanol. This system will allow lower capital, lower energy usage, and lower labor production of ethanol. This CRS is a new type reactor which allows simultaneous saccharification, fermentation, and ethanol separation in a combined process. Combining these reactions allows significant improvements in each operation.

In this project, two basic efforts are proposed, 1) lab scale development of the CRS followed by 2) pilot scale testing of the technology on the 5,000 liter scale. A process for ethanol from ground corn has been designed which incorporates near complete recycle of the ensymes, cells, and water, so that the only process effluent is a compressed wet distiller's grain. Two technologies will be developed in conjunction with the CRS during the lab scale testing in the first year of the project, 'no cook' saccharification, and extrusion cook liquefaction. The 'no-cook' process has energy advantages, but may not be ready for implementation on the pilot scale, while the extrusion cook has been reasonably well demonstrated by a number of researchers. During the first year, lab scale work will focus on batch experiments along with construction and operation of a 4 liter CRS. Based on batch tests, the simultaneous saccharification and fermentation of starch will be demonstrated on the bench scale CRS. The effects of the recycling the liquid from the effluent to the reactor inlet will be documented. During the latter part of year one, a 5,000 liter CRS will be constructed at a small ethanol facility. This pilot plant will then be operated during year two of the project. During year two of the project, lab scale experiments will focus on using biomass (cellulose-hemicellulose streams) for reactor feed.

The reactor-separator consists of stirred tank type reactors operated in series, with the liquid streams moving from tank to tank contacted with a stripping gas to remove the ethanol product. Saccharification (of both starch and cellulose)is sped by the reduction of sugar concentration as the sugar is fermented to ethanol. Fermentation is sped by the removal of the toxic ethanol product, and ethanol purification and concentration costs are reduced by the enrichment of the ethanol in the vapor phase. The gas stream is co-current to the tank to tank liquid flow in the enriching section, and counter-current in the stripping section. The final effluent from the CRS is characterized by complete saccharification of all polysaccharides, complete fermentation of sugars to ethanol and complete removal or separation of the ethanol into the gas phase. 


\section{Rationale for Project}

Current batch fermentation technology for ethanol production requires large scale operations (12-50 million gal/yr of ethanol), a large capital investment (\$2-4.00/ annual gallon), and is energy intensive with an energy usage of 60-110,000 BTU/gal of ethanol produced from com. About half of this energy is associated with drying and evaporating the stillage, and half with fermentation and distillation. Current ethanol production level in the USA is at about 800 million gallons/yr. The total market for ethanol as a $10 \%$ blend in gasoline would be 12 billion gallons. As more and more ethanol is produced, it is important to our net energy position that ethanol be produced domestically in an energy efficient fashion. A Continuous Reactor Separator (CRS) consisting of stirred reactors matched with gas-liquid contactor stages has been designed and modeled. A patent $(\# 5,141,861)$ has been recently issued which decribes this reactor technology. This CRS is a new type reactor which allows simultaneous saccharification, fermentation, and ethanol separation in a combined process. Combining these reactions allows significant improvements in each operation. The CRS offers a low energy, reduced capital, and reduced labor process for the production of ethanol from starch or cellulose. The CRS system allows both high concentrations and low levels of substrate to be converted to anhydrous ethanol with low net energy consumption. Energy requirements for corn or grain to anhydrous fuel ethanol have been estimated at only 8,500 BTU/gal for smaller scale operations where the distillers grain is fed wet, and 28,500 BTU/gal for larger operations where the spent grain is dried. This represents a reduction of 70 to $91 \%$ of energy production cost for each gallon of ethanol produced. Total savings to the USA as this technology is implemented and retrofitted could be as high as $8 \times 10^{13}$ BTU/yr. As our nations oil supplies are depleted, and clean air requirements are stiffened, the need for ethanol fuels is becoming a national priority. If, however, current high energy technology (utilizing coal fired boilers) uses 60 to 120,000 BTU's of coal energy to produce 84,000 BTU's of liquid fuel energy per gallon of ethanol, the net effect is to produce a lot of coal fired boiler stack gas emmisions to reduce car exhaust emmisions. The net effect on the US environment of this trade-off is open to debate. We feel there is a strong need for new low energy ethanol production technology in the USA.

Reduced export markets suggest that it is critical to develop internal uses for grain products in the USA. Rapid changes in commodity prices make it important for grain processors to be able to produce a variety of products based on immediate evaluation of demand and profitability of these various products. The profitability of smaller grain processors and local grain elevators could be improved by a smaller scale, lower cost, low labor ethanol producion process. The current economics of scale for ethanol production force very large (6 to 40 million gallons ethanol/yr at a cost of $\$ 2-3.00 /$ annual gallon) plants in order to be competetive. With these large plants, a minimum investment of \$18-80 million is required, transportation of the grain, grain storage, and effluent handling are major problems. Smaller, more numerous ethanol facilities would allow use of substandard grain, com fines, or waste starch streams from corn or potato processors on a local level. Hauling costs would be minimized, and stillage utilization by local farmers can be maximized on a small 'community' level. In order to make this practicable, the capital, energy, and labor expenses associated with ethanol production must be minimized through new 
technology. Design and experimental work at Purdue University suggests that a new reactor/separator should offer dramatic reductions in ethanol production costs. Total utility costs for the fermentation, separation, and production of anhydrous ethanol can be held to under $\$ 0.10$ per gallon for a concentrated sugar stream based on preliminary design estimates. Initial cost estimates further suggest that capital, labor, space and effluent treatment costs are low in comparison to conventional fermentation systems. The integrated fermenter-separator was developed to allow continuous conversion of sugars to ethanol, and an immobilized cell type reactor-separator (ICRS) has been tested on whey lactose, glucose and sucrose streams. The ICRS concept has been tested, scaled-up and proven for concentrated lactose streams. We now wish to expand this technology to grain and cellulosic streams in a low effluent process.

In this proposal a two year project is proposed to allow experimental and design work to be performed to test a continuous two step (starch or cellulose to sugar/ sugar to ethanol), high efficiency, low effluent process for ethanol production. It is expected that this technology will make ethanol production economic on a small scale $(200,000-2$ million gal/yr). This work will further include modeling, design, and optimization of various sized operations. During the first year of this project, we will be focussing on grain (starch) to ethanol production which currently represents the largest feedstock utilized for ethanol production. Lab scale batch and CRS experiments will be performed. A 5,000 liter CRS will be designed and constructed during the latter part of the first year. This CRS will be operated during year two of the project while in the lab the use of cellulosic feed stocks will be studied with the intent of developing ethanol processes from non-food sources.

\section{Decription of the Research}

There are three major goals for this project:

1) Determination of starch hydroysis/fermentation kinetics in the CRS
a)'no-cook' kinetics
b) extrusion cook kinetics
c) construction and operation of bench scale 4 L CRS
d) effects of broth recycle on reactor performance

2) Design and construction of 5,000 L CRS for operation on ground corn, starch, and waste sugars at a small ethanol facility and

3) Demonstration of a cellulose/hemi-cellulose to ethanol process using the CRS technology (bench scale tests). 


\section{Apparatus (CRS-Solvent Ethanol Recovery) Design}

During the last several years, our research group has been working extensively in the area of immobilized cell reactor technology, combining the continuous advantages of immobilized cell reactors with separation of an inhibitory fermentation product (Dale et al, $1985 \mathrm{a}, \mathrm{b})$. This work has led to the design of several reactor separators (Park et al, 1989, Lee et al. 1990) for the volatile production of products other than ethanol. We have also been scaling-up an Immobilized Cell Reactor Separator (ICRS) for large scale ethanol production from clear liquid substrates. The ICRS incorporates a similar gas phase stripping concept as being developed for the CRS. We have thus gained a good deal of experience with gas-liquid separations. A 50 liter ICRS has been built and operated at Purdue over the last few years for operation on concentrated whey permeate (Dale et al, 1991) and is currently being modified for operation using solvent ethanol recovery. Currently, one 7,500 liter ICRS reactor is being built for installation at an lowa site by Permeate Refining Inc.(Dale, 1992) with several others in various stages of design and siting. The ICRS utilizes cells immobilized onto a special matrix having adsorbant properties. Despite several advances in scaling-up and improving this immobilization matrix there is currently no way a stream containing insoluble solids could pass through the system without clogging the matrix.

A reactor-separator using stirred tanks in series has been developed and patented which should allow the feeding of insoluble solids. This continuous continuous reactor-separator (CRS) consists of a series of reactor stages, where each stage consists of a stirred tant: reactor coupled to a gas/liquid contacting portion as shown in Figure 1. The stages are stacked in such a way that there are two basic gas/iquid flow portions of the reactor. A co-current gas/iquid flow section termed an enricher where the ethanol level is allowed to build-up, followed by a countercurrent gas/liquid portion where the reaction is completed and the ethanol stripped, with the net effect that the fermentation broth leaving the final stage of the stripper has no fermentable sugars or ethanol remaining. The method of stacking the stages is shown in Figure 1. The calculated ethanol and lactose profiles of a 8 stage CRS are shown in Figure 2. It is the goal of this proposal to build and operate this reactor on a bench scale, using ground corn and starch during year 1 , and cellulose-hemicellulose during year 2. A 4 liter bench scale reactor will be operated to test the ability of the CRS to complete its three objectives: 1) saccharification, 2) fermentation, and 3) separation of ethanol. This unit will consist of four 1 liter stages as shown in Figure 1. The concept incorporates conventional stirred tank in series reactor technology with co- and counter-current gas phase product stripping from the fermentation broth as the broth moves from stage to stage. This separation has the effect of decreasing the ethanol concentration in the stirred tank reactors, increasing the rate of ethanol production by the cells. The design and construction of a gas-liquid contactor portion of the CRS stage should have the properties of: a) close approach to gas-liquid equilibrium b) low gas phase pressure drop and c) non-clogging. A long trough type bubble cap type contactor will be used in the test CRS which should allow good turn-down performance.

During the last part of the first year of this project, a 5,000 liter CRS (5-1,000 L stages) will be constructed. This unit will have a diameter of 4.5 feet, and a height of 23 feet. The kinetics of extrusion and/or 'no-cook' saccharification will be used to predict the performance and help in the design of the unit. An Iowa company which is in the business of converting waste sugars 


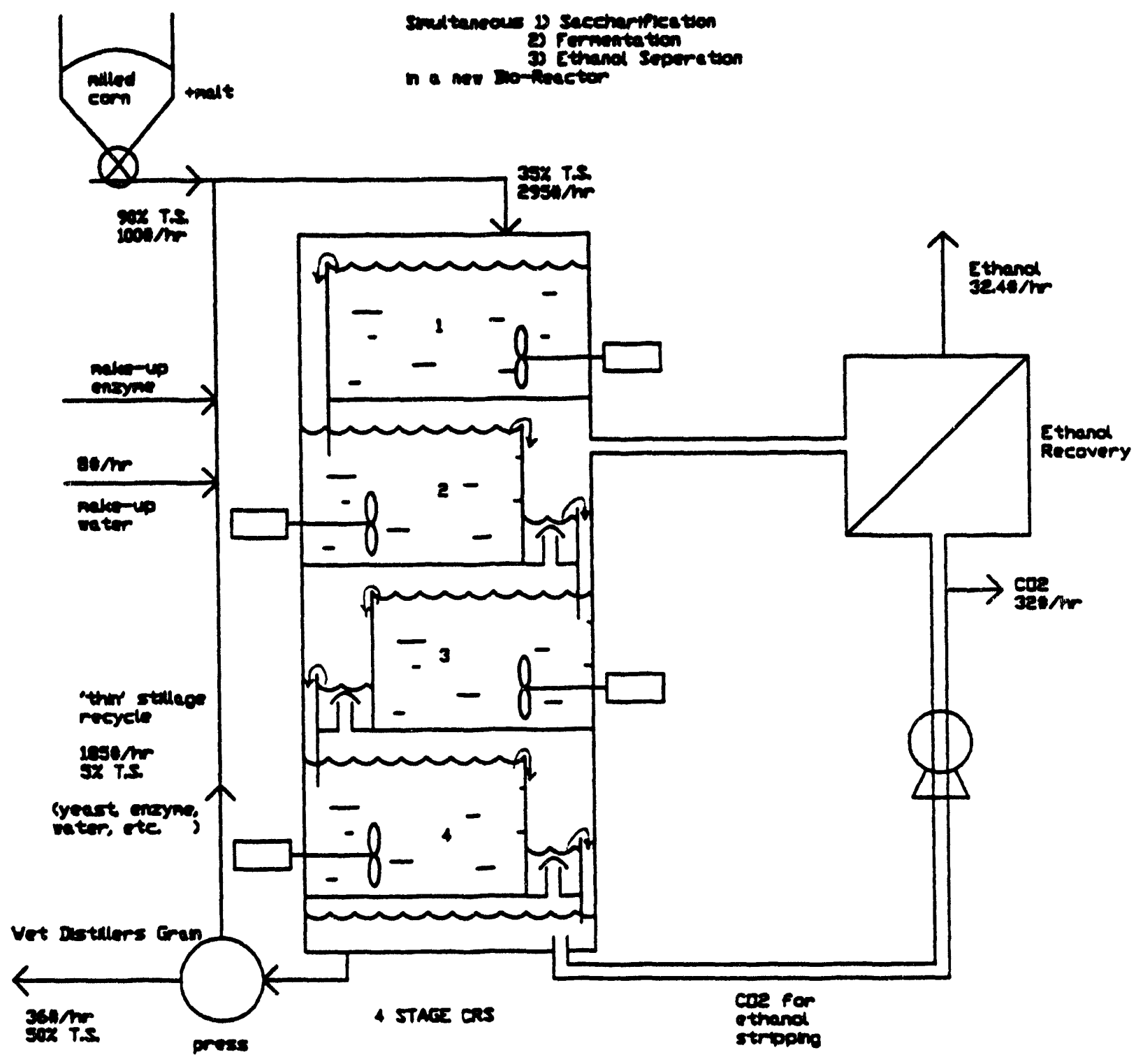

Figure 1. The CRS concept with simultaneous starch hydrolysis in a 'no-cook' process. 
Table 1

Comparison of Echanol Fermencuion Processes (2 Mmion Gal/Y. Scale)

\begin{tabular}{|c|c|c|c|c|}
\hline Rescror Type & $\begin{array}{c}\text { Reacdor Rale } \\
\left.\left(C^{4}\right)^{4} \mathrm{br}\right)\end{array}$ & $\begin{array}{l}\text { Res. Time } \\
\text { (tri) }\end{array}$ & $\begin{array}{l}\text { Reace Vol } \\
\text { (gai) }\end{array}$ & $\begin{array}{l}\text { Capivil Cost } \\
\text { for fermencer }\end{array}$ \\
\hline 1) Bach & 20 & 48 & {$[24,000]^{-7}$} & $\$ 1,066,000$ \\
\hline 2) $\operatorname{CSTR}$ (I stage) & 0.6 & 160 & 300,000 & $\$ S \$ S, 000$ \\
\hline 3) $\operatorname{CSTR}$ (3 stage) & 3.7 & 24 & {$[16,000]^{* 3}$} & 5312,000 \\
\hline 4) $\operatorname{CSTR}$ (5 seage) & 4.9 & 15 & {$[7,500]^{* 5}$} & $\$ 425,000$ \\
\hline 5) CSRSS (5 stage) & 355 & 25 & {$[1,000]=5$} & $\$ 155,000$ \\
\hline 9) CSRSS (8 stare) & 41.3 & 22 & {$[600]=8$} & $\$ 192,000$ \\
\hline
\end{tabular}

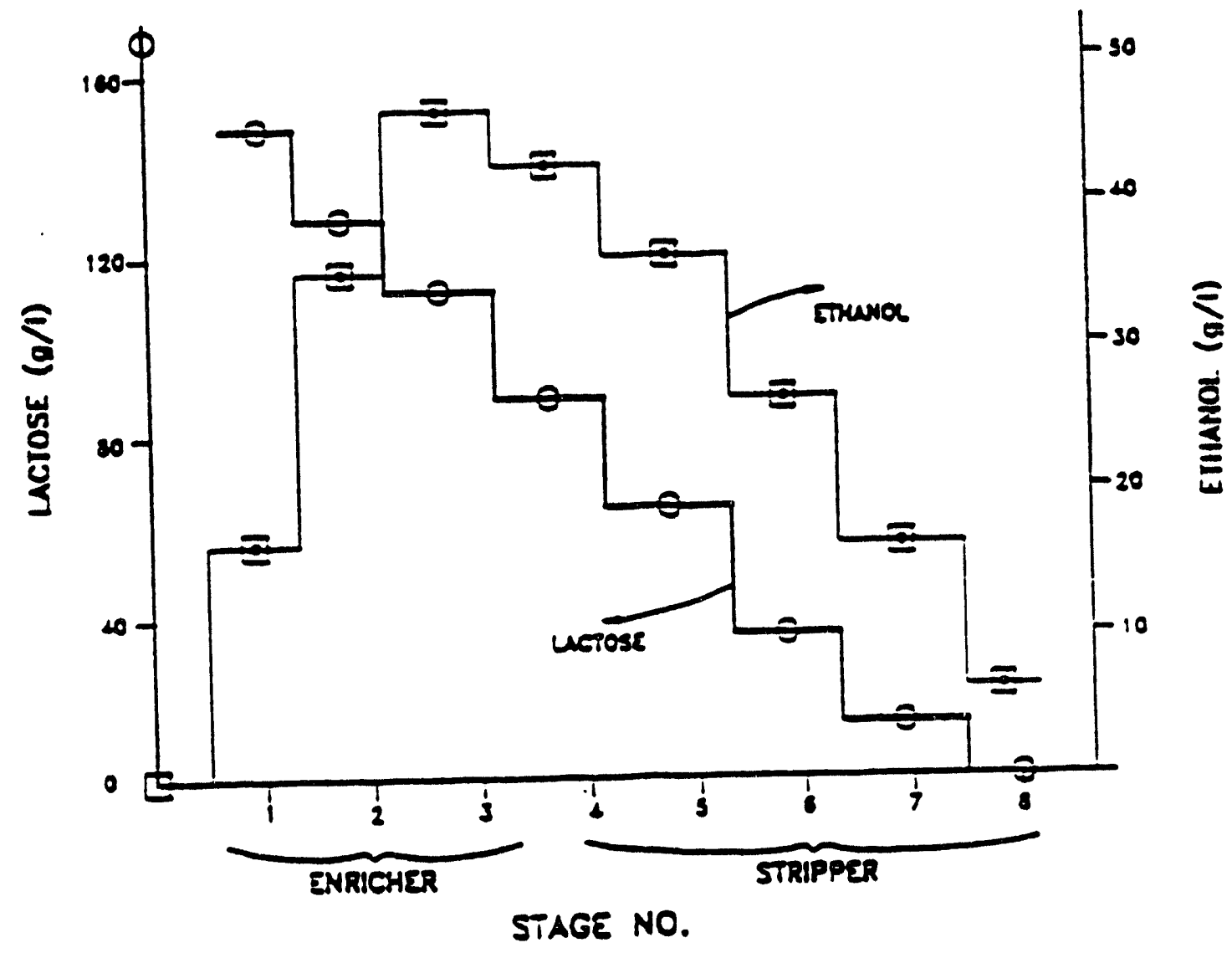

Figure 2. Calculated lacrose and ethanol concentrations in an 8 sage CRS. 
to ethanol has agreed to participate in this project by siting the 5,000 liter unit. Negodations are still underway about actual contractual and funding arrangements for the CRS siting. Permeate Refining Inc. is currently siting a 7,500 liter ICRS for the conversion of whey permeate concentrate to ethanol at this same site. PRI also receives large amounts of waste starches and sugar streams, as well as being sited within 100 feet of a grain handling facility. Ethanol recovery from the CRS will be integrated with the ethanol recovery system used with the ICRS.

A high cell density in the CRS stages will be maintained by l) the continuous addition of a small number of DADY type Saccharomyces cerevisae yeast or a thermotolerant, osmotolerant strain of $S$. pombe maintained in our lab. 2) recycling the cells from the effluent stream to the inlet stream. $\mathrm{pH}$ of the reactors will be controlled at 3.5 to 4.0 so as to minimize problems with bacterial contamination. The rate of ethanol production can be determined as a function of the environment in each stirred reactor.

$$
\frac{1}{x_{1}} \frac{d P}{d T}=v(e, P, s)=v_{\max }^{*} f(P)^{*} f(e)^{*} f(s)
$$

Where $X_{1}$ is live cell density, $f(P)$ is an ethanol inhibition function, $f(\varepsilon)$ is an osmotic inhibition function, and $f(s)$ is a low sugar concentration inhibition function. Ethanol inhibition, $f(P)$ is generally linear with concentration,

$$
f(P)=\left[1-\frac{P}{P_{m}}\right]
$$

Osmotic inhibition is generally linear beyond an initial threshold concentration, $\varepsilon_{i}$.

$$
f(\varepsilon)=\left(1-\frac{\varepsilon-\varepsilon_{i}}{X_{\varepsilon}}\right)
$$

Dale et al, (1990b) showed that both ethanol and high substrate inhibition for several strains of yeast are largely an osmotic effect so that equation 3 may sometimes be used to describe substrate, osmotic and ethanol inhibition. Inhibition due to substrate exhaustion is generally modeled using the Monod model.

$$
f(s)=\left[\frac{s}{K_{s}+s}\right]
$$

By removing ethanol from the fermentation broth, net fermentation rates are improved. For a basal case of $20 \%$ glucose feed, $50 \mathrm{~g} / \mathrm{l}$ cells in the fermentation broth, the fermentation 
performance of several fermenters were calculated using a basal size of 2 million gal/yr ethanol plant scale (Table 1). For batch operations, seven 24,000 gallons fermenters would be required, while for a single stage CSTR (Continuous Stirred Tank Reactor) with final ethanol concentration of 98 g/, a 123,000 gallon tank would be required. Fermentation performance is improved when three CSTR's are run in series. Average reactor productivity jumps from $0.6 \mathrm{~g} / \mathrm{h}$-hr to 3.7 $g /$-hr as only the final stage of the reactor is seeing the $98 \mathrm{~g} /$-hr ethanol which is quite inhibitory. Average productivities rise again when five stages are utilized, but net capital cost is higher due the added expense of more fermenters. The CRS has a productivity of $35.5 \mathrm{~g} /$-hr with complete fermentation of a $20 \%$ feed in a 2.5 hour residence time. Ethanol levels are held to under $50 \mathrm{~g} /$ on any stage to maximize fermentation rates and minimize ethanol catalyzed cell death. Captital cost for the CRS with 5 stages is only $15 \%$ of the cost of a batch reactor system. As with the CSTR's, added stages, while improving average productivity, cause net capital cost to be somewhat higher (an 8 stage CRS costing more than a 5 stage system).

Energy savings are attained by combining the CRS reactor concept with solvent absorption of the ethanol from the gas stream exiting the CRS as shown in Figure 3. The ideal solvent for absorption of ethanol from a gas stream would have the following properties: low vapor pressure of the solvent, solvent miscible with ethanol, solvent vapor carry-over non-toxic to fermenting microbes in CRS, low solubility of water in the solvent, and low solubility of solvent in water. The ideal solvent would absorb only ethanol allowing an anhydrous ethanol product to be stripped off from the solvent/ethanol stream from the absorber. However, all solvents having the ability to solvate ethanol also dissolve some water. Tedder et al. (1986) state that the solvents they tested for direct solvent extraction of ethanol have a 3 to 5\% water weight fraction in the solvent phase when contacted with an aqueous phase. By not actually contacting the solvent with the aqueous phase, the water concentration in the solvent is reduced in the CRS/solvent absorption process. Solvents have been screened for direct solvent extraction of ethanol by several researchers (Roddy, 1980; Arenson et al, 1990; Kollerup and Daugulis, 1985; Munson and King, 1983). Each solvent can be characterized by an equilibrium distribution coefficent for ethanol between the water and solvent phase, as well as a distribution coefficient for water between the aqueous and solvent phases. Dividing the ethanol distribution coefficient by the water distribution coefficient gives a separation factor, $\alpha$, which describes the relative affinity of the solvent for ethanol over water. Dodecanol, found by Minier and Goma (1982) to be nontoxic in direct solvent extraction in-situ separation, has an ethanol distribution coefficient of .21, and an ethanol/water separation factor of 21 . Work by Kollerup and Daugulis, (1985) indicated that dodecanol was somewhat toxic to micobes. Research in our labs has shown that dodecanol in direct contact with immobilized cells was toxic to yeast, but when used as vapor ethanol absorber, the dodecanol vapors carried over to an immobilized cell type reactor were not toxic, with fermentation rates of immobilized cells stable over 4 to 6 days (Lee and Dale, 1991 unpublished data). We are currently evaluating solvents with separation factors of 50-90, whict would give the ethanol concentrations as shown in Figure 4 when water and ethanol are strippled from the solvent. By not actually contacting the cells with an organic phase, toxicity problems and solvent loss into the water phase are both minimized.

Combining the ethanol enrichment of the CRS (vapor concentration of 5 to 8 times higher than liquid) with the enrichment of ethanol in the solvent absorber (limited water solubility in 


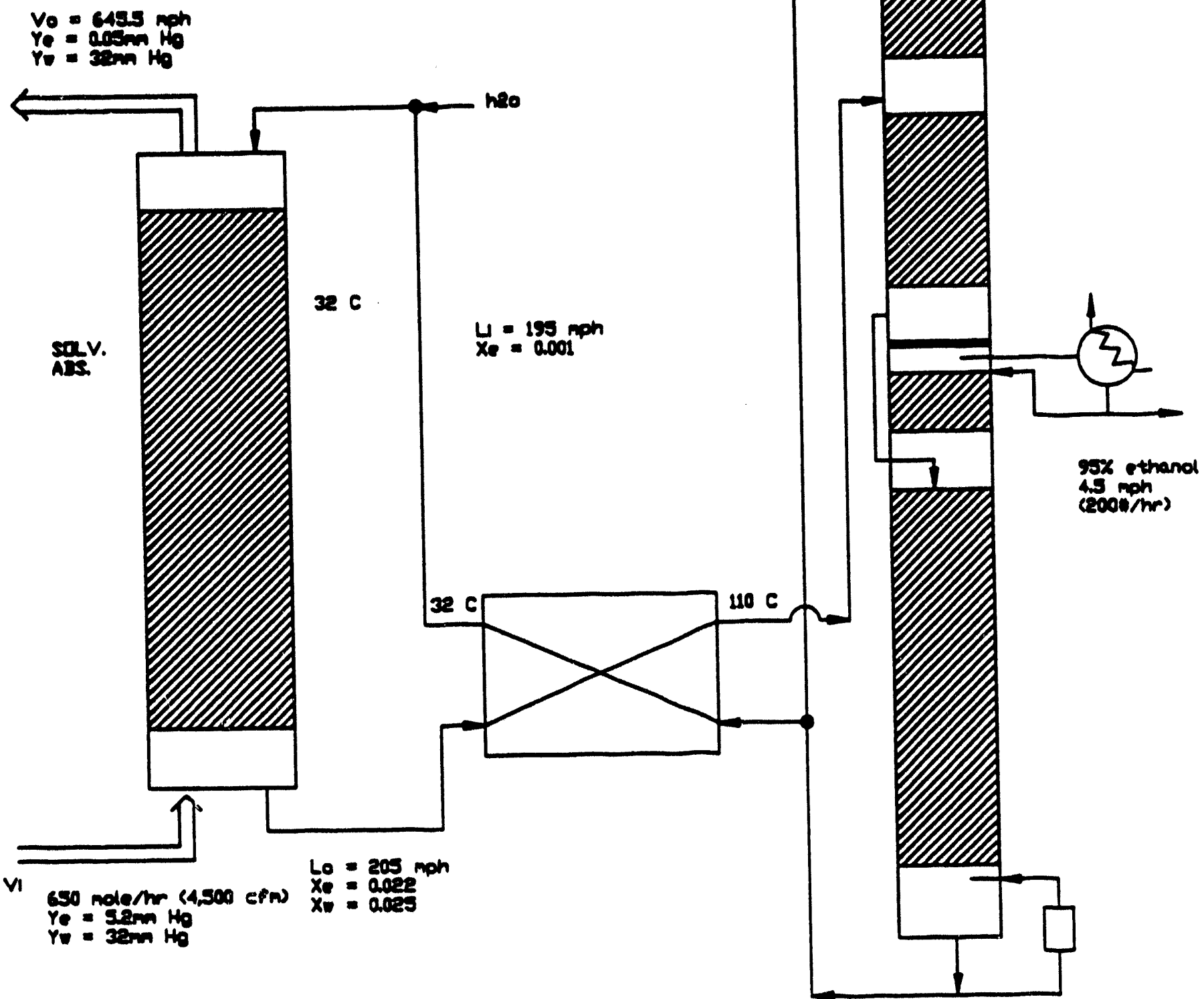

Figure 3. The Solvent Absorption-Extractive Distillation (SAED) process for ethanol recovery from gas streams. 
the solvent) allows highly concentrated ethanol to be easily recovered from the solvent in a solvent stripping column. As the solvents currently under consideration are 'high boilers' only trace amounts of solvent vapor enter the CRS, and based on studies to date with an immobilized cell reactor, these vapors leave the reactor at the same concentration as they enter.

An anhydrous ethanol product may be recovered from the solvent using a simple extractive distillation procedure using the same solvent used for the ethanol absorption. This process has been designed, tested, and is in the process of being incorporated into a detailed stage-by-stage mult-component model of the separation system. Preliminary hand calculations indicate the system will allow an an anhydrous product to be obtained at a low energy cost as shown in Figure 4. It can be seen that as the ethanol concentration in the stage from which the gas exits is allowed to increase, energy costs for ethanol recovery drop. The selection of solvents and testing of the SAED system was decribed in a paper recently given by Dale (1993).

\section{Demonstration of a continuous low-effluent dry milled corn to ethanol process}

The major year one effort of this project involves utilizing the CRS test reactor for milled grain first on the bench scale CRS, and then the construction of a 5,000 liter pilot unit. The corn grits must be converted to fermentable sugars before or during the fermentation process. Research goals during the operation of this $4 \mathrm{~L}$ test unit include:

a) Determining the kinetics and feasibility of a 'no-cook' saccharification of raw starch using extrusion. We have begun some preliminary 'no-cook' saccharification studies in our lab Preliminary results using a commercial ensyme with both alpha amylase. and glucoamylase functions were fairly successful. Glucose inhibition of ensymatic action was noted to increase at lower temperatures. This suggests that simultaneous fermentation and saccharification may prove very important to being able to use the 'no-cook' saccharification process for raw starch at high concentrations. These results are similar to the kinetics determined by Matsumura et al $(1987,1989)$ for raw starch saccharification using a glucoamylase with sweet potato starch. We found up to $80 \%$ conversion of purified corn starch and dry milled com could be attained in a 'no-cook' ensymatic process. Our lab found that the use of milled malt enhanced the saccharification process as shown in Figure 5 (Dale et al., 1993). During year one, we will do more extensive kinetic studies on this 'no-cook' process and test it for a 3 week (21 day) continuous run with the CRS. The basic design of the feed and effluent flows for the proposed process is shown in Figure 1. We see that dry milled corn is introduced on a continuous basis to the first stage of the CRS, along with the liquid recycle from the reactor effluent. The corn solids will be separated using a sieve (fine mesh screen) press. (A semi-continuous separation of the solids will be practiced in the lab. The use of a cheese press available in the Food Science pilot plant is being considered for liquid-solids separation). These solids will be taken off, while the liquid stream containing cells, ensyme, water, and some soluble non-fermentables will be taken back to the first stage of the CRS. Some preliminary tests will also be run on the effects of growing various strains of Aspergillus niger on wet com and using this as a ensyme source. Several researchers report good results with this type process (Han and Steinberg, 1986; Fujio et al, 1984; Ueda et al, 1981). 


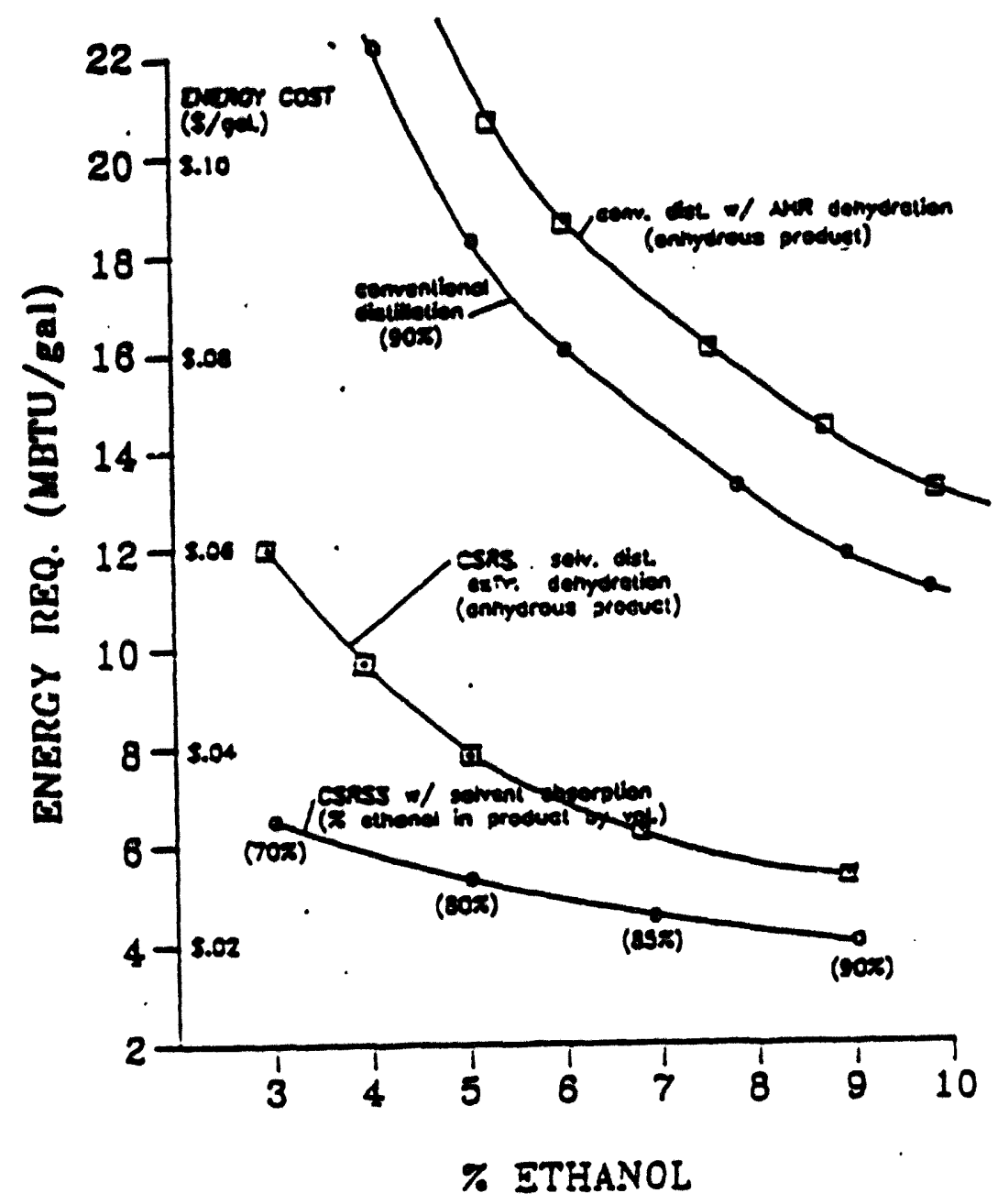

Figure 4. Energy requirments for recovery of anhydrous ethanol from the SAED process compared to conventional distillation.

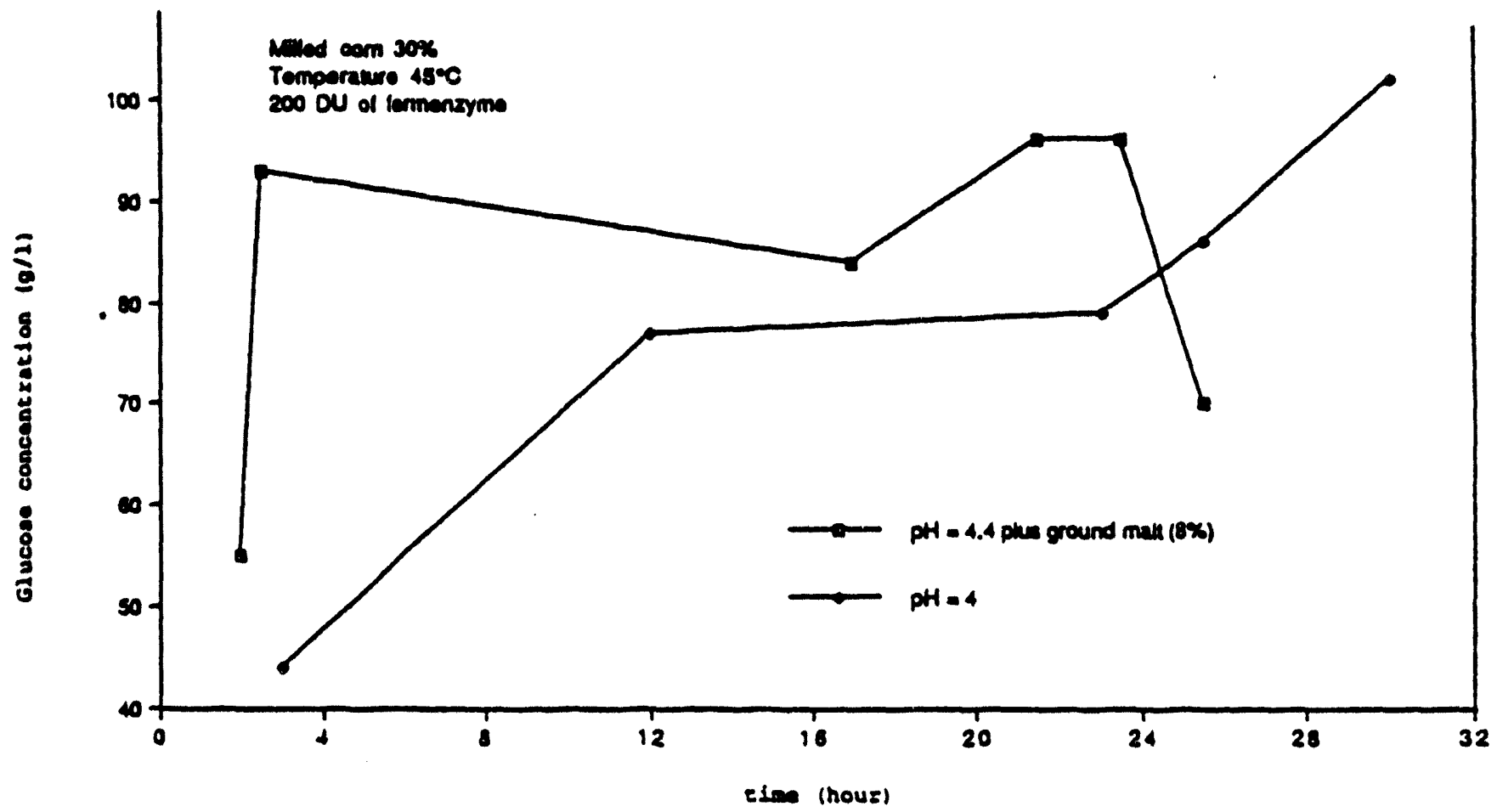

Figure 5. 'No-cook' saccharification of com grits. 
b) Testing of a continuous high pressure, high temperature extrusion gelatinization of starch.

The possibility of extrusion cooking of milled com has been examined by a number of researchers (Ben-Gera et al. 1983; Linko et ai., 1983; Park et al., 1987; and Downs et al, 1982 among others). This has been shown to be a quick and effective method of cooking the com. Because the corn is cooked at low moisture, much less energy is reqired, there is no need to heat up 8* of water with 2* corn as in conventional cooking processes(9-12,000 BTU per gal. ethanol). Downs et al. suggest 15-18\% moisture is ideal for 'dry cooking' of starch. Ben-Gera et al. (1983) show that energy requirements for dry extrusion gives a $50 \%$ decrease in net energy use, while wet extrusion cook (25-40\% moisture) can reduce energy use by $75 \%$ to about 3,000 BTU/gal.

In our work, we will use 30-40\% moisture extruded corn grits and feed these to the CRS along with the liquid recycle suream. An extruder (Brabender model 2003) with alpha-amylase (Taka-therm by Solvay Ensyme) added to the feed will be used to obtain a liquified starch (corn grits) stream following the procedures suggested by Ben-Gera et al (1983). The saccarification kinetics of the liquified corn grits/starch stream from the previous liquifaction step will be determined at various concentrations (20-50\% solids) using both fresh water and recycled fermenter effluent to dilute the inlet starch stream. Commercially available glucoamylase enzymes ('Gasolase' by Bio- Con, or Diazyme by Solvay Enzyme) will be added at various concentrations. These experments will be conducted in small stirred batch reactors, and the best conditions replicated in a the CRS reactor. A 20 to 30 day run of the CRS on extruded com grits will be performed using the results of the batch experiments to optimize extruder operation parameters (moisture and temperature).

c) Testing of high pressure, high temperature acid hydrolysis of starch using extrusion.

Acid hydrolysis may be cheaper and more effective than ensymatic starch hydrolysis. In general, higher temperatures allow lower acid levels, so that the high temperatures created by the extrusion process may allow a fairly low acid concentration to give good hydrolysis. This might be aided by the use of yeasts which have some ability to break down starches. Amyolytic and glucolytic ensymes are produced by yeast strains such as Schwannonyces castelli, Endomycopsis fibuligera, and others (Stewart et al, 1984). Sample strains of several of these amyolytic yeasts have been obtained for preliminary experiments. Acidic conditions during fermentation are advantageous for yeast as long as the $\mathrm{pH}$ is above 3.5 The performance of the extruder as an acid-starch hydrolysis reactor will be evaluated in preliminary tests. If the tests seem successful, or if process modeling indicates that this process has major cost or energy benefits, this process will be more thoroughly studied.

d) Determination of the effects of 'thin stillage' recyle on long term reactor performance.

The processes proposed use recycling of the supernate from the centrifugation or straining of the reactor effluent. This will allow recycie of cells, ensymes, and non-fermentable solubles. There will be some build-up of these non-fermentable soluble solids, so in the course of our work, we will determine the net long term inhibitory effect of this recycle stream. Work by Nofsinger et al. (1981) showed no major problem with thin stillage recyle, but our system will be running at a higher total solids. The limits of total solids which can be handled by the system are 
set either by the ability of the fermenting microbes to withhstand highly concentrated environments or the total viscosity of the fermentation broth. The limit on feed concentration becomes the ability of the fermenting organism to tolerate highly concentrated feeds. Organisms can be chosen which are more tolerant of high osmotic environments. Dale et al (1991), showed the long term ability of a strain of S. pombe to ferment $50 \%$ solids molasses or up to $60 \%$ sucrose solutions in an immobilized cell reactor separator. In an immobilized reactor, conditions at each point in the reactor must allow some growth for stable reactor performance (Dale et al, 1990a; Chen et al, 1990), while for the CRS, as long as there are conditions for growth in some of the reactors, stable performance can be maintained (as long as net cell growth rates exceed loss and death rates). Dale et al (1990b) however, also showed that growth of yeast tends to be more strongly inhibited by high osmolality than is ethanol productivity, so if cell growth is required for long term operation of the CRS, solution osmolality may limit permformance.

\section{e) CO2 management}

The $\mathrm{CO} 2$ will be circulated through the reactor at a ratio $\mathrm{mV} / \mathrm{L}$ of 2.5 where $\mathrm{V}$ is the molar flow rate of $\mathrm{CO} 2$ and $\mathrm{L}$ is the molar liquid flow rate. $\mathrm{CO} 2$ given off by the reactor will be taken off after the absorption of the ethanol as shown in Figure 1. The $\mathrm{CO} 2$ will be circulated using a small $26 \mathrm{lpm}$ diaphram type Gast pump on the lab scale, and with a centrifugal blower in the pilot plant. Pressure drop through the CRS is estimated at 1.5-2" $\mathrm{H} 2 \mathrm{O}$ per stage or about 8" through the 4 to 5 bubble or tray cap plates. Pressure drop through the absorber and inlets and outlets will be designed to be less than 4" for a total pressure drop of about 12" H20. The amount of $\mathrm{CO} 2$ given off will be monitored as an easy method of detemining the reaction rate, as $\mathrm{CO} 2$ and ethanol are generated on an equimolar ratio when sugar is fermented. Temperature of the reactor system will be controlled by the circulating gas stream. The $\mathrm{CO} 2$ acts as a temperature control device, as it takes a lot of energy both to heat and saturate the $\mathrm{CO} 2$ at 38C. (A 2 degree increase in temperature raises the ethalpy of the gas stream from 72 BTU/\# to 82 BTU/\# or $14 \%$.)

\section{f) 5,000 L CRS Pilot Scale Unit}

A 54" ID cylindrical CRS consisting of 5 stages will be constructed. This unit should have an ethanol production capability of between 150 to $450,000 \mathrm{gal} / \mathrm{yr}$ depending on yeast density and activity in the reactor. The unit will be about 23 feet high and have five 1,000 liter stages. $\mathrm{CO} 2$ will be taken from the $\dot{\mathrm{C}} \mathrm{RS}$ to a solvent absorber for ethanol removal, with the $\mathrm{CO} 2$ then recirculated back to the CRS system. The system will be designed to have a gas flow which can be varied between 4,000-8,000 CFM at 12" pressure drop. The unit will be constructed from 304 stainless steel. During the latter part of year one, the findings of the research performed during the first 9 months will be used to select a process for saccharification to be used at the PRI site. The system urilizing extrusion cook is the system requiring the least developmental effort as this system has already been demonstrated to work by our lab and others, but exactly which method of saccharification will be utilized will be determined as a function of experimental results. 


\section{The CRS for cellulosic feeds (Year 2-lab experiments)}

The simultaneous saccharification and fermentation of cellulose allows improved saccharification kinetics. This combination has been suggested and utilized by various researchers (Schell and Walter, 1991; Spindler et al,1991; Bowman and Geiger, 1984). Standard enzyme kineties for starch or cellulose saccharification generally follow Michaelis-Menton kinetics:

$$
V=\frac{V_{m} S}{K_{m}+S}
$$

where $S$ is the concentration of multisaccharide that the enzyme is hydrolysing. As the multisaccharide has a high molecular weight, the molar fraction of the substrate $\mathbf{S}$ decreases sharply as the multi-saccharide is hydrolysed to glucose. Simultaneous fermentation with saccharification reduces product inhibition and the formation of undesirable side-products generally associated with the saccharification process of both cellulose and starch. Product (glucose,or s) is more inibitory to enzymatic cellulose conversion than enzymatic starch conversion. Cellulose hydrolysis is more strongly product inhibited than starch with there being significant product (glucose) inhibition or enzyme binding. Currently available cellulases are not particularly thermo-stable, so that saccharification generally takes place at the same temperatures as fermentation. Thus simultaneous saccharification and fermentation of cellulose allows much improved rates for saccharification.

Biomass such as corn stalks, wood chips, or straw is a mix of cellulose, lignin, and hemicellulose. In order for the ensyme to be able to attack the cellulose, the biomass must be pretreated in some fashion. Treatments include physical, chemical, and biological methods. Physical methods include grinding, shearing, extruding, or irradiating. Chemical treatments include alkalis, acid and solvents, while biological methods use lignin degrading organisms such as rotfungi. According to Ladisch and Swartzkof (1992), extrusion w/pressure seems to offer the most economical method with an energy cost of about $\$ 0.005 / \#$ of biomass. We propose to cooperate with Xylan Inc. who are developing an extrusion de-lignification process for biomass. Xylan will run samples of various biomass products through their extrustion process and this will be fed to the CRS process during year 2 of the project. In conversations with Mr. George Tyson, president of Xylan, he indicated that he would be happy to work with our project, and that we could just pay him a 'supplies' fee for the extruded biomass product. Commercially available cellulase will be used and strains of yeast able to convert xylose as well as glucose to ethanol will be used. Sliniger (1988) worked with Pachysolen tannophilus, and other yeast strains have been developed which can develop 6\% ethanol on xylose (Chen, 1992).

\section{Educational Features}

This project will provide educational feanures for undergrads as we have been hosting British chemical engineering students for research semesters for the last 3 years. We also generally have one part-time undergraduate helping with the research and tests. The project will also provide funding for one graduate student who will be focussing his research based on this project, 
and finally we will be hiring on post-doctoral student who will be paid partly through this project.

\section{Facilities and Equipment}

A well equipped biochemical and food process engineering laboratory and food processing pilot plant are available at Purdue for this work. Instruments to be used for sugar and ethanol analysis include a Waters HPLC fitted with a column for sugars and organic acids using an acided water eluent, a gas chromatograph with an flame ionization detector, autoclaves, a laminar flow hood for cell transfers and sterile manipulations, many peristaltic type sterile pumps, water baths, magnetic stirrers, incubators, etc. A Brabender extruder, with a four zone electrically heated barrel, and temperature sensors is available for the liquifaction of starch. There is also a Sacco pilot scale starch cooker available for research purposes. Several lab type centrifuges are available in our lab, along with one pilot scale basket centrifuge (for the separation of insoluble solids from the various fermentation and hydrolysis solutions.

\section{Matching Funds Narrative}

Matching funds will be provided for this project from three sources. 1) Permeate Refining Inc. has agreed to be a major project sponsor, providing capital, labor, and siting for a 5,000 liter pilot plant. 2) Purdue University will provide some matching funds in terms of cost share for Dr. Okos's salary, and 3) the fabricator for the pilot scale has agreed to provide project input in terms of design (CAD) and eliminating their profit mark-up on the unit. These inputs will be documented by April 1. as per MPBC requirements. It is estimated preliminarily that these inputs will be at approximately $\$ 150,000$.

\section{References}

Arenson, D. S. Kertes, and J. King. 1990. Extraction of Ethanol from Aqueous Solution with Phenolic Exuractants. IEC Res. 29:607.

Bowman. L. and E. Gieger. 1984. Optimization of Fermentation Conditions for Alcohol Production. Biotech. Bioeng. 26:1492

Chen, C., M.C. Dale and M.R. Okos. 1990. The Long Term Effects of Ethanol on Immobilized Cell Reactor Performance. Biotechnology and Bioengineering. 36:975

Chen, L.F. 1992. "Production of Ethanol from Xylose with Selected Yeasts Strains" Personal Communication.

Dale, M.C., C. Chen and M.R. Okos. 1990. The Effects of Ethanol and Temperature on Immobilized Cell Reactors: Cell Growth and Death Rates as Critical Factors in Reactor Modeling and Design. Biotechnology and Bioengineering. 36:983

Dale, M.C., M.R. Okos and P.C. Wankat, 1985. An Immobilized Cell Reactor with Simultaneous Product Separation: I. Reactor Design and Analysis. Biotechnology and Bioengineering. 27:932. 
Dale, M.C., M.R. Okos and P.C. Wankat, 1985. An Immobilized Cell Reactor with Simultaneous Product Separation: II. Experimental Reactor Performance. Biotechnology and Bioengineering. 27:943.

Dale, M.C, M.R. Okos, and P.C. Wankat 1987. U.S. Patent \# 4665027. An Immobilized Cell Reactor with Simultaneous Separation and Methods for Design and Use Thereof.

Dale, M.C., A. Eagger and M. Okos. 1990. Osmolality Effects on Free and Immobilized K. fragilis. AICHE. Nov.

Dale,M., N. Perrin and M. Okos. 1991. Fermentation of Concentrated Sucrose and Molasses streams use Free and Immobilized S. pombe. AICHE COFE, Mar.

Dale, M.C., M. Molhman, C. Stwalley, and M.Okos. 1991. Long Term Performance of an ICRS on Acid Whey Permeate Concentrate. Final Report to Dairy Farm Products Co.

Dale, M.C., 1992. Design and Construction of a 7,500 liter ICRS for Ethanol Production from Whey Permeate. AICHE Nov. Paper 161-a

Dale, M.C., 1992. A Continuous Multi-Stage Stirred Reactor-Separator for Production of Volatile Fermentation Products. Patent \# 5,141,861.

Dale, M.C., S. Michel, and M. Okos. 1993. Conversion of raw milled corn to sugars as a function of temperature and ensyme use. COFE Chicago, Feb.

Dale, M.C., 1993. "A Solvent Absorption-Extractive Distillation (SAED) Process for the Recovery of Ethanol from Vapor or Gas Streams." AICHE Conf. on Food Eng. Chicago, Feb.

Downs, H., B. Clary, and J. O'Neal. 1982. Ensyme Function and Control during Conversion of Grain Starches to Fermentable Sugars. ASAE Dec.

Fujio, Y., P Suyanadona, and S. Ueda. 1984. Alcoholic Fermentation of Raw Cassava by Rhiz. koji without Cooking. Biotech Bioeng 24:315

Farmweek, 1991. Com: the New US Treasure. 1/30/91

Han, I, and M. Steinberg. 1986. Solid State Fermentation of Raw Corn with Koji Hydrolysis. Biotech Bioeng Symp. 17:449.

Kollerup, F. and A. Daugulis. 1985. Mathamatical Model for Extractive Fermentation. Biotech Bioeng. 27:1335

Ladisch,M. and J. Svartzkopf, 1992. Ethanol Production from Biomass. Biomass Journal

Letoumeau, F. and P. Villa. 1987. Substrate and Product Inhibition of S. cerevisae. Biotech Letters 9:1, 53

Lin, J.J., M.C. Dale and M.R. Okos. 1991. Osmolality (Aw) effects on growth and ethanol production of free and immobilized Zymomonas mobilis. Process Biochemistry.

Linko,P., S. Hakulin, and Y. Linko. 1983. Extrusion Cooking of Barley Starch for the production of Glucose and Ethanol. J.Cereal Sci. 1:275 
Matsumura, M. and J. Hirata. 1989. Cont. SSF of Raw Starch in a Membrane Reactor. J. Chem. Biotech. 46:313.

Matsumura, M., J. Hirata, and S. Ishii. 1987. Kinctics of Saccharification of Raw Starch by Glucoamylase. J.Chem Biotech. 42:51.

Moulin, G., H. Boze, and P. Galzy. 1980. Substrate and Product Inhibition of Lactose Fermenting Yeasts. Biotech Bioeng 22:2375

Minier, M. and G. Goma. 1982. Ethanol Production by Extractive Fermentation. Biotech and Bioeng. 25:1565

Munson, C. and C. King. 1984. Factors influencing Solvent Selection for Extraction of Ethanol from Aqeous Solutions. IEC Proc. Des. 23:115

Nofsinger, G.W., R. Bothast, and J. Wall 1982. Fermentation Byproduct Recovery ProcessesRecycling Soluble Solution, and Chemical Preservation of Wet Spent Grain. from NRAES Feed and Fuel from Ethanol Production. Cooperative Extension Publication.

Park, C., M.Okos and P. Wankat. 1988. Effects of pH and Temperature on Free and Immobilized S. cerevisae. AICHE, Aug.

Park, C., M. Okos and P. Wankat. 1989. Acetone-Butanol- Ethanol Fermentation in an Immobilized Cell Reactor Separator. Biotechnology and Bioengineering, 34:18

Patterson, J.P., 1985, Scale-up Parameters of a Trickle bed Reactor-Separator, M.S.E. Thesis, Pundue University.

Rollings, J. 1978. Batch and Continuous Studies on Corn Starch Liquifaction. M.S.E. Thesis, Purdue University.

Philippidis, G., D. Spindler, and C. Wyman. 1991. Mathamatical Modeling of Cellulose to Ethanol by Simultaneous Saccharification and Fermentation Process. Paper \#25. Biotech. Symp. for Fuels and Chemicals. Colorado Springs.

Roddy, J., 1980. Distribution of Ethanol-Water Mixtrues to Organic Liquids. IEC Proc. Des. Dev. 20:104.

Schell, D., and P. Walter. 1991. Simultaneous Saccharification and Fermenation of Com Stover Hydrolysate to Ethanol. Paper 72. Biotech. Symp. for Fuels and Chemicals. Colorado Springs.

Spindler, Phililppidis, and Wyman. 1991. Key Parameters in Simultaneous Saccharification and Fermentation of Biomass to Ethanol. Paper \#74. Biotech. Symp. for Fuels and Chemicals. Colorado Springs.

Tedder, D., W. Tawfic, and S. Poelheim. 1987. Ethanol Recovery by Solvent Exraction and Extractive Distillation- the SEED Process. Chem. Sep. Vol

Ueda, S., C. Zenin, D. Monteiro, and Y. Park. 1981. Production of Ethanol from Raw Cassava Starch. Biotech Bioeng. 23:291 


\title{
Appendix 3.1
}

\author{
Lactic Acld Production
}




\section{Lactic Acid Production from Lactose by Lactobacillus bulgaricus C.N. Burgos, M.C. Dale, M.R. Okos, and P.C. Wankat}

\section{Introduction:}

The production of various chemicals utilizing renewable resources such as whey lactose is becoming more important. A number of anaerobes or facultative anaerobes ferment lactose to ethanol, lactate and acetate. Kinetics of growth and lactic acid production by L. helviticus (Roy et al, 1987) and L. delbrueckii (Leudeking and Piret, 1959) have been reported. Yabannavar and Wang (1987) have established the effect of disassociated and undissociated lactic acid on the specific growth rate. Anaerobic bacteria use the Emden-Meyerhoff pathway (EMP) for converting lactose to pyruvate. Lactose is converted to glucose and galactose with the help of the enzyme beta -galactosidase. The effect of $\mathrm{pH}$ on the activity of this enzyme has been determined, and the initial step of lactose metabolism is thought to be rate limiting (Shah and Jelen, 1990). Betagalactosidase has a very low activity below $\mathrm{pH} 4$ and has optimum activity around $\mathrm{pH} 5.5$. The effect of $\mathrm{pH}$ on the growth of Lactobacillus delbrueckii by the conversion of glucose to lactic acid was shown by Yabannavar and Wang (1987). A similar study is performed for L. bulgaricus utilizing lactose for growth in this study. Substrate inhibition has also been included as a factor in growth and lactic acid productivity.

In this paper detailed batch kinetics for the growth of Lactobacillus bulgaricus, including the effect of $\mathrm{pH}$, substrate and lactate are presented. The effect of $\mathrm{pH}$ on the fermentation is assumed to follow enzyme beta-galactosidase kinetics. Keller and Gerhardt (1975) have studied the performance of continuous fermentation at $\mathrm{pH} 5.6$. They determined that three stages are sufficient for complete utilization of sugar, and they operated the continuous system for more than 40 days. In this paper continuous fermentation in CSTR mode has been modelled for Lactobacillus bulgaricus. The effect 
of $\mathrm{pH}$ and substrate on the continuous fermentation was determined. The number of stages required for complete utilization of lactose was also determined.

\section{Materials and Method:}

The Lactobacillus bulgaricus NRR B-548 was obtained from the United States Department of Agriculture (Peoria). The MRS growth medium contained bactopeptone $10 \mathrm{~g} / \mathrm{L}$, bactoyeast extract $5 \mathrm{~g} / \mathrm{L}$, bactomalt extract $10 \mathrm{~g} / \mathrm{L}$, dipotassium phosphate $2 \mathrm{~g} / \mathrm{L}$, sodium acetate $5 \mathrm{~g} / \mathrm{L}$, magnesium sulphate $0.1 \mathrm{~g} / \mathrm{L}$, manganese sulphate $0.05 \mathrm{~g} / \mathrm{L}$ and varying lactose concentration of $20-100 \mathrm{~g} / \mathrm{L} .250 \mathrm{ml}$ batch experiments were carried out in $400 \mathrm{ml}$ flasks and shaken at $200 \mathrm{rpm}$ in a Aquatherm water bath shaker at a temperature of $45^{\circ} \mathrm{C}$. Samples of $0.5 \mathrm{ml}$ of the broth were pipetted out for analysis and $\mathrm{pH}$ was checked every fifteen minutes. $\mathrm{pH}$ was controlled by the addition of $2 \mathrm{~N}$ ammonium hydroxide. The fermentation chamber was not aerated. Another batch experiment at initial pH 6 and initial pH 6 and initial lactose concentration of $50 \mathrm{~g} / \mathrm{L}$ was run with no $\mathrm{pH}$ control. $\mathrm{pH}$ was measured over the course of the fermentation.

To measure cell growth a Turner spectrophotometer model 350 was used at $660 \mathrm{~nm}$ It was found that $1 \mathrm{OD}$ unit corresponds to $0.54 \mathrm{~g} / \mathrm{L}$ of cell mass. The samples were diluted to keep the $\mathrm{OD}$ measurements in the linear range from zero to $0.3 \mathrm{OD}$. Lactose and lactic acid concentrations were determined by using an HPLC, installed with a column for carbohydrate analysis (Bio-Rad, Aminax HPX-87H).

\section{Experimental Results:}

Several experiments were nerformed in a batch reactor. As specified in previous works, there are several factors involved in increasing the productivity. Some of them were studied in detail. A set of experiments was run with no $\mathrm{pH}$ control. In these experiments growth inhibition was observed. We proposed that this is due to a $\mathrm{pH}$ 
decrease as lactic acid was formed. There is a need of determine the optimum $\mathrm{pH}$ conditions and run future experiments under well controlled $\mathrm{pH}$ conditions.

These experiments were performed and very good yields were obtained. The growth yield of Lactobacillus bulgaricus was increase three fold compared with the no $\mathrm{pH}$ control experiments. The conversion of lactose to lactic acid was very efficient. About a $90 \%$ of the initial lactose was converted to lactic acid under this conditions. Using this microorganism an homolactic fermentation occurs and the presence of any by-product was not detected using HPLC techniques. No $\mathrm{CO}_{2}$ was produced during this fermentation. In addition high concentrations of lactic acid were obtained $(65 \mathrm{~g} / \mathrm{L})$. Figure \#1 illustrates these results.

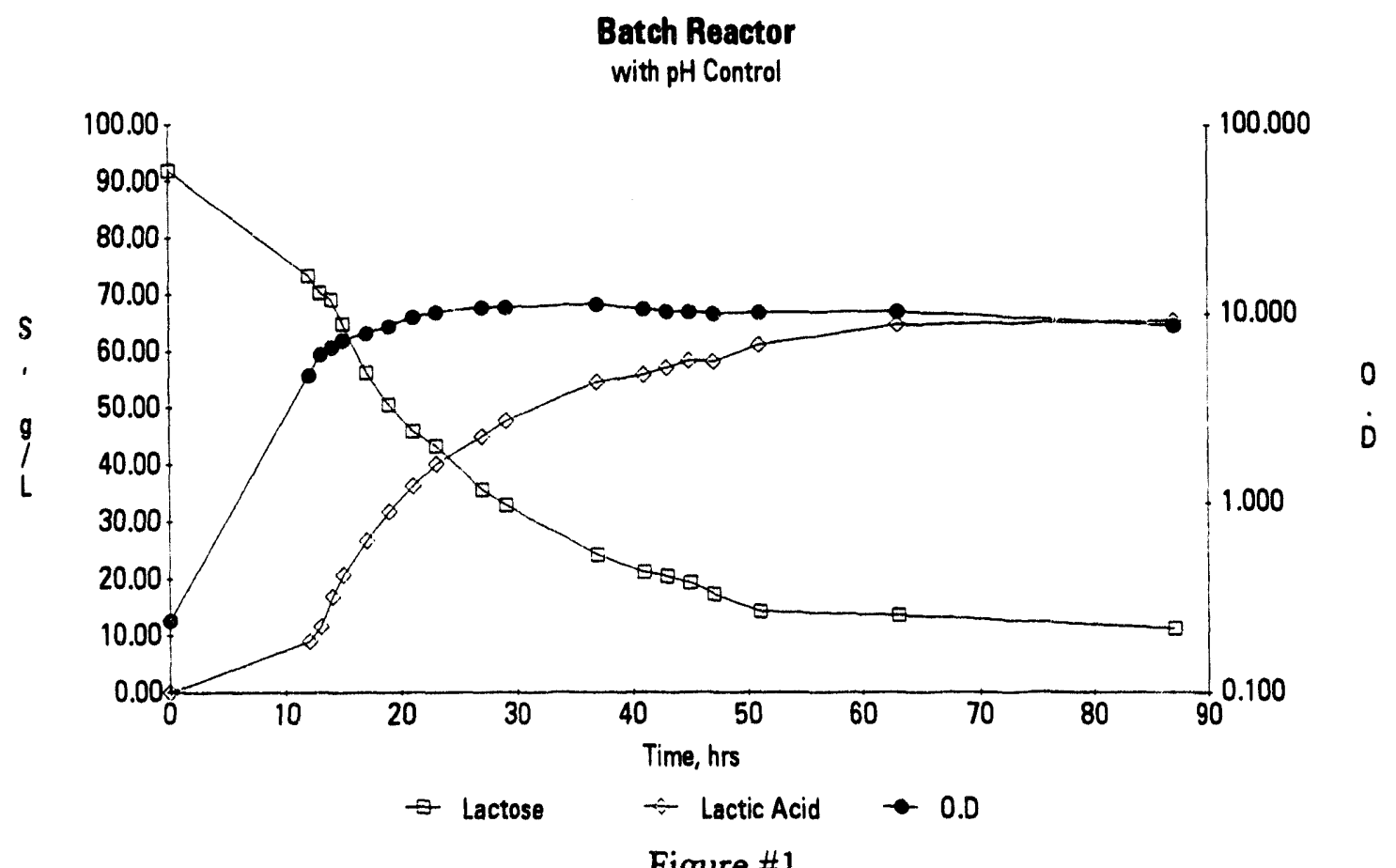

Figure \#1 


\section{Conclusions:}

Experimental results on the batch fermentation of Lactobacillus Bulgaricus in lactose medium were presented. The fermentation time increases considerably with substrate concentrations more than $60 \mathrm{~g} / \mathrm{L}$. At this concentrations is also observed that the initial specific growth rate is low due to substrate inhibition. There is a considerably increase in lactic acid productivity for $\mathrm{pH}$-control batch fermentations as compared to the ones with no $\mathrm{pH}$-control. In addition high concentrations of lactic acid were obtained $(65 \mathrm{~g} / \mathrm{L})$ along with a high efficiency in lactose uptake.

\section{References:}

Keller and Gerhardt, Biotechnol. Bioeng., 15, 1020 (1975)

Leudeking, R. and Piret, E.L., J. Biochem. Microbiol. Technol. Eng., 1, 393 (1959)

Roy, D.; Leudy, A. and Goulet, J., Can. J. Chem. Eng., 15(2), 233 (1987)

Shah, N. and Jelen, J., J. Food Sci., 55(2), 506 (1990)

Yabannavar, V.M. and Wang D.I.C. Ann. NY. Acad. Sci., 506, 523 (1987) 


\title{
Appendix 3.3
}

\author{
Production of IIIgh Value Products \\ From Immoblized Plant Cell Tasue Cultures
}




\section{OBJECTIVES}

The objective of this study is to develop a continuous process with immobilized plant cells enhancing secondary metabolite production. Overall goal of this study will show the immobilization of plant cells can enhance the secondary metabolite production. The major problem associated with immobilization is the release of secondary metabolite from cells. Using permeabilization reagent, this problem can be solved. Also elicitation technique is used to enhance the production of phytoalexin, a typical secondary metabolite from plant cells. Continuous process to produce secondary metabolite from plant cell can give a commercial production of useful product from plant cells.

A model system is being studied for the production of sesquiterpene aldehydes, hemigossypol and related derivatives, from cotton cell, Gossypium arboreum. To reach major goal, four different researches have been done or will be performed. Cotton cell culture was characterized in terms of growth and production relationship and phytoalexin production. The effects of permeabilization using Dimethyl sulfoxide (DMSO) have been studied to find out optimal time and DMSO level for effective permeabilization. Mass transfer model will be proposed to explain the mechanism of permeabilization. The effects of elicitation using culture broth of $V$. dahliae has been examined to investigate the mechanism of elicitation and find the optimal elicitor concentration. Kinetic study will be performed to explain the effect of elicitation on growth and production of phytoalexin. Batch cultures with immobilized plant cells have been performed to compare with suspension culture and study stability of immobilization process. A packed bed reactor will be designed to perform continuous process with enhanced sesquiterpene aldehyde production. Immobilized cell reactors will be packed with spirally wounded terry cotton and stainless steel spacer which can support the shape. Bioreactor operation will be performed by changing flow rate to determine the mini- 
mum flow rate for operation, and by cyclic treatment of DMSO and elicitor to minimize the detrimental effect. A production model will be proposed to explain the operation of packed bed reactor combining the effect of permeabilization and elicitation. More detailed description is summarized in followings;

* Main Objective

Develop a continuous process with immobilized G. arboreum cells to enhance secondary metabolite, gossypol, production.

$\because$

* Model System

Production of gossypol related compounds from G. arboreum

* Subobjectives

Characterization of $G$. arboreum

Permeabilize cells to release gossypol

Enhance phytoalexin, gossypol, production by elicitation using culture broth of $V$. dahliae

Build, operate, and model immobilized cell reactors with enhanced gossypol production. 


\section{PRELIMINARY RESULTS AND FUTURE WORKS}

Enhancement of secondary metabolite production can be achieved by immobilization and elicitation. However,a continuous process with immobilization needs product release from cell. In order to establish a continuous process which produce the secondary metabolite, it is needed to characterize the factors which influence the secondary product formation. Four different approaches have been tried including the characterization of $G$. arboreum, the permeabilization of product from cells, the elicitation of phytoalexin, and the immobilization processes. Preliminary results were focused on batch cultures to study the characterization of G. arboreum, the effects of DMSO on permeability of the cells, the effects of elicitors on enhanced production of phytoalexins, and the effects of immobilization. Future works will be focused on the modeling and the reactor operation. The effects of permeabilization and elicitation will be modeled and these models finally will be combined to explain the secondary metabolite production in packed bed reactor.

\section{Characterization of G. arboreum}

The growth conditions for various species of cotton cells, including G. arboreum, have been reviewed in 'Characterization of cotton cell' section in literature review. Since defining growth conditions for $G$. arboreum cells is not an objective of this study, general growth conditions has been selected from review. All experiments and maintenance of cells were performed in dark room because illumination can result adverse effect on gossypol production for $G$. arboreum cells. Sucrose is selected as a carbon source due to its versatility for both growth and production. Linsmier-Skoog medium with NAA and 2,4-D is recommended for $G$. arboreum cells.

The growth and production chawacteristics is important in order to develop a kinetic mod- 
els for growth and production. Figure 2-4 shows a typical growth and production pattern of $G$. arboreum cultivated in $30 \mathrm{~g} /$ sucrose medium in terms of dry weight and specific production of gossypol, respectively. From this figure, gossypol production from $G$. arboreum cells occurred only after growth had slowed or ceased in batch operation. Although it can not be said as strict non-growth associated pattern since production is somewhat related to growth, major increase in production is in late growth phase or stationary phase. The production in early phase can be explained by the non synchronized nature of cells. There might be some portion of old cells in that phase and production can caused by the old cells. Although growth production pattern is not strictly non-growth associated pattern, immobilization technique is still recommendable since its slow growth rate and nature of decouple of growth and production mechanisms.

A range of sugar concentrations was tested to determine optimum concentration of sucrose for later experiments. Figure 2-5 a,b show the effect of different sucrose concentrations. During initial growth phase, phytoalexin accumulation shows a kind of gradient in terms of different sucrose concentration. It is thought that cells respond to higher sucrose concentration as a stress during early phase of growth and/or lag phase when cells are adopting those conditions to environments. From Figure 2-5 a, the optimal phytoalexin production is obtained from $30 \mathrm{~g} / 1$ sucrose concentration. Batch culture of $G$. arboreum cells shows different growth when different initial concentration of sucrose is added in the medium (Fig. 2-5 b). At low concentration of sucrose $(10 \mathrm{~g} / 1,20 \mathrm{~g} /)$, it seems no lag phase is observed while long lag period is observed in $50 \mathrm{~g} /$ sucrose. This result suggests growth is carbon limited and Monod equation can be applied for kinetic study. The relationship for the specific growth rate is ;

$$
\mu=\frac{\mu_{\text {max }} S}{\left(S+K_{s}\right)}
$$

The two constants in the equation, $\mu_{\max }$ and $\mathrm{K}_{s}$, can easily be determined from experi- 


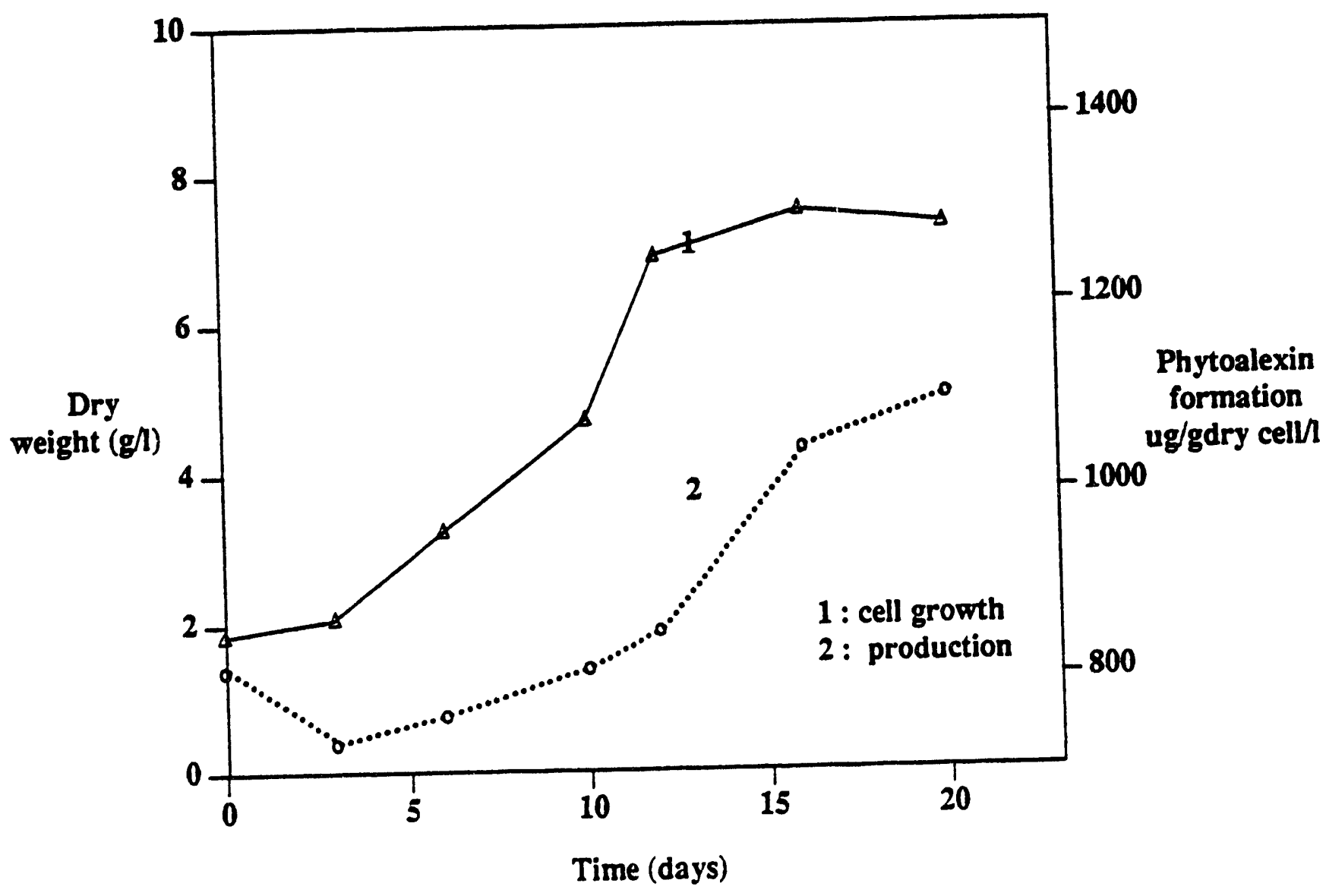

Fig. 2-4 Typical curve for G. arboreum cell growth and phytoalexin production 
Fig. 2-5(a). Internal gossypol concentration in different sugar conc.

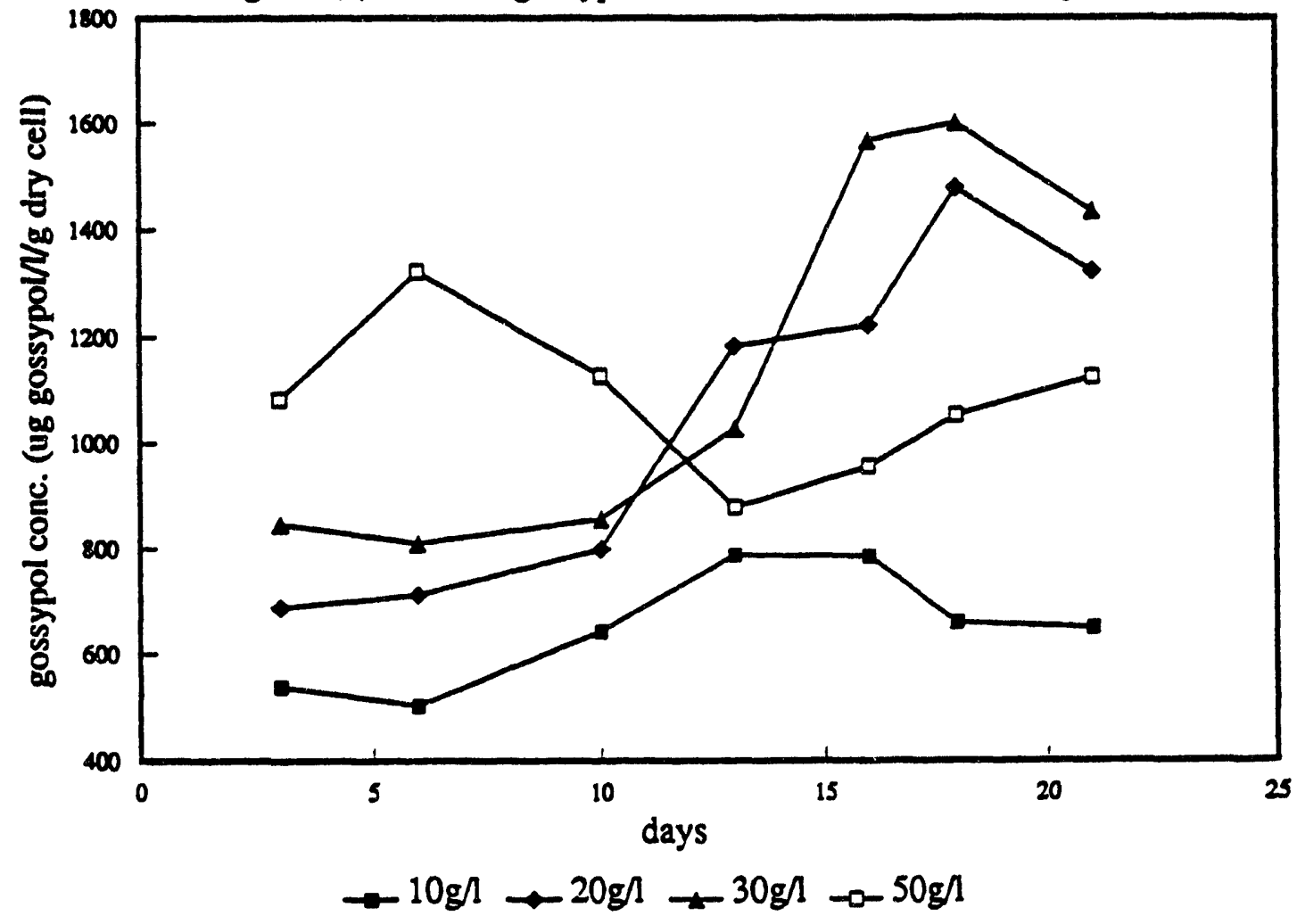

Fig. 2-5(b). Plant cell growth in different conc. of sugar

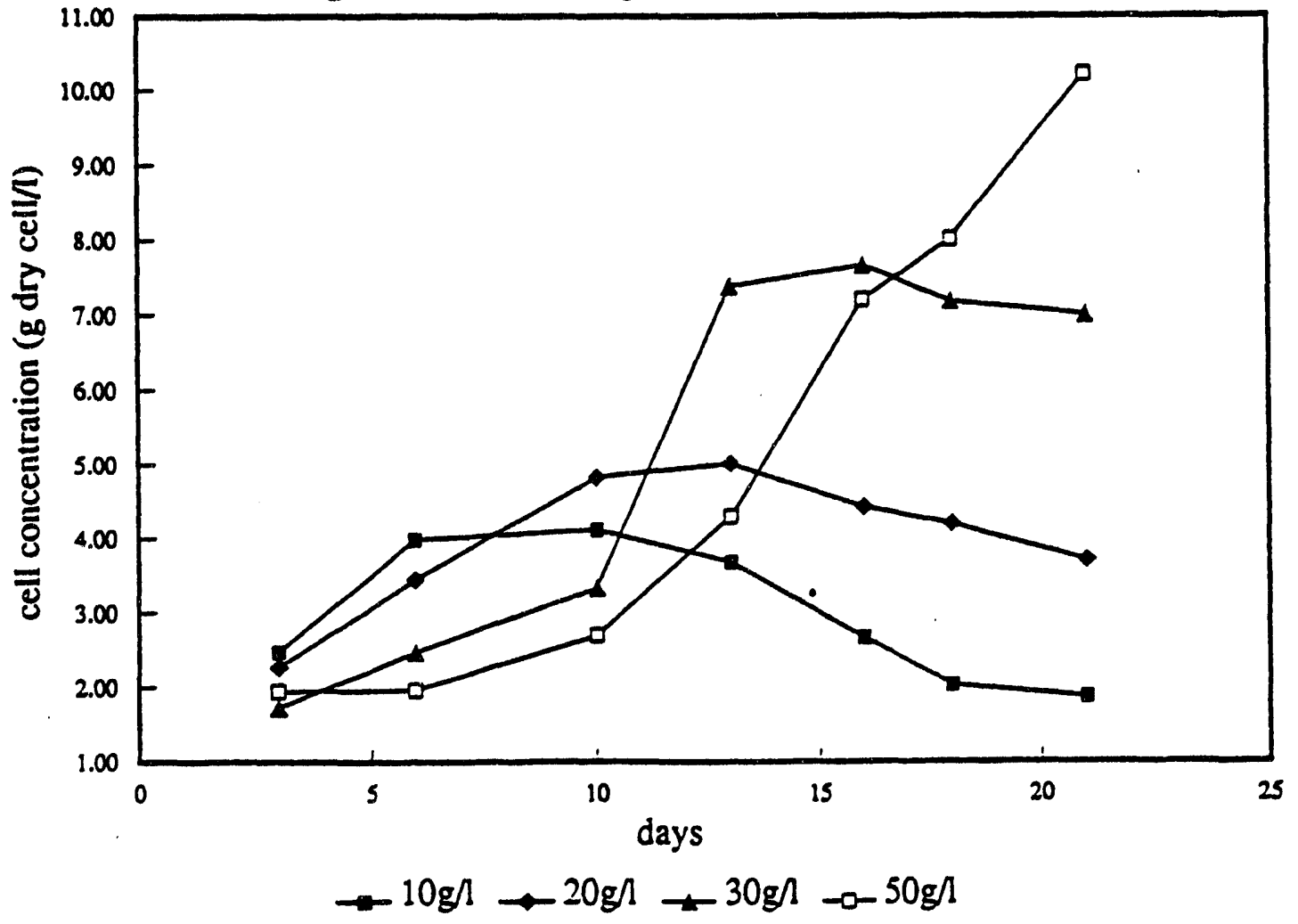


mental data by plotting the reverse of the specific growth rate vs. the inverse of substrate concentration (Lineweaver-Burk plot).

Leudeking-Piret kinetics has proved extremely useful and versatile in fitting product formation data from many different fermentations. This equation combines growth-associated and non-growth associated contributions:

$$
\mathrm{dP} / \mathrm{dt}=\alpha d \mathrm{X} / \mathrm{dt}+\beta \mathrm{X}
$$

If we assume that phytoalexin formation is dependent only secondary metabolite pathway, it can be considered as non-growth associated type production. Therefore above equation can be reduced to $\mathrm{dP} / \mathrm{dt}=\beta \mathrm{X}$ in which the production is only dependent upon cell mass. This production equation will be used in the kinetic study of elicitation and modeling of tubular reactor.

\section{Batch experiments for permeabilizing reagent.}

A continuous process with immobilized plant cells needs product release out of the cell. However, secondary products are often stored in the vacuole of the plant cells. In order to solve this problem, permeabilization with chemical solvent has been considered. Effect of permeabilizing reagent, Dimethylsulfoxide (DMSO) has been investigated in suspension cell cultures of $G$. arboreum. These cells naturally release sesquiterpene aldehyde but the rate is slow and it may be due to membrane disruption cause by cell death. Thus, the application of a permeabilizing agent is recommended to promote rapid product release for a continuous process.

Works to date

The effect of DMSO concentration on the permeability of $G$. arboreum cells was investigated with various concentration of DMSO $(0,1,3,5,10,15,20$, and $30 \mathrm{v} / \mathrm{v} \%)$ for $30 \mathrm{~min}$. 
Permeabilization is expressed by a ratio of released amount of gossypol related substance and total amount in control suspension culture which contained $7800 \mathrm{ug} / 1$ of sesquiterpene aldehyde. It is of importance to determine optimal concentration of permeabilizing reagent, i.e., the mildest conditions for maximal effect, since it can be expected that the viability of the treated cells is highly influenced by the DMSO concentration used. DMSO treatment of $G$. arboreum cells enhanced release of intracellular sesquiterpene aldehyde as shown in Figure 2-6. Slight permeabilization is seen with low concentrations $(1,3 \%)$ but greater than $5 \%$ is needed for significant permeabilization of the whole cell. Release increases with increasing levels of DMSO, but viability of treated cell is dramatically decrease with over 10\% DMSO.

In order to determine the optimal time for permeabilization, cells of $G$. arboreum were treated with same various concentrations of DMSO for various periods of time with subsequent measuring of gossypol related substances. Relative permeabilization was measured by same calculation. Figure 2-7 shows a distribution of relative permeabilization as a function of time. The rate of release is slowed after 30 minutes to on hour, taking in excess of 6 hours to reach about $70 \%$ permeabilization as $5 \%$ of DMSO treated. Also, permeabilization is not completed even after exposure of the cells for ten hour to DMSO levels causing near maximal permeabilization. It might be due to diffusional limitation of treated cell membrane and/or seems to be involved a slow dissociation of sesquiterpene aldehyde. Since the physiological mechanisms involved in product transport and storage in cotton cell culture is not well understood, it is difficult to study the dissociation of sesquiterpene aldehyde from the vacuole. Therefore permeabilization process should be considered as a function of diffusional process through altered membranes.

Figure 2-8 shows the effects of DMSO concentration and time ori viability. G. arboreum cells can not tolerate treatment with over $10 \%$ DMSO losing more than $75 \%$ activity in one hour. On the other hand, viability of cells can be retained with up to $5 \%$ treatment. Viabilities 
Fig. 2-6. Relative permeability as a function of DMSO concentration

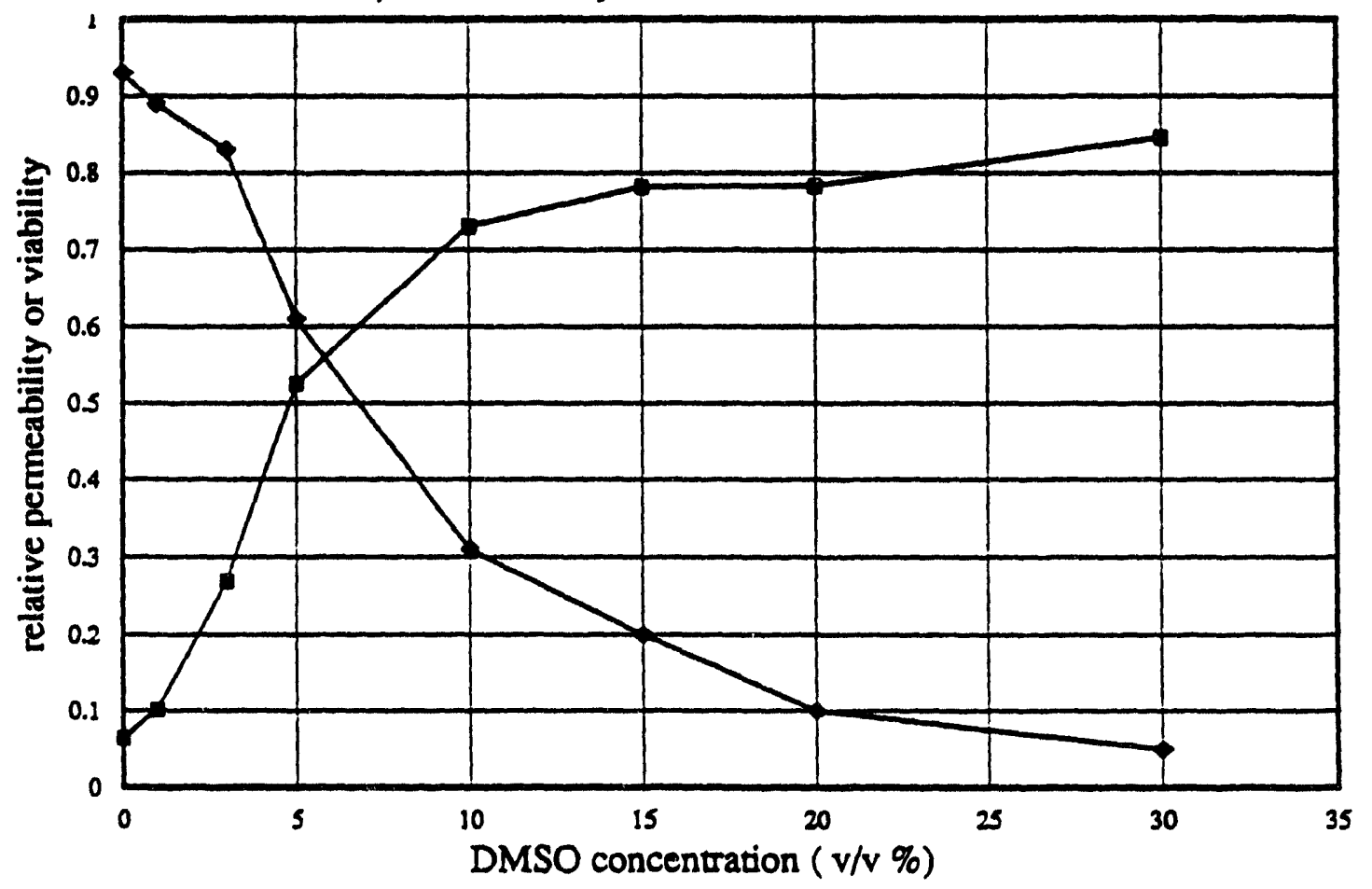

$\rightarrow$ permeability $\rightarrow$ viability 
Fig. 2-7 relative permeability as a function of time

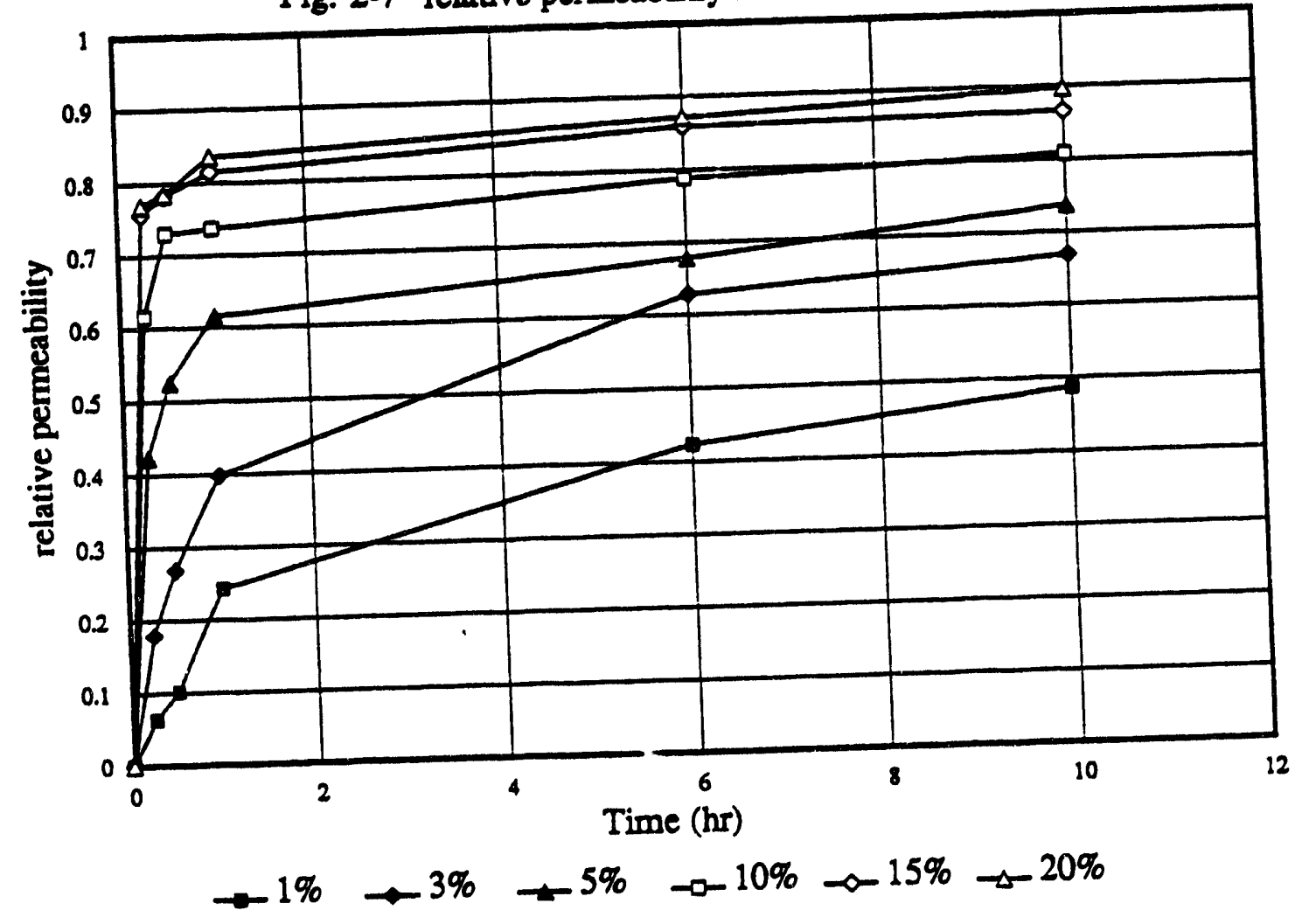


Fig. 2-8. viability as a function of time

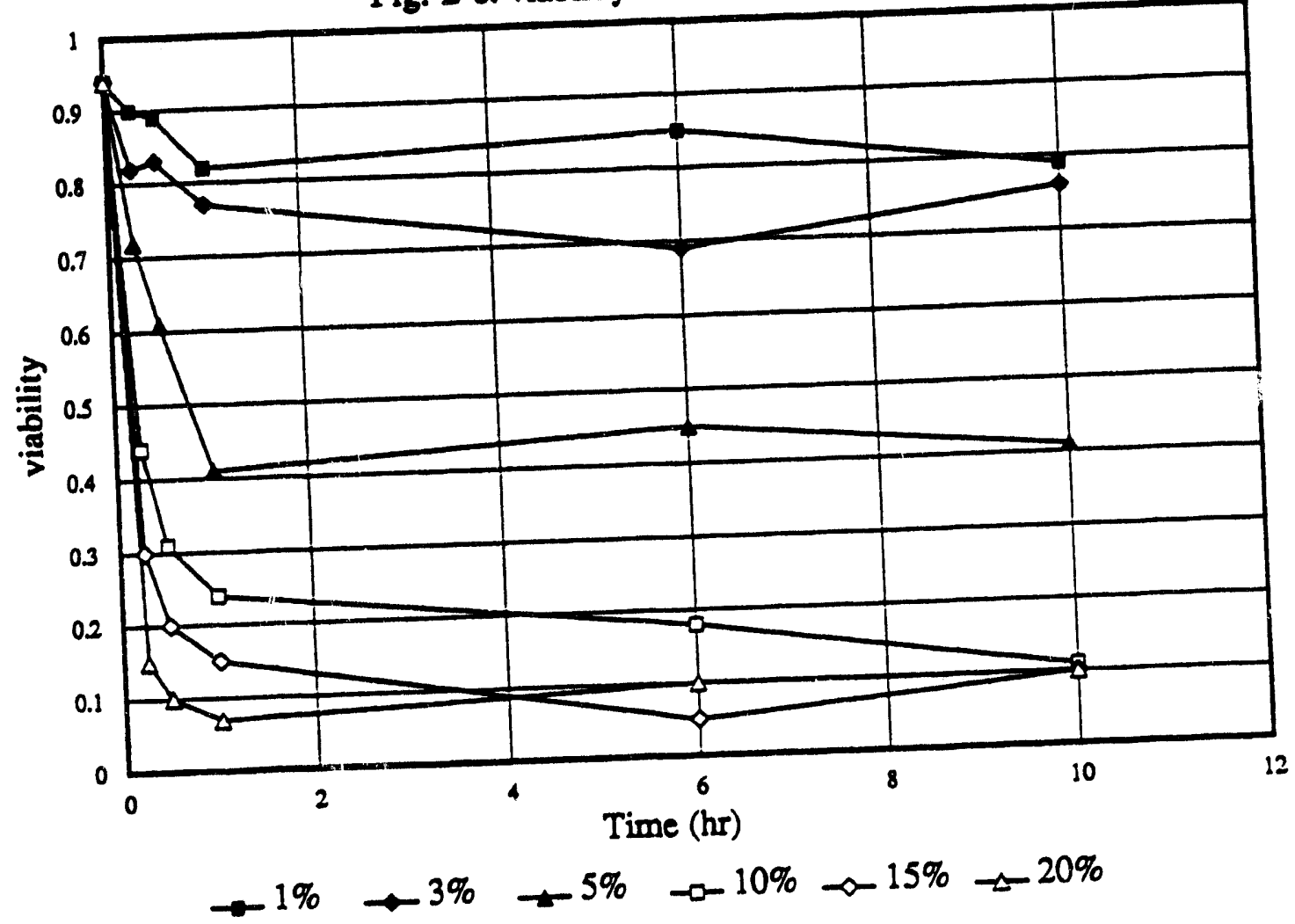


on 1 and 3\% level keep at least 70\% of activities during experimental period. Viability of cells treated with 5\% DMSO shows gradual decrease for one hour, then seems to retain $40 \%$ activity. In the case of low concentration of DMSO treatment, it appears possible to permeabilize the plant cells while preserving viability. From above results, the lowest concentration of DMSO required for significant permeabilization can easily be assumed as a range between $3 \%$ and $5 \%$. Also, optimal time for adequate permeabilization for G. arbreum cell can be estimated as one to six hour to reach over $70 \%$ release.

In order to test continuous feeding of DMSO for continuous processing, a long term batch culture was performed in the presence of permeabilizing reagent. DMSO levels are adjusted to $1,2,5,10 \%$ considering detrimental effect on the cell during cultivation period. It appears possible to permeabilize the plant cells while preserving viability. Figure 2-9 shows that DMSO treatment of $G$. arboreum cells enhanced the release of gossypol related compound about 12 times. The most efficient release of gossypol was performed at the concentration of 5 \% DMSO for long-term experiment. Release increased with higher level of DMSO, but viability in this levels was not retained at first time even though it has been restored gradually after 6 days ( Figure 2-12). Figure 2-10 shows the relationship between growth and DMSO concentration. The long lag period observed for the cells treated with over $5 \%$. It may be either due to survival of only a few cells or to slow recovery of the treated cells. Intracellular gossypol were not fully released at the levels of $1 \%$ and $2 \%$ of DMSO (Fig. 2-11). It might be due to poor configurational changes on membranes. Figure 2-12 shows the relationship between the viability and DMSO concentration. Viability was well retained at low concentration $(1,2 \%)$ of DMSO for 20 days batch culture, but plant cells were inactive at high concentration in three days. Viability of plant cells were partly restored at the concentration of 5\%, while viability was not detected at the concentration of $10 \%$ DMSO.

Permeabilization of plant cells has been tested in this experiment. From this experiment, 
Fig. 2-9. Effect of DMSO concentration on external production

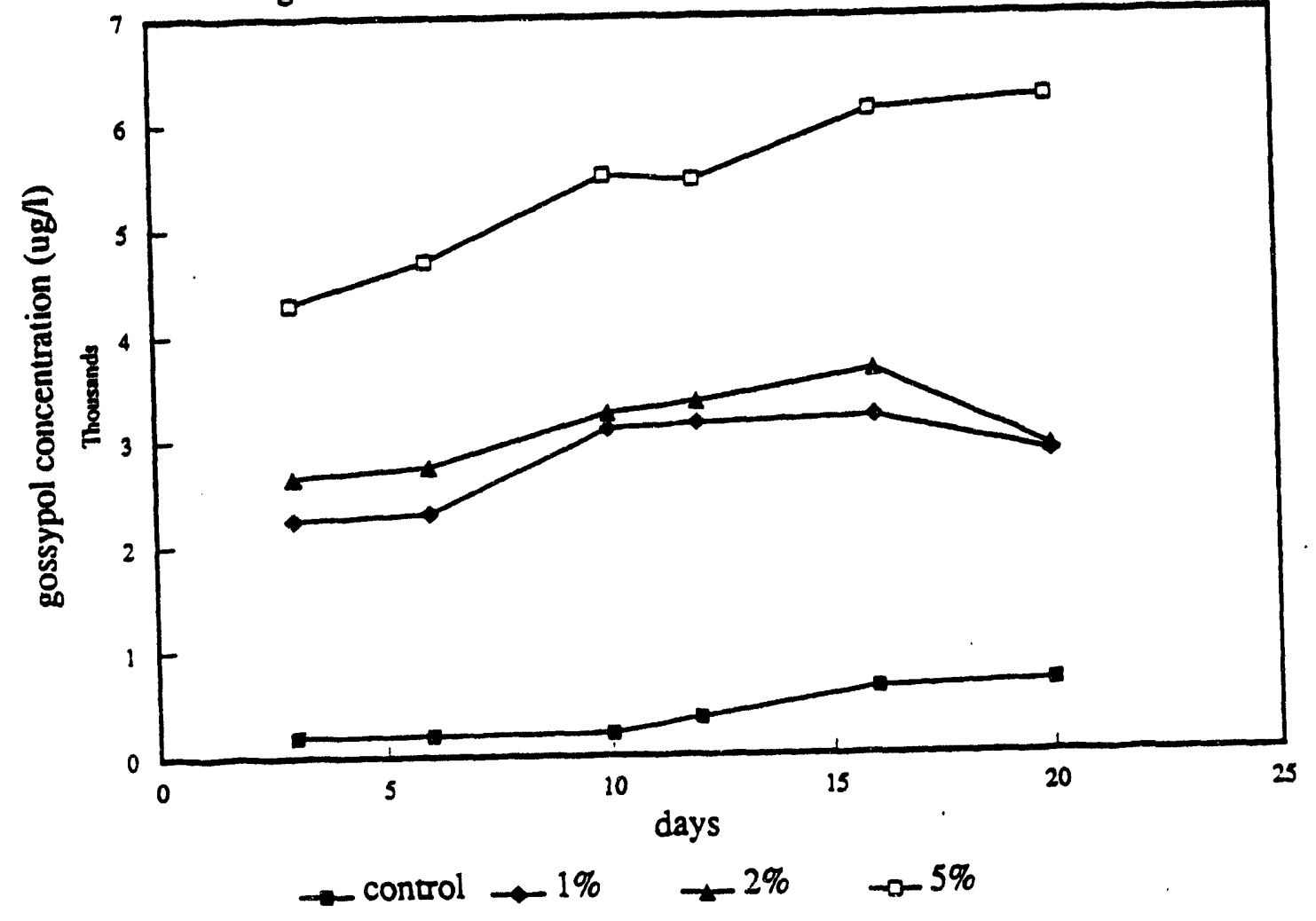


Fig. 2-10. Effect of DMSO concentration on cell growth

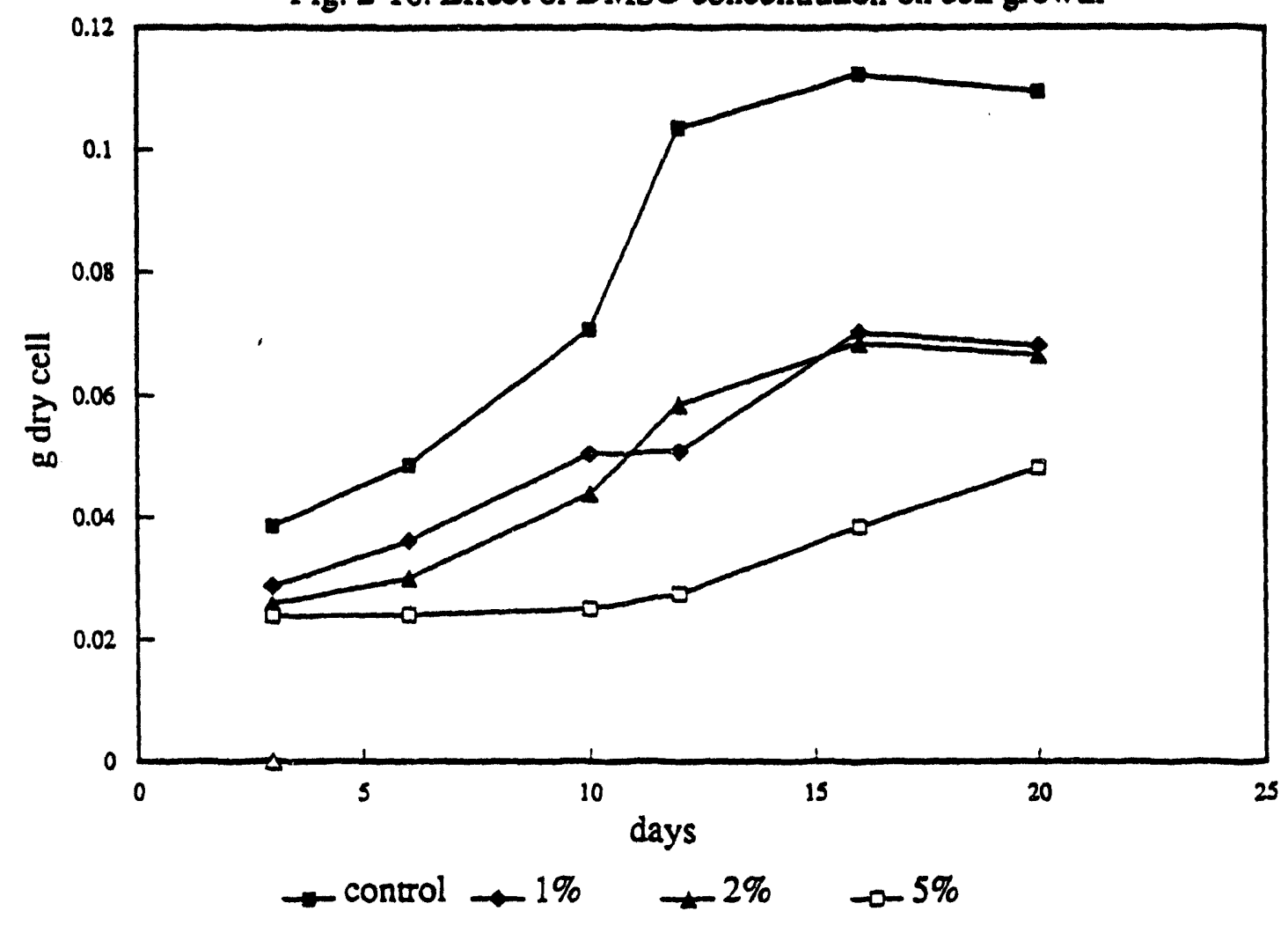


Fig. 2-11. Effect of DMSO concentration on internal production

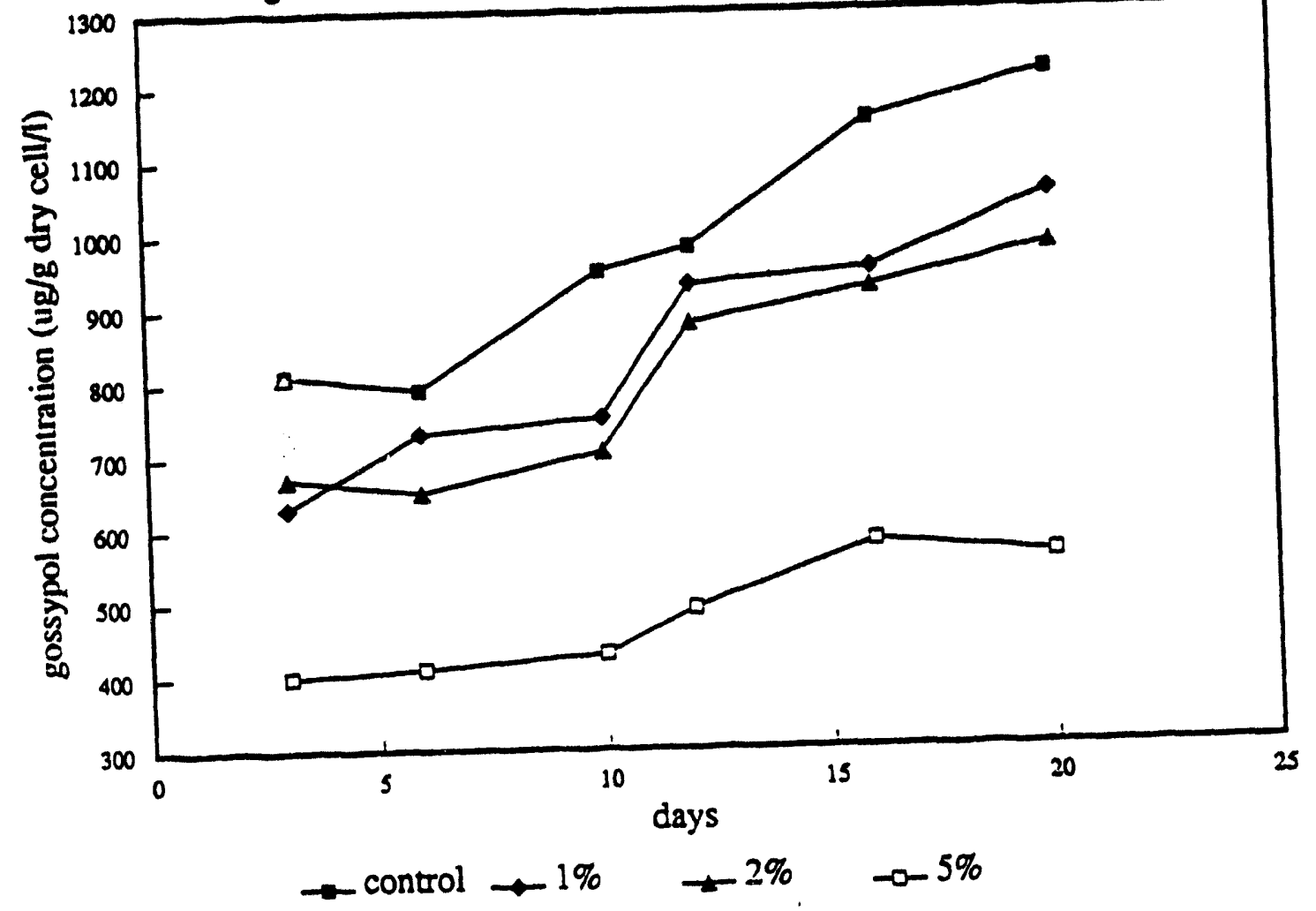



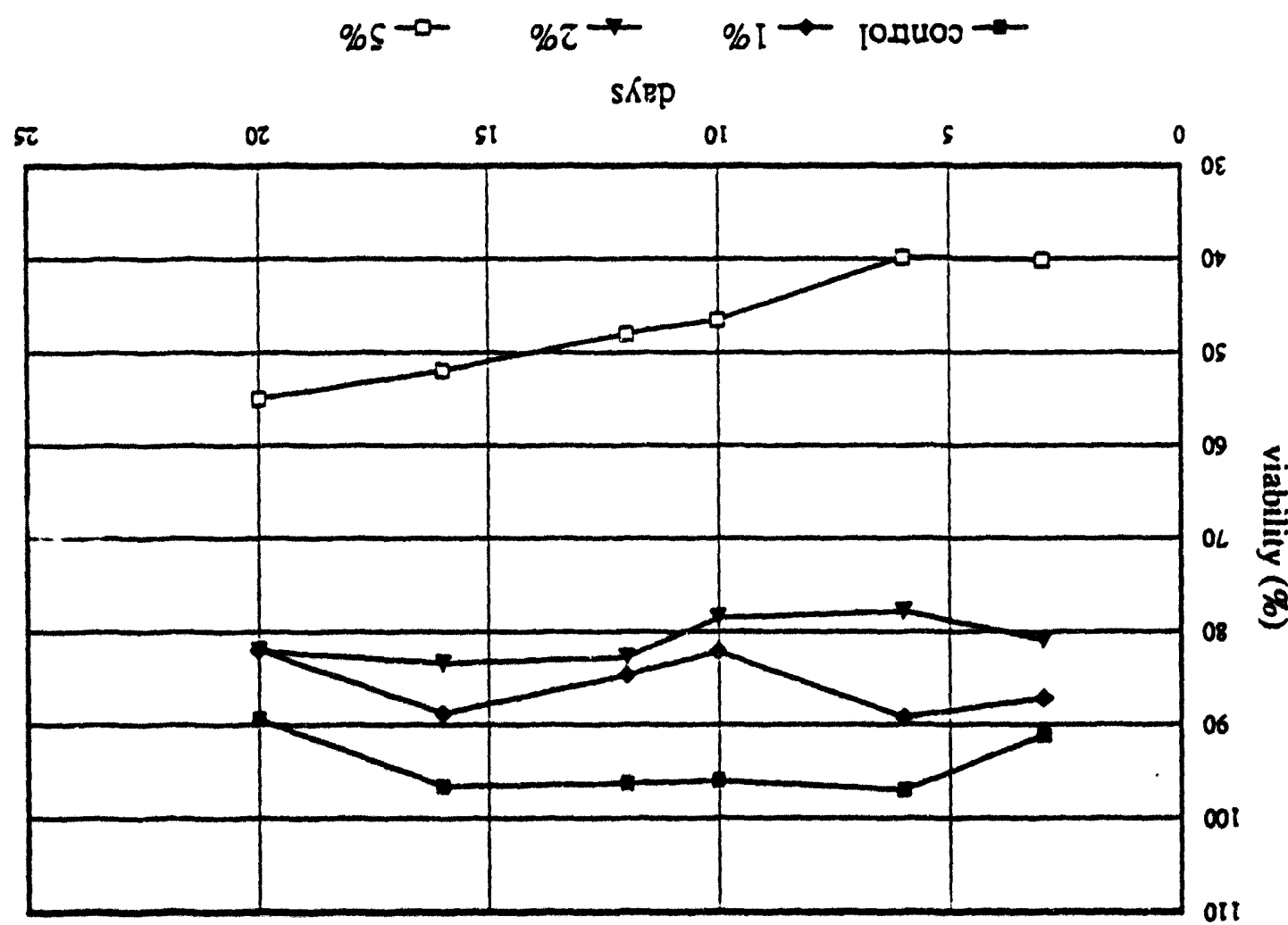

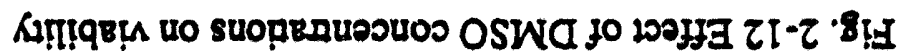


we can apply this technique to immobilized plant cells. Quantitative release of products is possible under conditions where the viability of the cells is not affected to any great extent. A continuous pror $3 s s$ based on release of products can be developed. Also above results suggest that it would be possible to release intracellular products by permeabilization.

\section{Batch experiments for elicitor.}

A number of plant products, i.e. the phytoalexins and related compounds, have antifungal or antibacterial properties and are produced in response to pathogens. Their synthesis is known to be triggered by specific elicitor molecules and this system is active in cell cultures as well as in intact plants. The mechanisms of elicitor recognition by the plant cell are still not revealed completely, but it is assumed as the induction of formation of the defense metabolites.

In this batch experiment, an application of elicitor has been studied to enhance the productivity. Elicitor has been prepared from the wilt-producing fungi, Verticillium dahliae, strain 277 (non-virulent to cotton). Verticillium dahliae strain 277 was chosen as fungal elicitor due to its broad host range as well as its low virulence to cotton cells (207). Typical elicitor preparation contained approximately $170 \mu \mathrm{g}$ protein/ml. In this experiment, A range of $5.6 \mathrm{x}$ $10^{-4}$ to $5.6 \times 10^{-3} \mathrm{~g} /$ concentrations of elicitors from $V$. dahliae were added to $15 \mathrm{ml} \mathrm{G}$. arboreum cell suspension culture medium. Figure 2-13 shows the time course experiment of specific gossypol production with medium containing different levels of elicitors. Optimum specific production was obtained with elicitor concentration of $8.5 \times 10^{-4}$ for the period of 25 days. However, treatment of $5.6 \times 10^{-3} \mathrm{~g} / \mathrm{l}$ elicitor concentration showed a decreased sesquiterpene aldehyde formation compared with other concentrations. The decreased rated might imply degradation of cell viability and/or cell lysis caused by toxic effect of high elicitor concentration (207). The specific production has been increased in any case of elicitor treatment 15 folds to 40 folds. Figure 2-14 shows the effect of different elicitor concentrations on $G$. 

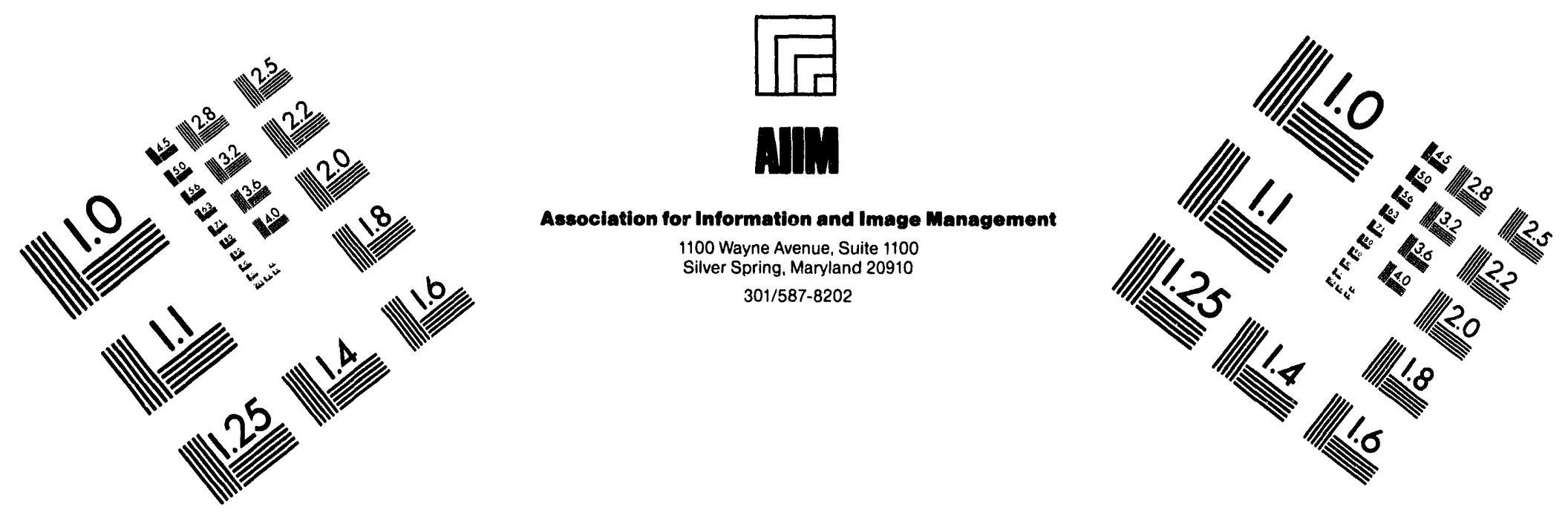

\section{Centimeter}

$\begin{array}{llllllllllllllll}1 & 2 & 3 & 4 & 5 & 6 & 7 & 8 & 9 & 10 & 11 & 12 & 13 & 14 & 15 & \mathrm{~mm}\end{array}$

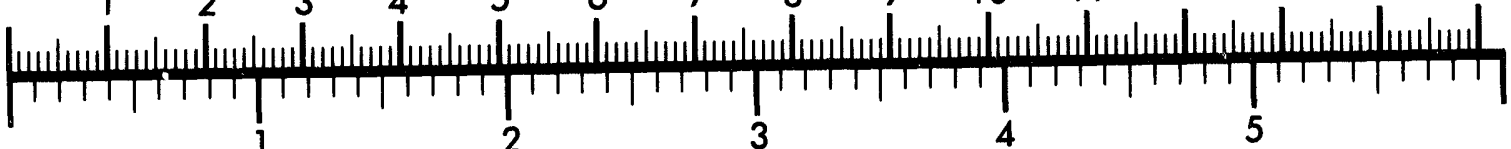
Inches

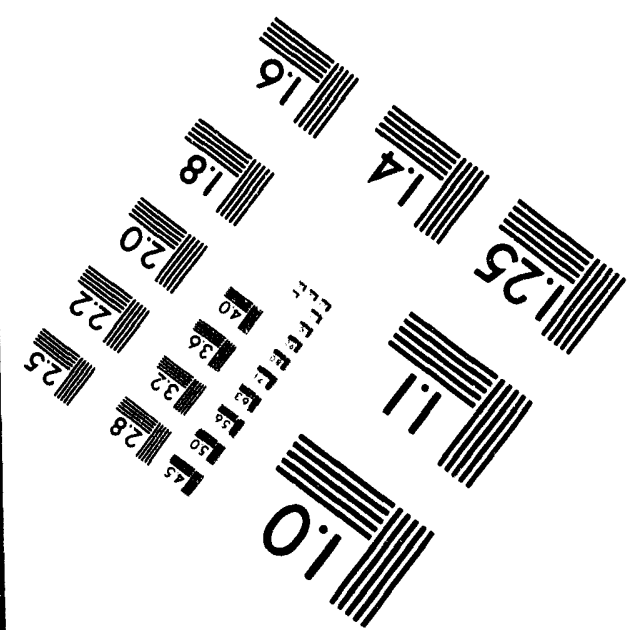

MANUFACTURED TO AIIM STANDARDS BY APPLIED IMAGE, INC.

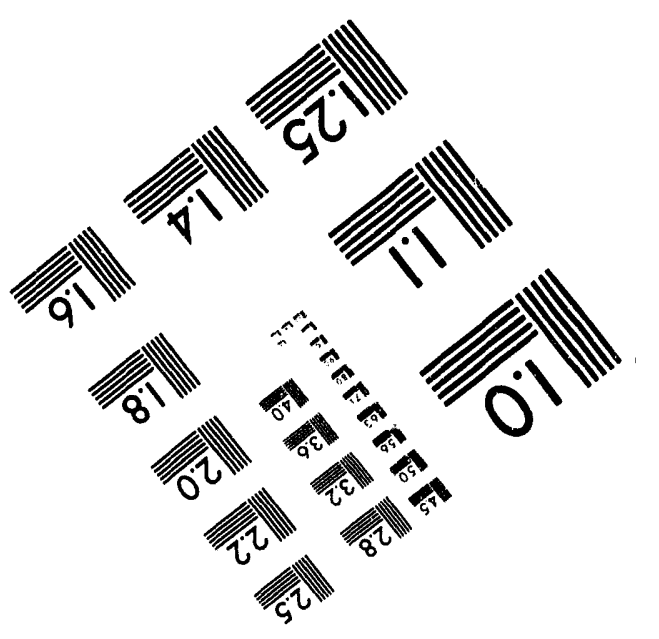



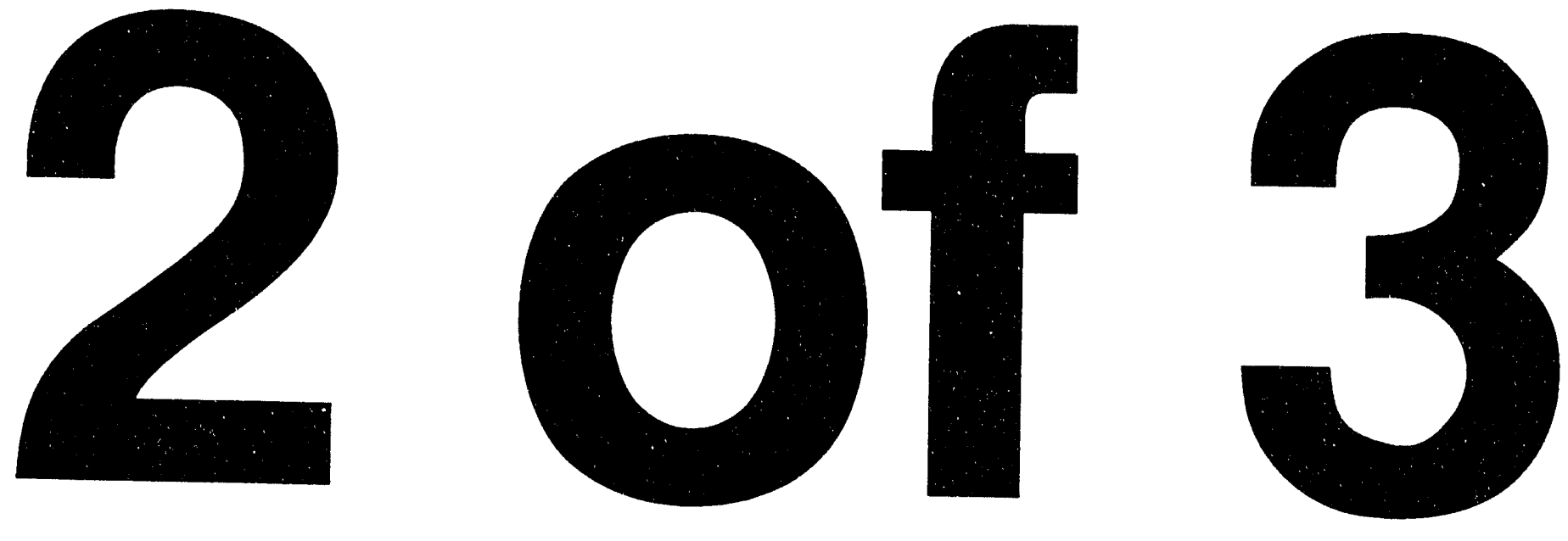


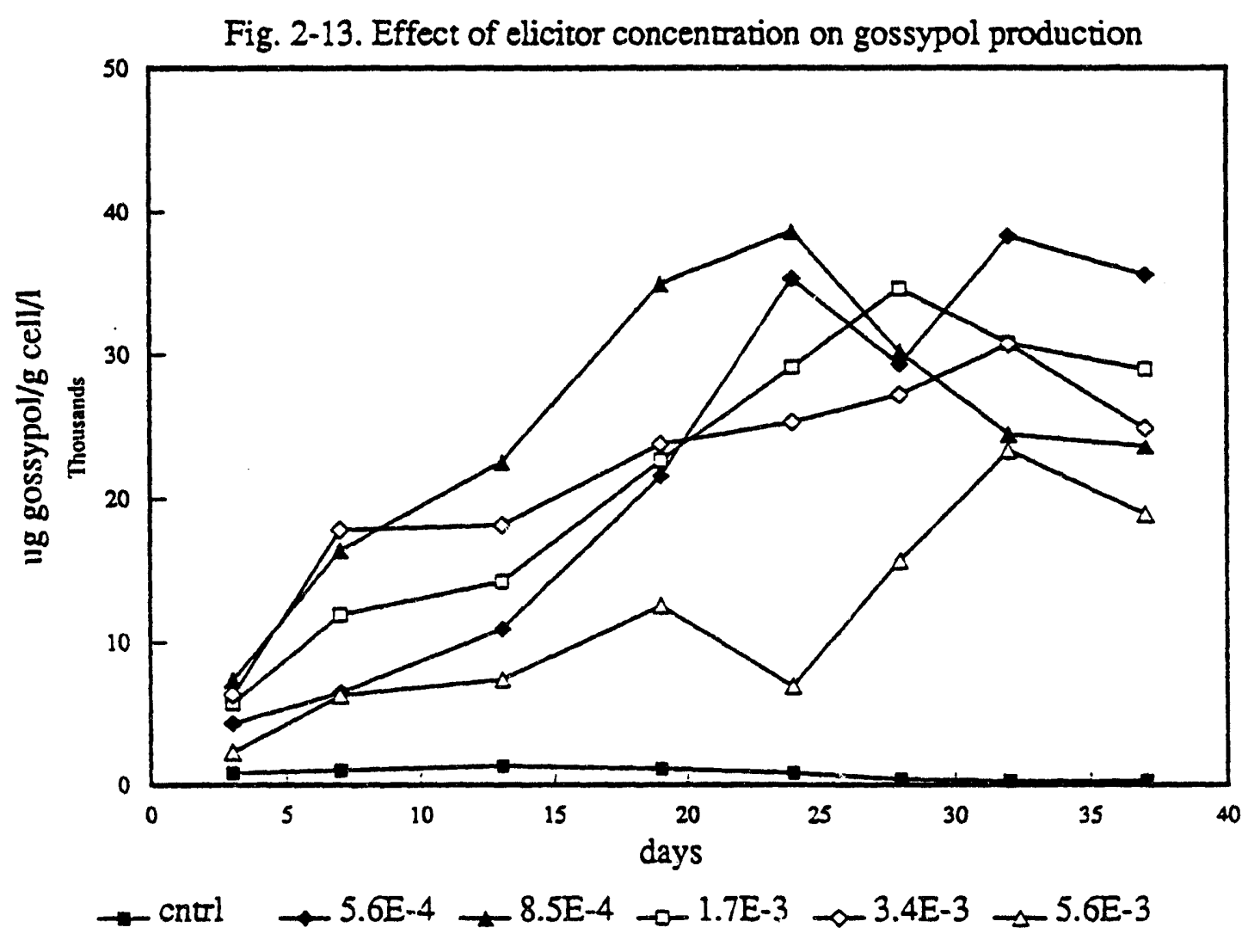


Fig. 2-14. Effect of elicitor concentration on growth

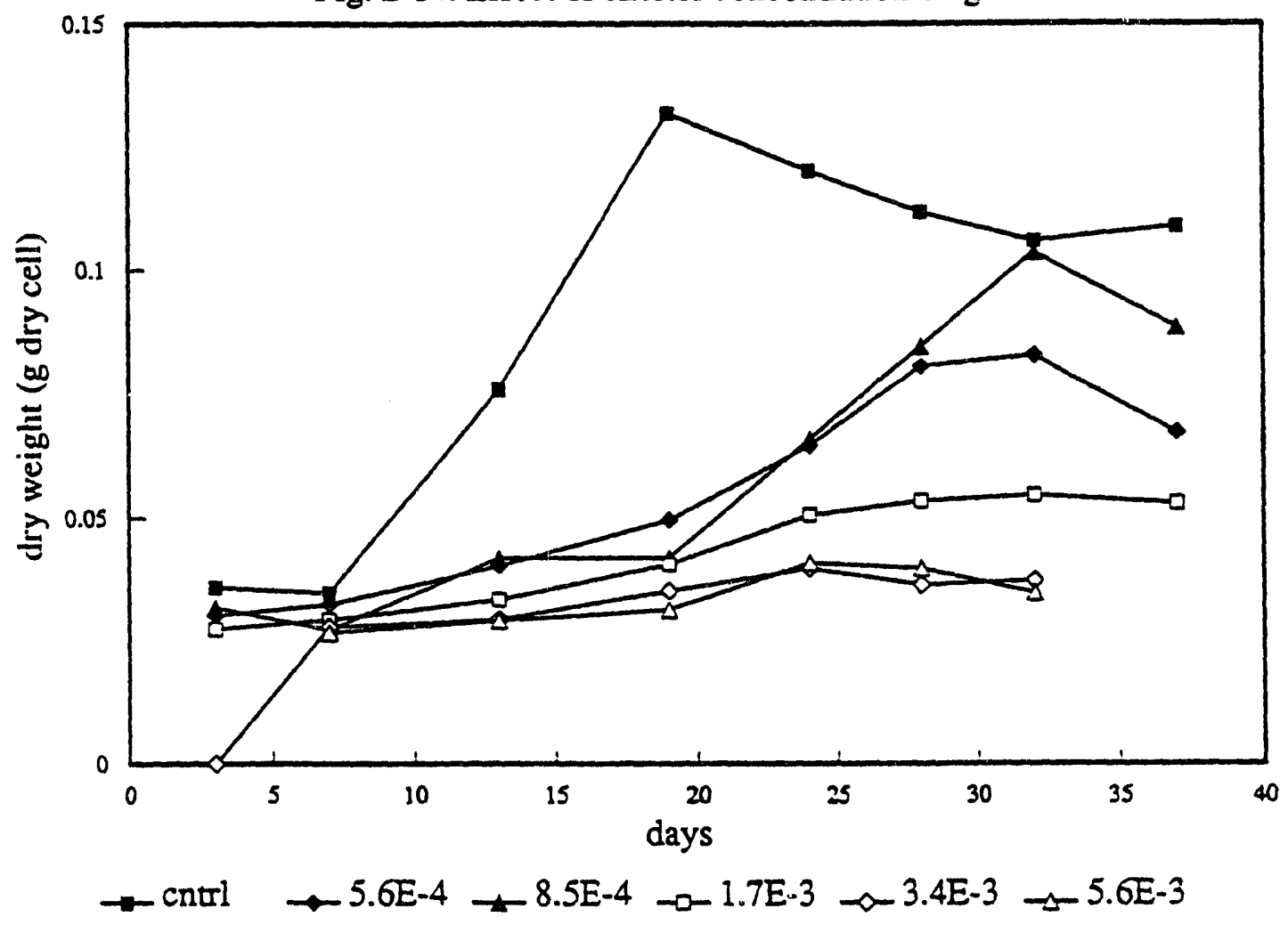


arboreum growth. Addition of elicitor to $G$. arborewm cell suspension cultures cause a decreased cell growth in all concentration ubserved. When higher concentrations of elicitor ( 5.6 $\times 10^{-3}$ and $3.4 \times 10^{-3} \mathrm{~g} / 1$ ) was applied, cell growth was very slow during experimental period. Cell growth was inhibited even in low concentrations of elicitor. In the treatment of $8.5 \times 10^{-4}$ g/ elicitor concentration, long lag phase was observed and active growth begun after 19 days when the specific productivity of sesquiterpene aldehyde started decreasing. This result suggests that sesquiterpene aldehyde formation by elicitation induces reduction of growth and its pattern is non-growth associated type.

\section{Experiments with immobilized plant cells}

Works to date

Major problems associated with secondary metabolite formation by plant cells are the slow metabolic rate and the low product yield of cells. Another factor that presents problems in using plant cells on a large scale is their sensitivity to shear. To solve these problems, immobilization of plant cell is considered. Based on review, adsorption method presents certain advantages over the existing immobilization technology by gel entrapment. This process is simple and not stressful for the fragile plant cells. It remains efficiently the inoculum and the growing biomass even at high mixing rates. It provides for a well separated two phase system with easier control over the hydrodynamics of the culture system.

\section{Stability of immobilization}

There are two mechanism which affect adsorption immobilization process. Since the fibrous nature of the substratum, passive entrapment of cells by the fibrous material probably functions in immobilizing a substantial number of cells. Plant cells immobilized on the surface 
of selected materials shows very close contact with the support surface and partly adapt their shape to the microconfiguration of the surface. At the contact area between the cell wall and the support material, cell wall is flattened at contact area indicating a secretion of a compound that might be acting as a gap filler and/or gluing agent (72). Another mechanism is adhesion. Adhesion of suspension cultured plant cells to substratum plays a fundamental role in the immobilization process. The immobilization efficiency generally increased with increasing surface tension of the substratum. The high surface tension substra can allow for greater initial cell loading and adherent-cell density than the low surface tension substrata. The greater density of the adherent cells implies that more cells are immobilized by the adhesion process (77).

Immobilization efficiency is defined as the capacity of the substratum to retain plant cells in the immobilized state measured as the percentage of immobilized cells versus the total biomass (i.e., immobilized and freely suspended cells) in the culture system. In order to test the immobilization efficiency, the loading capacity and time course experiments were performed using the cotton cloth.

Loading capacity was examined by inoculating a range of inoculum densities and collected after 4 days. For shake flask experiments a $2 \times 2 \mathrm{~cm}$ square piece of the cotton cloth was weighed and sterilized together with $50 \mathrm{~mL}$ of fresh culture medium in $250 \mathrm{~mL}$ Erlenmeyer flasks with gyratory shaking at $115 \mathrm{rpm}$. Figure 2-15 shows the percentage of cells immobilized as a function of the inoculum biomass after 4 days incubation. More than $60 \%$ of the cells were immobilized when $3 \mathrm{~g}$ fresh weight or less of cells were inoculated. When the inoculum contained $5 \mathrm{~g}$ fresh weight of cells, approximately $35 \%$ were immabilized while the percentage immobilized decreased to less than $25 \%$ when inoculum size increased. It seems immobilization process on cotton fiber is largely dependent upon entrapment of cells due to weak surface tension of cotton fiber. Kamath and D'Souza (238) suggested polyethylenimine (PED) treatment to improve adhesion of cells to cloth. Adhesion of ureolytic bacterial cells on 
cotton cloth was increased from 0.2 activity units to 30.4 with treatment of PEI to cells in relatively short time ( $2 \mathrm{hrs})$. However, toxicity of PEI to plant cell is not known and plant cells can adhere to cotton cloch secreting sticky polysaccharides from cell wall.

In order to find gentle method for plant cell immobilization loading capacity experiment was also preformed by inoculating a range of inoculum densities onto spiral wound type configuration (Fig. 2-16). Cells were loaded on $9 \times 16.5 \mathrm{~cm}$ cotton cloth by pouring medium containing designed amount of cells, then wounded with spacer. After 4 day incubation in 250 $\mathrm{ml}$ beaker, immobilization capacity were examined by measuring dry weight of each unit. $G$. arboreum cells were immobilized over $90 \%$ on the cotton cloth with spacer over a range tested. It appeared that this type of configuration retains the cells between cotton cloth and spacer not only by adhesion mechanism but also providing "filter effect" on relatively larger plant cells.

Time course experiments were performed in triplicate for free cell suspensions and immobilized cultures collected 3 day interval during 20-day growth cycle. In shake flask experiments, the immobilized cells were prepared with $9 \mathrm{~g}$ fresh weight inoculum on three $2 \mathrm{x}$ $2 \mathrm{~cm}$ cotton cloth for 7 days. Immobilized $G$. arboreum cells was inoculated in $100 \mathrm{ml}$ medium in $250 \mathrm{ml}$ Erlenmeyer flasks with approximately $1.26 \mathrm{~g}$ dry cell/. To compare with suspension culture, suspension cultures contained no cotton cloth were also cultivated as $100 \mathrm{~mL}$ cultures in $250 \mathrm{~mL}$ flasks. The effect of immobilizing cultured $G$. arboreum cells using a cotton cloth on growth is shown in Figure 2-17 which shows dry weight. Over 20 days examined, the immobilized cells grow at a slower rate than the suspension cultured cells. Suspension cultures reached the stationary phase after approximately 13 days. The immobilized cultures appeared to be in slowly decelerating growth phase for the entire 21 days but continued to increase in mass to the end of the period. This result can be explained either as a mass transfer limitation of essential nutrients and dissolved oxygen to the cells, or the packed environment which can 
Fig. 2-15. Loading capacity on cotton cloth as a function of inoculum size

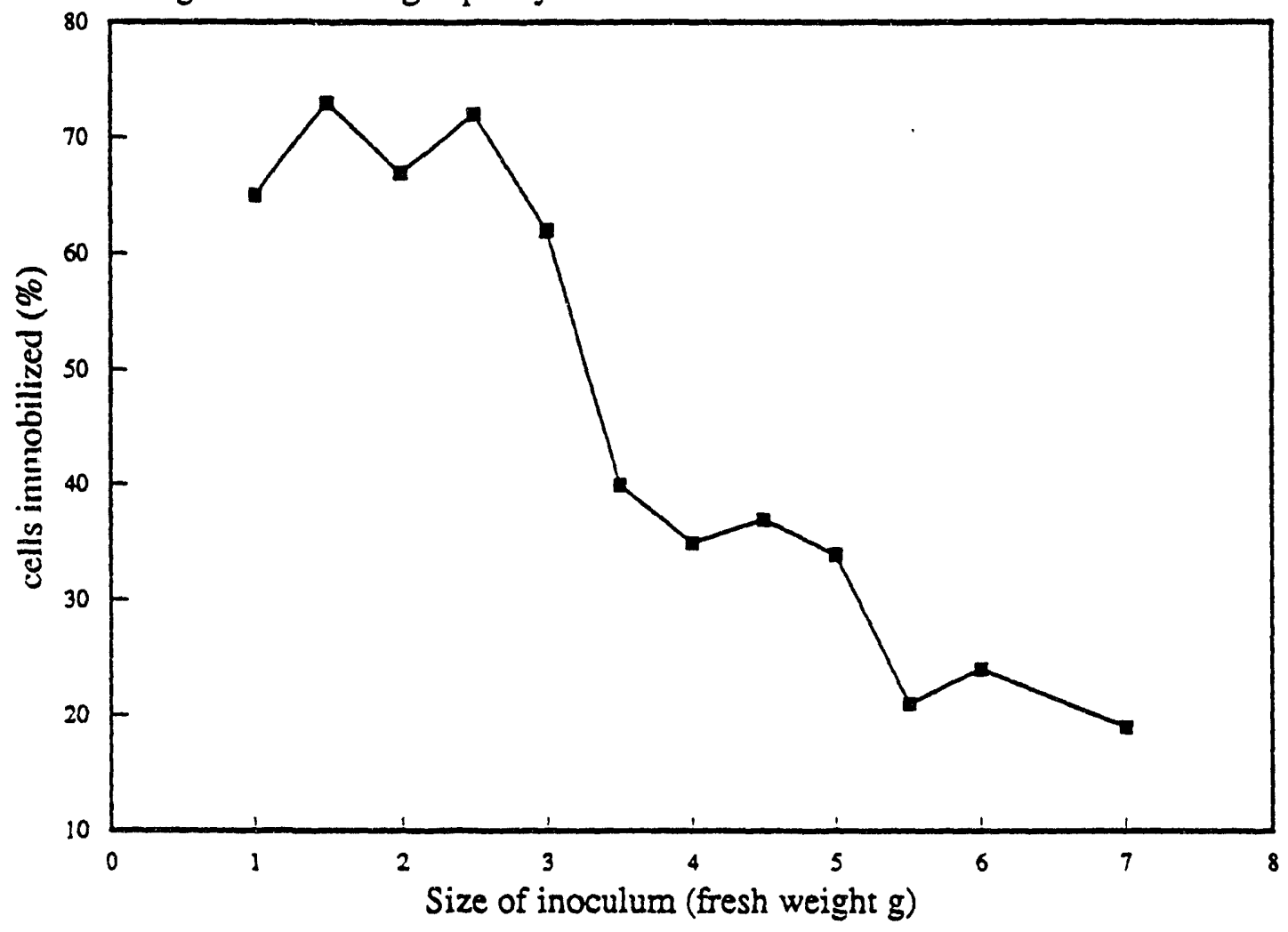


Fig. 2-16. Loading capacity on siral wound type configuration as a function of inoculum size

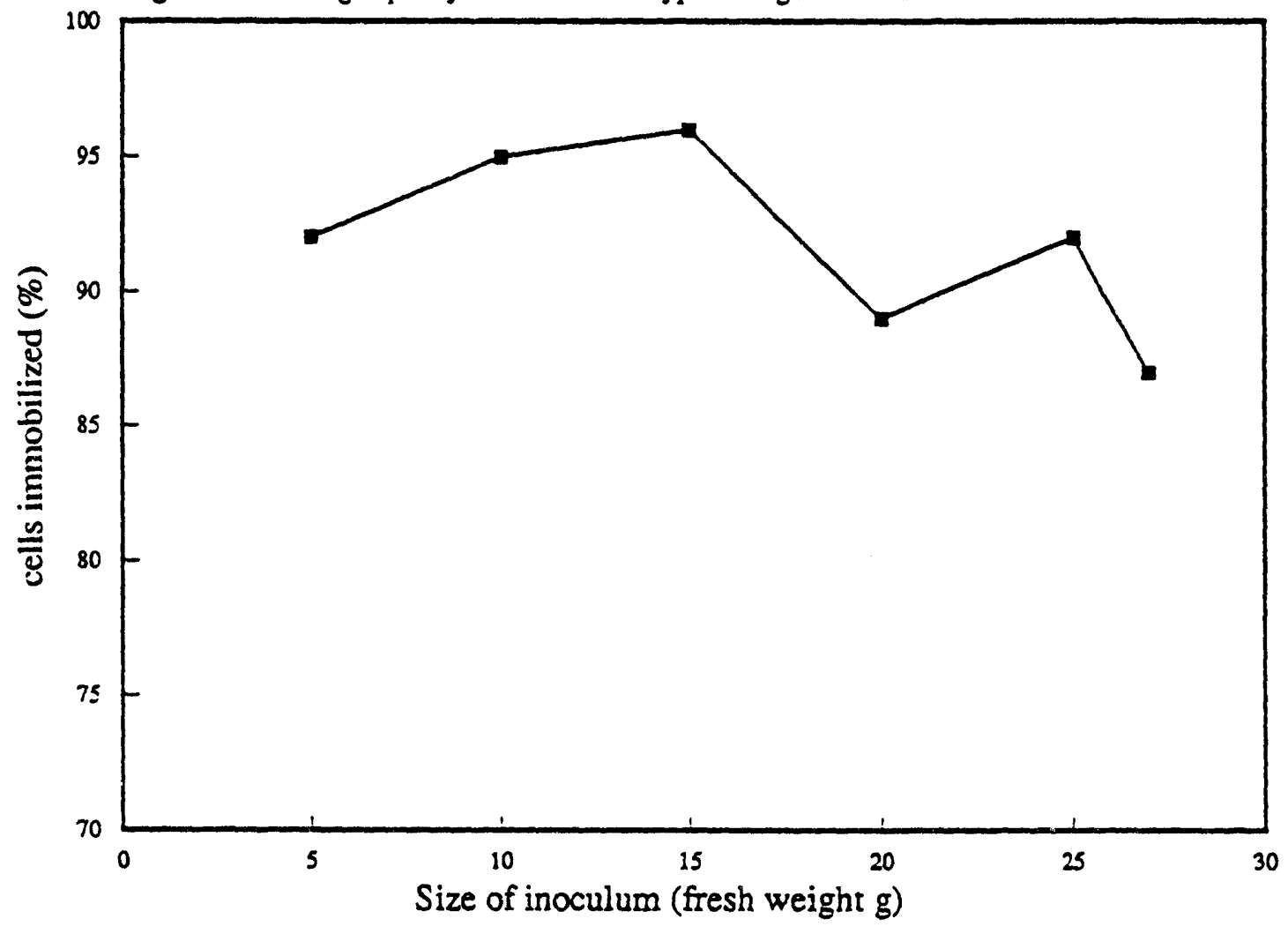


Fig. 2-17. Time course study of immobilization efficiency

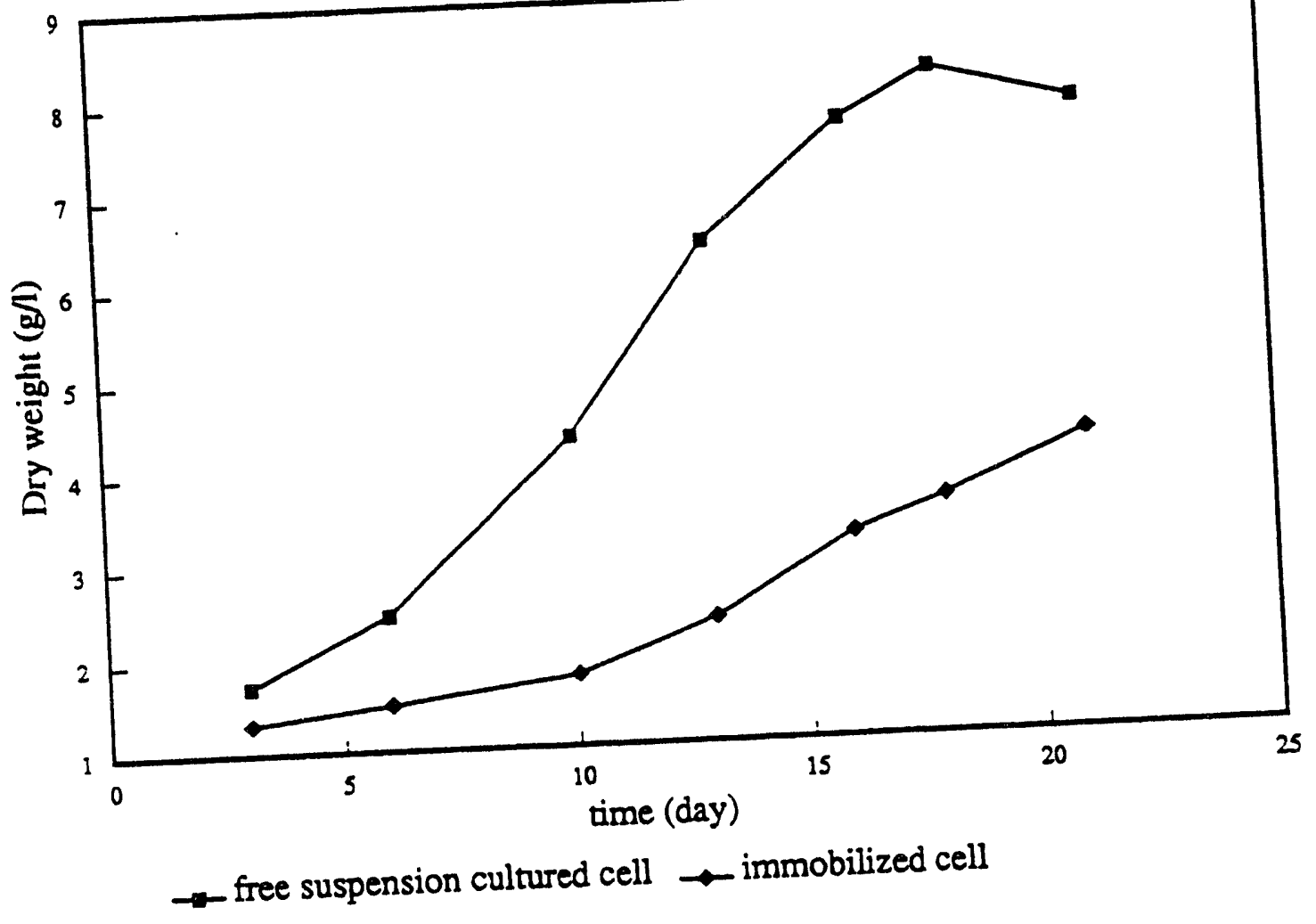


limit cell division and growth.

\section{Possibility of continuous culture - differential reactor}

Due to its slow growth rate (doubling time is $3-4$ days), it is needed to design a method which allows fast experiments such as small scale differential reactor. The differential reactor is normally used to determine the rate of reaction as a function of concentration. It consists of a tube containing a small amount of catalyst. Because of the small amount of cell loading compare to packed bed reactor, the conversion of substrate in the bed is small, as is the change in substrate concentration through the bed. As a result, the substrate concentration through the reactor is essentially constant and approximately equal to the inlet concentration. So the reactor is considered to be gradientless, and the design equation will be similar to the CSTR design equation ( $\mu=D$ ). A material balance of substrate is

substrate accumulation $=$ substrate feed - growth - product synthesis- substrate removal

$$
\mathrm{dS} / \mathrm{dt} \quad=\mathrm{F}_{\mathrm{i}} \mathrm{S}_{0} N-\mu \mathrm{X} / \mathrm{Y}_{\mathrm{x} / \mathrm{s}}-\mathrm{q}_{\mathrm{p}} \mathrm{X} / \mathrm{Y}_{\mathrm{p} / \mathrm{s}}-\mathrm{F}_{0} \mathrm{~S} / \mathrm{V}
$$

At steady state $\mathrm{dS} / \mathrm{dt}=0, \mathrm{D}=\mathrm{F} / \mathrm{V}$ and assume product synthesis is proportional to cell weight (assume non-growth associated product synthesis $q_{p}=1 / x d P / d t$, where $d P / d t=\beta X$ ), the equation is

$$
D(\text { So }-S)=\mu X / Y_{x / s}+\beta X / Y_{p / s}
$$

In order to relate $\mathrm{X}$ and $\mathrm{S}$ to the dilution rate, a model expressing the growth rate as a function of limiting nutrient is required. Monod model is recommendable for sugar limiting system. For continuous culture equation specific growth rate is substitute by dilution rate.

$$
\mathrm{D}=\mathrm{DcS} /(\mathrm{Ks}+\mathrm{S})
$$

where Dc is critical dilution rate representing maximum dilution rate. Solving this equation for $S$ as a function of $D$ yields an equation for the steady state concentration of the limiting nutrient 


$$
S=D K s /(D c-D)
$$

Substitution of this equation into equation provides an expression relating the steady state cell concentration to the dilution rate

$$
X=\frac{(S o-D K s /(D c-D)) Y_{x / s} Y_{p / s}}{\left(D Y_{p / s}+\beta Y_{x / s}\right)}
$$

Differential reactor has been set up and run for 45 days using $30 \mathrm{~g}$ wet weight of plant cells as a type of tubular reactor with working volume of $27.5 \mathrm{ml}$. During this period the possibility of continuous culture was tested. Immobilized cells were removed in order to measure cell weight and viability when flow rate changed. Figure 2-18 shows a time course experiment with different feed rate. Viability was well maintained during the period of experiments. Immobilized cells in the reactor glow slowly. Although production of phytoalexin is not stable, figure shows increased production compared with batch culture ( approximately 6 - $10 \mu \mathrm{g}$ gossypol/g dry weight cell///day for external and 65 - 80 for internal productivity). Since phytoalexin production in this experiment based on external formation, the productivity might be increased with combined permeabilization and elicitation. 
Fig. 2-18. Reactor operation changing flow rate.

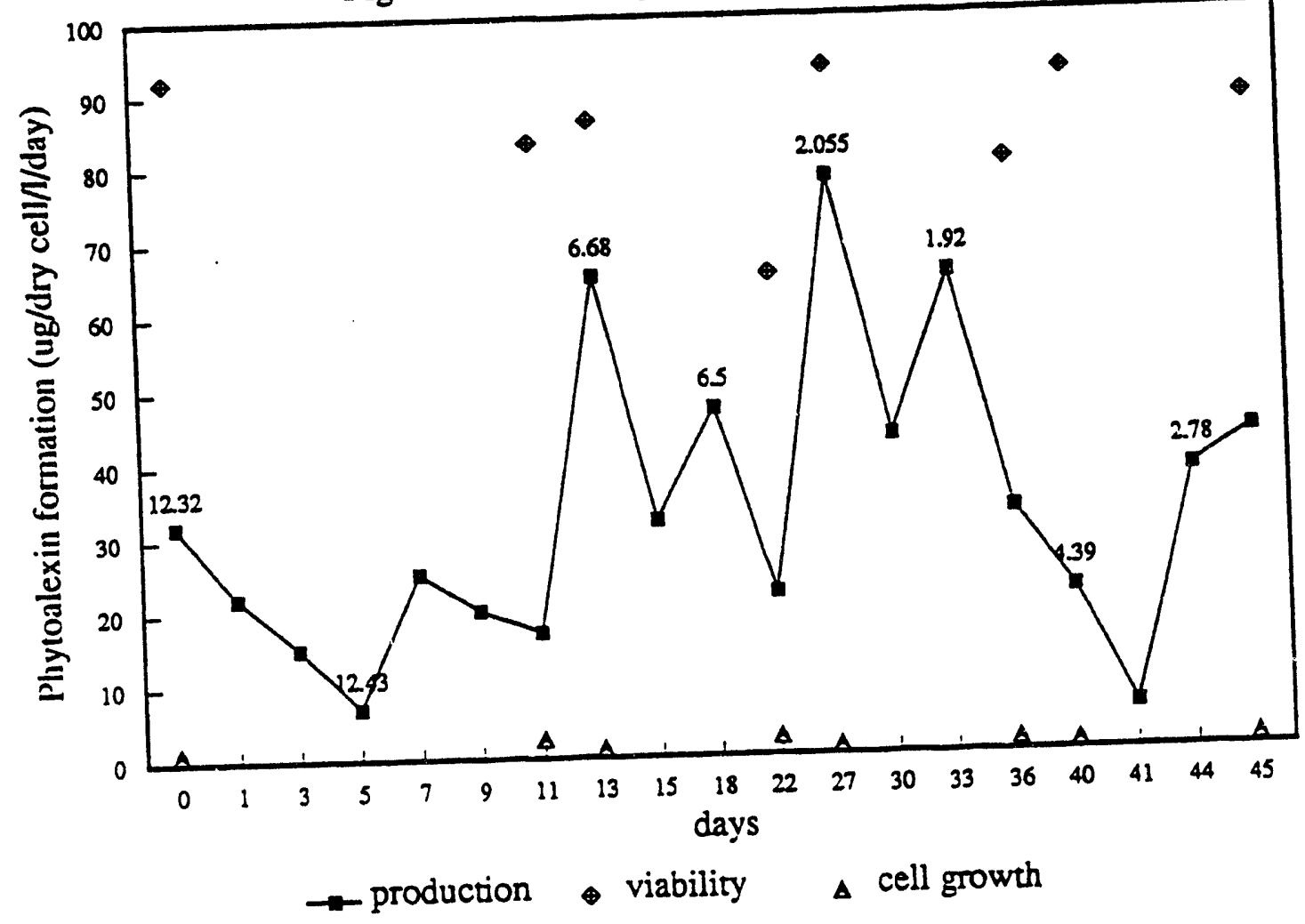




\section{SUMMARY OF FUTURE WORK}

Study Permeabilization

1. pretreatment of cells with low concentration of DMSO

2. possible mass transfer model

Study elicitation

3. possible rate kinetics

Study Immobilized cell system

4. experiment with immobilized cell reactor

a. find optimum operation regime

b. cyclic treatment of DMSO

c. cyclic treatment of elicitor

5. modeling of packed bed reactor

production mode! in tubular reactor combining permeabilization, elicitation.

$\mathrm{dP} / \mathrm{dt}=\mathrm{f}(\mathrm{v}$, elicitor, $\mathrm{DMSO})$

1. pretreatment of cells with low concentrations of DMSO

Although cells treated with DMSO shows growth, viability is not well retained over $5 \%$ DMSO. To avoid harmful conditions, continuous permeabilization of preconditioned cell has been suggested by Park (237). When Coleus blumei cells were preconditioned at $0.1 \%$ DMSO, they could mairitain high viability under higher DMSO concentrations of $0.5 \%, 1.0 \%$, and 1.5 $\%$ at which nonpreconditioned cells died. This process might loosen cell wall and plasma membrane of plant cells in some extent which have no effects on cell viability. In next experiment, this technique will be tested to G. arboreum cells. If pretreated cells can secrete secondary metabolite more than untreated cells while maintain viability, this technique will be applied to immobilized cells and reactor operation.

2. possible mass transfer model for permeabilization

Release of secondary metabolite is mainly dependent upon diffusion through membranes. It is thought that DMSO treatment results in substitution of bound water from the cellular 
structure and reversible alterations in protein structure on cell membrane. This mechanism causes alteration of permeability of cell wall and/or plasma mebrane. Thus, this process affect to the mass transport from the cell to the bulk solution and diffusion coefficient will be a function of DMSO concentration. The flux $\mathrm{N}_{\mathrm{A}}$, inner and bulk concentrations can be considered as a function of time. Assuming that shape of plant cell is sphere, diffusion of sesquiterpene aldehyde through cell membrane including generation term can be expressed by following equation.

$$
\bar{N}_{A}(t)=-4 \pi r^{2} D_{\text {eff }} \frac{d C_{A}(t)}{d r}
$$

where $\mathrm{N}_{\mathrm{A}}$ is $\mathrm{kg}$ moles of $\mathrm{A}$ diffusing per second or $\mathrm{kg} \mathrm{mol} / \mathrm{s}, \mathrm{D}_{\text {eff }}$ is diffusion coefficient through membrane, and $C_{A}(t)$ is sesquiterpene aldehyde concentration as a function of time. Rearranging and integrating between inner memorane radius, $r_{i}$, and outer membrane radius, r,

$$
\bar{N}_{A}=\frac{-4 \pi D_{\text {eff }}\left(C_{A_{i}}(t)-C_{A 0}(t)\right)}{\left(1 / r_{i}-1 / r_{0}\right)}
$$

where $C_{A i}(t)$ and $C_{A 0}(t)$ are intracellular and bulk phase sesquiterpene aldehyde concentration as a function of time, respectively. Assuming perfect mixing, lumped analysis can be applied to this study.

$$
\cdot \bar{N}_{A}(t)=V \frac{d C_{A}(t)}{d t}
$$

where V represents volume of bulk phase. Combining equations $2-4$ and 2-5 gives following equation. 


$$
\begin{aligned}
\frac{d C_{A}(t)}{d t} & =\frac{-4 \pi D_{\text {eff }}\left(C_{A_{i}}(t)-C_{A_{0}}(t)\right)}{V\left(1 / r_{i}-1 / r_{0}\right)} \\
& =K D_{\text {eff }}\left(C_{A i}(t)-C_{A 0}(t)\right)
\end{aligned}
$$

where $K=4 \pi /\left(1 / r_{i}-1 / r_{0}\right) V . d C_{A}(t) / d t$ will be calculated by either initial slope of curve or differentiation of fitted curve. $C_{A i}(t)$ and $C_{A 0}(t)$ will be obtained from experimental data. This study will give $D_{\text {eff }}$ value as a function of different concentrations of DMSO.

3. possible rate kinetics for elicitation

G. arboreum growth was inhibited by addition of elicitor in culture medium. Inhibition mechanism is not well understood. However, it is generally suggested that elicitation can cause a alteration of gene expression which cause a shift from primary metabolism to secondary metabolism (109). Also it is thought elicitation can cause a degradation of cell viability and/or cell lysis in the presence high concentration of fungal elicitor (207). Based on these concepts, a kinetic study of inhibition on G. arboreum cell growth will be proposed. One possible inhibition model is based on noncompetitive inhibition. In this type of inhibition, the inhibitor bind with enzyme and substrate randomly, reversibly, and independently at different sites. It suggest noncompetitiv: inhibition can explain both alteration of gene expression and degradation. Simple competitive inhibition model is as follows:

$$
\mu=\frac{\mu_{\max } S}{\left(S+K_{s}\right)} \frac{K_{E i}}{K_{E i}+E}
$$

where $\mathrm{E}$ is elicitor concentration and $\mathrm{K}_{\mathrm{Ei}}$ is inhibition constant. This model will be tested by experimental data. If this model will not fit to experimental data, a semi-mechanistic model will be suggested by correcting mechanistic model, for example, adding an exponential correction term. 
In cotton cells, phytoalexin production does not occur or very little without the presence of elicitor. As mentioned above, elicitor treatment can cause a dramatic increase of phytoalexin production altering the gene expression and/or inducing enzymes related to secondary metabolic pathway. Therefore, we can have an insight that phytoalexin production is a function of elicitor concentration. The phytoalexin production can be expressed as a zero order reaction in equation 2-2 ( $d P / d t=\beta X)$. For such reactions the constant $\beta$ is expressed as a function of elicitor concentration as follows

$$
\beta=\beta_{0} e^{-E_{2} / E}
$$

where $\beta_{\mathrm{o}}$ is a production constant without elicitor, and Ea is the activation constant of the reaction. By plotting $\log \beta$ against $1 / \mathrm{E},-\mathrm{Ea}$ can be obtained as a slope. Combining equation 2-8 to equation 2-2, a production model is proposed as follows:

$$
d P / d t=\beta_{0} e^{-E a / E} X
$$

4. experiment with immobilized cell reactor

a. optimal operation regime

A schematic diagram of the tubular type reactor is thown in Figure 2-19. The column will be set in constant temperature chamber controlled by heating or cooling fan. Medium will be supplied by peristaltic pump. Air will be sparged into medium reservoir. Several sampling ports will be located on the reactor wall. Cell will be immobilized onto cotton cloth then spirally wounded with stainless steel spacer.

The optimal operation regime will be tested by changing flow rate of medium and initial concentrations of permeabilization reagent and elicitor. From batch cultures, DMSO concentrations from 2 - $5 \%$, elicitor concentrations from $1.7 \times 10^{-3}$ to $5.6 \times 10^{-4} \mathrm{~g}$ elicitor protein/1 was approximately defined as optimal region for operation. Based on this result, 
optimal operation regime concerned with DMSO concentration and elicitor concentration will be defined.

Regime analysis is possible in a number of ways. In tubular reactor operation, feed rate is a quantity that can generally be varied easily. If this results in an increased conversion rate, then transport processes are important. An experiment will be performed to determine the effect of changing feed ratz on production of sesquiterpene aldehyde.

\section{b. cyclic treatment of DMSO}

From long term experiment with presence of DMSO (Fig. 2-12), viability of cells is shown to be improved after 6 days and restored approximately $50 \%$ in 14 days. This result suggests that it would be possible to intermittently release intracellular products by permeabilization of the immobilized cells with using the minimal concentration of DMSO required for viability. If optimal concentration of permeabilization reagent for pretreatment can be established, the repeated permeabilization of cells can be performed by the cyclic treatment. The cycle can involve three phases such as production phase, permeabilization period, and restoration phase. Secondary metabolite produced by plant cells are accumulated in vacuole in production phase. After production phase, products are released by permeabilization in short period. Followed by permeabilization period, plant cells can be restored by removing permeabilization reagent in the restoration phase. This process may also repeated several times. Experiments will include the examination of optimal period for each phase, the comparison of pretreated system with untreated system. This kind of technique will be useful for practical operation of bioreactor with permeabilization.

c. cyclic treatment of elicitor

Plant cells not only synthesize phytoalexins but also catabolize phytoalexins. This is nat- 
ural mechanism because phytoalexins are also toxic to the plants that synthesize them. Therefore, if elicitors are applied once in a experiment in order to reduce the detrimental effects on cell viability caused by the presence of elicitor in the medium, the effect of elicitor on phytoalexin production is reduced after several generations. To minimize the detrimental effect and maximize the secondary metabolite production, cyclic treatment of elicitor will be considered in this study. Elicited G. arboreum cells can initiate sesquiterpene aldehyde formation even after removing elicitor from culture medium (207). This suggest that finding of adequate contact interval can reduce the detrimental effect of fungal elicitor. This kind of technique is rather practical than theoretical. In this experiment, elicitors will be pumped into immobilized cell reactor intermittently and contacted with immobilized cells for certain period to trigger the phytoalexin synthesis, then removed with continuous feeding of medium. Similar to cyclic treatment of DMSO, experiments will define the optimal contact time of elicitor and immobilized plant cells. Viability and productivity of cells in this process will be compared with those of continuous medium feeding system.

\section{5. modeling of tubular reactor}

Plant cells attached to a solid support in a tubular reactor can be considered as a biocatalyst. Mass balances for cell, substrate for a plug flow heterogeneous reactor at steady state can be written as ;

$$
\begin{aligned}
& v \mathrm{dX} / \mathrm{dx}=\mathrm{A} / \mathrm{V} r_{\mathrm{x}} \\
& v \mathrm{dS} / \mathrm{dx}=\mathrm{A} / \mathrm{V} \mathrm{r}_{3}
\end{aligned}
$$

where $v$ is the fluid linear velocity, V/A is the surface to volume ratio of the packing in the reactor, adn $\mathrm{I}$ is the reaction rate per unit area. These balances are based on the assumptions of constant density fluid, no axial dispersion, steady state, and reaction occurs only on surface of the packing. From batch modeling, $r_{x}$ can be substituted by equation 2-7 which 
explains noncompetitive inhibition of elicitor.

Mass transfer is a function of the support configuration and of the medium flow hydrodynamics in adsorption based immobilization. Although packed bed reactor will be designed with sufficient contact areas, mass transfer might be a problem in operation of bioreactor. When fluid moves through a large pipe or channel, it may approximate plug flow, which that there is no variation of axial velocity over the cross section. If we assume that plug flow prevails in the system, we can formulate the mass balance on the plug flow reactor easily using the differential section approach. A mass balance for product for a tubular reactor with dispersion system is given by;

$$
v d P / d x=V / A r_{p}-D \frac{d^{2} P}{d x^{2}}
$$

with boundary conditions of $\left.P\right|_{x=0}=P, d P /\left.d x\right|_{x=L}=0$.

$r_{p}$ andis defined in equation 2-9 as a function of elicitor concentration. $D_{\text {eff }}$ is also explained as a function of DMSO concentration, i.e., $D_{\text {eff }}(\delta)$, where $\delta$ is concentration of DMSO. Substituting equation 2-9 and $D_{\text {eff }}(\delta)$, equation 2-17 gives

$$
v d P / d x=V / A \beta_{0} e^{-E 2 / E} X-D_{e f f}(\delta) \frac{d^{2} P}{d x^{2}}
$$


$90 I$

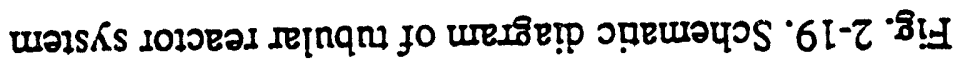

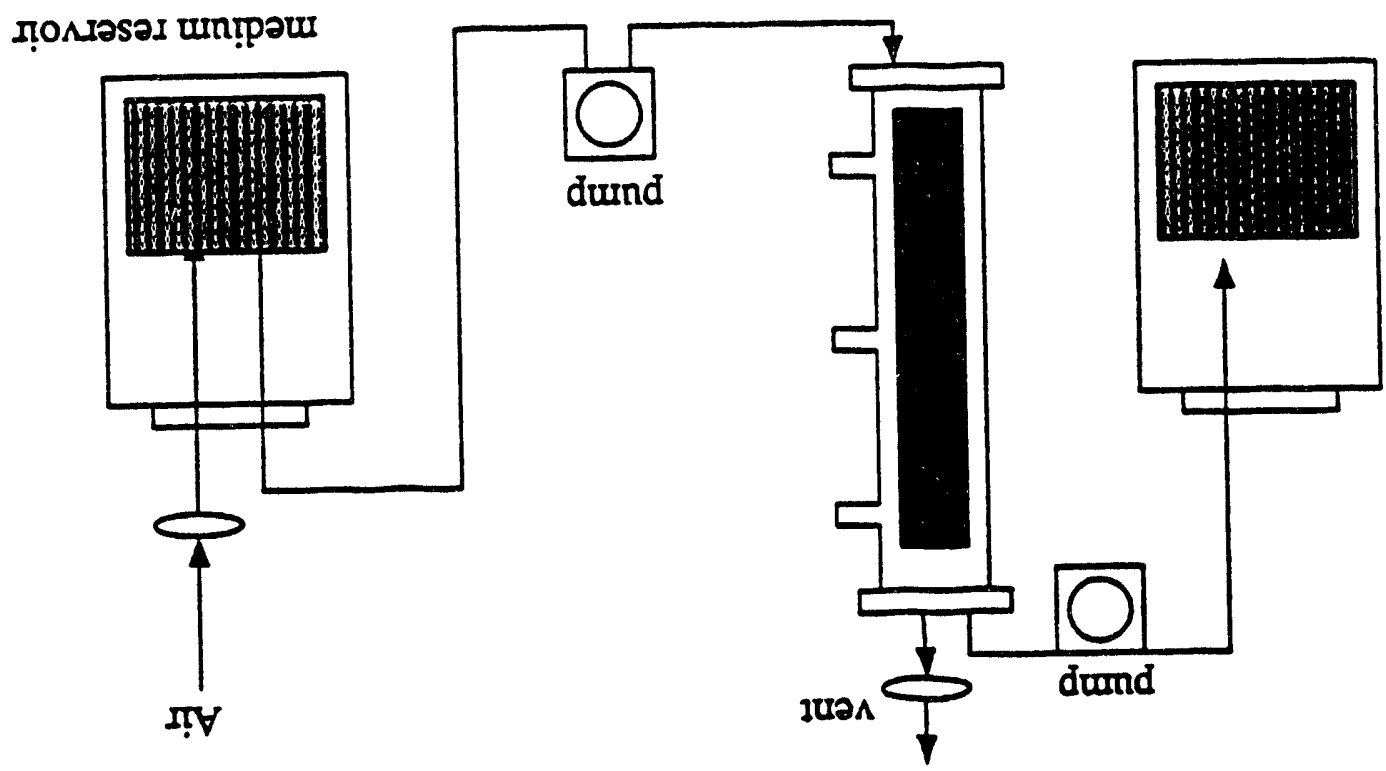




\title{
Appendix $3.5 a$
}

\author{
Acetic Acld
}




\section{Milestone 3.5}

\section{Production of Acetic Acid in an Immobilized Cell Reactor}

\section{Introduction}

Acetic acid, or vinegar, is produced in either submerged culture using an aerated tank, or by surface culture, traditionally using beechwood shavings, with the broth circulated over a bed of the shavings, and air introduced to the bottom of the bed. In this project, we attempted to improve on the surface culture type reactor, using a fibrous absorbant material to adsorb the acetobactor, and spacing the aborbant material about $8 \mathrm{~mm}$ using a plastic spacer mesh, through which air was passed. The intent was to produce a 'plug flow' type reactor where the inlet substrate ethanol was converted to acetic acid in a single pass.

\section{Methods}

A $80 \mathrm{~cm}$ long by $7 \mathrm{~cm} \mathrm{DD}$ glass column was packed with spiral wound terry cloth and nylon spacer mesh. The liquid hold-up of the pack portion of the reactor $(70 \mathrm{~cm})$ was about $400 \mathrm{ml}$, or an liquid fraction of 0.15 as determined by weighing the column dry and after saturating the cloth. The column was seeded with an acetobactor strain A. aceti \# 65, received from NRRL culture colection. Sterile air was introduced to a feed-air humidifier bottle, to eliminate drying problems in the reactor. Air was fed to the reactor at rates of between 1 and $6 \mathrm{liters} / \mathrm{min}(0.5$ to $2.5 \mathrm{vvm}$ ) Feed was introduced to the feed-humidifier bottle in two streams, a concentrated nutrient stream made up as:
$40 \mathrm{~g} / \mathrm{glucose}$
$1 \mathrm{~g} / \mathrm{MgSO} 4$
$1 \mathrm{~g} / \mathrm{Na}$ citrate
$20 \mathrm{~g} /(\mathrm{NH} 4) 2 \mathrm{PO} 4$
$4 \mathrm{~g} /$ Peptone

This nutrient stream was then blended on a $1: 4$ ratio with a $100 \mathrm{~g} / \mathrm{l}$ ethanol solution which was membrane sterilized. This system allowed long term operation with feed broth only prepared atlong intervals. A sketch of the apparature is shown in Figure 1.

\section{Results}

The acetobactor column was run in a continuous fashion for an extended period of time. Effluent $\mathrm{pH}$ and acetic acid concentrations were monitored. Initially, a $6 \%$ ethanol feed solution was fed. As shown in Figure 2, the outlet acetic acid concentration varied from 15 to $47 \mathrm{~g} / 1$ during the first two months of operation, and reached as high as $70 \mathrm{~g} / \mathrm{l}$ during the second two months of operation (Figure 3 ) when the ethanol feed solution averaged $80 \mathrm{~g} /$. A flow rate of 21 $\mathrm{ml} / \mathrm{hr}$ of feed was used for the first month of operation. Nutrient and feed ethanol concentrations were varied, along with flow rates. The $\mathrm{pH}$ of the effluent, which is closely related to the acid concentration is shown in Figures 4 and 5. 
The acetobacter strain used: 65 .

Media used at startup: $6 \% \mathrm{E}+\mathrm{OH}$

$$
\begin{aligned}
& 1 \mathrm{~g} / \mathrm{YE} \text { pep } \\
& 10 \mathrm{~g} / \mathrm{Salt} \text { solution } \\
& 5 \mathrm{~g} / \mathrm{L} \text { glucose }
\end{aligned}
$$

From HPLC readings $70 \mathrm{~g} / \mathrm{L}$ of acetic acid produced. $\mathrm{pH}=3.00$. The $\mathrm{pH}$ of effluent remains fairly constant through December at levels between 2.2 and 2.6.

8/11/91 A drop of acetic acid production was noticed suggested. reason: low Oxygen levels. Air supply increased.

8/20/91 feed changed to: $6 \% \mathrm{E}+0 \mathrm{H}$ by weight

$1 \mathrm{~g} / \mathrm{L}$ Glucose

$1 \mathrm{~g} / \mathrm{L}$ YE pep

Salt solution

This gave a resulting drop in acetic acid production $31.4 \mathrm{~g} / \mathrm{L}$ However it soon rose to $46 \mathrm{~g} / \mathrm{L}$ again.

9/30/91 Heat was evolved from column.

10/11/91 The column setup was modified. See diagram provided. Now getting acetic acid production at $45 \mathrm{~g} / \mathrm{L}$.

11/4/91 Flowrate increased to $50.7 \mathrm{ml} / \mathrm{hr}$. pH still stable at 2.23.

12/5/91 Effluent line pinched shut. Pressure increase and it blew its top.

From the beginning of January it was given feed and left to do its own thing.

3/16/92 Possible yeast contamination. HPLC readings are giving a much lower acetic acid production also $\mathrm{E}+\mathrm{OH}$ peaks are being found.

5/18/92 Effluent examined under microscope no yeast found.

$5 / 31 / 92$ Air rate changed from 2-41/min. This resulted in much better use of $E+O H$ and improved acetic acid production.

To date the acetobacter column has a decreased acetic acid production due to the fact that it was without feed for $3 / 4$ days after a power cut also due to other experiments taking place. The air rate had decreased from the 4 to about $3 \mathrm{pH}$ at end of test period is 4.5 .

\section{Conclusions}

The system ran well, largley unattended for almost a year of continuous operation. Acetic acid was produced in a plug flow fashion, with a continuous output of up to $70 \mathrm{~g} / \mathrm{l}$. Data was 
taken only sporadically after the first four months of operation, but the reactor seemed to perform well, even after period of feed interuptions, air interuptions, and other mishaps. We feel that this system may have commercial applications, and will be looking for industrial sponsors in the next year of the project. 


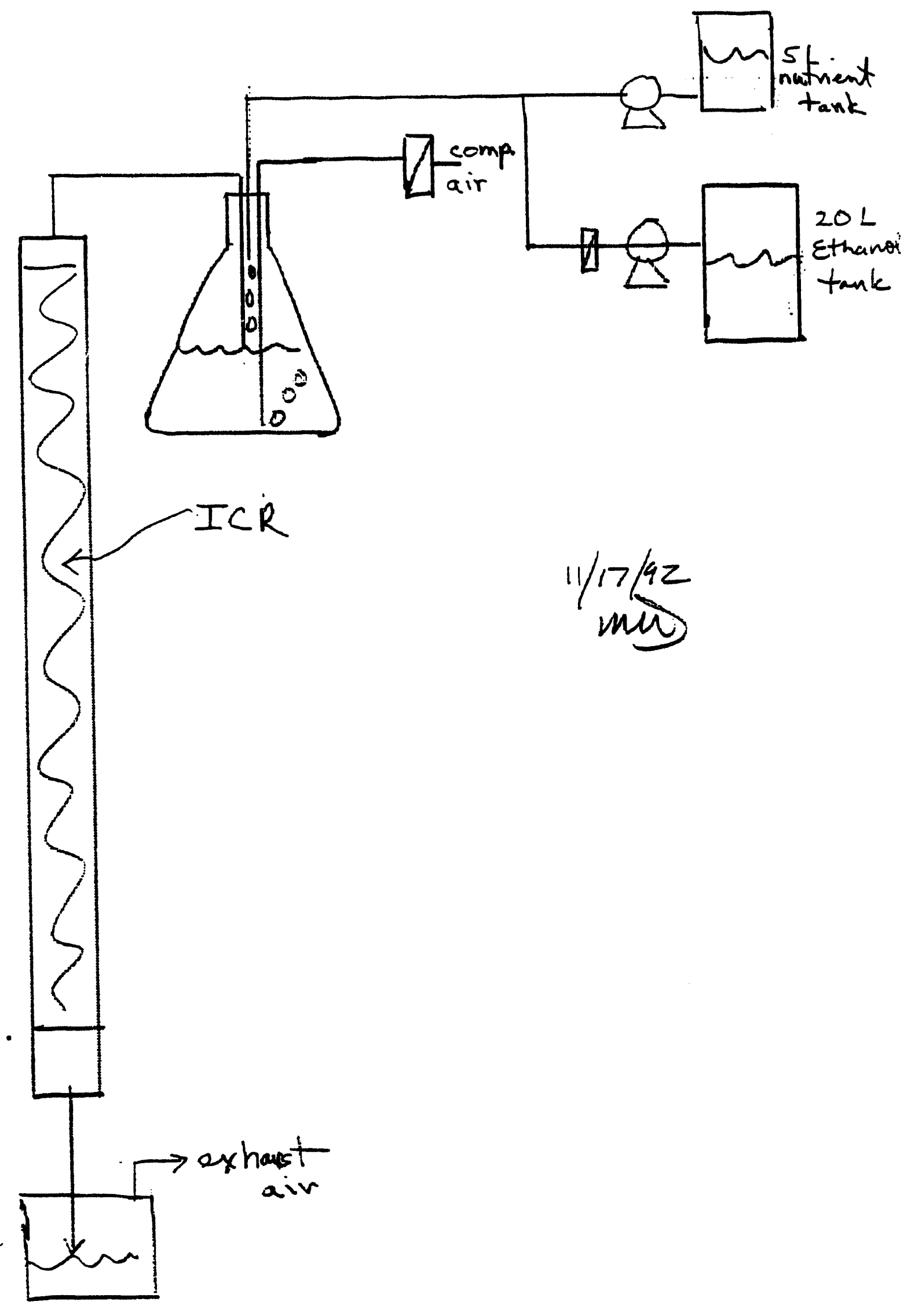




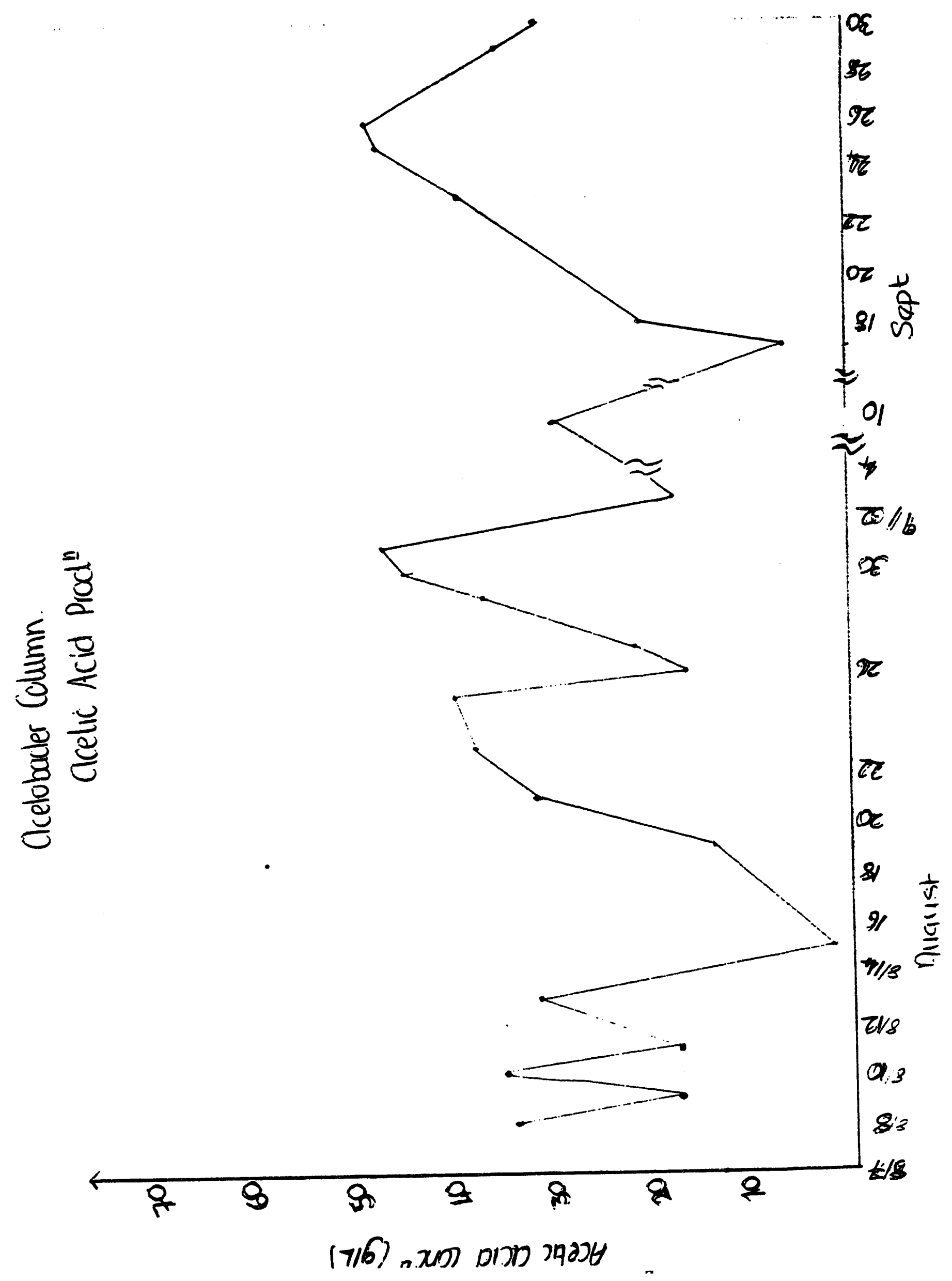




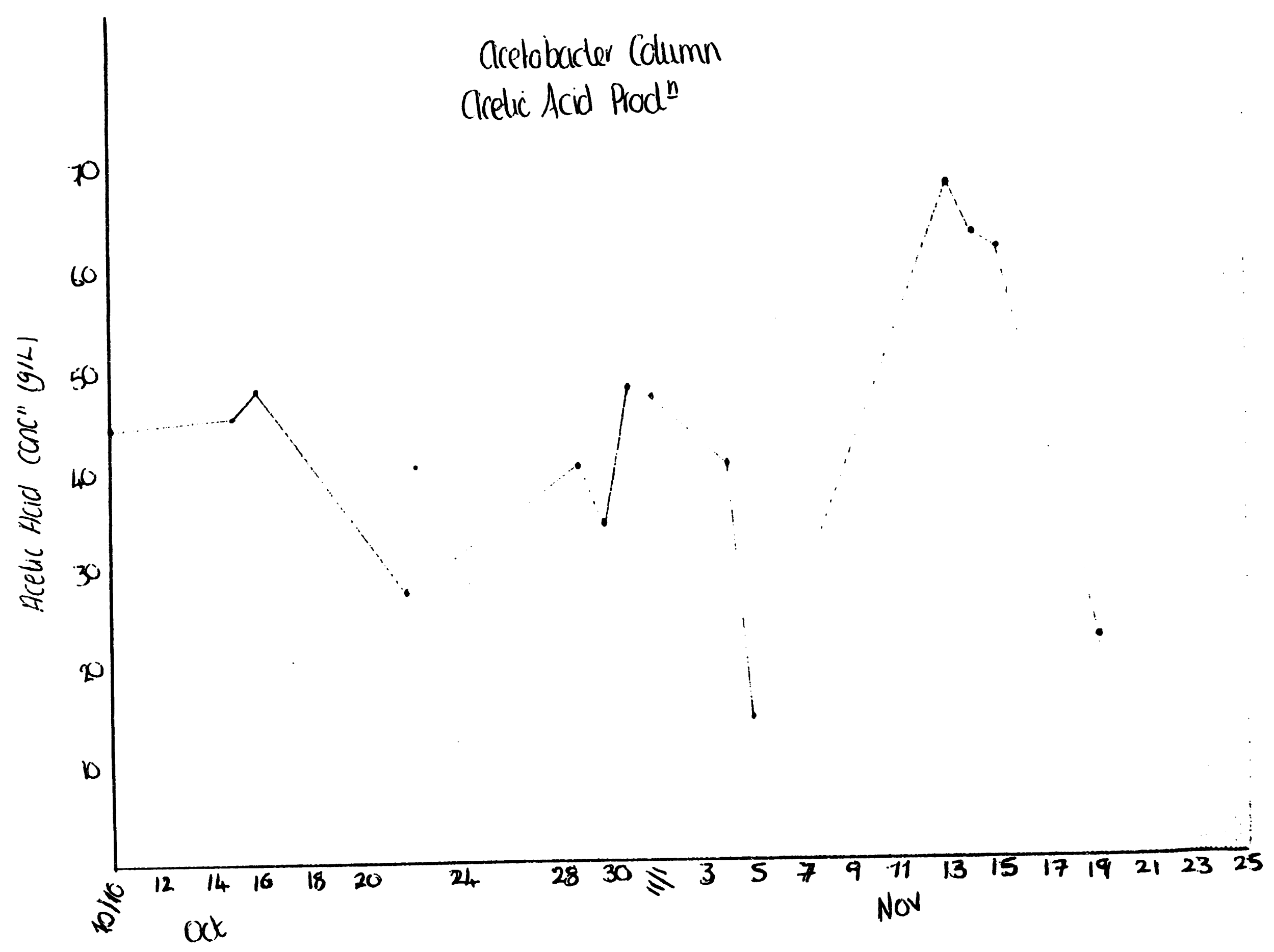




\section{* actobacter Column reoults Table}

vate Flaw rate $(\mathrm{ml} / \mathrm{h})$ PHeff pH Heed acetic Acid (g/L)

\begin{tabular}{|l|l|l|l|}
\hline tug 1. & 15.3 & 4.31 & 3.92 \\
\hline 7 & & 3.08 & \\
\hline
\end{tabular}

8

9

16

12

12

13

14

15

$16 \quad 46.1$

17

18

\begin{tabular}{|l|l|l|}
19 & 29.0 & 2.57 \\
\hline 20 & 28.9 & 2.6
\end{tabular}

$-20 \quad 28: 9$

21

22

23

24

25

26

27

28

29

30

31
2.78

2.67

2.66
30

55

40

43.2

$\left.\mid \begin{array}{l}3.0 \\ 3\end{array}\right]$

2.83

2.66

$2: 44$

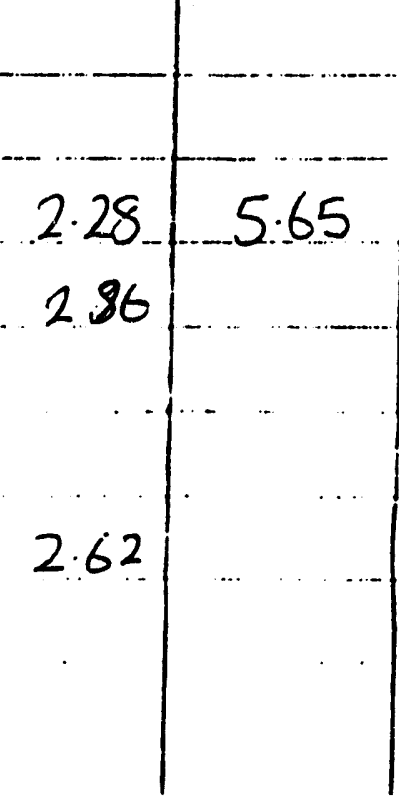

\begin{tabular}{|l|l|}
\hline 13.3 & \\
33.3 & \\
17.0 & \\
34.7 & \\
14.8 & \\
\hline 31.6 & \\
\hline 2.69 & 0.079 \\
\hline
\end{tabular}

73

\begin{tabular}{l|l}
31.4 & 0.062 \\
\hline
\end{tabular} 


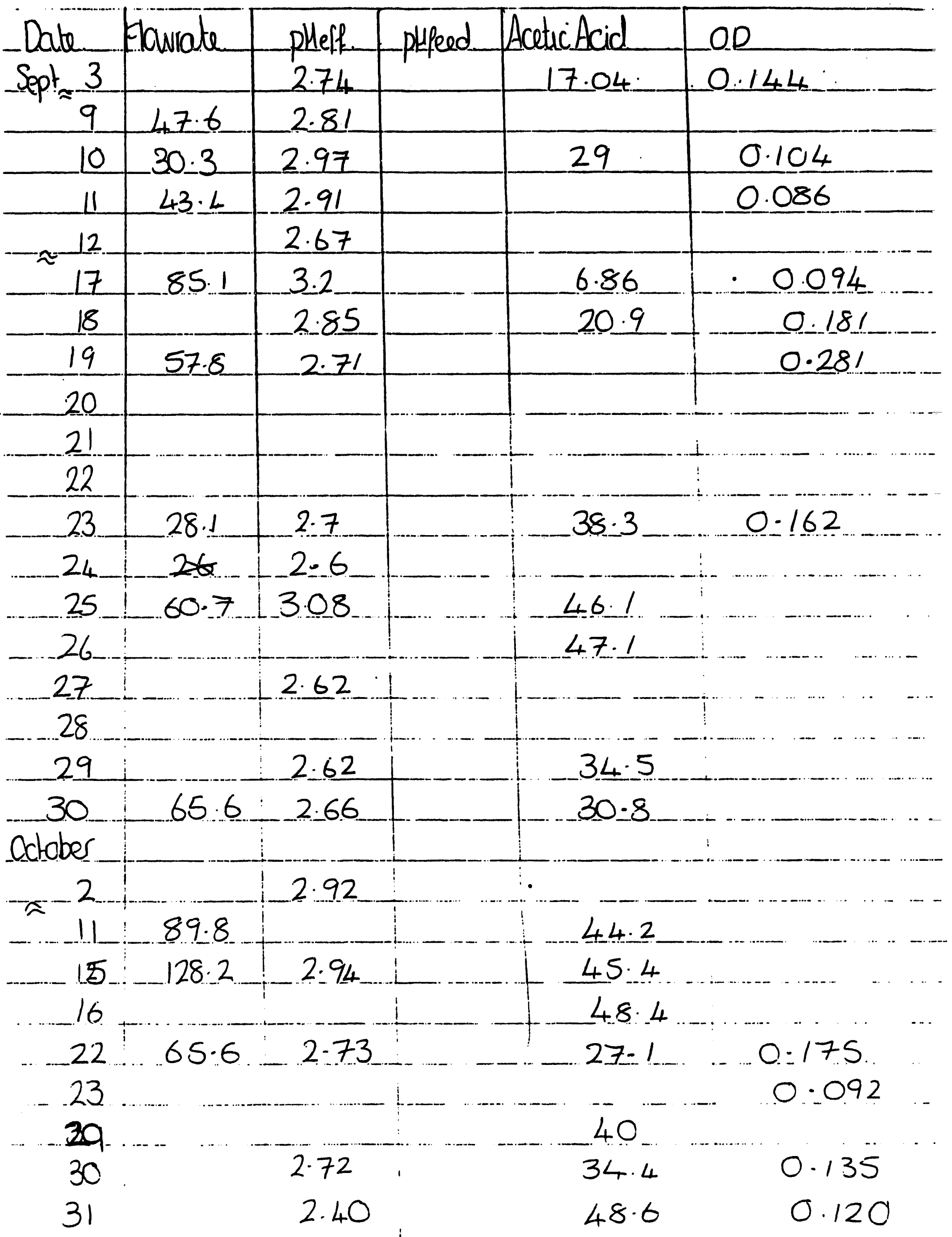









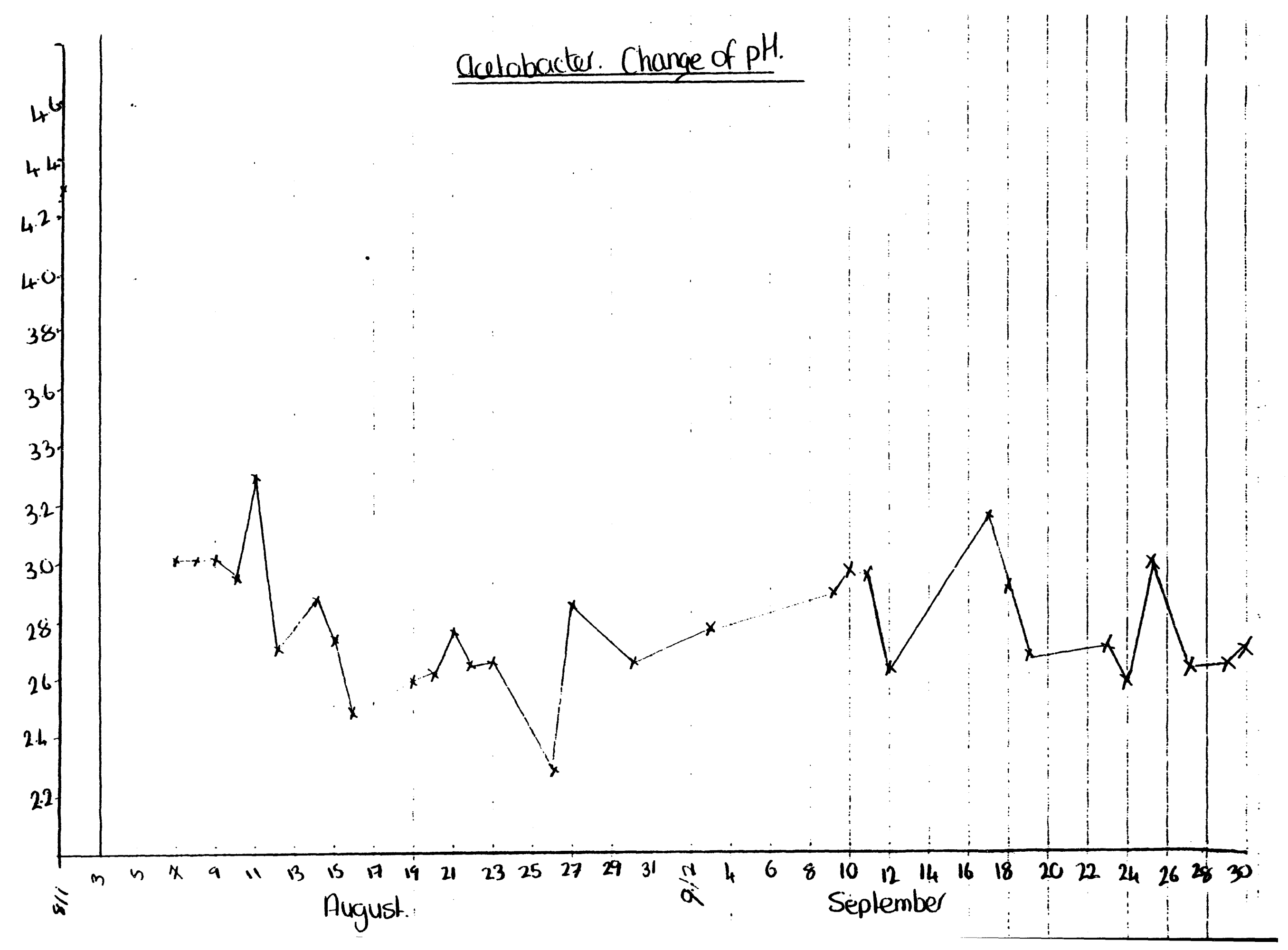




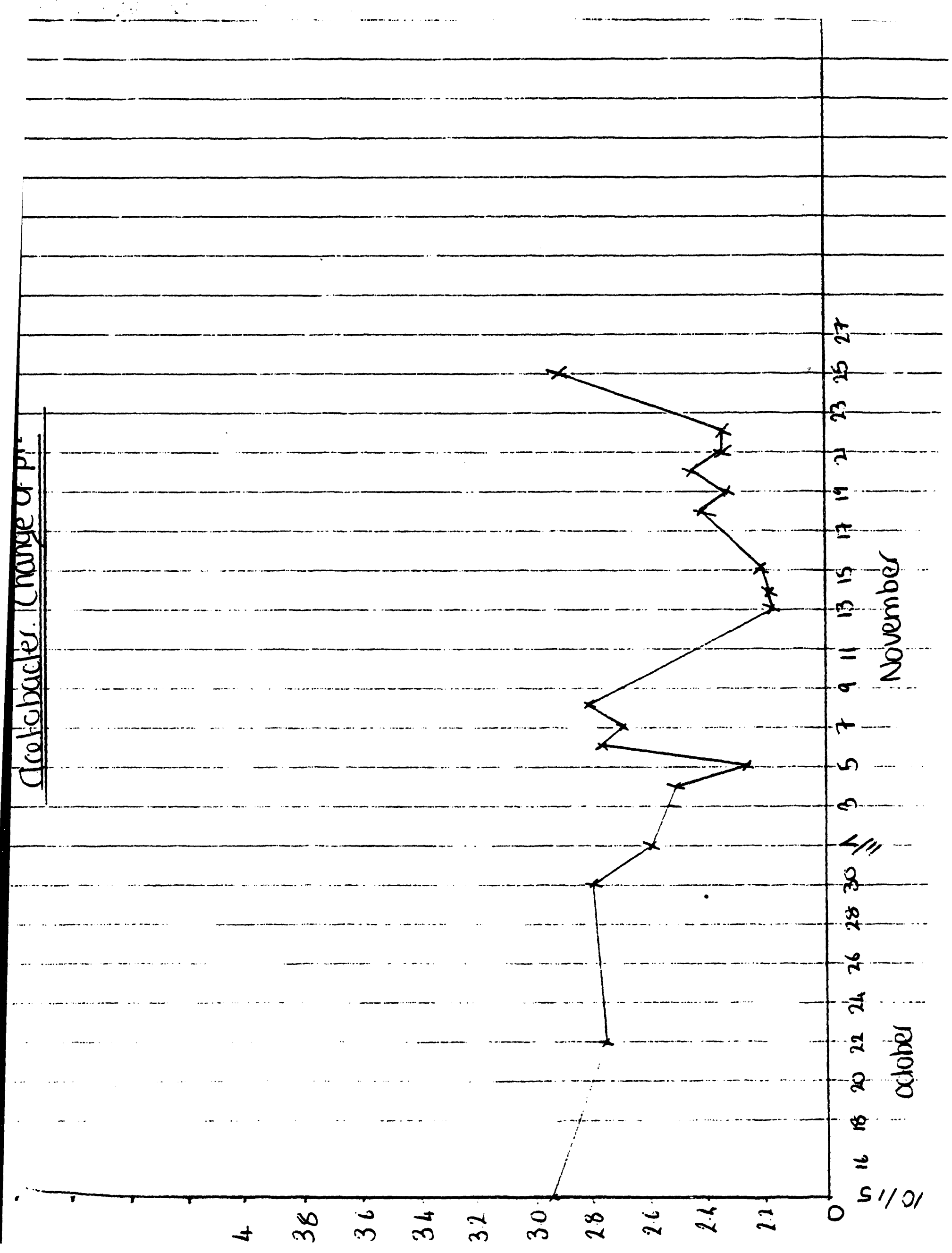




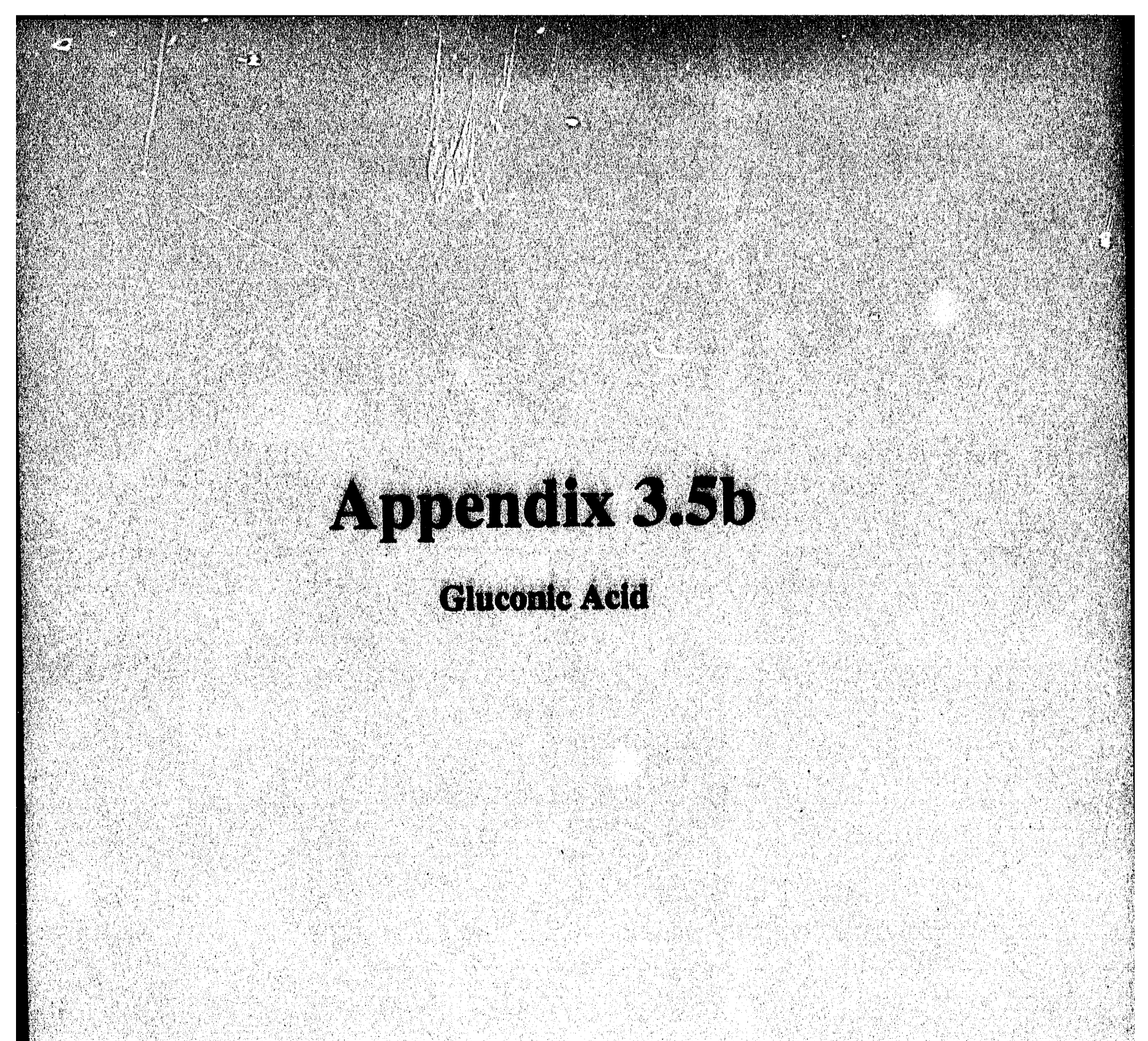


ENSIA

Placement at PURDUE UNIVERSITY, West Lafayette IN - USA

- Agricultural Engineering Department -

Iuly to December 1993

\author{
PRODUCTION OF GLUCONIC ACID \\ BY GLUCONOBACTER SUBOXYDANS \\ IN AN IMMOBILIZED CELL REACTOR
}

Supervisor : Dr M.Clark DALE

Associate Professor : Dr J.Y. LEVEAU 


\section{ACKNOLEDGEMENTS}

At first, I would like to thank Dr Gary KRUTZ and Dr Martin OKOS in the Agricultural Engineering Department of Purdue University, thanks to whom I had the opportunity to experience a trainceship in the USA.

I want to acknowledge my supervisor - Dr M.Clark DALE - for his guidance throughout my work and for his care off duty. I would like to thank everyone I worked with all along the summer and the fall in the B-76 laboratory in the Smith Hall too; especially Mark Moelhman, for his help and advice churing my trainee and for his kindness and sense of humour, making everyday merrier.

Finally, a grateful thought to the students responsible for the computing center in the Stewart Center at Purdue University for their help with the software in the making of this report. 


\section{Introduction}

The first immobilization research was made with enzymes by Nelson and Griffith, 1916. Then in the early seventies, after great developments in the enzyme immobilization procedures, some researchers attempted to immobilize cells rather than the sole enzymes, trying to avoid some problems concerning enzyme activity and cost efficiency of the procedures. This was the opening of a very large field of research that is still vivid now. Four main ways of immobilization have been investigated so far, leading to the set up of several industrial processes.

In 1983, a research program about Immobilized Cell Reactors was set up at Purdue University. The main concern was to take advantage of waste food products such as cheese whey, molasses and lactose whey; aiming to recover partially the large source of energy lying in these products.

Dr M.Clark DALE, who was my supervisor during this traineeship, is a Senior Research Engineer in the Agricultural Engineering deparment and is working on the development through conversion of some agricultural byproducts - especially whey permeate and starch - in Immobilized Cell Reactors, using different strains of yeasts, molds and bacteria. In some studies, simple sugars such as lactose, glucose or xylose are also used. My project was part of these latter studies, immobilizing an oxidative bacteria (Gluconobacter oxydans ssp. suboxydans) to produce gluconic acid from a glucose source. 


\section{V-Literature review}

A former trainee had already started to work for a few weeks on this project and had started a literature research about the previous experiments made on the immobilization of Gluconobacter suboxydans. He had also collected some notes about the gluconic acid, which is the product of the reaction expected in the Immobilized Cell Reactor.

Then I made further research about the bacteria and about the immobilization procedures, I also found more articles about previous studies of this special ability of Gluconobacter suboxydans.

\section{A-The bacteria}

The information in this paragraph are taken from "Biology of microorganisms" - Brook and Madigan.

The Gluconobacter bacteria are part of a larger group called acetic acid bacteria. As originally defined the acid acetic bacteria comprised a group of Gram-negative, aerobic, motile rods that carried out an incomplete oxidation of alcohols, leading to the accumulation of organic acids as end products. With ethanol as a substrate, acetic acid is produced; hence the derivation of the common name for these bacteria. Another property is the relatively high tolerance to acidic conditions, most strains being able to grow at $\mathrm{pH}$ values lower than 5 (Gluconobacter suboxydans actually grows at $\mathrm{pH}$ lower than 3). This acid tolerance should of course be essential for an organism producing large amounts of acid. The genus name Acetobacter was originally used to encompass the whole group of aceric acid bacteria, but it is now clear that the acetic acid bacteria as so defined are an heterogenous assemblage. The polarly flagellated organisms are related to the Pseudomonads, differing mainly in their acid tolerance and their inability to carry out a complete oxidation of alcohols. These organisms are now classified in the genus Gluconobacter. All acetic acid bacteria group phyllogenetically with the purple bacteria.

The genus Acetobacter comprises the peritrichously flagellated organisms; these have no definite relationship to other Gram-negative rods. In addition to flagellation, Acetobacter differs from Gluconobacter in being able to further oxidize the acetic acid it forms to $\mathrm{CO}_{2}$. This difference in ability to oxidize acetic acid is related to the presence of a complete citric acid cycle. Gluconobacter, which lacks a complete citric acid cycle, is 
unable to oxidize acetic acid, whereas Acetobacter which has all enzymes of the cycle, can oxidize it. Because of these differences in oxidative potential, Acetobacter genus bacteria are sometimes called overoxidizers; the Gluconobacter genus ones, underoxidizers. Hence the use of the species name : suboxydans.

In addition to ethanol, these organisms carry out an incomplete oxidation of such organic compounds as higher alcohols and sugars. For instance, glucose is oxidized only to gluconic acid, galactose to galactonic acid, arabinose to arabonic acid, and so on. This property of underoxidation is exploited in the manufature of ascorbic acid (vitamin C).

In our study the strain NRRL B-72 (Also named ATCC 621, from American Type Culture Collection) was used; it had been ordered from NRRL (Northem Regional Research Laboratory - Peoria, II USA).

\section{B-The products}

The information in this paragraph are taken from "Microbial technologies, Vol 1 - Microbial processes" - Peppler and Perlman.

\section{1-Gluconic acid and by-products}

The product in which we were interested was gluconic acid $(2,3,4,5,6$ Pentahydroxy-1-hexanoic acid). The oxidative enzyme which leads to the production of gluconic acid in Gluconobacter suboxydans is glucose dehydrogenase. But the direct dehydrogenation product of glucose by this enzyme is the glucono- $\partial$-lactone. This latter molecule is partially transformed in the free acid form (gluconic acid), obeying an equilibrium. The ratio of the two products involved in this equilibrium depends to a certain extent on the $\mathrm{pH}$ and the temperature. Usually, about $40 \%$ of the gluconic acid is in the glucono- $\partial$-lactone form. Furthermore, two other byproducts appear in the fermentation broth, and a third one can appear too. The three of them are ketogluconic acids derivating from the gluconic acid form. The major one in quantity is 5-ketogluconic acid, the other important one is 2-ketogluconic acid and in trace amounts 2,5 -ketogluconic acid can appear from the 2-ketogluconic acid form. 

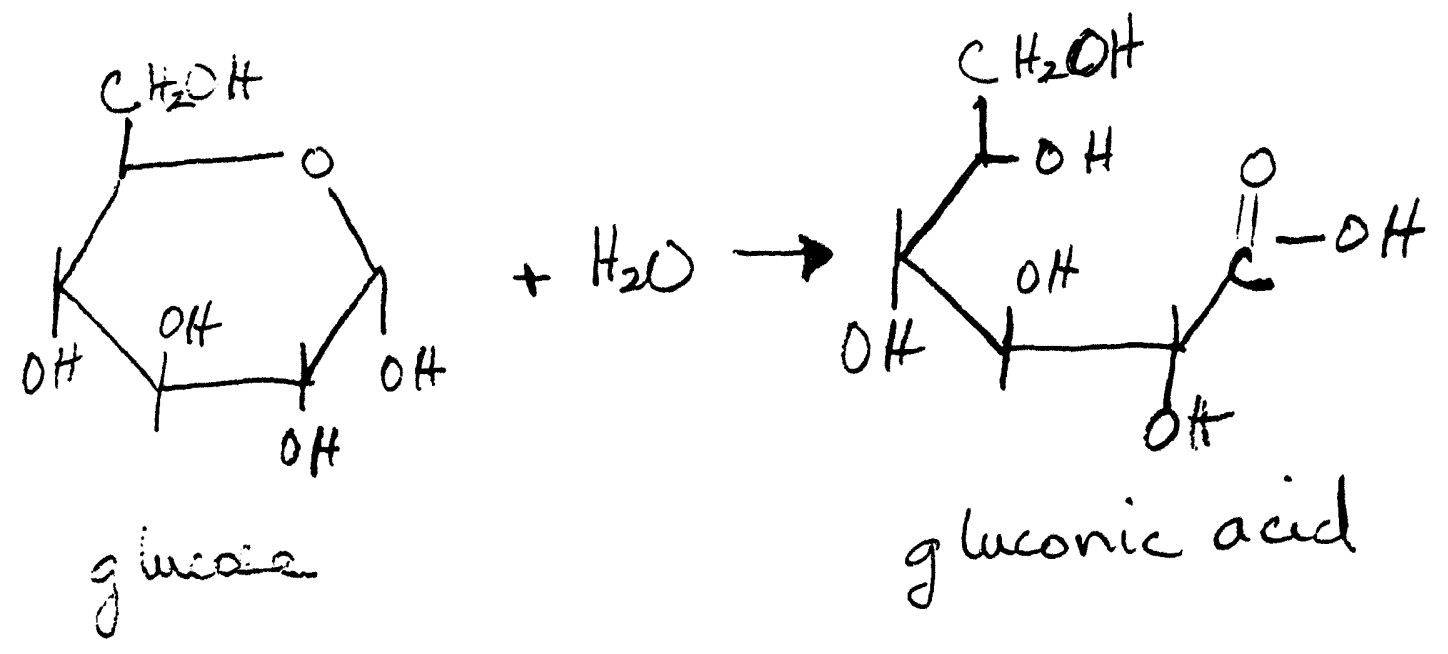

Eigure 1-Molecules structures

\section{2-Analysis and separation of the molecules}

To test the samples drawn from the experiments and analyse the production you have to be able to tell the difference between all these molecules though they are close to each other in structure and properties. There are only a few analytical methods to obtain this separation; the two main ones, used in the articles that I had found, are :

-The use of an HPLC seems to be the easiest way to make this separation. For instance, Seiskari et $A l,(1985)$ heated and filtered their samples to remove the cells and then used a Varian 5000 Series Liquid Chromatograph (Varian Aerograph, USA) together with an UV detector. The column used was Aminex HPX-87 H+, particle size $9 \mu \mathrm{m}, 300 * 7.8 \mathrm{~mm}$ I.D. (BioRad 'Labs, USA) with sulfuric acid as an eluent. Shiraishi et $A l$ (1989) used the same method but with another fitting for the HPLC; the column was a TSK gel SCX(H+) (Tosoh Co Ltd; Tokyo, Japan) with phosphoric acid as an eluent.

-These products can be assayed enzymatically (Rehr et $A l, 1991$ ) using the test kits of Boehringer (Mannheim, Germany).

\section{3-Commercial uses of the products}

The principal market for gluconic acid and its derivatives is for the saits, especially the sodium one. Hydroxyl groups of the molecule bind diand trivalent metallic ions in soluble form, thus preventing precipitation of calcium, magnesium or iron compounds from solutions used in bottle and 
dish washing. Alkaline bottle washing compounds which contain 2.5-10\% sodium gluconate, depending on the hardness of the water, are used extensively in automatic cleansing equipment. Metal carbonate precipitates are removed by sodium gluconate containing products for the washing of painted walls or metals without inducing appreciable corrosion. The acid and sodium salt are used as sequestring agents to prevent formation of insoluble soap films in alkaline cleaning formations for glassware and food-processing equipment. Sodium gluconate is used in cleaning, derusting and paintstripping of metals and as a concrete additive to lengthen setting time and to enhance compressive strength.

Gluconate salts and the $\partial$-lactone are used in dyeing and in textile printing; glucono- $\partial$-lactone is used extensively in baking powders as a result of its latent acidity.

In pharmaceutical use, calcium gluconate has long been used as a preferred source of calcium in cases of calcium deficiency due to diet or pregnancy, and for rapid relief of symptoms of allergies. Many drugs can be administered more effectively when combined with gluconates.

\section{D-Cell immobilization}

\section{1-Historical backoround}

Although enzymes have many advantages as catalysts, they are essentially produced by an organism for its own requirements; and out of their usual environment, enzymes are very fragile molecules. They are generally unstable and cannot be used in organic solvents or at elevated temperatures. However, recent developments in the fields of biochemistry, applied microbiology and genetic engineering have markedly accelerated the utilisation of enzymes. Since the sixties, Tosa et $A l$ have been investigating immobilized enzymes with the goal of utilizing them for continuous industrial production; thus eluding a major drawback of batch processing : the difficulty to recover the active enzyme from the reaction mixture for reuse. The process had other advantages such as improving the stability of the enzymes, making a continuous operation more practical or increasing yield and purity of the products. Furthermore, a better control of the reaction was possible.

The next step was the immobilization of the cell itself, which allowed to avoid many disadvantages of the use of the sole enzyme. Enzymes in the cell are maintained in their natural environment, neither extraction nor purification of the enzymes from the microbial cells is necessary; thus, loss 
of enzyme activity and cost of the process are reduced. However, according to "Applied Biochemistry and Bioengineering, Vol 4 - Immobilized Microbial Cells" - Chibata and Tosa; immobilized cell systems are only advantageous when :

- enzymes are normally intracellular

- the microorganisms contain no interfering enzyme

- the substrate and product are not high molecular weight compounds

- enzymes extracted from cells are unstable while immobilized

They also give a definition of immobilized cells :

"Microbial cells physically confined or localized in a certain defined region of space with retention of their catalytic activities, and which can be used repeatedly and continuously."

After thirty years of reseach on immobilization procedures, there are now a great number of them to choose from when immobilization of cells is required. Any subgrouping of methods is by no means absolute since in some cases it may be difficult to classify a certain method as belonging to a specific group. Different authors found three, four or even six categories of methods; I will here present a division in four groups that may not include some specific methods. More details can be found in many books - some of which are listed in the bibliography.

\section{2-The procedures}

The topic of immobilization methods is vast enough to fill an entire volume in itself, the intention with which this paragraph is written is just to introduce these methods.

A common statement about all these methods is that they allow a great increase of the cell density; thus improving the productivity of the mixture. 
a)-Entrapment

Entrapment methods are based on the confinement of the cells in a three-dimensional gel lattice. The cells are free within their compartments and the pores in the material allow substrate and product to diffuse to and from the cells. This is by far the most frequently used method in laboratory experiments and there are also some examples of industrial processes based on entrapped cells. Within this group of immobilization procedures, a lot of matrices have been employed : collagen, agar, carrageenan, cellulose triacetate, polystyrene and polyacrylamide - which is the gel that has been the most extensively used. These gels can be used in beads, cubes or membranes. They all have different characteristics, advantages and disadvantages.

b)-Adsorption (Carrier-binding method) 
This method is based on direct binding of microbial cells to water insoluble carriers. The cells are ionically bound to these carriers containing ion-exchange residus. The main materials that had already been used are wood, glass, ceramic, plastic and kieselguhr.

The influence of the cost of the immobilization on the overall cost of the process is of primary importance, especially in large-scale processes with cheap substrates. Adsorption is - in principle - a reversible process, meaning that the support may be recovered at the end of this process; that is why adsorption seems to be a promising technique. But these aforementionned advantages turn out to be disadvantages because the forces involved in adsorption are weak and the cells may enter the product stream at high flow rates.

$$
\text { c)-Covalent coupling - including cross-linking }
$$

The mechanism of this method is based on bond formation between activated inorganic supports and cells and requires the use of a binding (cross-linking) agent. To introduce the covalent linkage, chemical modification of the carrier surface is necessary. The main binding agents are silanized silica support, glutaraldehyde, isocyanate and metal hydroxyde precipitates. The advantage of this system compared with entrapment is that it is free from the diffusion limitation. Unfortunately, coupling agents are usually toxic and cells can retain only $60-75 \%$ of their enzymatic activity. 


\section{d)-Immobilization without support}

The properties of microbial cells such as surface charge or cell wall composition are the major factors responsible for immobilization in such cases.

For instance, all Aspergillus strains can be immobilized easily without support (Metz - Kossen 1977). When the spores are placed into continuous flow reactors, hyphae usually form agglomerates and become pellets. Hyphae-hyphae interactions are considered very important for microbial immobilization. The pellets are rather stable in airlift type fermentors and can be used for continuous production of citric acid - for instance.

\section{E- Gluconic acid production by Gluconobacter suboxudans}

Here are a few statements about the productivity of the immobilized bacteria I was interested in, according to some recent studies that were conducted with ceramic honeycomb (Shiraishi et $A l,, 1989$ ) and fibrous nylon (Seiskari et $A l, 1985$ ) as carriers.

\section{1-The parameters}

- Aeration rate

- Glucose concentration of the feed

- Residence time of the feed in the reactor

- $\mathrm{pH}$ and temperature

- Geometry of the reactor and configuration

\section{2-Optimisation of the procedure}

- The keto-gluconic acid production can be reduced with $\mathrm{pH}$ and temperature optimisation.

- The yield increases with an increase of the aeration rate and with an increase of the glucose concentration in the feed (up to $20 \% \mathrm{w} / \mathrm{v}$ ).

- The highest glucose conversion is reached when there is a long residence time (low substrate feed rate) and a relatively low aeration rate.

- The optimal range of $\mathrm{pH}$ for Gluconobacter suboxydans growth is between 4 and 5 . 


\section{3-The problems}

- At high aeration rates, channelling of air results in a decrease of gluconic acid yield.

- At high glucose concentration, the pH decreases to values close to 2 and then, the bacteria growth rate will be limited significantly.

- The by-products seem to be produced in larger quantities when the residence time is being increased.

- A higher glucose conversion goes along with an increase of ketogluconic acid production.

\section{II/-Materials and methods \\ A-The bacteria culture}

Gluconobacter oxydans ssp. suboxydans NRRL B-72 was used. The culture was maintained in culture tubes containing $20 \mathrm{~g} / \mathrm{glucose}$ and $2 \mathrm{~g} / \mathrm{l}$ of each yeast extract, malt extract and peptone.

The organisms were subcultured monthly and stored at room temperature.

Then the bacteria were grown in a 61 bottle containing $50 \mathrm{~g} / \mathrm{l}$ glucose and $5 \mathrm{~g} /$ of each yeast extract, malt extract and peptone with the $\mathrm{pH}$ set at 6 . The culture was continuously aerated, the air providing a shaking effect too.

\section{B-The fermentation apparatus}

The reactor itself was prepared in a glass tube with an inner diameter of $5 \mathrm{~cm}$ and a height of $65 \mathrm{~cm}$. The package for the immobilization support was prepared with a plain cotton towel and a fiber nylon mesh rolled together tightly. The towel was used for the proper immobilization itself on the cotton fibers and the nylon mesh layer were inserted between the cotton ones to provide the room for a good air dispersion. The package itself was $40 \mathrm{~cm}$ high and $5 \mathrm{~cm}$ large, so the height to diameter ratio was 8 .

The reactor was fed and aerated from the top. The pumps used for both air and feed supplies allowed a wide range of speed. The air inlet was connected to a flask of de-ionized water used as an humidifier. This humidification provided a higher rate of oxygen use by the bacteria. This humidified air then passed through a filter in order to avoid any 
contamination, all the more as different strains of yeasts, molds and other bacteria were used in the same time in the laboratory.

The outflow came from the bottom of the reactor through a long plastic hose with a copper tube at its tip. Most microorganisms can not stand copper, this particularity was used as another mean to avoid contamination. 


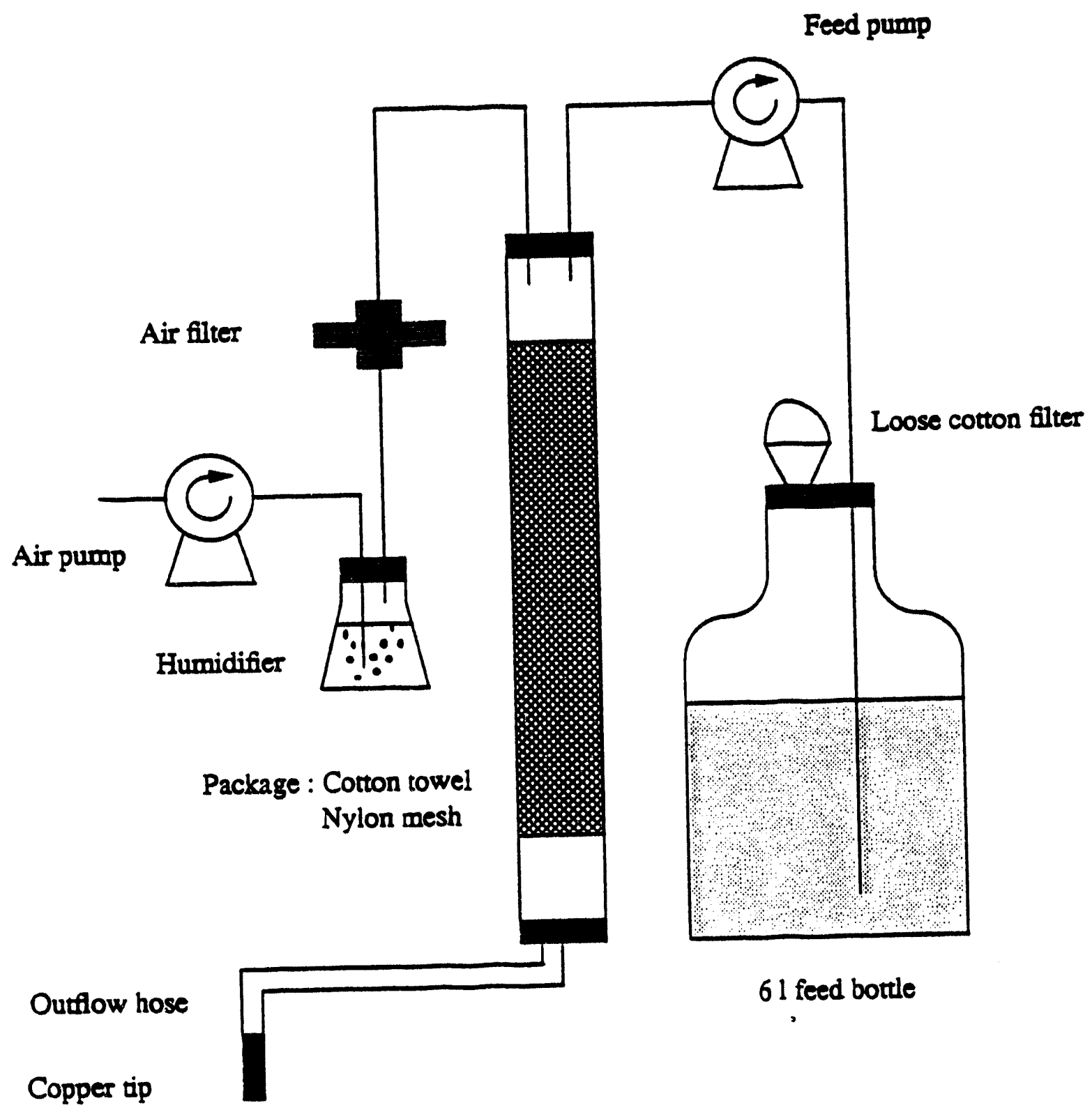

Fioure 2 - Fermentation apparatus 


\section{C-Immobilization procedure}

The 61 bottle of medium containing the bacteria culture was run like a feed into the reactor for 24 hours at a slow rate (about 11 during these 24 hours).The reactor was aerated during this immobilization procedure. Then, the first bottle of classical feed started to run.

The type of immobilization procedure is not well defined, including entrapment in the cotton fibers and adsorption on the protein charges. To my knowledge, no previous study using this technique has been reported.

\section{D-Maintenance}

-The main task of the maintenance was the preparation of the feed. At the rates which were used, the feed consumption was between 11 and 1.51 per day; consequently a new 61 bottle had to be prepared once or twice a week.

The glucose source was pure glucose (Purchased from J.T.Baker Inc. Phillipsburg, NJ USA), except for the first three bottles where Karo - which is a corn syrup containing 75\% of glucose and a few ions and vitamins - was used (Purchased from Best Foods, CPC International Inc. Englewood Cliffs, NJ USA). The nitrogen and mineral supplies were provided by yeast and malt extracts and peptone (The three of them purchased from Difco Laboratories Detroit, MI USA). Then, according to a pH study a pH 5 buffer was or was not added to the medium. Finally, the $\mathrm{pH}$ was set at 6 with ammonia.

Then, the bottle was closed with a plastic stopper pierced with two stainless tubes, one would be connected to a plastic hose and used for the feed pumping, the other one connected to a cotton and gauze filter necessary to let the air enter while the bottle is emptying. This filter was also essential during the autoclaving due to the evaporation of liquid from the bottle according to the pressure and temperature conditions within the autoclave.

Before the autoclaving the plastic hose was clamped, the stopper was sealed with some heatproof duct tape and the cotton filter was protected with aluminum foil to avoid its humidification when the steam would condensate in the autoclave during the cooling down phase. This humidification would clog the filter and then no air would go through it. Each bottle was autoclaved two hours, the temperature increasing up to $115-120^{\circ} \mathrm{C}$ and the pressure increasing up to $2 \mathrm{~atm}$. This procedure ensured the feed to be sterile, at least free of any living microorganism. After allowing the bottle to 
cool down, it was connected in place of the empty bottle, using a flame to create a sterile area and ethanol to sprinkle the hoses tips.

- The flask of de-ionized water had to be filled up every other day; the consumption was between 100 and 200 ml per day, depending on the air flow rate.

-The samples were drawn every day from the copper tip of the outflow hose, just waiting for the test tube to be full enough to damp the $\mathrm{pH}$ electrode.

\section{E-Analytical methods}

Three kinds of data were taken everyday from the samples :

- The $\mathrm{pH}$ was measured to follow the evolution of acid production.

-The absorbance or optical density was taken (A $660 \mathrm{~nm}$ wavelength) in order to evaluate the cell density of the outflow and follow approximately the discharge rate of cells from the reactor. This data had no absolute significance and was just used in a comparative way from day to day to evaluate the way the reactor was working. The readings were usually made after a dilution of the samples, but the values given are the actual ones.

The spectrophotometer used was a Model 340, Sequoia-Turner Corporation Mountain View, CA USA.

-The brix was measured with a refractometer to evaluate the glucose consumption.

A few times, a back titration of the outflow up to the initial $\mathrm{pH}$ of the feed was made in order to have an approximate assessment of the reactor productivity. For these titrations, $\mathrm{NaOH}$ was used.

The absorbance in the UV range (210 $\mathrm{nm}$ wavelength) was used too; this matter will be furtherly developed in the paragraph referring to this particular study. 


\section{IIIV-Results and discussion}

At first the Immobilized Cell Reactor itself was not used for the experiments but was run in order to know whether it was possible to perform fermentation for an extended period of time in this reactor.

The first part of the study experimented of $\mathrm{pH}$ values at different levels in the fermentation process; both on the cell growth of the bacteria and its productivity of gluconic acid. Since we needed to set different values of $\mathrm{pH}$ and regulate them it was easier to conduct these experiments in batch reactions. It was easier to draw the everyday samples too.

The results from these batch experiments were then applied to the ICR, studying the effect of $\mathrm{pH}$ setting and the use of a buffer in the feed.

As long as the aim of the experiments was to compare the effects of different values of the $\mathrm{pH}$ parameter, the evaluation given by the $\mathrm{pH}$ and the OD of the outflow was meaningful enough to tell the best value for the productivity of the bacteria. But when we started to work on the ICR itself and that we wanted to analyse the gluconic acid production more precisely, the approximate yield given by a back titration of the outflow was not enough accurate anymore. At this time arose the problem of the gluconic acid analysis and different experiments were made to solve this problem.

Another problem created by the contamination appeared quite in the same time and then the study of the ICR productivity was left apart and the main concern had became to find a solution to this problems. We were especially concerned about the gluconic acid analysis, since this problem enabled us to investigate with accuracy the effect of any change in any parameters likely to influence the ICR productivity.

\section{A-Influence of the $\mathrm{oH}$ on the productivity \\ 1-The batch experiments} a)-Effect of the initial pH

Since Gluconobacter suboxydans is able to grow and live in acidic conditions, we prepared two experiments to know whether the growth is better in a neutral or more acidic medium. So, two 11 erlen-meyer flasks were prepared, one with an initial pH at 4 (We will refer to it by the name "TV") and the other one with an initial pH at 6 (Will be referred to as "VI").

The medium was formed with $2 \mathrm{~g} / \mathrm{l}$ of each yeast extract, malt extract and peptone as peptide and mineral sources. The glucose source used was $50 \mathrm{~g} /$ 
Karo - which represents $37.5 \mathrm{~g} / \mathrm{glucose}$. Each batch had a volume of 500 $\mathrm{ml}$; the $\mathrm{pH} 6$ was set with ammonia and the $\mathrm{pH} 4$ with phosphoric acid.

The flasks were closed with stoppers including an aerator, a long needle with a plastic septum to draw the samples from and a loose cotton filter, then sealed with beatproof duct tape and autoclaved. After allowing the time for the broth to cool down, the inoculation was made from the same bottle which had been used to start the ICR and had been stored at $4^{\circ} \mathrm{C}$ since then.

The batches were run twelve days, taking $\mathrm{pH}$ and OD everyday. (See graphs 1\&2). The air rate in each batch was set at $1 \mathrm{~V} / \mathrm{min}$, and the flasks were stirred with a magnetic stirrer.

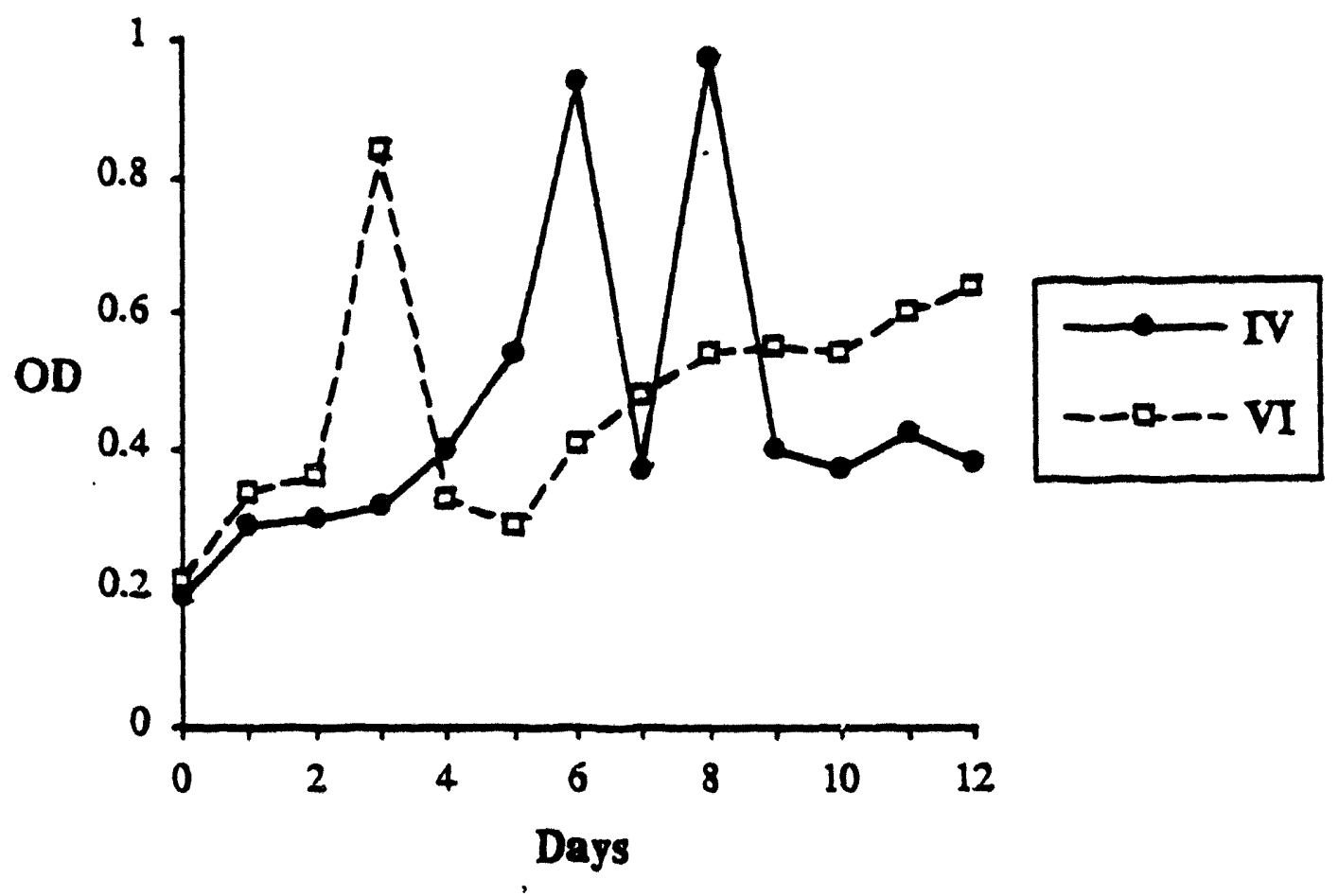

Graph 1 - OD vs Time 


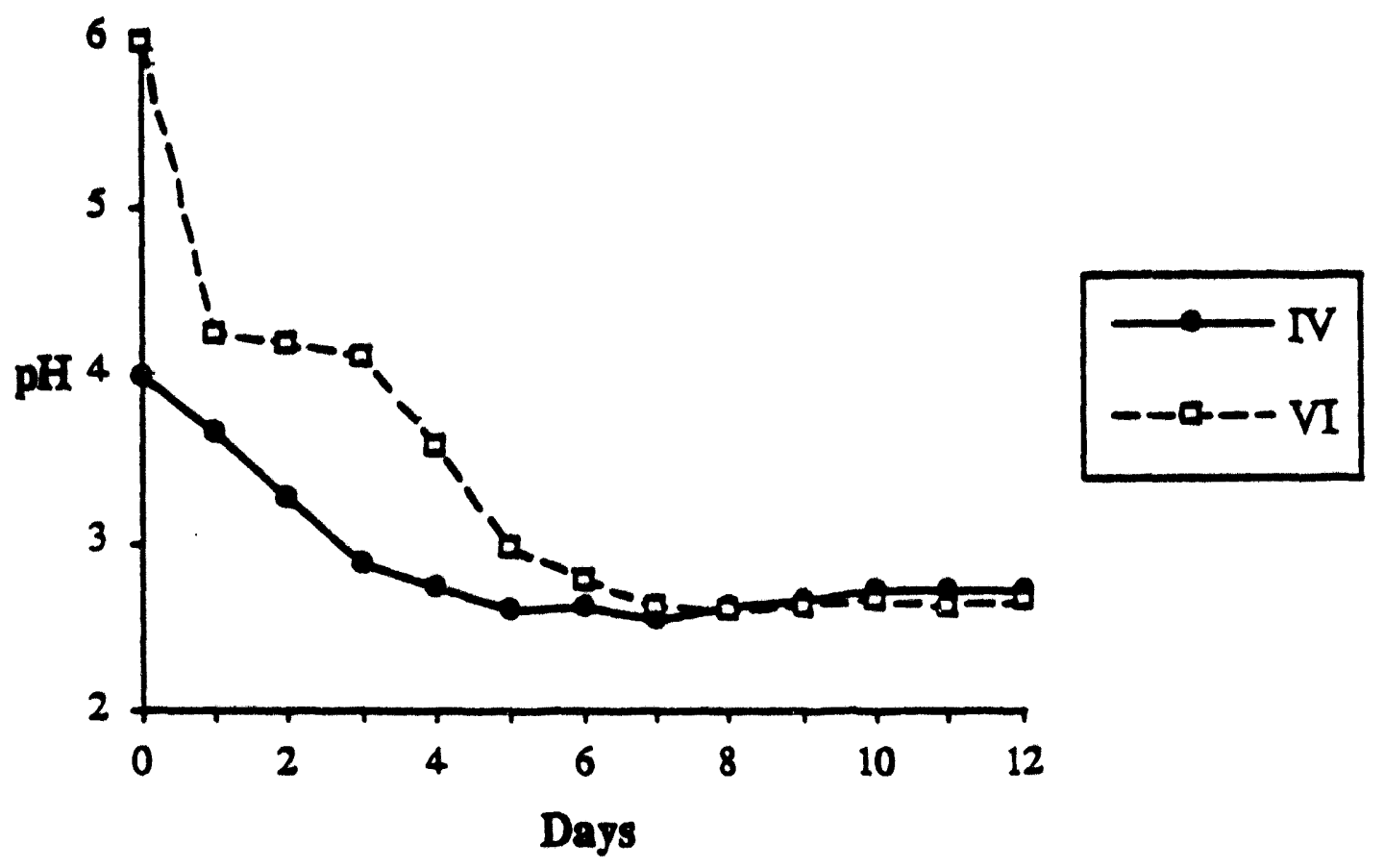

Graph 2-oH vs Time

After six days, the $\mathrm{pH}$ was more or less stable around 2.6-2.7 which meant that the stationnary phase had been reached. VI had a lower $\mathrm{pH}$ though the initial one was higher, which allows to think that this higher initial pH is better for the bacteria - if we consider that the acid production can be used as a parameter to draw this conclusion. Anyway, after twelve days, the OD of VI was about $25 \%$ higher than the one of IV, which proves that the growth rate had been higher in VI. This was asserted by a back titration that was made with the broth after twelve days. For both experiments, $\mathrm{NaOH} 1 \mathrm{M}$ was used to bring the $\mathrm{pH}$ of $50 \mathrm{ml}$ of broth up to the initial value. Then it was assumed that one mole of base was the counterpart of one mole of gluconic acid produced ("Gluconic acid" including here the gluconic acid itself and its ketonic derivatives). This assumption was made in order to evaluate the productivity; and the results were : - IV : $7.5 \mathrm{~g} /$

$-V I: 12.5 \mathrm{~g} /$

Of course the initial OD of VI was about $10 \%$ higher than the one of IV, but these meaningful results can not be attributed to this slight difference. 
Consequently to this study, the pH of the feed prepared for the ICR was set at 6 before the autoclaving. However, any significant difference in the results of the ICR could be observed; this was due to the fact that the $\mathrm{pH}$ of the feed was - anyway-close to 6 i.e. around 5.6-5.7.

\section{b)-Experiments with pH regulation}

After the two experiments without $\mathrm{pH}$ monitoring, we planned to test the growth and productivity of Gluconobacter suboxydans at different steady $\mathrm{pH}$ values. The row of experiments to measure the cell growth was started first. The two studies could not be done in the same batch since we wanted a low initial cell count for the growth evaluation and a high one for the yield evaluation.

The same medium as for the previous experiments was used, but some potassium sorbate was added ( $250 \mathrm{ppm}$ ) to avoid yeast contamination (See study p X for further explanations). The erlen-meyer flasks were prepared exactly the same way, with aerator and stirrer, however, the volume was 200 ml this time.

Four $\mathrm{pH}$ values were tested : 2, 3, 4 and 5. Phosphoric acid was used to set the values before autoclaving. Unfortunately, the $\mathrm{pH}$ monitor was not working well and so I did the monitoring myself, controlling the pH 5 or 6 times a day. Phosphoric acid and ammonia were used to decrease or increase the $\mathrm{pH}$ whenever it was necessary. The $\mathrm{pH} 4$ and $\mathrm{pH} 5$ flasks were a little bit hard to maintain at their expected value; decreasing respectively down to 3.5 and 4.2 overnight. 
After a lag phase of about 20 hours, the growth occured during 40 hours, then the experiments were stopped.

The pH 2 flask had a very low growth compared to the three other ones. This value is lower than any value obtained from the ICR - which was running without $\mathrm{pH}$ control and never went below a pH of 2.5. Such a low $\mathrm{pH}$ seemed to be out of the range of $\mathrm{pH}$ accepted by the bacteria metabolism for a good growth.

Apart from this pH 2 flask which had a really different result, the three other ones had fairly the same rate of growth, though it seemed to slightly appear that the higher the $\mathrm{pH}$ was, the better the growth was. An important comment to make is that the exponential growth phase on the graph for the pH 5 flask was much more intense. From these results we concluded that a $\mathrm{pH}$ around 5 might be preferred for a high growth rate of Gluconobacter suboxydans

After this row of experiments, a study of the use of a pH 5 buffer in the feed of the ICR was started, this will be presented in the next paragraph.

Then another row of experiments had to be started to study the yield of gluconic acid at this different $\mathrm{pH}$ values. At this time we absolutely needed to analyse precisely the quantity of gluconic acid produced; different attempts to do so were made, but this latter row of pH experiments remained a project.

\section{2-Use of a pH buffer solution}

Once we had noticed that a $\mathrm{pH}$ around five improved the Gluconobacter suboxydans growth and their productivity, we decided to add a buffer solution in the bottles of feed.

\section{a)-Choice and preparation of the buffer}

Since the bacteria is degrading carbohydrates for its metabolism, we did not want to use a buffer including this kind of molecules. The only datas concernig a mineral buffer were for a sodium phosphate onc (Handbook of Chemistry and Molecular Biology); unfortunately the lower $\mathrm{pH}$ presented was 5.7. So I had to make furether research at the library and found the Sorensen's potassium phosphate. I had to recalculate the datas for the sodium salt because it was the only one I had at my disposal. 
The two solutions were :

A : $0.2 \mathrm{M}$ solution of monobasic sodium phosphate $\mathrm{NaH}_{2} \mathrm{PO}_{4}, \mathrm{H}_{2} \mathrm{O}$

$(27.8 \mathrm{~g}$ in $1000 \mathrm{ml})$

B : $0.2 \mathrm{M}$ solution of dibasic sodium phosphate anhydrous $\mathrm{Na}_{2} \mathrm{HPO}_{4}$

$(28.4 \mathrm{~g}$ in $1000 \mathrm{ml})$

These compounds had been purchased from Mallindrockt Inc. ST Louis, MO USA. Then the blend for a pH 5 buffer was $96.3 \mathrm{ml}$ of A and $3.7 \mathrm{ml}$ of B diluted to a total of $200 \mathrm{ml}$.

Actually, the two chemicals involved in this buffer were used in a granulated form, weighed and directly added in the 61 bottle of feed.

\section{b)-The steps of the study}

The study included five steps, five differents concentrations of buffer in the feed. At first, the "blank" without buffer, then four differents amounts of potassium phosphates were added in the feed to reach buffer effects corresponding to four differents volume of pure buffer solution : $100 \mathrm{ml}, 500$ $\mathrm{ml}, 1 \mathrm{l}$ and $6 \mathrm{l}$. So the dilutions of the buffer solution in the 61 bottle were $1 / 60,1 / 12,1 / 6$, and $1 / 1$.

\section{c)-The results}

A back titration of $100 \mathrm{ml}$ of outflow from the ICR was done at each step in order to evaluate the quantity of gluconic acid produced. The process of these back titrations was exactly the same as the one used for the batch reactions concerning the study of the initial $\mathrm{pH}$. The same assumption - one mole of base is equivalent to one mole of gluconic acid (and its derivatives) was made too. The formula used to calculate the concentration of gluconic acid (in $g / 1)$ was :

$$
C_{G A}=C_{B} * V_{B} * F W * D
$$

$\mathrm{C}_{G A}$ : concentration of gluconic acid

$\mathrm{C}_{\mathrm{B}}$ : concentration of the base : $1 \mathrm{M}$

$\mathrm{V}_{\mathrm{B}}$ : volume of base added to meet the initial $\mathrm{pH} 6$

FW : formula weight of the gluconic acid : $196.2 \mathrm{~g} / \mathrm{mol}$

$D$ : factor ten due to the use of $100 \mathrm{ml}$ of outflow 


$\begin{array}{cccc}\text { DIIUTION } & \text { CONCENTRATION } & \text { YIEID } & \text { AVERAGE OUTFLOW PH } \\ \text { "Blank" } & 34.0 \mathrm{~g} / & 68.0 \% & 2.55 \\ 1 \text { for } 60 & 34.2 \mathrm{~g} / & 68.4 \% & 2.60 \\ 1 \text { for } 12 & 35.3 \mathrm{~g} / & 70.6 \% & 2.65 \\ 1 \text { for } 6 & 37.0 \mathrm{~g} / & 74.0 \% & 2.88 \\ 1 \text { for } 1 & 41.5 \mathrm{~g} / & 83.0 \%, & 3.05\end{array}$

\section{Table 1-Buffer results}

The two higher dilutions of the buffer were more or less ineffective. At so high dilutions the effect of the buffer was almost cancelled and the $\mathrm{pH}$ probably did not change; thus, the metabolism of the bacteria was barely affected. The 1/6 dilution noticeably improved these conditions since the $\mathrm{pH}$ of the outflow was raised by .23. Finally, the positive effect of the use of a buffer solution on the productivity of Gluconobacter suboxydans was completely assessed by the use of the $1 / 1$ dilution. The average $\mathrm{pH}$ of the outflow increased up to 3.05 ; meaning that the $\mathrm{pH}$ conditions in which the bacteria were living had increased at least of .5 compared to the "blank" solution. The yield increased from $34 \mathrm{~g} / \mathrm{l}$ up to $41.5 \mathrm{~g} /$ which corresponds to a $22 \%$ improvement.

\section{B - Problems encountered and divergence of the studv}

The first aim of the project was to improve the productivity of Gluconobacter suboxydans, but some experiments had to be made apart from this main line because of problems which occured during the study of the ICR.

\section{1-The contamination \\ a)-Description}

All along my traineeship, yeast and mold growths appeared frequently in the different batch experiments I made. This was due to their current presence in the laboratory since some collegues were using them for their 
own experiments. The ICR was contaminated too, the first time by a yeast which had probably come up in the outflow hose from the jar of waste where another outflow from a yeast/starch reactor was pourred too. These yeasts had reduced the yield of the ICR (The $\mathrm{pH}$ of the outflow gradually increased from 2.70 up to 3.10) and were still growing. So, we decided to start over the reactor with a new package and a new inoculum, now separating the outflows of the reactors.

Though, the batch experiments had been contaminated by yeasts living in the atmosphere of the laboratory, and to prevent any other problem in the ICR I tried to use a chemical to keep these yeasts from reappearing.

Dr DALE suggested me the use of sorbic acid (2,4-Hexadienoic Acid); and I actually used potassium sorbate which was available in the laboratory. It had been purchased from Sigma Chemical CO STLouis, MO USA.

Another contamination - by molds - occured too and we had to start over the reactor once more, but no investigation about this problem was made.

\section{b)-The experiments}

The batch experiments were made in aerated $(1 \mathrm{~V} / \mathrm{min})$ erlen-meyer flasks with a volume of $100 \mathrm{ml}$. The medium was $20 \mathrm{~g} /$ glucose and $2 \mathrm{~g} / \mathrm{l}$ of each yeast and malt extracts and peptone. The flaks were sealed as previously explained; the stoppers included a needle with a septum, necessary for the inoculation and to draw the samples. They were autoclave 1 thirty minutes.

The idea was to grow yeasts together with Gluconobacter suboxydans in the same broth, including different concentrations of potassium sorbate. Three values were chosen ; $100 \mathrm{ppm}(135 \mathrm{mg} / 1), 250 \mathrm{ppm}(336 \mathrm{mg} / 1)$ and $500 \mathrm{ppm}(673 \mathrm{mg} / 1)$. Two blanks - one with each microorganism alone were prepared too. days.

The experiments were stirred with a magnetic stirrer and were run six 
Yeast population (/ml)

Initial Final Growth factor Initial Final Growth factor

Yeast blank

$2.410 \mathrm{E} 6$

6.9 10ET

Bacteria blank

100 ppm sorbate

250 ppm sorbate

$500 \mathrm{ppm}$ sorbate

$\begin{array}{ll}3.4 & 10 \mathrm{E} 6 \\ 2.9 & 10 \mathrm{E} 6 \\ 3.1 & 10 \mathrm{E} 6\end{array}$

times 29

\begin{tabular}{|c|c|c|c|}
\hline - & $5.510 \mathrm{E} 6$ & $3.610 \mathrm{E} 7$ & times 6.5 \\
\hline times 4 & 2 10E6 & $1.5 \quad 10 \mathrm{E} 8$ & times 75 \\
\hline times 1.7 & 2.3 10E6 & 2 10E8 & times 87 \\
\hline times .3 & 1 10E6 & $3.210 \mathrm{E} 7$ & times 32 \\
\hline
\end{tabular}

\section{Table 2-Sorbate results}

The first striking point is that the higher the potassium sorbate concentration was, the lower the growth rate of the yeast was, which means that the effect expected from this chemical had been here demonstrated. At the highest concentration (500 ppm), the yeast population had even decreased.

Concerning the Gluconobacter suboxydans growth, the potassium sorbate seemed to have boosted it, though it appeared that the chemical was not so well supported at $500 \mathrm{ppm}$. However, the results fit according to the different concentrations since the bacteria growth to yeast growth ratio had increased with the potassium sorbate amounts : times 19 at $100 \mathrm{ppm}$, times 51 at $250 \mathrm{ppm}$ and times 106 at $500 \mathrm{ppm}$.

Though the $500 \mathrm{ppm}$ ratio seemed to be the better one, it was decided to use a $250 \mathrm{ppm}$ concentration of potassium sorbate in the feed of the ICR because it was the level where the bacteria growth was the highest - still with a good inhibition of the yeast growth.

\section{2-Analysis of the gluconic acid}

This problem arose when we wanted to study the influence of the $\mathrm{pH}$ on the productivity of Gluconobacter suboxydans. 


\section{a)-Use of an HPLC}

According to the literature, the use of an High Performance Liquid Chromatography was supposed to be the easiest way to analyse not only the gluconic acid production, but the ketonic acids and $\partial$-lactone ones too.

The column we had in the laboratory was an Aminex HPX-87 H+, particle size $9 \mu \mathrm{m}, 300 * 7.8 \mathrm{~mm}$ I.D. (BioRad Labs, USA) which was exactly the same as the one used by Seiskari et $\mathrm{Al}$ in their research. The eluent was sulfuric acid too, at $0.1 \mathrm{~N}$ concentration. But the detector used for the products at the exit of the column was based on the refractive index (156 Refractive Index Detector, Beckman) and Seiskari et Al used a 210nm UV detector, unfortunately, this characteristic was probably too close for the differnt products and any readable separation was possible, even with a high resolution accuracy. The different peaks were more or less confounded, just obtaining shoulders on the main peak as the best result.

\section{b)-Use of a UV detector}

Then we attempted to make the separation - at least between glucose and gluconic acid - with a UV detector, using a $210 \mathrm{~nm}$ wavelength. The spectrophotometer used was a U 1100 Spectrophotometer - Hitachi, Ltd. Tokyo Japan.

- Standard curve

I had first ploted a standard curve of the $O D$ versus the gluconic acid concentration. Five different concentrations of acid were used : 5, 10, 20, 30 and up to $40 \mathrm{~g} / \mathrm{l}$ since we were expecting a yield of $30-40 \mathrm{~g} / \mathrm{I}$ in the ICR. The gluconic acid had been purchased from Sigma Chemical CO ST Louis, MO USA. The test samples were actually diluted by 100 to fit the measurement range of the spectrophotometer.

A second row of samples was prepared with the same acid concentrations but glucose $(10 \mathrm{~g} /)$ was added in each solution to check if this was creating any interference with the pure acid.

The zero of the spectrophotometer was set with a cuvette of de-ionized water, which was used to prepare the samples. See graph below. 


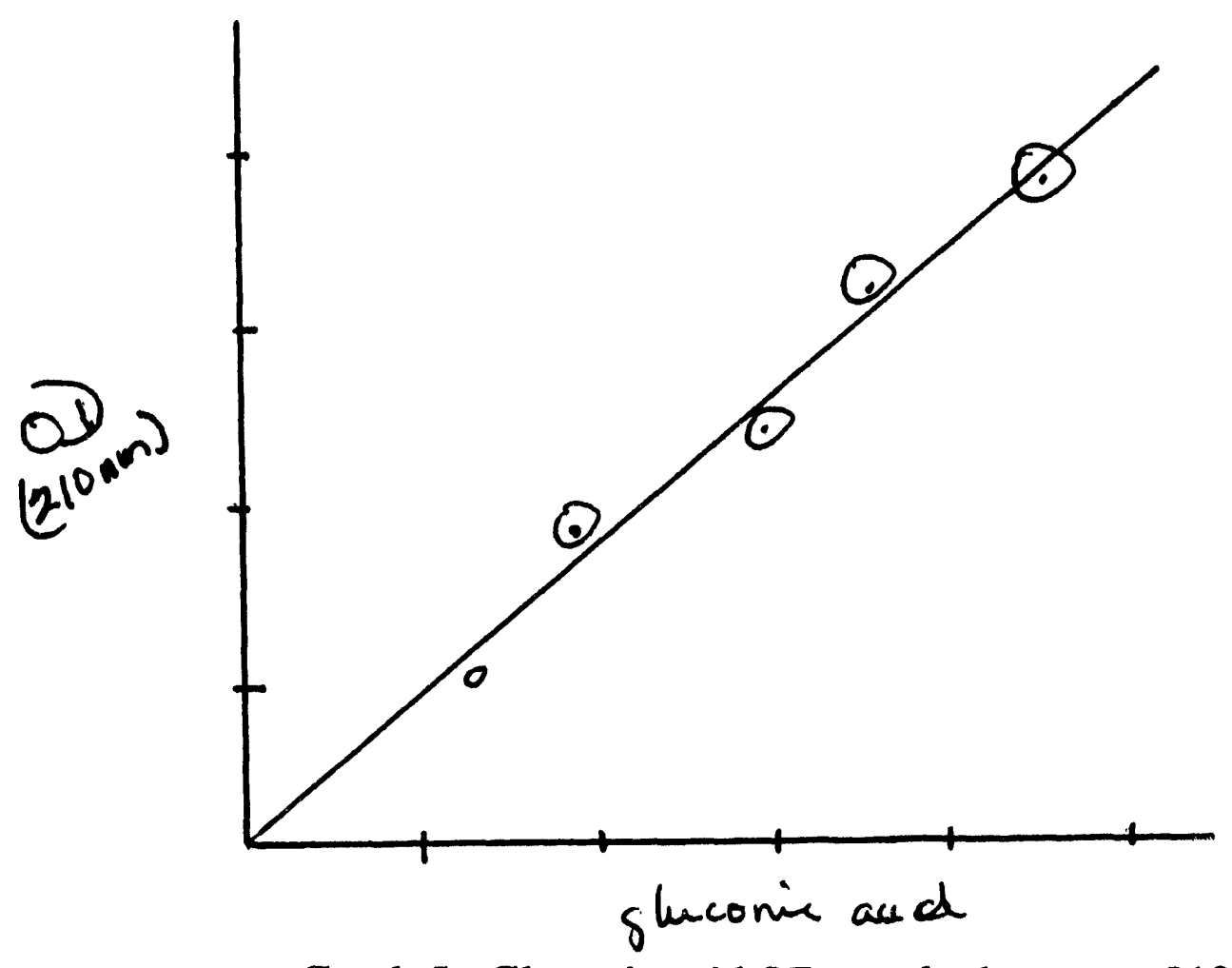

Graph 5 - Gluconic acid OD standard curve at $210 \mathrm{~nm}$

The results were very satisfying since the curve was linearized with a very small approximation. Furthermore, the glucose did not interfere at all in the OD values.

\section{$\sim$ The sample tests}

From the first try to read an OD in the UV range with a sample from the ICR outflow, the results were wrong. The first reading - made after the same dilution as the one made for the standards - gave an OD of 156. According to the standard curve, this was corresponding to a gluconic acid concentration of $250 \mathrm{~g} /$, which was obviously impossible with a glucose concentration of $50 \mathrm{~g} / 1$ in the feed. It had appeared that one or more other compounds were absorbing in the UV range; it was assumed that a peptidic molecule was, since we know that - for instance - tryptophane absorbs at 280 $\mathrm{nm}$, and the peptidic bound absorbs at $220 \mathrm{~nm}$.

I tried then to take the OD of the feed too, thinking that the acid concentration might be deduced from hte difference between the outflow and 
the feed ODs. This was done two days, but the results were impossible to use because the OD of the outflow was lower than the feed one. This fact assessed the hypothesis that a peptidic molecule (which had been degraded in the ICR) was involved in the high OD readings.

$\sim$ Use of the Shay medium

Since we thought that a peptidic molecule had made the results impossible to use, it was decided to prepare a batch with an exclusively mineral medium. The Shay medium was used $(0.1 \% \mathrm{w} / \mathrm{w})$, supplied with niacin, panthotenic acid and ammonia $(5 \mathrm{~g} /)$. Glucose was used at $50 \mathrm{~g} /$. carbon source :

Constitution of the Shay medium (Shay et $A l, 1987$ ) for $80 \mathrm{~g} /$

$25 \mathrm{~g}_{1}\left(\mathrm{NH}_{4}\right)_{2} \mathrm{SO}_{4}$

$2 \mathrm{~g} / \mathrm{H}_{3} \mathrm{PO}_{4}$

$.0031 \mathrm{~g} / \mathrm{Niacin}$

$.001 \mathrm{~g} \Lambda$ Panthotenic acid

And $1.5 \mathrm{ml} / \mathrm{l}$ of :

$$
\begin{aligned}
& 60 \mathrm{~g} / \mathrm{FeSO}_{4}\left(\mathrm{H}_{2} \mathrm{O}\right)_{5} \\
& 25 \mathrm{~g} / \mathrm{ZnSO}_{4}\left(\mathrm{H}_{2} \mathrm{O}\right)_{7} \\
& 5 \mathrm{~g} / \mathrm{CuSO}_{4}\left(\mathrm{H}_{2} \mathrm{O}\right)_{5} \\
& 2 \mathrm{~g} / \mathrm{MnSO}_{4}\left(\mathrm{H}_{2} \mathrm{O}\right) \\
& 1 \mathrm{~g} / \mathrm{Na}_{2} \mathrm{MoO}_{4}\left(\mathrm{H}_{2} \mathrm{O}\right)_{7} \\
& .2 \mathrm{~g} / \mathrm{CaCl}_{2}\left(\mathrm{H}_{2} \mathrm{O}\right)_{6}
\end{aligned}
$$

The flasks were sealed and autoclaved as usual, but the medium was burnt in the autoclave, a caramelization had probably occured. Another broth was prepared and then just boiled on a hot plate.

The results were disconcerting; eventhough the OD readings seemed to be possibly correct, increasing from 34.7 after the inoculation up to 47.1 within three days (A 12,4 difference which was correponding to a gluconic acid concentration of $20 \mathrm{~g} / 1$ according to the standard curve), the $\mathrm{pH}$ almost did not change during these three days (From 5.93 down to 5.84) indicating that no acid was produced. I did not try to investigate the reason of the OD increase; it seemed useless to me since - anyway - Gluconobacter suboxydans was not able to grow on the Shay medium. 
After this last attempt, the analysis of gluconic acid was no further investigated. However, another try that might be done with the UV spectrophotometer would be to use a protease in the sample before taking the reading; the smaller peptides and amino acids remaining might not interfere. 


\section{Conclusion}

Unfortunately, the problem of the analysis of the gluconic acid was not solved during my trainee; and as a consequence, the expectancies about the ICR productivity improvements were not met. The only result I had was the one reached after the study of the $\mathrm{pH}$ effect on the growth and productivity of Gluconobacter suboxydans, which led to a $22 \%$ increase in the gluconic acid production.

The easiest way to make a good analysis would be to use a new detector for the HPLC, but here rises the problem of the funding needed to purchase such an expensive appliance. The same problem would appear with the use of the Boehringer test kits, that can be used just once and are quite expensive.

Once this problems solved, several parameters remain to be tested. According to the literature, glucose concentration and the flow. rates of air and feed are the most influencing ones. Actually, the further studies should involve the three parameters at the same time, in order to find their best matching point with regard to glucose conversion and by-products percentage. The articles about Gluconobacter suboxydans immobilization give a lot of indications and directives that can be use as a guideline to improve this ICR with a new carrying material that Dr M.Clark DALE is trying to develop.

As a final word, I would like to say that I have enjoyed my placement in the Agricultural Engineering Department of Purdue University, and leamed a lot all along my traineeship. I gained a great deal in both knowledge and experience. 


\section{BIBLIOGRAPHY}

1- "Applied Biochemistry and Bioengineering, Vol 4 - Immobilized Microbial Cells" - CHIBATA I and WINGARD L.B.Jr. (Chapter 1) Edited by Academic Press, Inc NY, NY USA.

2- "Immobilized Microbial Systems : Principles, Techniques and Industrial Applications" - KOLOT F.B. (Chapter 1) Edited by Robert E. Krieger Publishing Company, Inc FLA USA - First Edition, 1988.

3- "Immobilized Cells and Organelles, Vol 1" - MATTIASSON B. (Chapter

1) Edited by CRC Press, Inc FLA USA - 1983.

4 "Process Engineering Aspects of Immobilized Cell Systems" - WEBB C., BLACK G.M. and ATKINSON B. (Chapters 1 to 4) Edited by The Institute Of Chemical Engineers - First Edition, 1986.

5- "Microbial Technology, Vol 1 - Microbial Processes" - Chapter 11 "Microbial Technology, Vol 2 - Fermentation Technology" - Chapter 17 PEPPLER H.J. and PERLMAN D. Edited by Academic Press, Inc NY, NY USA - 1979.

6- "Biology of Microorganisms" - BROOK T.D. and MADIGAN M.T. (Chapters 10 and 19) Edited by Prentice Hall NJ USA - Sixth Edition, 1991.

7- KHESGHI S., ROBERTS H.R and BUCEK W. 1954.

Studies on the production of 5-ketoglucouic acid by Acetobacter suboxydans.

8- REHR B., WILHELM C and SAHN H. 1991.

Production of sorbitol and gluconic acid by permealized cells of Zymomonas mobilis. In Appl. Microbiol. Biotectmol. , 35 : 144 -148. 
9- SHIRAISHI F., KAWAKAMI K, KONO S, TAMURA A, TSURUDA S and KUSUNOKI K. 1989.

Characterisation of production of fiee gluconic acid by Gluconobacter suboxydans adsorbed on ceramic honeycomb monolith. In Biotechnology and Bioengineering, $33: 1413$ - 1418.

10- SHIRAISHI F., KAWAKAMI K, TAMURA A, TSURUDA $S$ and KUSUNOKI K. 1989.

Continuous production of free gluconic acid by Gluconobacter suboxydans IFO 3290 immobilized by adsorption on ceramic honeycomb monolith : effect of a reactor configuration on further oxidation of gluconic acidto ketogluconic acid. In Appl. Microbiol. Biotechnol., 31 : 445 - 447 .

11- SEISKARI P., LINKO Y.Y. and LINKO P. 1985.

Continuous production of gluconic acid by immobilized Gluconobacter oxydans cell bioreactor. In Appl. MIcrobiol. Biotechnol., 21: $356-360$.

12- SHAY L.K., HUNT H.R. and WEGNER G.H. 1987.

High-produtivity fermentation process for cultivating industrial microorganisms. In Journal of Industrial Microbiology, $2: 79$ - 85. 


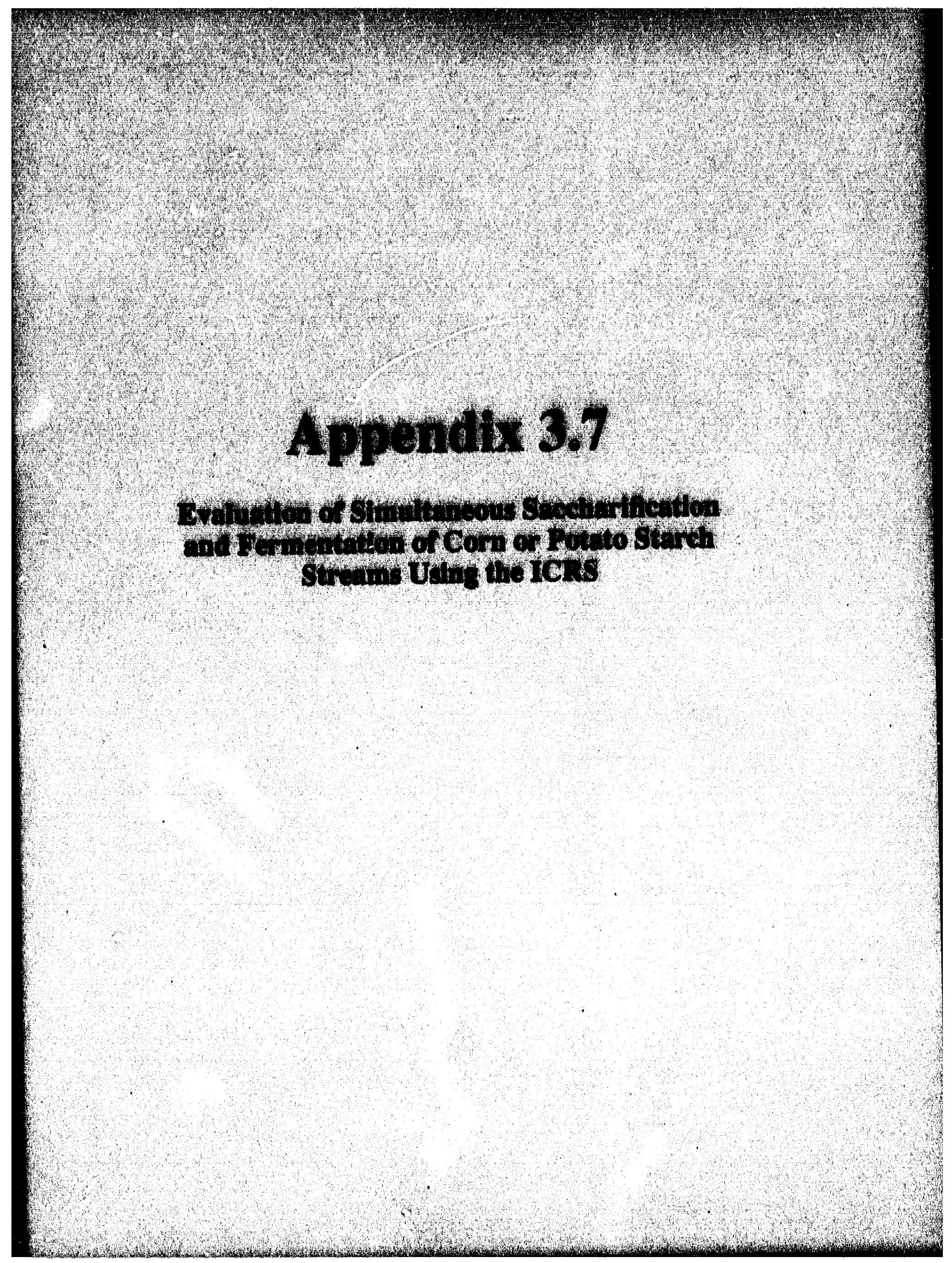


Feasibility and Availability Study for the Conversion of Raw Corn

Starch to Ethanol in the Continuous Reactor Separation

\section{Clark Dale \& Shuiwang Lei}

\section{ABSTRACT}

A system, comprised of a continuous reactor separator (CRS) column continuously producing ethanol and an absorbing column continuously removing and concentrating ethanol produced in the reactor, was developed. The CRS was a four stage reactor and total volume was about 4 liters. Fuur level of total solids, $10 \%, 15 \%, 20 \%$ and $30 \%$, was used in this study. $92 \%$ of the total solids was raw corn starch and $8 \%$ was ground malt. The yeast strain used was Kluyveromyces fragili 2415 and the enzyme was Fermenzyme L-200 in this study. Operation temperature $38^{\circ} \mathrm{C}$ was selected. The experiment ran continuously for 37 days. The experiment results indicated that $79 \%$ raw corn starch was converted to ethanol in CRS. Effect of PH, yeast density and malt content on conversion of raw com starch to glucose and glucose to ethanol was also investigated. The studies proofed that PH, Yeast density and malt ratio influenced significantly conversion of raw com starch to ethanol.

Key wards: Ethanol processing Starch fermentation Yeast

\section{INIRODUCTION}

Ethanol can be used for motor fuel, or as a fuel additive to replace lead in gasoline, or as a chemical feedstock. Ethanol production by fermentation processing constitutes a large section of biological and agricultural engineering. More attention has been paid to fuel ethanol production from biomass since 1970. It was stimulated not only by the limitation of non-renewable petroleum source, but also by agriculture and the environment.

Corn starch is widely used as raw materials in ethanol production. Theoretical calculations indicate that processing one ton of corn could obtain 400 liters ethanol (Rhonda Hosein \& Winston A. Mellowes 1988). However current batch fermentation technology for ethanol production involves liquefaction, saccharification and fermentation. These processes require large scale operation, large capital investment, and large energy consumption. About half of this energy is associated with drying and evaporating the stillage, and half with fermentation and distillation (M. Clark Dale, 1993 ). The Continuous Reactor Separator (CRS) is a novel system. In this system, continuous saccharification and fermentation of polysaccharides, such as starch, cellulose and other biomass, 
can be quickly completed. Raw com starch does not need to cook. Anhydrous ethanol may be obtained from feed concentration as low as 3 to $4 \%$ sugar with low energy consumption for ethanol recovery and dehydration when the CRS is coupled with solvent absorption recovery of the ethanol. This system will allow lower capital costs, lower energy usage, and lower labor costs.

Many factors are involved in the CRS. Any one of the factors will influence the conversion of raw starch to ethanol. This study focuses on the feasibility and availability for conversion of raw corn starch to ethanol in in a laboratory scale CRS. Goals of the research were to determine the factor of influence on the process and to analyze the effect of the factors on conversion.

\section{MATERIALS AND METHODS}

CRS fermentation equipment. A CRS experimental apparatus was designed and built in the laboratory. This apparatus consisted of a CRS column and an absorbing column (Fig. 1). The CRS column had four stages. The volume of each stage was about one liter. The first stage volume was a little bit bigger than the others. Feed solution, enzyme, yeast, and nutrient medium were continuously fed to the top of the column. Ethanol produced in each stages was stripped with air and the stripping stream was absorbed by an absorb column. Stripping air was supplied by a compressor and absorbing water was supplied by a special pump and tank.

Feed solution. Feed mash was made of raw corn starch and ground malt. Total solids levels used in this study were $10 \%, 15 \%, 20 \%$ and $30 \%$ by weight. The starch was $92 \%$ and malt was $8 \%$ by weight in the total solids. The starch used in this study was partly from Iowa (General Mills ) and partly from market (ARGO, CPC International). The raw starch samples were dried in an oven to determine moisture content. Drying temperature was $103^{\circ} \mathrm{C}$ and was for 72 hours. Average moisture content of the starch was $12.6 \%$ (wet basis ). The malt came from Sigma Chemical CO.. Before mixing, The ground malt was passed through a sieve NO.30 to remove bigger particles (USA Standard Testing Sieve). In order to prevent bacterial contamination, 250 ppm Sodium Bisulfite (SO2)(J. T. Baker Inc.) was added in the solution. After mixing, PH was adjusted to desired value with ammonia and phosphoric acid (H3PH4) (Mallinckrodt).

Enzyme. Enzyme used in this study was Fermenzyme L-200 (Solvay Enzymes Inc.). The enzyme was a liquid glucoamylase derived from selected strains of Aspergillus niger var and capable of hydrolyzing both alpha -D-1, 6 glucosidic branchiopods and the predominating alpha -D-1,4-glucosidic linkages of starch. The enzyme was necessary to break down the starch into fermentable sugars and increase alcohol yield. 


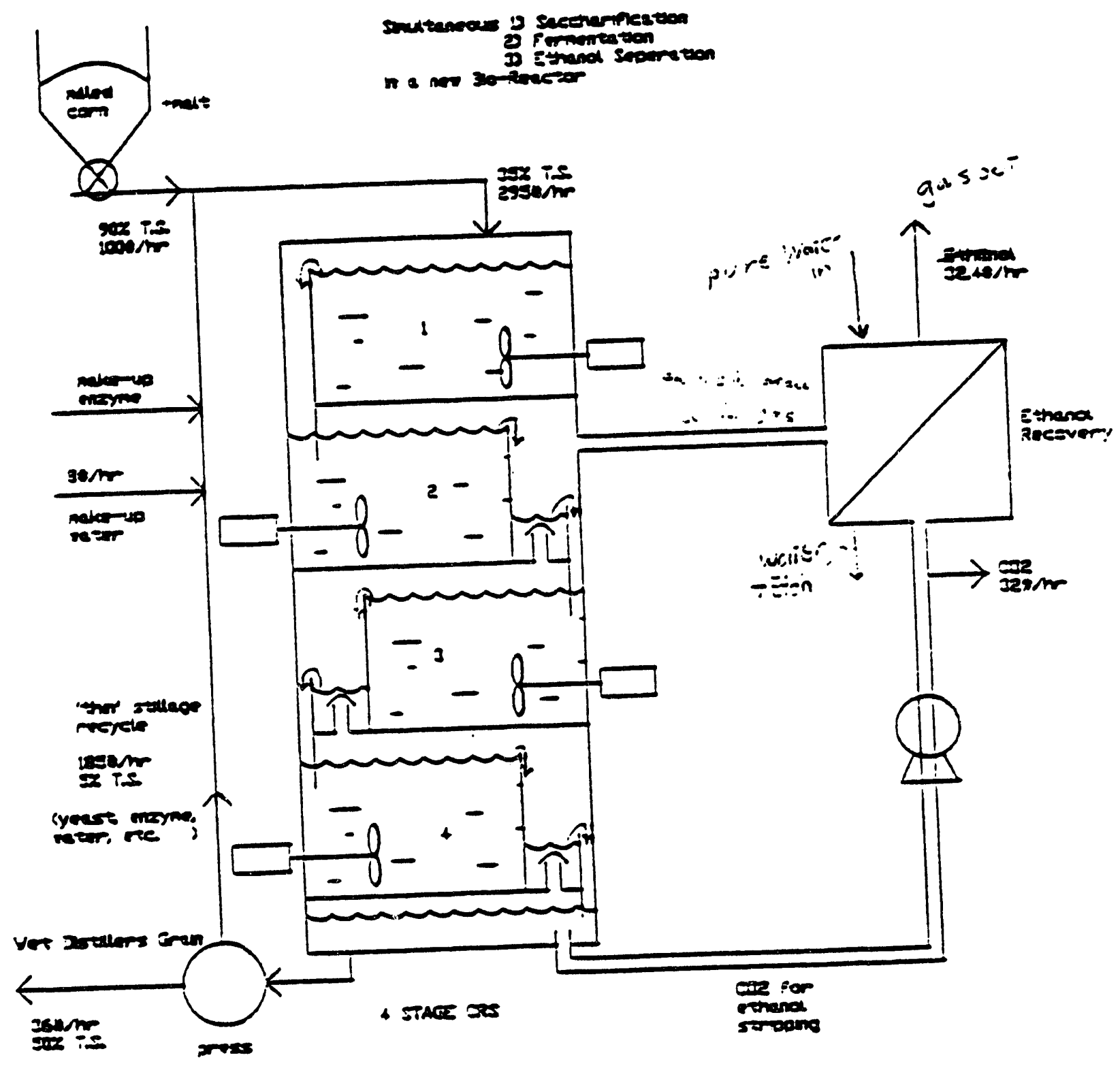

Figure 1. The Cos concept 'vith simuimeous stares hydroiysis:in a 'no--00k' process. 
Microorganism. The microorganism used in this study was Kluyveromyces fragilis 2415 . The strain had a high temperature tolerance and high fermentation rate. Both high temperature tolerance and high fermentation rate were desirable in fermentation and separation of ethanol production. The yeast was cultured for 24 hours before using.

Nutrient media. Two nutrient media were used in this study. The composition of the first medium was yeast extract 3 grams per liter, malt extract 3 grams per liter, and peptone 3 grams per liter. The second medium was composed of yeast extract 6 grams per liter, malt extract 6 grams per liter, and peptone 6 grams per liter. Before using, the media was autoclaved for 2 hours at temperature $120^{\circ} \mathrm{C}$.

Fermentation procedure. Continuous fermentation separation runs were performed. The feed solution, enzyme, and yeast were fed by a combined pump (Masterflex, Cole-parmert Instrument Co.). The pump was controlled by a timer. Supplying schedule of the feed was 1 minuter on and 9 minute off. The air and water was supplied continuously. Running each 24 hours, two ml sample from each stage and from the absorbing column outlet was taken. Concentrations of ethanol and glucose of the fermentation and separation were determined by high-pressure liquid chromatography (HPLC). The results were compared with a known standard ethanol and glucose concentration samples. Yeast density and remaining starch particles were checked by microscope. PH of slurry was checked by $\mathrm{PH}$ meter. Operating temperature was kept at $38^{\circ} \mathrm{C}$. The fermentation separation experiment ran continuously for 37 days.

\section{RESUITS AND DISCUSSION}

Theoretical conversion of raw starch to sugar and sugar to ethanol. Starch is a condensed polymer of glucose. In CRS, starch was continuously converted to glucose by the enzyme and glucose was converted to ethanol by the yeast. A summery of the chemical reaction involved in this conversion is as follows:

\section{$\mathrm{C} 6 \mathrm{H} 12 \mathrm{O} 6-->2 \mathrm{C} 2 \mathrm{H} 5 \mathrm{OH}+2 \mathrm{CO} 2+$ heat}

Preliminary calculations indicate that one unit of starch could convert to 0.51 units of ethanol theoretically. However not all of starch can convert to ethanol. In the fermenting process with yeast, about $5 \%$ of the sugar is used by the yeast to produce biomass and by-products. Therefore the best result of conversion of one unit starch to ethanol was about 0.46 unit. The maximum conversion to ethanol that could be obtained in the CRS was equal to 
Ethanol $(\mathrm{g} / \mathrm{hr})=0.46(\mathrm{~g}) *$ Feed solution $(\mathrm{ml} / \mathrm{hr}) *$ Total solids (\%)*Dry matter (\%)

Suppose the total solids of the feed was $20 \%$ ( w/v). Starch of the total solids was $92 \%$ and the ground malt was $8 \%$ by weight. Assume malt used in this study contains $70 \%$ starch and the moisture content was as same as corn starch. Ethanol should be produced at a rate of $7.9 \mathrm{~g}$ per hour. The one of the results was shown in Fig. 2 and the figure was presented in Table 1. HPLC analysis was shown in Fig 3. Conversion of total solids, ethanol and glucose was indicated in Fig. 4.

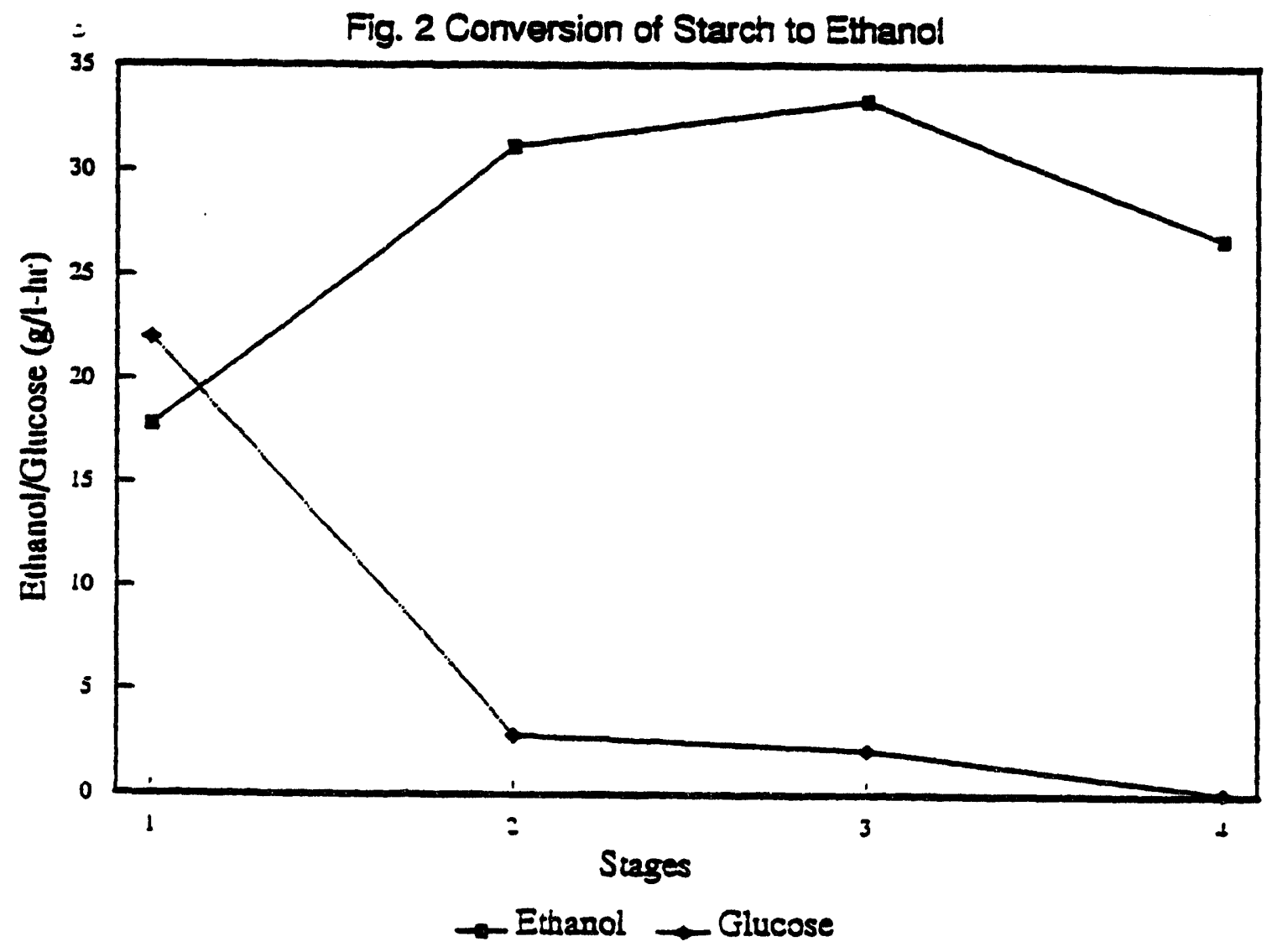

Fig. 3 HPLC Analyeis Results

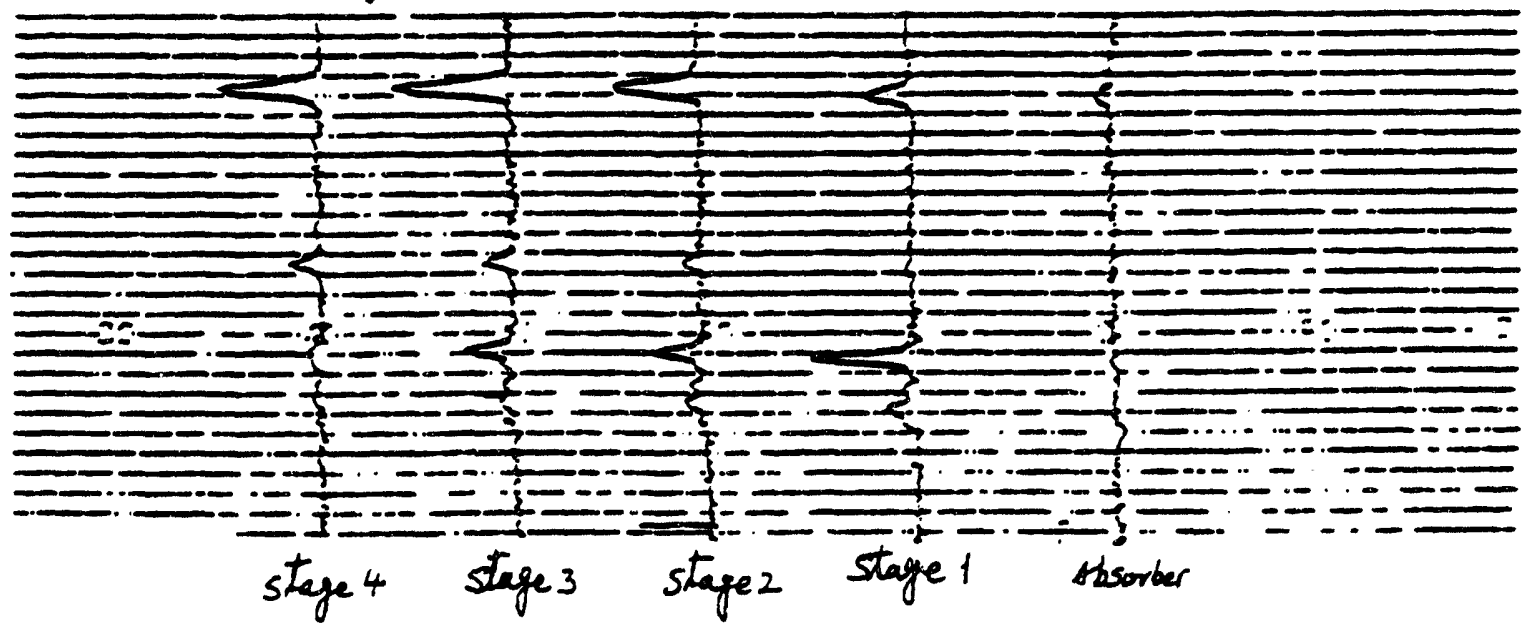


Fig. 4 Total Solids, Ethanol and Glucose in CRS

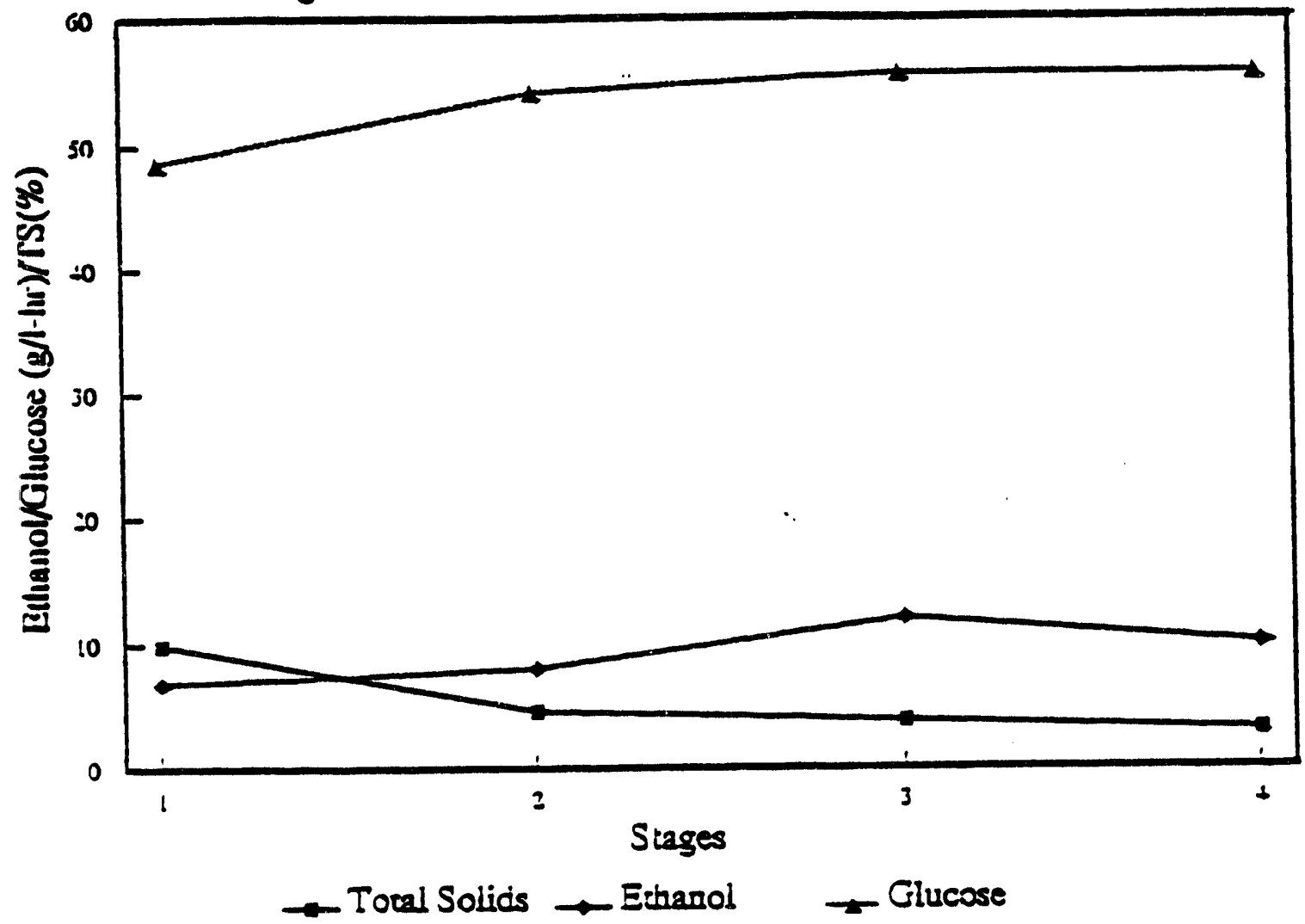

Fig. 5 Effect of Malt on Conversion of Stach to Ethanol

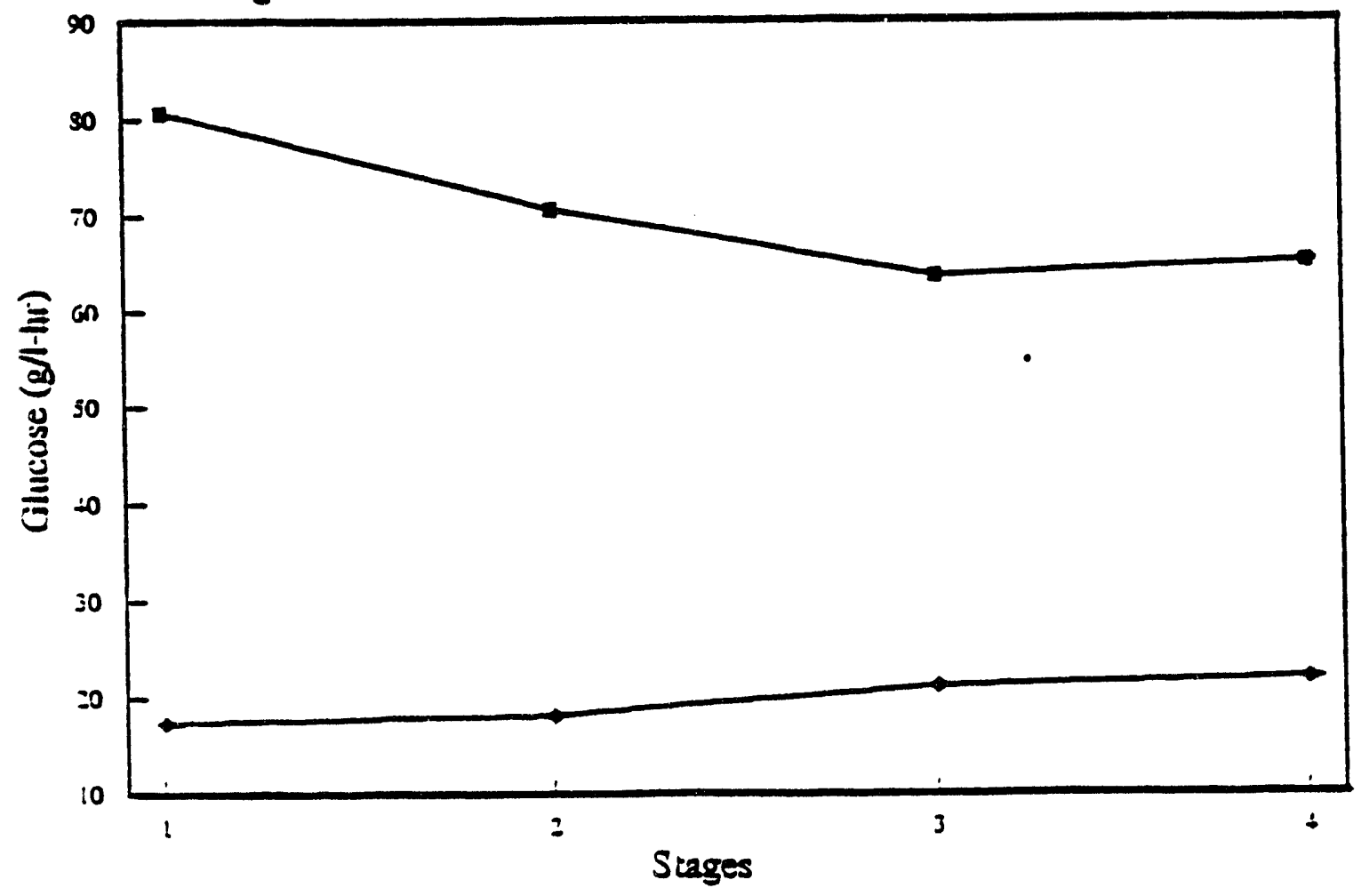

$\rightarrow 8 \%$ Vait in Tocal Solids $\rightarrow 0 \%$ Vart in Tocal Solids 
Table 1 Conversion of starch to ethanol

$\begin{array}{lll}\text { Stage } & \text { Ethanol }(\mathrm{g} / \mathrm{h} \mathrm{hr}) & \text { Glucose }(\mathrm{g} / \mathrm{h} \mathrm{hr}) \\ 1 & 17.8 & 22 \\ 2 & 31.1 & 2.8 \\ 3 & 33.3 & 2.1 \\ 4 & 26.7 & 0.1 \\ \text { absorber } & 8.9 & \end{array}$

The results indicate that $79 \%$ of the raw starch had been converted to ethanol. The ethanol stripped and absorbed was $57 \%$ and that remain in the last stage was $43 \%$. The glucose was nearly exhausted by yeast. Experimental conditions were $\mathrm{PH}=3.5-4.0$, YMP 3,3,3.. The enzyme level was 200 and yeast density was over 15 million per cubic millimeter.

Effect of malt on conversion of starch to glucose

The effect of malt on conversion of raw starch to glucose was investigated. experimental results was shown in Fig. 5 and the data was presented in Table 2.

Table 2 Effect of malt on conversion of starch to glucose

Stage malt in total solids $8 \% \quad 0$

1 80.62 17.42

2

70.6

3

63.6

21.2

4

65.0

22.0

It is obvious that malt can help the conversion of starch to glucose. The glucose concentration using ground malt in the different stages increased to as high as aboaa3ut 1.9 - 3.6 times when compared to experiment using no malt. Furthermore, the saccharification time was shortened. It was helpful to accelerate conversion of glucose to ethanol.

Effect of PH on conversion of starch to ethanol

The fermentation environment was important. One of the important factor was PH. The effect of PH on conversion of starch to ethanol were studied. Test results was shown in Fig. $6 \mathrm{~A}$ and Fig. $6 \mathrm{~B}$ and the Data was indicated in Table 3. 
Fig. 6A Effect of PH on conversion of Starch to Ethand:

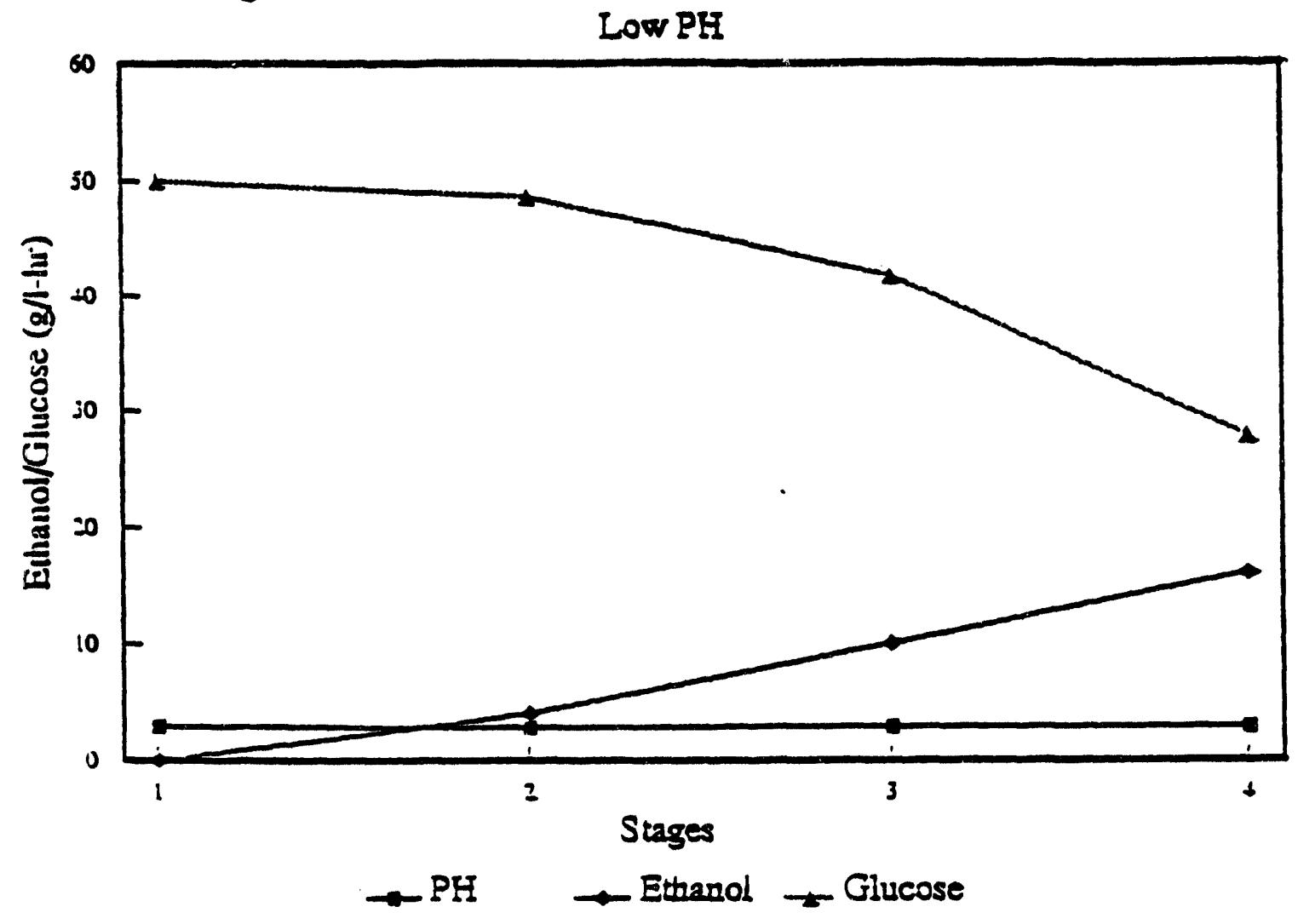

Fig. 68 Effect of PH on conversion of Starch to Ethanol

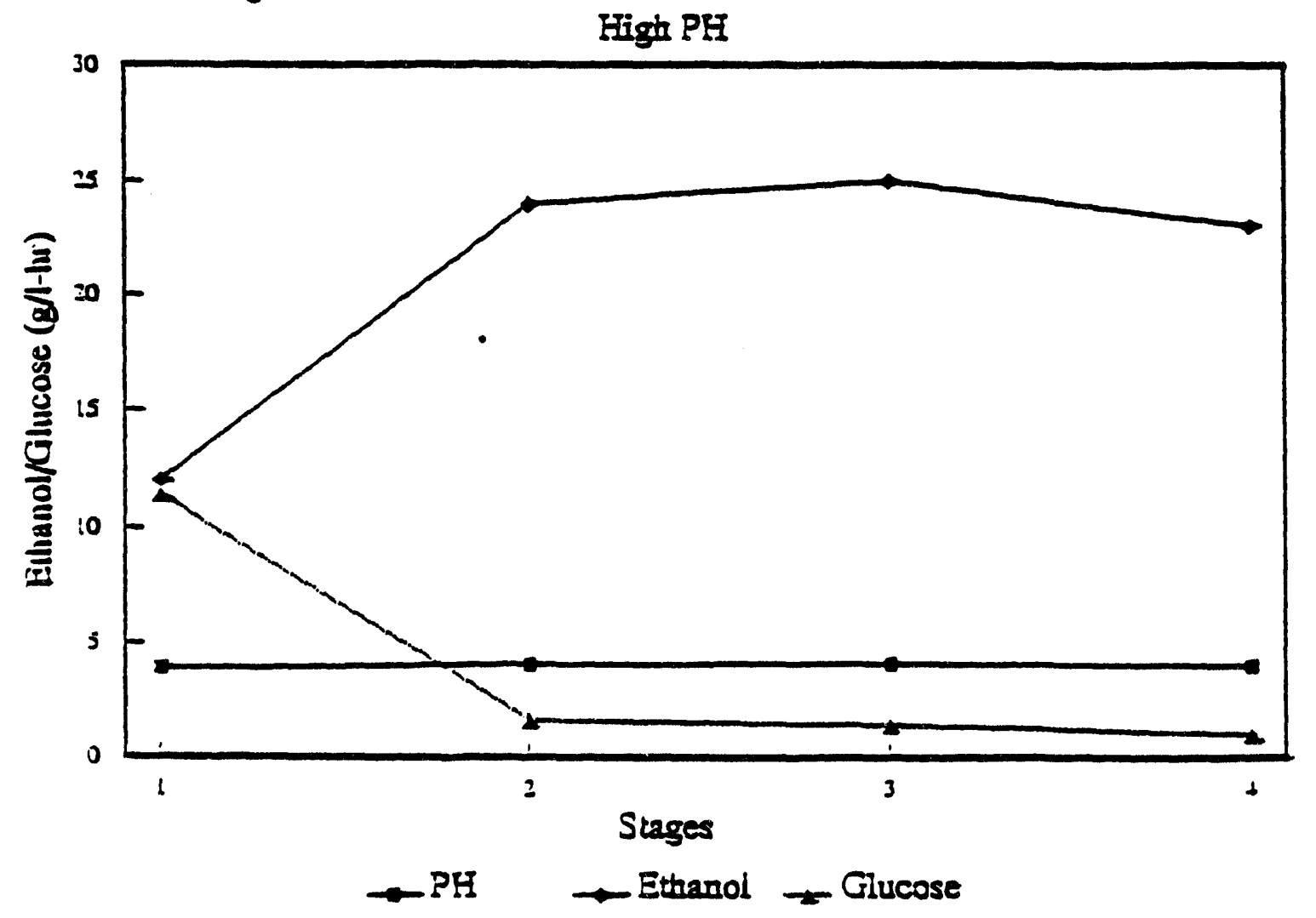


Table 3 Effect of $\mathrm{Ph}$ or conversion of starch to ethanal

\begin{tabular}{lccccccc} 
Stage & \multicolumn{4}{c}{ Low PH } & & \multicolumn{4}{c}{ High PH } \\
& Ph & ethanol glucose & Ph & ethanol glucose \\
1 & 2.9 & 0 & 50 & & 3.9 & 12 & 11.4 \\
2 & 2.83 & 4 & 48.6 & & 4.04 & 24 & 1.6 \\
3 & 2.88 & 10 & 41.7 & & 4.09 & 25 & 1.4 \\
4 & 2.9 & 16 & 27.8 & & 3.98 & 23 & 1 \\
absorber & & & & & & & 6
\end{tabular}

The experiments indicated clearly that yeast did not work well when PH was lowed to 3. It was much better to control the PH at about 4 .

The effect of yeast density on conversion of starch to ethanol

Test results using different yeast densities are shown in Fig. 7A and Fig. 7B and the data was represented in Table 4.

Fig. TA Effect of Yeast Density on conversion of Starch to Ethanol Low Yeast Deasity

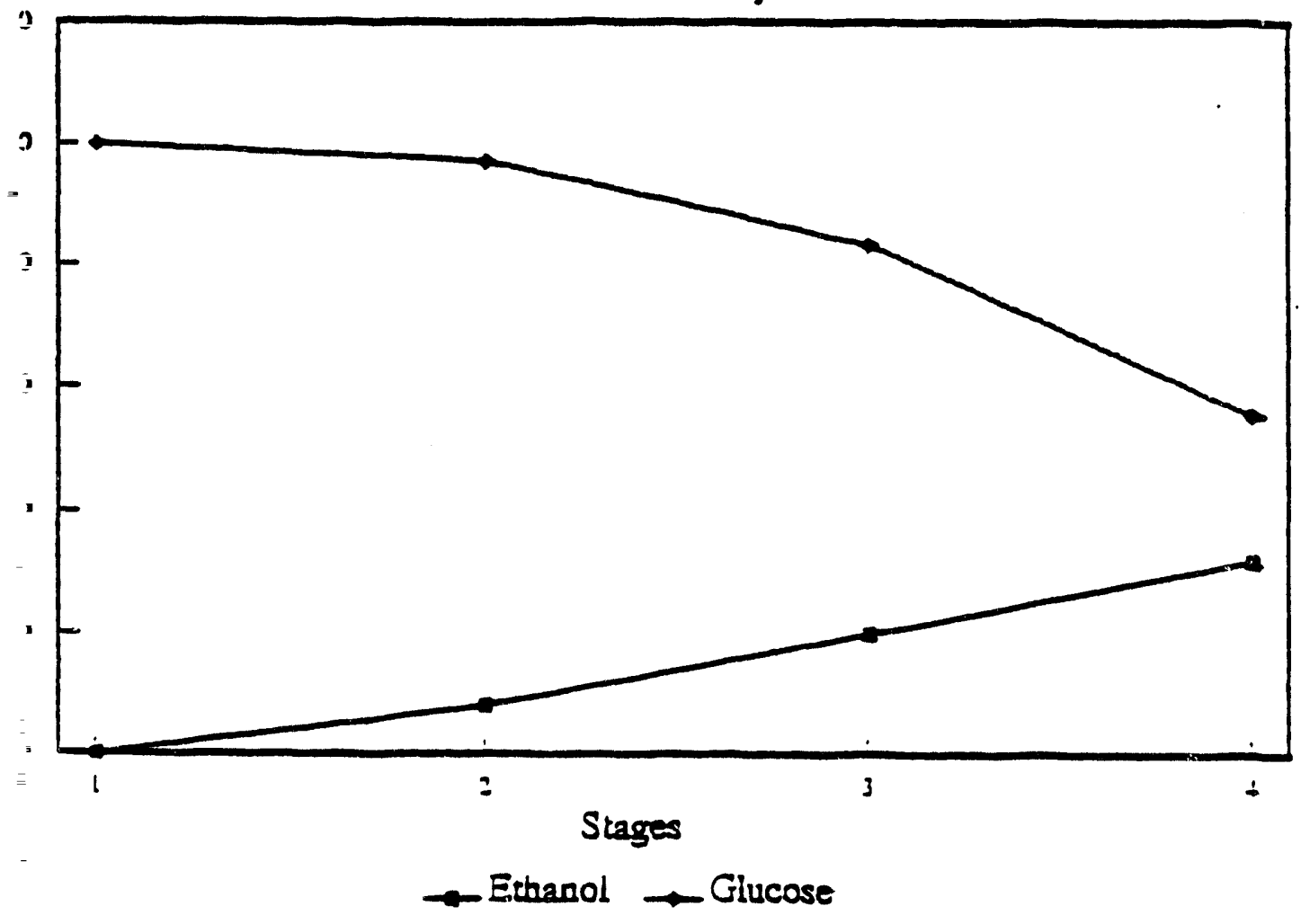


Fig. 78 Effect of Yeast Density on conversion of Starch to Ethanol Figh Yeast Deasity

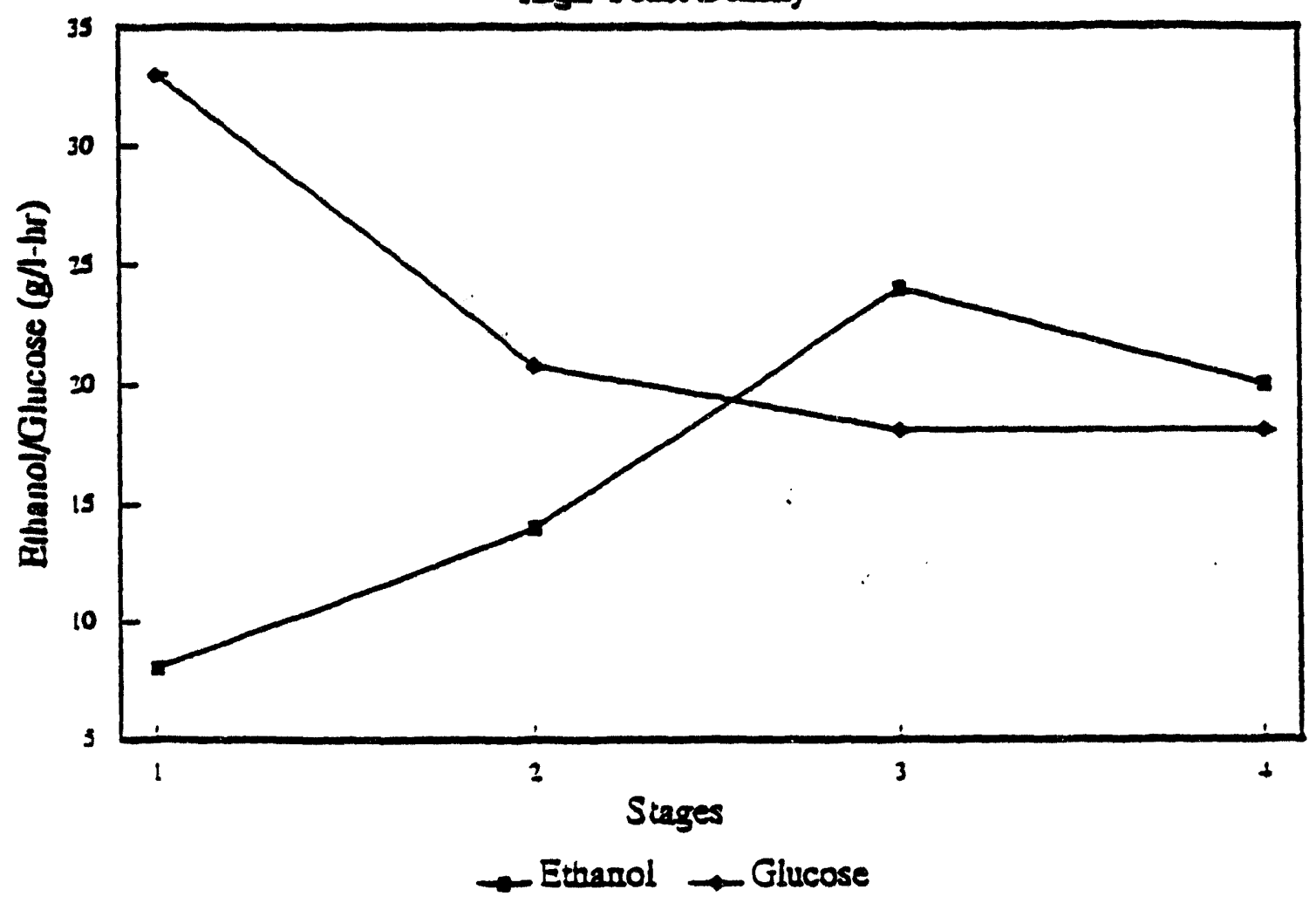

Table 4. Effect of yeast density on conversion of starch to ethanol

\begin{tabular}{lcccc} 
Stage & \multicolumn{2}{c}{$\begin{array}{c}\text { Low density } \\
\text { ethanol }\end{array}$} & \multicolumn{3}{c}{$\begin{array}{c}\text { High density } \\
\text { ethanol glucose }\end{array}$} \\
1 & 0 & 50 & 8 & 33 \\
2 & 4 & 48.6 & 14 & 20.8 \\
3 & 10 & 41.7 & 24 & 18.1 \\
4 & 16 & 27.8 & 20 & 18.1
\end{tabular}

The results show that conversion of raw starch to ethanol can be condiucted successfully. The density of the yeast should be over 15 million per cubic cent meter.

Effect of nutrient level on conversion of starch to ethanol

The nutrient level used mainly in this study was yeast extract $3 \mathrm{~g} / \mathrm{l}$, malt extract $3 \mathrm{~g} / \mathrm{l}$, and peptone 3 $g / 1$ ( YMP 3, 3, 3). The second nutrient level, yeast extract $6 \mathrm{~g} /$, malt extract $6 \mathrm{~g} /$, and peptone 6 $g / 1$ ( YMP $6,6,6$ ), was used for 3 days. No significant effect on conversion of starch to ethanol was found under these experimental conditions. 


\section{CONCLUSIONS}

The CRS is a economical process in the conversion of raw starch to ethanol. It was found that $79 \%$ of raw starch was converted to ethanol on a laboratory scale.

PH and microorganism density have a significant upon the conversion of raw starch to ethanol. PH should be controlled at about 4 and yeast density should be over 15 million per cubic cent meter. Malt concentration also has an effect upon the conversion of raw starch to glucose.

\section{REFERENCES}

C. L. Weller, M. P. Steinberg \& E. D. Rodda, Fuel Ethanol from Raw Com by Aspergilli Hydrolysis with Concurrent Yeast Fermentation. Biotechnology and Bioengineering Symp. No. 13 437-447 (1983).

M. Clark Dale, A low-energy Continuous Reactor-Separator for the Production of Ethanol from Starch or Cellulose. A unpublished propose, 1993.

Prianto Moeljadi, Effect of Temperature on the Ethanol Production by Kluyveromyces Frigalis 2415. Unpublished report, 1993.

Rhonda Hosein \& Winston A. Mellowes, Malt Hydrolysiis of Sweet-potatoes and Eddoes for Ethanol Production. 29(1989) 263-270.

Severine Michel, Feasibility of a No-cook Process for the Conversion of Dry Milled Corn to Sugars, and the Sugars to Ethanol. Unpublished report, 1993.

Toshihito Ashikari, Shin-ichi Kunisaki, Nobuya Matsumoto, Teruo Amachi, and Hajime Yoshizumi, Direct Fermentstion of Raw Corn to Ethanol by Yeast

Transformants Containing a Modified Rhizopus Glucoamylase Gene. Applied Microbiology and Biotechnology. 32:129-133 (1989)

Y. Shabtai, S. Chaimotitz and Katchalski-Katzir, Continuous Ethanol Production by Immoblized Yeast Reactor Coupled With Membrane Pervaporation Unit. Biotechnology and Bioengineering, Vol. 38, 869-876 (1991). 


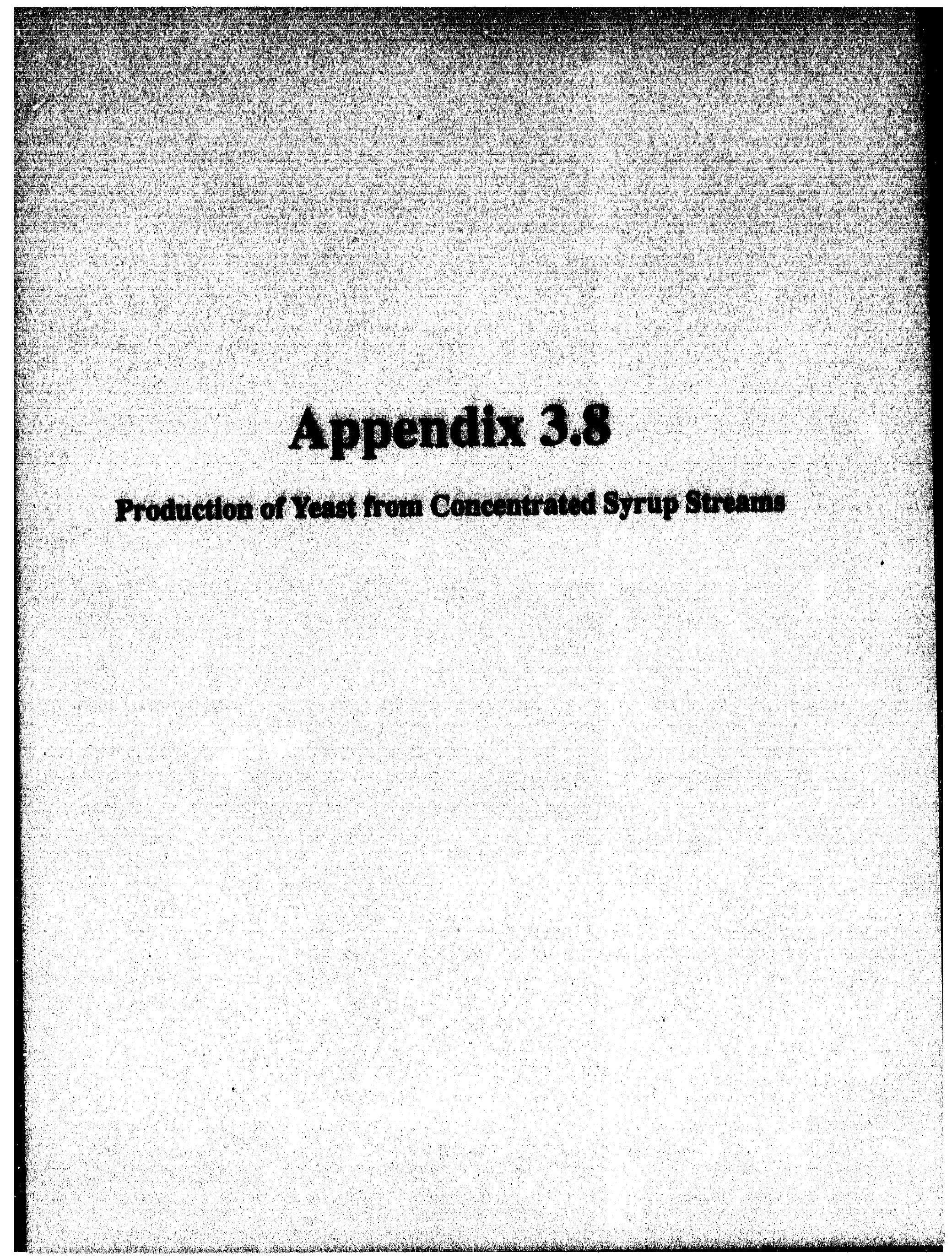




\section{Introduction}

The nutritional value of yeast has been recognized for hundreds of years, as yeast is a good source of proteins and vitamins. There has been some work on growing a number of different unicellular microbes (Single Cell Protein or SCP) such as yeast on various substrates as a possible solution to malnutrition in the third world. Yeast as a single cell protein can meet many of the nutritional needs of humans, but if used at high levels in a diet, can lead to an overconsumption of nucleic acids. High levels of nucleic acids in the human diet can lead to physiological problems such as gout.

Currently in the USA, yeast has many different applications. Yeast has a major use as a leavening agent in the baking industry. The production of "bakers yeast" and/or active dried yeast for baking is an important, but not a growing outlet for yeast. There is a current movement towards using yeasts to provide flavors in the food processing industry. Red Star Specialty Products produce a bulletin about the use of yeast as a flavoring ingredient......

"For centuries, yeast has been extensively used in the food and beverage industry. With the increase in consumer awareness of the use of salt, monosodium glutamate, and hydrolyzed vegetable protein in processed foods, as well as consumer desire for natural ingredients, food processors have turned to yeast extracts for flavor enhancement. Bulletin includes information on manufacturing operations, properties, nutritional benefits, and economic advantages of yeast" (F.P. 8/92)

Yeast is extensively utilized in cattle and swine feeding, with there being a current research effort noting a "pro-biotic" beneficial result from the feeding of live yeast to both dairy and beef cattle.

Yeast production can be classified as primary, where yeast is the desired main product of the operation, or secondary, where yeast is a byproduct of the operation i.e. alcohol production. For 
primary yeast production, a variety of substrates are utilized including molasses, glucose (starch), sulfite liquor, or wood hydrolysate. Industrial production of yeast from lactose or whey was pructiced by Amber Labs of Juneau, WI, with several publications describing the plant design and operating characteristics (Berstein et al, 1977). To the best of my knowledge, no company is now currently producing primary yeast from whey lactose.

A variety of strains of yeast are identified as "food grade", indicating that these strains produce no toxic by-products as far as the FDA is aware. These strains include S. cerevisae, and all other Saccharomyces strains, Candida utilis, and $K$. marxianus, a lactose utilizing strain. Kluyveromyces marxianus behaves very similarly to standard Saccharomyces cerevisae except for being able to assimilate lactose, being somewhat more temperature tolerant, and slightly less ethanol tolerant.

Yeast have two basic metabolisms, anaerobic fermentation- where sugars are converted to ethanol, and aerobic respiration-where sugars are converted to $\mathrm{CO} 2$ and cell mass. During the fermentative conversion of lactose to ethanol, the yeast acts as a biological catalyst (required for the conversion, but not actually wanted as a product). Substrate and nutrients used for cell growth reduce the conversion ratio of substrate to ethanol production slightly. Ethanol production is considered a 'growth associated fermentation'. In general, yeast will 'ferment' or produce ethanol in an anaerobic environment, and 'respire' and produce cell mass when oxygen levels are high enough for the aerobic metabolism of the sugars. Saccharomyces strains exhibit a phenomena called the 'Crabtree' ef:ect at high sugars, where even in the presence of high dissolved oxygen, the cells fementatively produce ethanol. According to Phaff (1965), K. marxianus does not exhibit this effect, but data by Mahmoud and Kosikowski (1982) show that even 
under aerated and agitated conditions, a $30 \%$ demineralized whey permeate solution gave a 30 $\mathrm{g} / \mathrm{l}$ ethanol solution and final cell density of $15 \mathrm{~g} / \mathrm{y}$ yeast with when all the lactose was utilized.

It is well known high sugars and ethanol inhibit fermentative cell growth and ethanol productivity. Dale et al, $(1990,1993)$ show that both substrate and product inhibition of $K$. marxianus can be determined to be largely an osmotic effect in the fermentative metabolism. At a solution osmolality of $2.2 \mathrm{os} / \mathrm{kg}$, anaerobic cell growth is totally inhibited, while for a commercial strain of Saccharomyces cerevisae, Dale et al. $(1990,1993)$ show that there is no growth at $1.8 \mathrm{os} / \mathrm{kg}$ or above. In general, for primary yeast production, sugar levels are kept low (under 3\%) to limit the amount of ethanol produced. Oura (1974) states that when the glucose solution concentration used for yeast growth exceeds $50-100 \mathrm{~g} / \mathrm{l}$ the metabolism goes partly fermentative, no matter what level dissolved oxygen (DO) is maintained in the reactor. These glucose levels (50-100 g/l) correspond to $0.29-0.63 \mathrm{os} / \mathrm{kg}$ solution osmolality (CRC, 1973). Following the reasoning of Dale et al. $(1990,1993)$ a low osmotic environment may be required for efficient conversion of sugars to cell mass. Moresi et al. (1990) show a constant yield of $0.49 \mathrm{~g}$ yeast $/ \mathrm{g}$ lactose at whey feed concentrations of under $30 \mathrm{~g} /$, after which the yield began to drop (due to ethanol production). At $50 \mathrm{~g} /$ lactose, cell mass yield $(\mathrm{Y} \mathrm{x} / \mathrm{s})$ was reduced to $0.35 \mathrm{~g} / \mathrm{g}$. Marison and von Stockar (1987) showed that during the aerobic fermentation of single strength whey permeate, some ethanol was formed. This ethanol was noted despite the aeration of the broth. Marison states that dissolve oxygen (DO) never fell below $80 \%$ of saturation. 


\section{Nutritional Requirements}

When yeast is the primary product, the nutrient mix in the broth must be adequate to meet both the primary nutrients (nitrogen, phosphorus, and potassium) and trace vitamins and minerals requirements for the yeast to grow and thrive. When yeast is produced from carbohydrate streams, typical 'best' conversion ratios (g. yeast/g. sugar) are 0.49 to 0.59 . Yields reported by various researcher are given in Table 1. Wasserman (1953) determined a 'theoretical' maximal (100\%) conversion yield of $0.6 \mathrm{~g} / \mathrm{g}$ with $65 \%$ of the sugar carbon being assimilated by the yeast, and $35 \%$ converted to $\mathrm{CO} 2$ by a respirometer study, but found actual maximal yield to be $55 \%$.

$$
\begin{aligned}
& \left.1 \text { gram } \mathrm{C}_{12} \mathrm{H}_{12} \mathrm{O}_{6} \text { (lactose or carbohydrate }\right)+ \text { nitrogen }+ \text { oxygen } \\
+ \text { vitamins }+ \text { minerals } \longrightarrow & \longrightarrow 0.4-0.63 \text { gram yeast }+ \text { water }+\mathrm{CO}_{2} \text { +heat }
\end{aligned}
$$

Moresi et al. (1990) came up with very similar oxygen and conversion coefficient, and determined the total reaction stochiometry as:

$$
\begin{gathered}
\mathrm{CH}_{1.83} \mathrm{O}_{.917} \text { (lactose) }+0.11 \mathrm{NH}_{3}+0.8 \mathrm{O}_{2} \longrightarrow 0.60 \mathrm{CH}_{1.84} \mathrm{O}_{0.58} \mathrm{~N}_{0.18} \text { (yeast) } \\
+0.33 \mathrm{CO}_{2}+\mathrm{H}_{2} \mathrm{O}+.07 \mathrm{CH}_{s} \mathrm{O}_{t} \text { (ethanol or other solvents) }
\end{gathered}
$$

Moo-Young gives the following similar stoichiometry for yeast growth on glucose:

$$
\begin{gathered}
1.68 \mathrm{CH}_{2} \mathrm{O} \text { (glucose) }+0.19 \mathrm{NH}_{3}+0.68 \mathrm{O}_{2} \longrightarrow \mathrm{CH}_{1.7} \mathrm{O}_{0.5} \mathrm{~N}_{0.19} \text { (yeast) } \\
+0.71 \mathrm{CO}_{2}+1.14 \mathrm{H}_{2} \mathrm{O}+80 \mathrm{Kcal} \text { (heat evolved) }
\end{gathered}
$$

The highest yield reported is by Bechtle and Clayton (1975) who state that with a $3 \mathrm{X}$ concentration of cheddar whey, a $102 \mathrm{~g} / 1$ cell mass was attained using a mix of yeast cultures (C. utilis, $T$. cremoris, and others including $K$. marxianus). These researchers also used a variety of supplements such as yeast extract and corn steep liquor which may have exaggerated their yield. 
Table 1. Yields of yeast on whey

\begin{tabular}{|r|l|l|l|l|}
\hline $\begin{array}{c}\text { Whey } \\
\text { con-g/ } 1\end{array}$ & $\begin{array}{c}\text { Yeast } \\
\text { con-g/ }\end{array}$ & $\begin{array}{c}\text { Yield } \\
\text { Yx/s }\end{array}$ & $\begin{array}{c}\text { rxtr } \\
\text { Reference }\end{array}$ & \\
\hline \hline $60 \mathrm{~g} / 1$ & 25 & 0.45 & CSTR & Shay \& Wagner 1986 \\
120 & 45 & 0.46 & CSTR & Shay \& Wagner 1986 \\
180 & 60 & 0.44 & CSTR & Shay \& Wagner 1986 \\
240 & 85 & 0.44 & CSTR & Shay \& Wagner 1986 \\
300 & 97 & 0.43 & CSTR & Shay \& Wagner 1986 \\
\hline 87 & 25 & 0.45 & fed batch & Bernstein \& Everson 1973 \\
60 & 11.7 & 0.24 & batch & Beasseiou et al 1981 \\
62 & 11.2 & 0.22 & batch & Geic \& Kosikowski \\
150 & 28.5 & 0.23 & batch & Geic \& Kosikowski 1982 \\
58 & 18.4 & 0.40 & batch & Maroiella \& Costello \\
\hline 74 & 23 & 0.51 & batch & Wasserman et al 1959 \\
18 & 7.1 & 0.47 & CSTR & Moresi et al 1990 \\
37 & 11.4 & 0.38 & CSTR & Moresi et al 1990 \\
56 & 16.2 & 0.36 & CSTR & Moresi et al 1990 \\
65 & 14.6 & 0.28 & batch & Blake Ray \& Mores 1981 \\
\hline 25 & 12.2 & 0.61 & CSTR & Moulin et al 1983 \\
25 & 11 & 0.55 & batch & Vananvat \& Kimselda 1975 \\
50 & 14 & 0.33 & batch & Michel et al 1987 \\
300 & 17 & 0.06 & batch & Mahmoud \& Kosikowski 1982 \\
15 & 6.2 & 0.42 & CSTR & Bivou \& Stockar 1988 \\
\hline 240 & 102 & 0.66 & batch & Bechtle \& Clayton 1975 \\
80 & 25.4 & 0.50 & batch & Bechtle \& Clayton 1975 \\
60 & 23.0 & 0.51 & batch & Marison \& von Stockar \\
\hline
\end{tabular}


Table 2 gives the basic composition of whey permeate, and various yeast streams grown on whey. To successfully produce maximal yields of yeast, each nutritional need of the growing yeast must be met, and all environmental conditions ( $\mathrm{pH}$, temperature, osmotic environment, etc.) be optimal for the yeast. By examining the various nutritional requirements and environmental variables required for yeast production from concentrated whey streams as reported in the available literature, and applying this knowledge to our new reactor technology, the successful conversion of whey permeate to yeast should be able to be accomplished.

Nitrogen. As per Table 2, yeast are about $50 \%$ by weight protein. A simple mass balance on single strength whey can be made. Assuming $48 \mathrm{~g} /$ liter lactose and a conversion ratio $(\mathrm{Y} x / \mathrm{s})$ of $0.45,21.6 \mathrm{~g} /$ liter yeast can be produced. Therefore, $11-12 \mathrm{~g} / \mathrm{l}$ of protein will be produced by the yeast, and this nitrogen must be supplied by the medium.

On a dry basis, whey permeate has a composition of $78-80 \%$ lactose, $11-12 \%$ minerals, and 3-3.5\% crude protein. For single strength permeate solution ( $55 \mathrm{~g} / \mathrm{T} . \mathrm{S}$.) only $1.7 \mathrm{~g} / \mathrm{l}$ protein is available in the solution (Table 2), and there have been several studies that indicate that whey protein is not readily assimilated by the yeast (Wasserman,1960, Barnes 1976), while ammonium is rapidly utilized for cell growth. Therefore, nitrogen is a major nutrient that must be supplied when growing yeast on permeate. Wasserman (1960) determined that $5 \mathrm{~g} / \mathrm{l}$ $(\mathrm{NH} 4)_{2} \mathrm{SO} 4$ along with $1 \mathrm{~g} / 1$ yeast extract was adequate nitrogen supplementation to achieve a yield $(\mathrm{Y} \mathrm{x} / \mathrm{s})$ of 0.55 or $92 \%$ of theoretical $(25 \mathrm{~g} / 1$ cells from $40 \mathrm{~g} / 1$ lactose $-5.5 \mathrm{~g} / 1$ lactic acid) in both whole and heat deproteinated acid whey. An elemental nitrogen balance can be run to determine minimum ammonia nitrogen needed to ferment $48 \mathrm{~g} / \mathrm{l}$ lactose (single strength sweet whey permeate). If the nitrogen fraction of crude protein is $1 / 6.28$, then $22 \mathrm{~g} / 1$ yeast at $55 \%$ 
Table 2.

Composition of Whey and Whey Yeast Products

\begin{tabular}{|c|c|c|c|c|c|c|c|c|}
\hline & \multicolumn{2}{|c|}{ whey ${ }^{1}$} & \multirow[t]{2}{*}{ whey permeate ${ }^{2}$} & \multicolumn{2}{|c|}{ mineral yeast } & \multicolumn{3}{|c|}{ washed yeast } \\
\hline & (1) & (6) & & (3) & (4) & (6) & (4) & (5) \\
\hline $\begin{array}{l}\text { Lactose } \\
\text { Carbohydrate }\end{array}$ & 76.5 & 78 & 79 & 24 & & 30.1 & & 42 \\
\hline Protein & 12.5 & 11.4 & 3.5 & 43.8 & $32-40$ & 57.4 & $45-55$ & 50 \\
\hline Ash & 6.0 & 9.2 & 11.5 & 18.8 & $15-20$ & 5.4 & $5-7$ & \\
\hline $\begin{array}{l}\text { lipids/fats } \\
\text { moisture }\end{array}$ & 4.5 & -. & $\ddot{4.5}$ & 4.3 & $\begin{array}{l}2-3 \\
3-4\end{array}$ & 7.1 & $3-4$ & \\
\hline
\end{tabular}

1. Porges et al. 1951

2. Formost Dairy Products

3. Shay \& Wagner, 1985

4. Bernstein \& Everson, 1973

5. Mairorella \& Castillo, 1985

6. Beausejour et al, 1981 
protein will require $1.93 \mathrm{~g} /$ nitrogen. $\left(\mathrm{NH}_{4}\right)_{2} \mathrm{SO} 4$ is $21.1 \%$ nitrogen, thus, if this is the sole source of protein, $9.1 \mathrm{~g} / \mathrm{l}$ would be required. From Moresi et al.'s (1990) (Eq. 2) balance on the yeast growth system, it can be calculated that $.13 \mathrm{~g}$ of $\mathrm{NH} 3$ will be required for each $1 \mathrm{~g}$ of lactose converted to yeast, or $6.24 \mathrm{~g} / 1 \mathrm{NH} 3$ for single strength whey.

Minerals. Minerals make up about $5 \%$ (d.b.) of washed dried yeast, while permeate is $12 \%$ minerals. The basic composition of whole whey powder, washed dried Kluyveromyces marxianus, and baker's yeast are shown in Table 2. Bayer (1983) compared the mineral fraction in single strength whey with the minerals to be found in $20 \mathrm{~g}$ of yeast (assumes a $60 \%$ yield of Candida intemidia type yeast) as shown in Table 3. The major mineral requirements of yeasts are phosphorus, potassium, calcium, and magnesium, all of which are available in whey. This does not explain why Wasserman et al. (1958) noted a major beneficial ( $21 \%$ increased yield) effect from the addition of $0.5 \%$ of potassium phosphate. Trace elements are probably more critical, Wasserman et al. (1958) noted a $100 \%$ increase in yield when $1 \mathrm{~g} / 1$ yeast extract was added to the medium along with ammonium, phosphate, and potassium. Bayer (1983) examined the composition of milk and deproteinized whey east for trace minerals and found a substantial loss in $\mathrm{Cu}, \mathrm{Zn}$, and $\mathrm{Fe}$. Bayer found that supplementing whey with $1 \mathrm{ml}$ of a solution containing: $0.3 \mathrm{~g} / 1 \mathrm{CuSO} 4,0.8 \mathrm{~g} / 1 \mathrm{MnSO} 4,0.4 \mathrm{~g} / 1 \mathrm{MoO} 4,3.0 \mathrm{~g} / \mathrm{ZnSO} 4,4.0 \mathrm{~g} / \mathrm{FeCl} 3$, allowed a $76 \%$ yield of yeast to be attained ( $22 \mathrm{~g} / 1$ of cells to be obtained from a $48 \mathrm{~g} / 1$ lactose in whey solution). Shay et al similarly suggest a trace mineral supplementation of $1.5 \mathrm{ml}$ of a similar solution containing $60 \mathrm{~g} / 1 \mathrm{FeSO} 4,25 \mathrm{~g} / \mathrm{ZnSO} 4,5 \mathrm{~g} / \mathrm{CuSO} 4,2 \mathrm{~g} / 1 \mathrm{MnSO} 4,1 \mathrm{~g} / \mathrm{MoO}$, $0.2 \mathrm{~g} / 1 \mathrm{CoCl} 2$ to ferment a $100 \mathrm{~g} / \mathrm{l}$ concentrate whey permeate solution.

Table 2 gives the composition of dried yeast produced from whey permeate when the broth 
Table 3. Mineral composition of whey and protein

\begin{tabular}{|l|ccc|cc|}
\hline & \multicolumn{3}{|c|}{$\begin{array}{c}\text { mg/ in } \\
\text { whey (6\% TS) }\end{array}$} & \multicolumn{2}{c|}{ mg per 20g dried } \\
& $(1)$ & $(1)$ & $(2)$ & $(1)$ & $(1)$ \\
\hline \hline & 4,100 & 436 & 6,400 & 476 & 290 \\
Phosphorus (p) & 1,000 & 1,422 & 2,600 & 192 & 458 \\
Potassium (K) & 1530 & 344 & 4,300 & 334 & 30.5 \\
Calcium (Ca) & 94 & 137 & 60 & 14. & 30.5 \\
Magnesium (mg) & 436 & - & 1,100 & 14 & - \\
Sodium (Na) & \multicolumn{1}{|c|}{} & &
\end{tabular}

(1) Bayer, 1981

(2) Bectle \& Clayton 
is dried with the yeast. The high mineral content is due to the fact that whey minerals are included with the yeast when the whole broth is dried. The minerals not needed or assimilated by the yeast will remain in the broth. Thus the mineral concentration of the Kluyveromyces marxianus/whey product is more than double the standard levels (18-20\% versus $5-7 \%$ in washed yeast). This high mineral content could be reduced by washing the cells, but this would required extra processing, and the production of a waste water stream. It was suggested by Shay et al (1985) that the mineral content could be reduced by the addition of some further sugars to the broth such as sucrose, glucuse or corn syrup.

Other Nutrients; complex autrients such as yeast extract, malt extract, and corn steep liquor are suggested by a number of researchers, but the cost of these nutrients, particularly yeast extract, is high. Micronutrients such as niacin, biotin, and pantothenic acid are suggested by Shay and Wegner (1985). A table describing nutrient concentrations as determined by of a number of different researchers growing yeast was presented by Oura (1974).

\section{Oxygen.}

Supplying dissolved oxygen to the growing yeast is one of the most critical, and power consuming parameters involved with yeast production. Oxygen is only sparingly soluble in water, with a saturation level of $8.5 \mathrm{ppm}$ at $25^{\circ} \mathrm{C}(1.26 \mathrm{~mole} / \mathrm{l})$. Sugars and salts reduce this solubility further, with a $1 \mathrm{M} \mathrm{NaCl}$ solution reducing the saturation concentration of oxygen to $6 \mathrm{ppm}$ yeast will be met. As previously stated, when oxygen is available, the yeast will convert sugars using a respirative pathway, while if oxygen is absent, the sugar will be converted to ethanol. The dissolved oxygen level at which the organism has sufficient oxygen to respire or have its oxygen needs met is termed the critical oxygen value. Baily and Ollis (1977) list a critical oxygen value 
for yeast as $0.5 \%$ at $35 \mathrm{C}$, and $0.2 \%$ at $20 \mathrm{C}$. Yeast need trace oxygen even for anaerobic fermentation. Cysewski and Wilke (1978) shows that optimal fermentative ethanol productivity occurs at an oxygen tension of $0.1 \mathrm{~mm} \mathrm{Hg}$ or $0.06 \%$ of saturation (saturation oxygen tension would be $152 \mathrm{~mm} \mathrm{Hg}$. They also show that the sugar metabolism changes from fermentative to respirative at $1.7 \mathrm{~mm} \mathrm{Hg}$ (1.1\% of saturation) for a Saccharomyces type yeast. Other researchers (Von Stockar and Birou, 1989) show that there is no solvent production as long as even $0.5 \%$ dissolved oxygen (DO) is measured in the fermentaion broth, although yeild drops about $3 \%$ at $0.5 \%$ DO compared to higher DO levels. Moresi et al (1990) show good biomass yields at DO of $0.5 \%$, although yeilds drop when feed rates are higher than the oxygen supply capabilities of the reactor. (I would suspect that the DO readings are not too accurate, i.e. $0.5-2 \%$ may have been nearer to zero). Therefore, critical oxygen values for $K$. fragilis would seem to be in the range of $0.5-1 \%$,so that as long as DO levels in the fermentation broth are held at $1 \%$ or higher, all oxygen needs of the cells are satisfied for the respirative oxidation of sugars.

Oxygen is generally introduced to a reactor through a gas sparger, with a turbine used to help break-up the bubbles and improve mass transfer of oxygen with-in the bubble to the fermentation broth. There is a large body of information on the oxygen transfer capabilities for this sort of standard 'chemostat' bio-reactor. Oxygen transfer as a function of gas flow rates and turbine speed are developed for each reactor so as to be able to provide the required oxygen to the cells. Oxygen transport is often a limiting factor on yeast growth. Actively growing yeast may require $0.3 \mathrm{~g} \mathrm{O} / \mathrm{hr}^{*} \mathrm{~g}$ cell, while the dissolved oxygen saturation in air is only $6.9 \mathrm{ppm}$. Thus an actively respiring yeast cell density of $20 \mathrm{~g} / 1$ will require about $6 \mathrm{~g} / 1^{* h}$, so that the $6 \mathrm{ppm}$ available in the original broth will need to be replaced 1,000 times within that hour (in fact an oxygen 
saturation of about 20-50\% will probably be reached, so that actual replacement times are probably 2,000-5,000 per hour). Wasserman (1960) reported a maximal oxygen utilization rate of 8 $g / \Lambda^{*} h r$ in the batch fermentation of whey, but noted that a Waldorf type aerator could only provide $4.8 \mathrm{~g} /$ *hr on a continuous basis. The ability of a reactor to provide the oxygen to the cells is described as:

$$
Q_{O 2}=k_{1} a\left(c_{O 2}^{*}-c_{O 2}\right)
$$

where $k_{l}$ is the mass transfer coefficient, $a$ is the gas-liquid interfacial area, and $c_{O 2}$ is the concentration of oxygen in the liquid. $K_{l} a$ values are often combined into a single value. Blakesbrough \& Morresi (1981) show $k_{l} a$ values of $200-1200 \mathrm{hr}^{-1}$ for a conventional sparged stirred bioreactor. This would corespond to an oxygen transfer rate of between 1 and $6 \mathrm{~g} / \mathrm{hr}$ based on 20\% DO maintained in the reactor. Moresi et al. (1990) show that the limits of their laboratory fermenter for oxygen transfer was about $4 \mathrm{~g} / \mathrm{khr}$, as once the sugar feed rate went above 8 $\mathrm{g} / \AA^{*} \mathrm{hr}$, the ability of the reactor to utilize the sugar drops. Wasserman and Hanson (1960) determined an oxygen transfer effectiveness of a number of turbine types and got rates of oxygen transfer ranging between 2 and $12 \mathrm{~g}$ of oxygen $/ * \mathrm{hr}$. This compares to a maximal batch oxygen utilization rate of $9.6 \mathrm{~g} \mathrm{O} / 1 * \mathrm{hr}(5 \mathrm{~mole} / 1 * \mathrm{~min})$ for high rate yeast growth.

The net oxygen demand for yeast growth has been calculated by a number of researchers. Moresi et al. (1990) (Eq. 2) determined a yield ( $\mathrm{Y} \times / 0$ ) of about $1 \mathrm{~g}$ yeast per $\mathrm{g}$ oxygen consumed. This corresponds to a $\mathrm{Y}$ o/s of $0.6 \mathrm{~g} 02$ per gram sugar metabolized. Muo-Young (1975) show a $\mathrm{Y}$ o/s of about $.45 \mathrm{~g} O 2$ per $\mathrm{g}$ sugar. Wasserman (1960), using a Warburg respirometer, determined that 150 micoliters of oxygen were utilized to consume $500 \mathrm{mg}$ lactose, while on a lab scale reactor it was determined that 12 to 14 liters of oxygen were required to convert one liter of single strength acid whey ( $48 \mathrm{~g} /$ lactose, $5 \mathrm{~g} /$ lactic acid). This is $17 \mathrm{~g}$ of 
oxygen per $55 \mathrm{~g}$ carbohydrate, or a $\mathrm{Y}$ o/s of $.31 \mathrm{~g} 02$ per $\mathrm{g}$ sugar.

Shay and Wagner (1985), developed a reactor with very high 02 transfer capabilities which allowed the production of up to $35 \mathrm{~g}$ yeast $/ *$ hr. This means that the oxygen transfer capabilities of this reactor are at least $35 \mathrm{~g} / \mathrm{I}^{*} \mathrm{hr}$, about 10 times higher than conventional sparged, stirred reactors. This mass transfer ability was attained by the enriching of the air sparged in oxygen. With this new technology reactor $22 \mathrm{~g} /$ *hr cells were able to be produced with un-enriched air, which corresponds to $22-25 \mathrm{~g} / \mathrm{A} \mathrm{hr}$ of $\mathrm{O2}$, still $5-6 \mathrm{X}$ better than conventional reactors.

\section{Power Utilization}

Obviously, oxygen transfer is critical to yeast growth. In conventional reactors, the gas is sparged into the bottom of the reactor below an agitator. Power requirements for air compression and stirring are large. A higher aeration rate and stirring velocity improve mass transfer, however, these inputs require more energy. Blakesbouragh and Moresi (1981) show $k_{l} a=9.5 \times 10^{-3} * N^{1.76} * V_{s}^{32}$ where $\mathrm{N}$ is $\mathrm{RPM}$ and $V_{s}$ is the superficial air velocity in the reactor (air sparging rate). Similarily, Vogel (1983) shows that oxygen transfer of $2.3 \mathrm{~g} / \mathrm{1}^{* \mathrm{hr}}$ can be attained in a stirred, sparged fermenter with an gas rate of 5.3 VVM, at a power input to the propeller of $2 \mathrm{HP} / 1000 \mathrm{gal}$, while if the power is increased to $4 \mathrm{HP} / 1000 \mathrm{gal}$ (higher prop speed), an oxygen transfer rate of $5.4 \mathrm{~g} / 1 * \mathrm{hr}$ can be reached. Air compression costs must then be added. To add air to a 30,000 gallon fermenter with an H/D ratio of 3, a $350 \mathrm{HP}$ compressor is required. Total energy requirements to run this tank are thus about $470 \mathrm{HP}$, if an 02 transfer rate of 5.4 $\mathrm{g} / \mathbb{A}^{\mathrm{hr}}$ is desired.

Finally, yeast growth, stirring and air compression generate heat, so the fermenter must be 
designed to remove large amounts of heat. Heat removal coils must be mounted in the fermenter to remove the heat energy. These coils add to capital cost of the reactor, and the cooling water needs increase operating costs.

High energy costs associated with aeration and stirring, along with high capital costs required for yeast fermenters, yeast separation (centrifuges) and drying (roller or spray), cause the cost of yeast production to be high. Maiorella and Castillo, 1984, in an economic analysis of yeast production from whey permeate, calculated the profit per pound of yeast produced from whey permeate to be approximately negative $\$ 0.53 / \#$ assuming yeast paste could be sold wet at $\$ 0.22 / \%$. In other words, yeast production was a losing proposition (based on their analysis) even without incurring the expense of drying the yeast. 


\section{Process Improvements}

The costs associated with making yeast could be reduced by:

a) reducing the cost of the fermenter

b) reducing the energy costs associated with stirring,

c) reducing the capital and energy costs associated with cooling

d) reducing the capital and energy costs associated with aerating (oxygen transfer) in the bioreactors

e) making high concentrations of yeast which can then be dried with the broth, eliminating both the need for yeast separation and the generation of large volumes of waste water.

Shay et al. ( 1985,1987$)$ with their efficient reactor showed that it was theoretically possible to produce yeast at very high concentrations, and thus meet the goal e) as listed above. However, their reactor is expensive to build and operate, and the power input and cooling requirements are high. By moving to a CSTR type reactor, Shay et al. were able to achieve a nearly constant yeast production yield $(\mathrm{Y} \times / \mathrm{s})$ of 0.45 , an efficiency of $75 \%$ (based on a theoretical max of $0.6 \mathrm{~g}$ cells $/ \mathrm{g}$ sugar) which is nearly as good as anyone has reported even at low feed concentrations (Table 1). In a CSTR type reactor, substrate concentration is held low. When yeast see high concentrations of sugars/salts, cell mass yields drop and ethanol/solvent production increases. Mahmoud and Kosikowski (1982), show yields ( $\mathrm{Y}$ x/s/0.6) of between 6 to $13 \%$ efficiency with 3 to $6 \%$ ethanol produced when a $30 \%$ demineralized whey permeate solution was aerobically fermented.

Proposed Reactor Design- A gas continuous, immobilized cell yeast generator has been conceptualized. Dale et al, (1991) suggested the use of this sort of reactor for the reduction of dairy 
waste water BOD for low level multiple substrate feeds ( lactose, ethanol, lactic acid, and glycerol). Under the sponsorship of WMOMB, Dale has been continuing the development of this work, and has a $\mathrm{Ph}$. J student actively developing the system currently (Salicetti et al, 1992). W. Harris of Kenyon Enterprises, saw that this reactor technology might also be applicable to yeast production from concentrated sugar streams.

Harris and Dale have collaborated on this project, developing a gas continuous Immobilized Cell Yeast Reactor (ICYR). A basic sketch of an ICYR is shown in Figure 1 which shows the design flows and power inputs to a 10,000 liter ICYR unit. As per Figure 1, this unit has an estimated yeast production rate of $10-15 \mathrm{~g}$. yeast/ liter*hr, leading to the production of $100 \mathrm{Kg}$ of yeast/hr $(220 \# / \mathrm{hr})$ with $140 \mathrm{Kg} / \mathrm{hr}(308 \# / \mathrm{hr})$ of dry yeast/mineral product coming off a dryer behind the ICYR. Total power requirements for liquid recycling and air delivery are only 4 HP, for a energy cost of $\$ 0.0005 / \#$ dry product. This compares to an energy cost of $\$ 0.065 / \#$ for electricity and cooling water as determined by Maiorella and Castillo (1984) for a conventional yeast fermenter. Thus the ICYR is able to reduce energy requirements for yeast production by a factor of over $100 \mathrm{X}$.

This ICYR design has the following advantages over conventional yeast production:

1. elimination of cooling water requirements- no cooling tower, no cooling coils, etc. Cooling requirements are snet by the inlet air stream; the temperature of the reactor is easily controlled by reducing the temperature or RH of the inlet air.

2. elimination of the need for a high pressure air compresscr-for this size reactor, nominally a 40 HP positive displacement air compressor would be required, instead, a one HP low pressure centrifugal blower can provide all the air needed for the ICYR. 

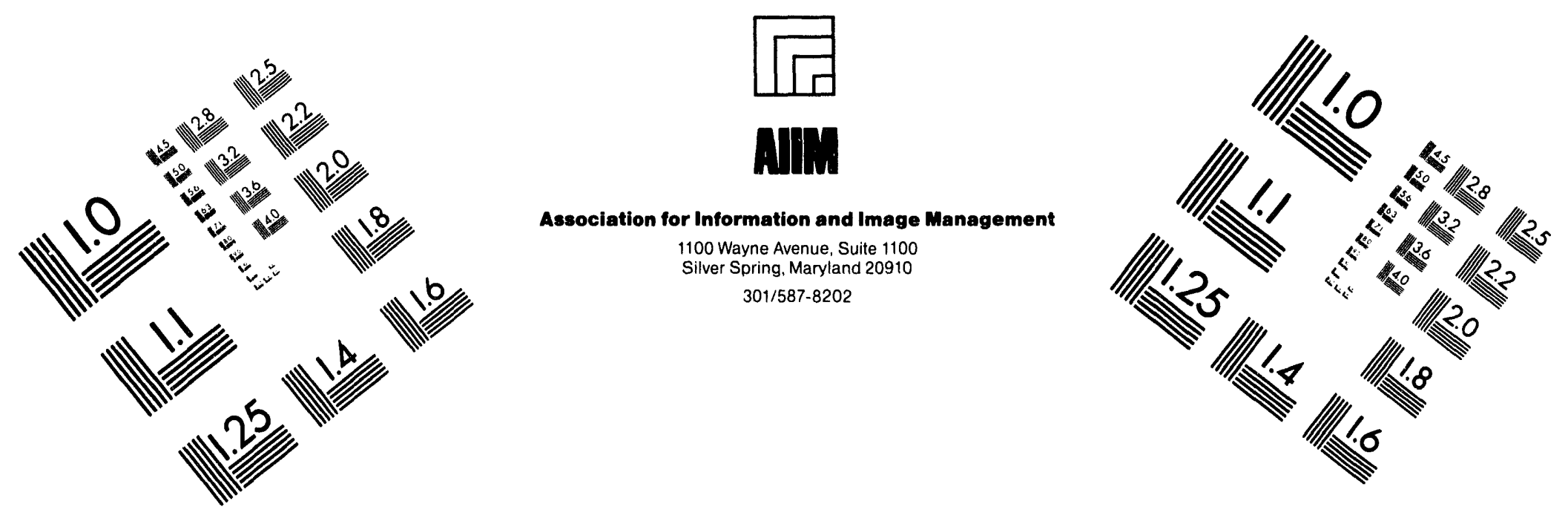

\section{Centimeter}

$\begin{array}{llllllllllllllll}1 & 2 & 3 & 4 & 5 & 6 & 7 & 8 & 9 & 10 & 11 & 12 & 13 & 14 & 15 & \mathrm{~mm}\end{array}$

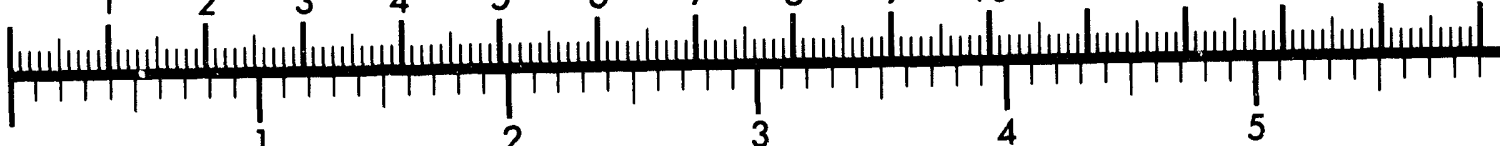
Inches

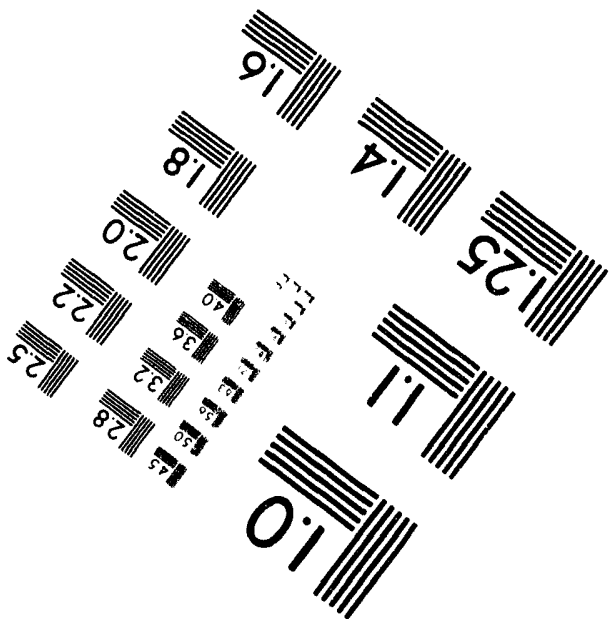

MANUFACTURED TO AIIM STANDARDS

BY APPLIED IMAGE, INC.

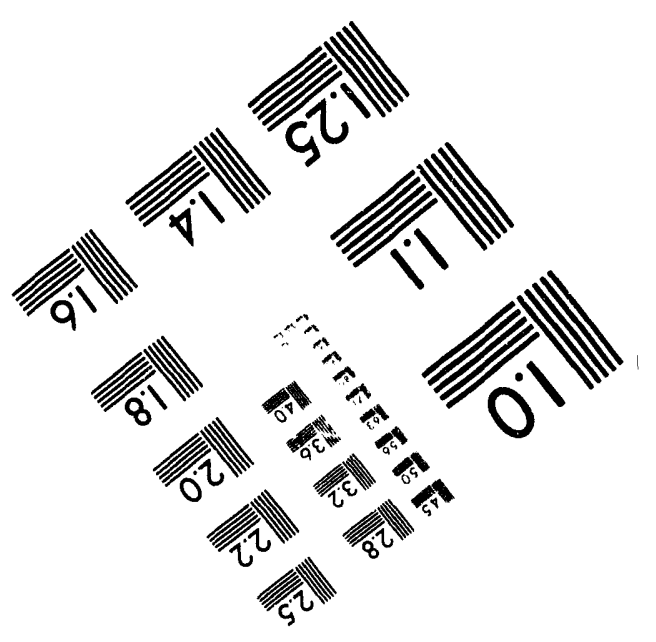



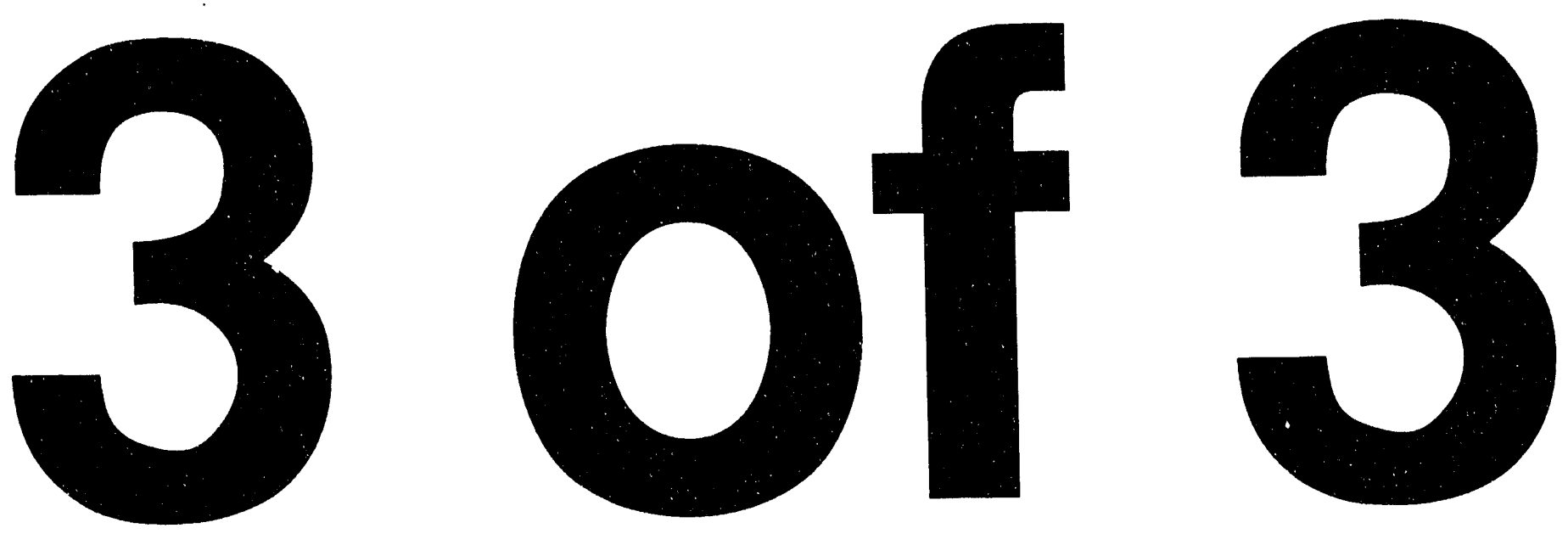


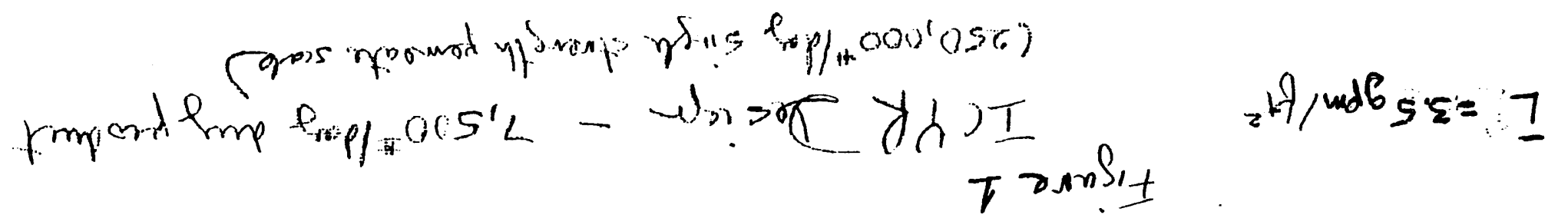

syortim $e_{x /} b 50$ ?

sinh $\left.e_{\lambda} \mid b_{001}\right\}$

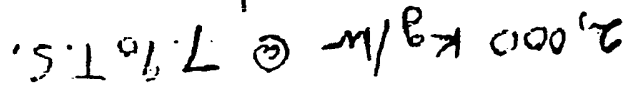

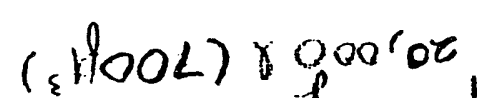

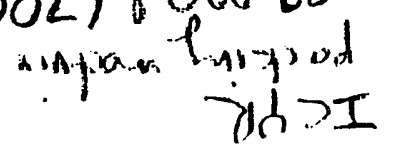

$=b / 1 / a$

rinu

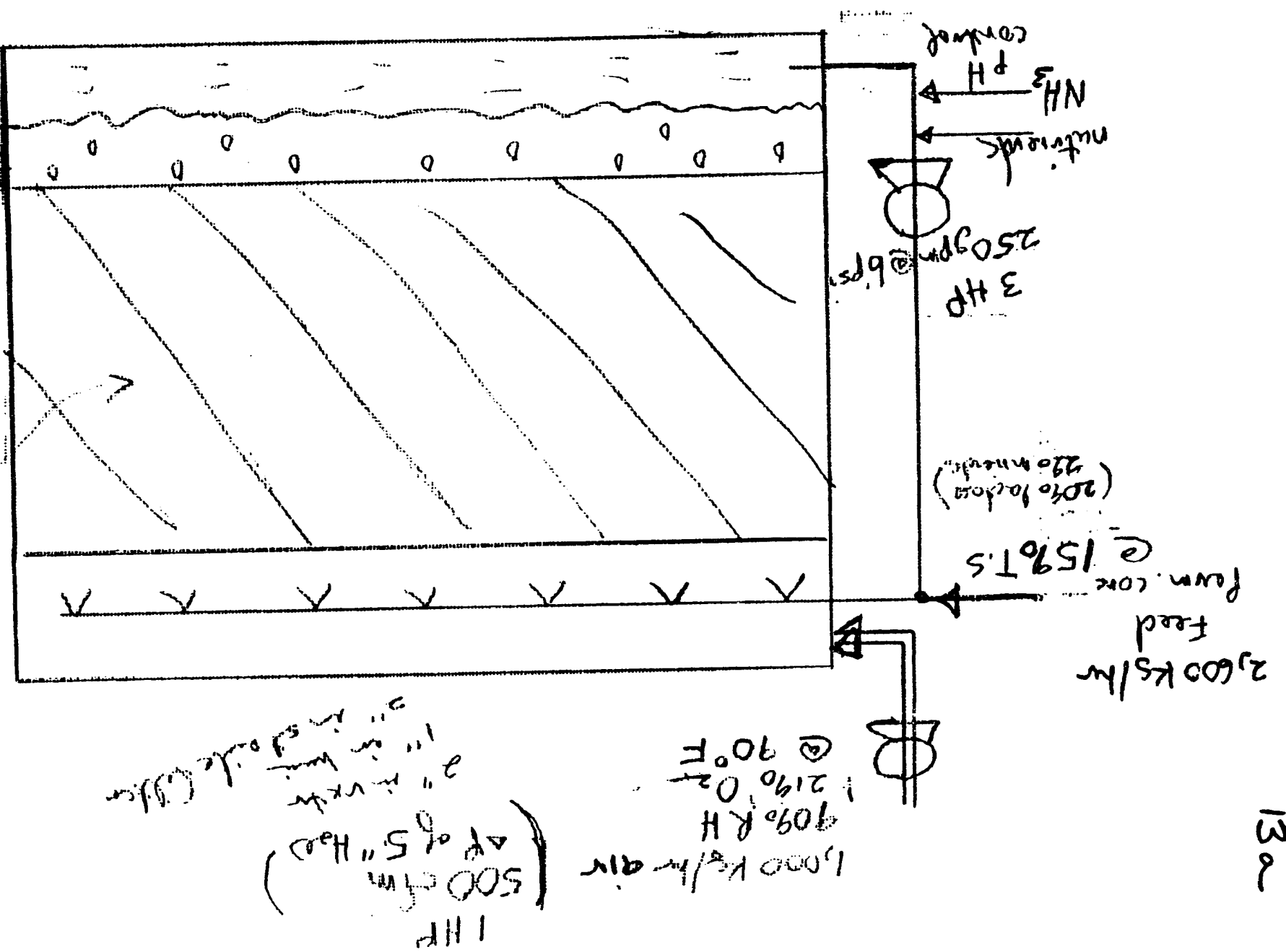


3. elimination of agitation requirements, in a conventional fermentor, a $12 \mathrm{HP}$ stirrer would be used, while for the ICYR, a 3.0 HP pump can recirculate the yeast broth to provide a 3.5 GPM/ft2 circulation rate.

4. elimination of centrifugal cell harvesting. Centrifugal yeast separators are both expensive to purchase and require large motors. By moving to a concentrated feed, no centrifuge is required, as the cell broth is highly concentrated in yeast within the reactor. Nominally, a centrifuge can give a 15 to $18 \%$ solids yeast cream, while the ICYR, with no centrifuge should give a $14 \%$ solids yeast cream.

5. elimination of waste water generation. The process suggested concentrates all the yeast broth, including the whey minerals and other trace compound. If a centrifuge is used, the clear broth separated from the yeast will be a waste water stream, with a BOD of $6-8,000$ ppm- high in phosphates and calcium, which will have to be treated in an on or off-site waste water treatment facility. This compares with the ICYR where the only output from the system is $\mathrm{CO} 2$. The product stream is high in minerals $(18-20 \%)$ making the product somewhat different from a standard 'washed yeast' product (5-7\% minerals).

The elimination of all these auxillary components normally associated with yeast production can reduce capital requirements by a factor of 10 for the ICYR system, and total energy requirements by a factor of 3 (drying the yeast still requires heat input) as compared to normal yeast production. We are thus quite optimistic about this technology allowing the profitable production of yeast from whey permeate. Oxygen transfer is accomplished by the air flowing down between the plates containing immobilized cells. Preliminary design of plate spacings gives a mass tranfer area of $450 \mathrm{~m} 2 / \mathrm{m} 3(0.45 \mathrm{~m} 2$ per liter of packed reactor volume), this compares well 
to a stirred agitated bioreactor with $2.5 \mathrm{~mm}$ average bubble size, and an air hold up of 100 milliter which gives a mass transfer area of $0.24 \mathrm{~m} 2$ per liter. Oxygen mass transfer rates of between 10 and $25 \mathrm{~g} / 1^{*} \mathrm{hr}$ are expected, which would translate to a yeast production rate of 10 to $25 \mathrm{~g} / 1^{* h \mathrm{hr}}$. The lower value, $10 \mathrm{~g} / \AA^{* \mathrm{hr}}$, was used in our calculations.

Kenyon Enterprises built and operated a test 200 liter ICYR during November and December with design, equipment, monitoring and operational consulting input from Dale at Purdue. This test successfully demonstrated that:

1. the reactor could be run continuously for extended periods of time under non-sterile conditions and still produce only the desired product.

2. reactor cooling and temperature stability could be easily regulated by the saturated air temperature inlet to the system.

3. stable, low maintenance, low labor operation was demonstrated.

Unfortunately, yields (gram yeast/gram lactose utilized) were not particularly good based on preliminary analyses. A very high level of whey solids (35-40\%) was fed for much of the tests, which was then concentrated further by the addition of nutritive salts, resulting in a high solution osmolality. This high osmolality tends to move the fermentation towards ethanol production rather than yeast production as discussed previously. It is also possible that oxygen transfer may have not been adequate as rather low DO readings were noted. (Oxygen transfer capabilities of the system must be matched with the feed rate. Feed sugar rates higher than the maximum oxygen transfer rates will lead to anaerobic conditions and solvent production.) 


\section{Lab Scale ICYR Results}

A $600 \mathrm{ml}$ ICYR was built as per the diagram in Figure 2. This reactor has been undergoing continuous testing since June of 1992 . It has been run using various concentrations of whey permeate and nutritional supplements. For the first 4 months of operation (June through Nov.), the nutrional supplements suggested by Wasserman $(5 \mathrm{~g} / 1$ potassium phosphate, $10 \mathrm{~g} / \mathrm{l}$ ammonium sulfate, and $1 \mathrm{~g} / 1$ yeast extract per each $50 \mathrm{~g} / 1$ whey solids in the feed) were used. Yeilds at high solids were not particularly good. It was possible to utilize the lactose, but yeast solids as determined by optical density were much lower than would be expected based on a expected value of 0.48 yeild $(\mathrm{Y} x / \mathrm{s})$. It was decided, based on the low yields, that high solution osmolality was probably contributing to production of solvents rather than cells. Adding the nutrients as salts (NH4SO4 and $\mathrm{K} 2 \mathrm{HPO} 4)$ was increasing the net osmolatity of the solution. Therefore, we moved to adding ammonia as ammonium hydroxide, with the addition being controlled by a $\mathrm{pH}$ controller. The addition rate was monitored by weighing the bottle. A trace mineral supplementation as suggested by Shay and Wenger (1986) and Bayer (1981) was implemented with ammonia delivered as either a $\mathrm{pH}$ control or added to the feed. Phosphoric and sulfuric acid were added as suggested by Shay and Wenger (1986).

A feed concentration of $5 \%$ was fed until a yeild of .48 was obtained (effluent cell density of $22 \mathrm{~g} / 1$ ), after which the feed strength was increased to $10-12 \%$ solids ( $100 \mathrm{~g} / \mathrm{l}$ lactose). This system has been run on a continuous basis since Dec. 17th. The yeild over time is shown in Figure 3. It can be seen that yeilds varied between .1 and .45 , with average yeilds of between .2 and .3 noted. Cell density over time (Figure 4) follows closely the performance shown in Figure 3, with higher cell densities corresponding to higher conversion efficiencies. Oxygen levels were 
$16 a$

$2 / 502$

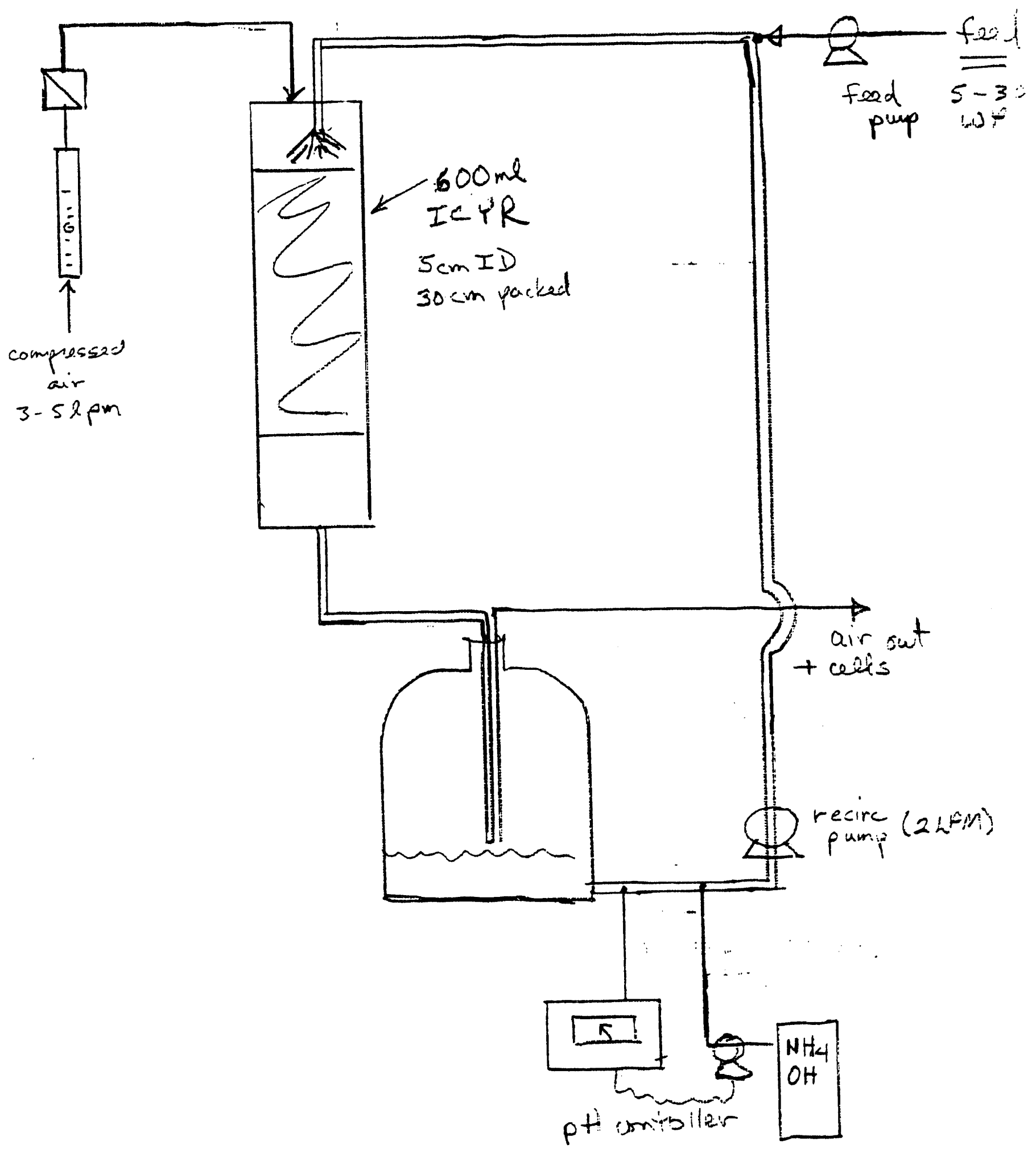


Yeast Conversion Efficiency vs. Time

Initial Lactose Feed Conc. $=100 \mathrm{~g} /$

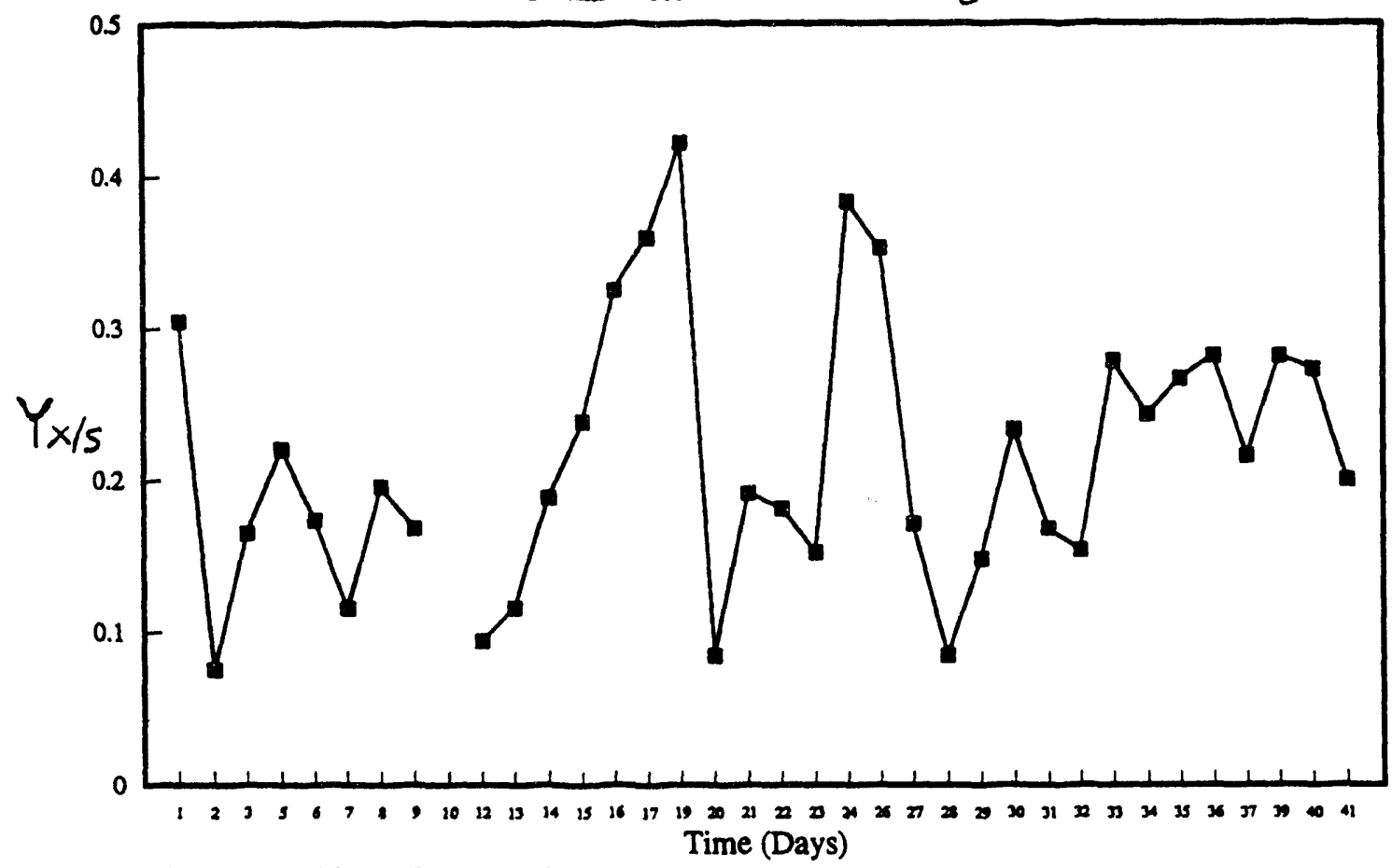

Lactose Utilized $=$ Cell Mass/In. Lactose Feed Concentration

-Initial Lactose Conc. $=200$ gl from Day 20 to 23 
Cell Mass ( $g / l)$ vs. Time (days)

Initial Lactose Feed Conc. $=100 \mathrm{~g} /$

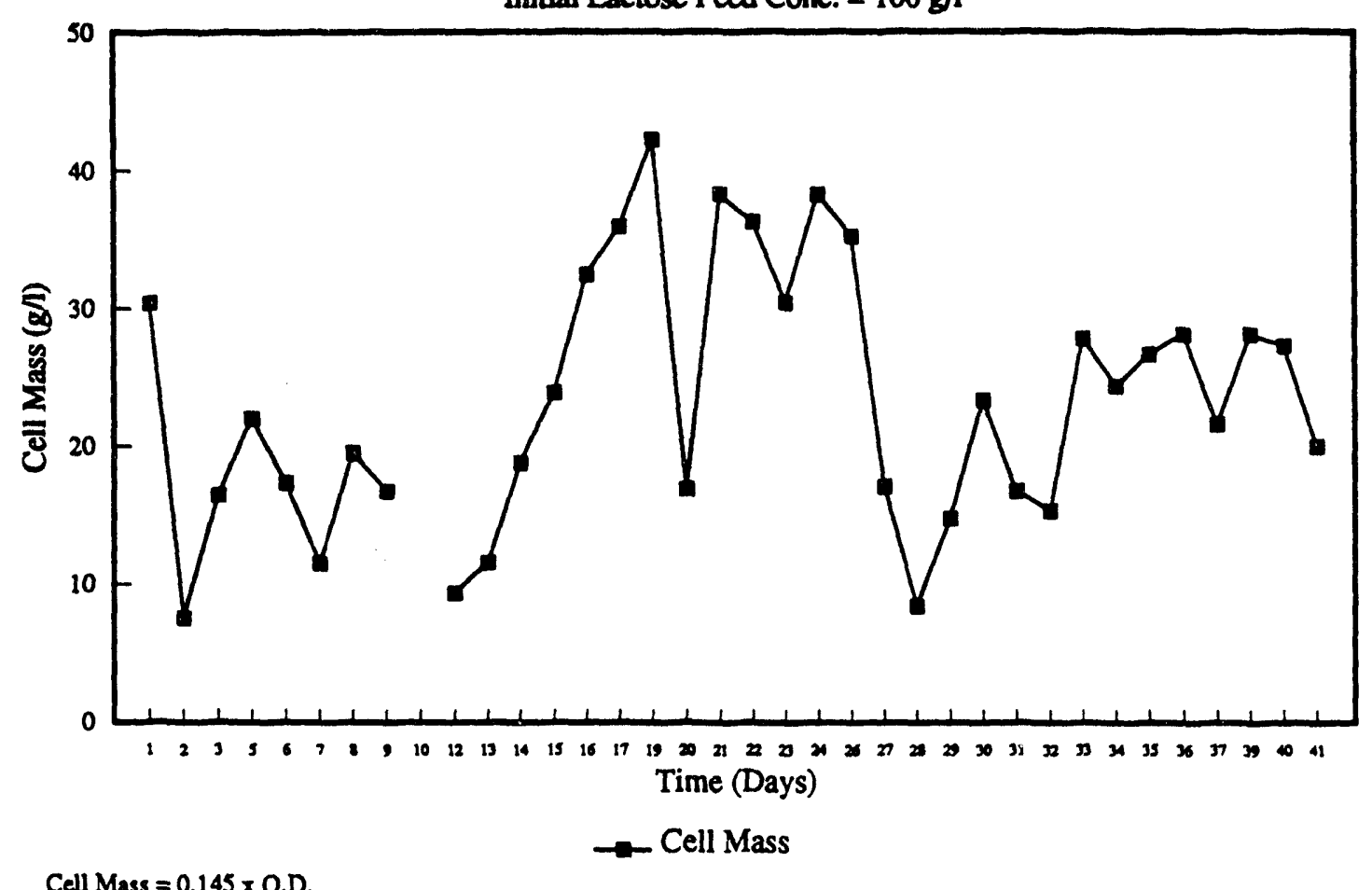

Cell Mass $=0.145 \times$ O.D.

*Initial Lactose Conc. $=200$ \& 1 from Day 20 to 23 
Net Cell Mass Product ( $\left./ / /^{*} h r\right)$ vs. Time (days) Initial Lactose Feed Conc. $=100 \mathrm{~g} /$

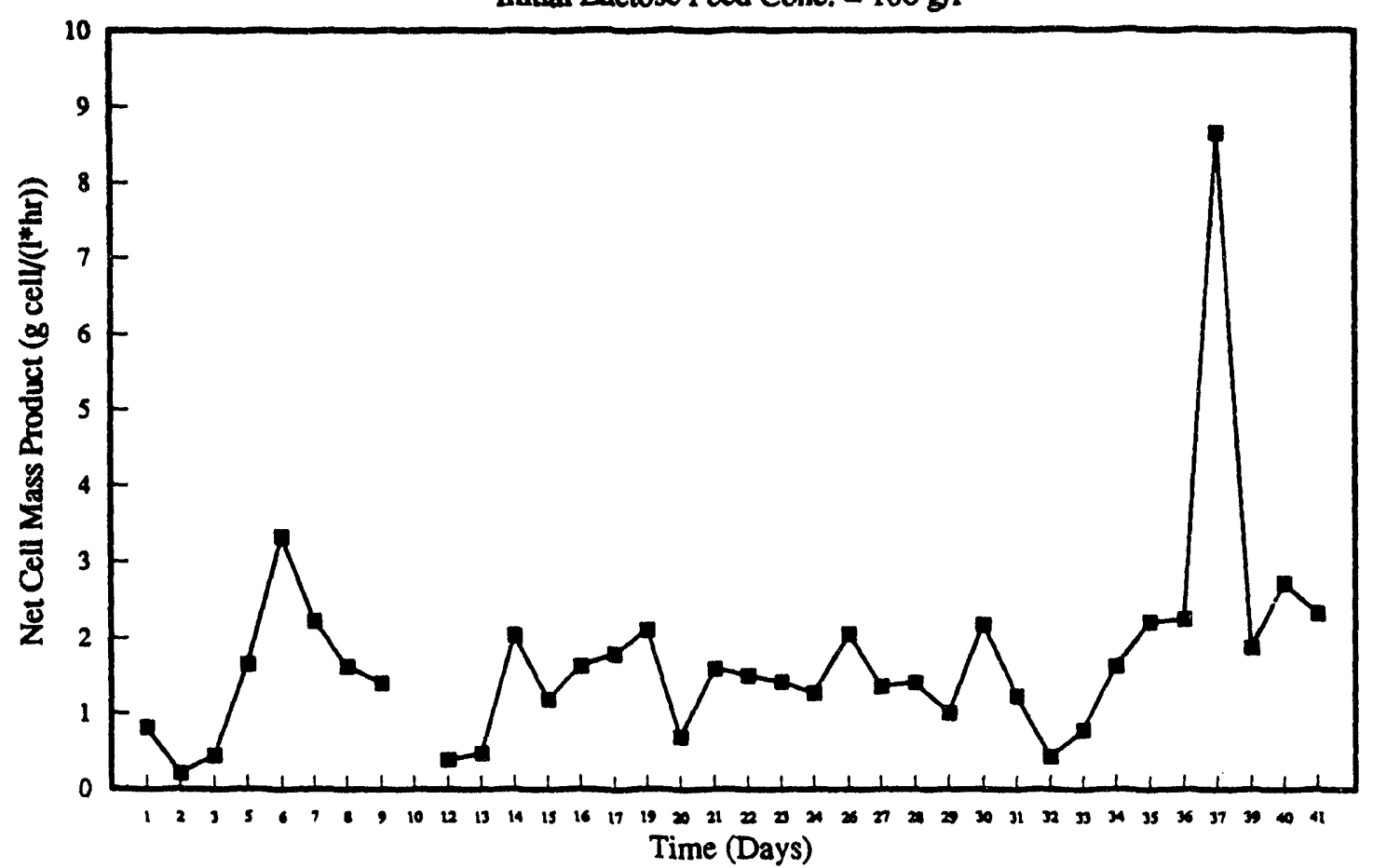

Net Cell Mass Produca $=($ Cell Mass $\times$ Flow Rate) .600

Inicial Lactose Conc. $=200 \mathrm{~g} /$ from Day 20 to 23 
checked, and tended to fall between 15 and $35 \%$ of saturation. Lower conversion efficiencies were obtained when the solids level was raised to $20 \%$ on day 20 . Even the actual cell density dropped as seen in Figure 4. We are currently feeding a $20 \%$ feed, but are not getting particularly good conversion ratios. The experiments to date seem to indicate that quantitative yeilds of better that 0.4 can be obtained using our reactor and strain 2415 of $\mathrm{K}$. fragilis at feed concentrations of up to $12 \%$ solids, but that higher feed concentrations do not allow good yeilds. This is contrary to the results determined by Shay and Wenger (1986) who state that feeds of up to $30 \%$ solids gave good $(0.45)$ conversion efficiencies. This work is continuing, with some experiments on yeild as a function of feed osmolality being performed along with operation of the $600 \mathrm{ml}$ test reactor with $20 \%$ feed.

The actual productivity of the reactor is shown in Figure 5, and we see that yeild of yeast range from 0.5 to $3.5 \mathrm{~g} / \mathrm{l}-\mathrm{hr}$, with one point of $9 \mathrm{~g} / \mathrm{l}-\mathrm{hr}$ being determined. In general, we were more interested with complete lactose utilization than high rate conversions, as higher throughput means having to prepare feed more often. We would predict rates of 2 to $10 \mathrm{~g} / \mathrm{l}$-hr for this reactor system if lactose levels of greater than $0.5 \%$ are maintained.

Discussion-Geic and Kosikowksi (1982) show yields dropping from $0.15 \mathrm{~g}$ yeast/g lactose at $40 \mathrm{~g} /$ lactose to $0.09 \mathrm{~g} / \mathrm{g}$ at $115 \mathrm{~g} /$ lactose in whey permeate solutions. Beausejour et al (1981) show the generation of solvent metabolites when a single strength whey was aerobically fermented with a yield of $0.25 \mathrm{~g}$ cells/ $\mathrm{g}$ lactose obtained. Marison (1987) shows ethanol being generated even when DO is maintained at $80 \%$ during the batch fermentation of whey. Based on the literature a 3 to $5 \%$ whey permeate solution is probably the maximum which will allow 'pure' aerobic respiration leading to cell growth. Based on osmotic studies by Dale et al, 1990, 
$3-4 \%$ WP corresponds to a total solution osmolality of $0.13-0.17 \mathrm{os} / \mathrm{kg}$. Whey minerals contribute an osmolality of about $0.04-.06 \mathrm{os} / \mathrm{kg}$ for single strength whey permeate (6.0\% TS), which would indicate that at $4 X$, or $24 \%$ solids, the whey minerals alone will be responsible for a solution osmolality of $0.16-0.24 \mathrm{os} / \mathrm{kg}$. Shay et al. (1987) however, state they obtained constant 0.45 $\mathrm{g} / \mathrm{g}$ yields up to a feed concentration of $30 \%$ whey permeate solids in a CSTR type reactor. At $30 \%$ solids, whey minerals will be contributing to a total solution osmolality of $0.27 \mathrm{os} / \mathrm{kg}$, so apparently respirative metabolism (with the strain of yeast used by these researchers) was maintained up to at least this osmolality. (Some of the yeast minerals are metabolized or consumed by the yeast, as the yeast tends to have an internal mineral content of $5-7 \%$, suggesting that of the total $18 \%$ minerals in dried whey/yeast, $11-13 \%$ are free minerals which are contributing to the solution osmolality. Thus actual solution osmolality due to whey minerals may be reduced by $33 \%$ due to mineral uptake by the yeast. This would reduce the osmolality of the minerals remaining in Shay et al.'s $30 \%$ feed from $0.27 \mathrm{os} / \mathrm{kg}$ to 0.18 , which is below the suggested maximal osmolality of $0.24 \mathrm{os} / \mathrm{kg}$ suggested in this report as a limit below which there can be 'pure' respirative sugar utilization, with no production of solvents). We intend to test a few different strains of yeast (K. marianus) to determine the effect of osmolality, but the experiments to date are quite positive, and the ability of this reactor to produce a mineral yeast stream from $10-12 \%$ whey permeate is well documented.

\section{Acknowledgements}

This study was run with the able assistance of Mark Moelhman in running and adapting the ICYR over the last few months. Mr. Moelhman also took charge of feed preparation and data collection. Lorenzo Salicetti's assistance in assembling a large volume of background literature 
on yeast production is appreciated. The help of Jennifer Phifer in operating the ICYR and preparing the graphs and data analysis from the reactor is also appreciated. Financial support from the Wisconsin Milk Marketing Board as relayed by Kenyon Enterprises is acknowledged. 


\section{REFERENCES}

1. Barnes, M. 1977. "Growth of Yeast on Whey and Thier Effectiveness for Protein Metabolism." N.Z. J of Ag Res 19:537

2. Bayer, K. 1983. "Trace Element Supplementation of Cheese Whey for the Production of Feed Yeast." J. Dairy Sc. 66:214

3. Baily, J. and D. Ollis. 1977. "Biochemical Engineering Fundamentals". McGraw Hill.

4. Beausejour, D., A Leduy and R. Ramalho. 1981. "Batch Cultivation of K. fragilis in Cheese Whey. Can J ChE 59:522

5. Bechtle, R. and T. Clayton. 1972. "Accelerated Fermenation of Cheese Whey." J. Dairy Sci 54 11:1595

6. Bernstein,S. and T. Everson. 1973. "Protein Production from Acid Whey via Fermentation." Food Processing Waste Management Conf.

7. Berstein, S, C. Tzeng, and D. Sisson. 1977. "Conversion of Cheese Whey to Protein and/or Alcohol." Biotech. Bioeng. Symp. 7:1

8. Birou, B. and U. von Stockar. 1989. "Application of bench-scale Calorimetry to chemostat Cultures." Ensy Micro Tech 11:12

9. Blakebrough,N. and M. Moresi. 1981. "Modeling of Process Yeilds of a Whey Fermentation." Eur J App Microb Biot 13:1

10. Dale, M.C., A. Eagger, and M. Okos. 1990. "Osmolality Effects on Free and Immobilized $K$. marxianus Growth and Productivity in Whey Permeate Concentrate. AICHE Paper 286b, Chicago.

11. Dale, M.C., L. Saliceti, B Truax, and M Okos. 1991. "Lactic Acid Conversion to SCP." ASAE paper \#91-6585.

12. Giec, A. and K. Kosikowski. 1982. "Activity of Lactose Fermenting Yeast in Producing Biomass form Conentrated Whey Permeates." J. Food Sci 47:1892

13. Harris, W., 1992. "Production of Yeast in an Immobilized Cell Yeast Reactor. WMMB Report.

14. Mahmoud, M., and F. Kasikowski. 1982. "Alcohol and Single Cell Protein from Whey." J. Dairy Sci. 65 11:2082

15. Maiorella, B. and F. Castillo. 1984. "Ethanol, Biomass, and Ensyme Production from Whey." Proc. Biochem Aug: 157

16. Marison, I, and U. van Stockar. 1987. "A Calorimetric Investigation of the aerobic Cultiviation of $\mathrm{K}$. fragilis on various Substrates". Enz Micro Tech 9:33.

17. Mansour, M., R. Ben-Hassan, and A. Ghaley. 1991. "Modeling of $K$. fragilis growth in Cheese Whey. ASAE paper\# 916597 
18. Michel, M, F. Jacob, F perrier, and SS. Poncet. 1987. "Yeast Production from Crude Sweet Whey." Biotech Bioeng 30:780

19. Moresi, M. A. Trunfio, and E. Parente. 1990. "Kinetics of Continuous Whey Fermentation by K. fragilis." J Chem Tech Biotech 49:205

20. Moresi, M., M. Patele, and A. Trunfio. 1989. "Scaling-up of a batch Whey Fermenation by $K$. fragilis.

21. Moulin, G., B. Malige, and P. Galzy. 1983. "Production of Yeast from Whey using Balanced Flora in an Industrial Fermenter." J. Dairy Sci 66:21

22. Oura, E., 1974. "Effect of Aeration Intensity on Baker's Yeast: Factors Affecting Metabolism." Biotech Bioeng 14:1197

23. Pace, G, and D. Goldstein. 1978. "Economic Analysis of UF/SCP from Cheese Whey." Chapt. 15. Yeasts.

24. Porges, N., J. Pepinski, and L. Jasewicz. 1951. "Feed Yeast from Dairy By-Products." J. Dairy Sci. 34:615

25. Salicetti, L., M.C. Dale, M. Moelman, M. Okos, and P. Wankat. 1992. "Free and Immobilized Yeast for BOD reduction of Dairy Wastes." AICHE paper 165k.

26. Shay, L.K. and G. Wegner. 1986. "NonPolluting Conversion of Whey Permeate to Food Yeast Protein." J. Dairy Sci 69:676

27. Shay, L.K. and G. Wegner. 1985. "Improved Fermenation Process fro Producing Torula Yeast." Food Tech. Oct:61

28. Shay,L., H. Hunt, and G. Wegner. 1987. "High-Productivity Fermenation Process for Cultivating Industrial Microbes." J. Ind Microb 2:79

29. Wasserman, A., J. Hampson, and N. Alvare. 1961. "Large Scale Production of Yeast in Whey." J WPCF 33:10 1090.

30. Wasserman, A., W. Hopkins, and N. Porges. 1959. "Rapid Conversion of Whey to Yeast." Proc 15th Int Dairy Congr 2:1241

31. Wasserman,A. 1959. "Amino Acid and Vitamin Content of S. fragilis Grown on Whey." J. Dairy Sci. 44:379

32. Wasserman, A. 1960. "Availability of Whey Protein for Growth of S. fragilis. J. Dairy Sci 43:1231

33. Wasserman. A., J. Hampson, and N. Alvare. 1961. "Growth of S. fragilis in whey in a Pilot Plant." J. Dairy Sci 44:387

34. Wasserman, A. 1960. "Oxygen Requirments of S. fragilis Growing in Whey." Appl. Microb 8:291

35. Vananuvat, P. and J. Kinsella. 1975. "Production of Yeast Protein from Crude Lactose". J. Food Sci 40:336 


\section{Appendix 4.1}

Foods 


\section{FOODS - Food Operations Oriented Design System: \\ A Steady State Process Design and Analysis Program}

Progress Report - 3/15/94

\section{Summary:}

The overall goal of the FOODS project is to develop a user-friendly software package to aid in the design and analysis of food processing systems. A multi-media package has been explored and rejected as a possible user-interface for the FOODS program. Similar programs designed for other industrial fields are currently being evaluated and compared to FOODS in order to generate ideas for improving and updating FOODS. A few unit operations are in the processes of being generalized and converted into the $\mathrm{C}$ programming language.

\section{Authorware $^{\mathrm{m}}$ Status:}

Authorware ${ }^{\text {tw }}$ is an object oriented Windows programming software package developed by Macromedia, Inc. A more detailed description of Authorware is enclosed. It came highly recommended as an environment in which to create a more user-friendly interface for FOODS. Further, it was suggested that the entire FOODS program be converted into the Authorware language which would thoroughly document the program and make adding new unit operations quite simple.

The first major limitation of the Authorware programming environment was discovered when we tried to construct a flowsheeting screen. We had envisioned creating a flowsheet screen in which unit operation icons could be randomly connected into processes. Due to Authorware's linear structure, branching was found to be impossible. That is, Authorware can only pass stream data from one unit operation to another along the primary stream; secondary streams could not be branched off for the construction of other processes.

A second major limitation was found after a number of the FOODS FORTRAN mathematical functions were reprogrammed in Authorware. It was discovered that the environment has only a single one-dimensional array. Attempts to overcome the array limitation can be seen in the function enthc.f (Appendix A). All array elements were made into variables. The number of variables that would be created in converting FOODS to Authorware would quickly exceed Authorware's capacity.

Authorware's is primarily a multimedia tool for interactive learning. While the Authorware environment has been found to be incompatible with the goals for FOODS, it does offer excellent potential for individual instruction. Tutorials covering such topics as unit operations, economics and optimization can be programmed to complement the FOODS program. 
Table 1. Broad characterization of computer-aided design packages.

\begin{tabular}{|c|c|c|c|}
\hline Property & FOODS & ASPEN PLUS & BIOPRO \\
\hline $\begin{array}{l}\text { Input/Output General: } \\
\text { Units } \\
\text { Language } \\
\text { Modes of Operation } \\
\end{array}$ & $\begin{array}{l}\text { Eng. } \\
\text { FORTRAN } \\
\text { Continuous } \\
\end{array}$ & $\begin{array}{l}\text { Eng.; SI; Mix } \\
\text { FORTRAN } \\
\text { Continuous } \\
\end{array}$ & $\begin{array}{c}\text { SI } \\
\text { C } \\
\text { Batch \& Cont. }\end{array}$ \\
\hline $\begin{array}{l}\text { Input: } \\
\text { Type }\end{array}$ & & $\begin{array}{l}\text { Flowsheet; Menu; } \\
\text { ASPEN language }\end{array}$ & Flowsheet; Menu \\
\hline Change while entering & no & yes & yes \\
\hline $\begin{array}{l}\text { Reload \& change } \\
\text { Problem Definition }\end{array}$ & $\begin{array}{c}\text { no } \\
\text { yes; } 70 \text { characters }\end{array}$ & $\begin{array}{l}\text { yes } \\
\text { yes }\end{array}$ & $\begin{array}{c}\text { yes } \\
\text { no }\end{array}$ \\
\hline $\begin{array}{l}\text { Material Stream Specs: } \\
\text { Flow } \\
\text { Breakdown }\end{array}$ & $\begin{array}{c}\text { mass } \\
\text { nutritional } \\
\text { component }\end{array}$ & $\begin{array}{l}\text { mass; mole; vol. } \\
\text { pure substance }\end{array}$ & $\begin{array}{c}\text { mass } \\
\text { pure substance }\end{array}$ \\
\hline Other & $\mathrm{P}, \mathrm{T}$ & & $P, T$, extracellular \\
\hline Heat and Work Streams & not separate & separate & not separate \\
\hline $\begin{array}{l}\text { Output: } \\
\text { Tables } \\
\text { Plots }\end{array}$ & $\begin{array}{c}\text { extensive } \\
\text { equipment specs } \\
\text { no } \\
\end{array}$ & $\begin{array}{c}\text { extensive } \\
\text { yes }\end{array}$ & $\begin{array}{l}\text { extensive } \\
\text { limited }\end{array}$ \\
\hline $\begin{array}{l}\text { Thermal/Physical } \\
\text { Properties: } \\
\text { Data Banks } \\
\text { User Defined } \\
\text { Models }\end{array}$ & $\begin{array}{c}\text { selected items } \\
\text { selected questions } \\
\text { limited } \\
\end{array}$ & $\begin{array}{c}\text { ASPEN SET (400+) } \\
\text { In-House } \\
\text { User-Defined } \\
44 \text { option set } \\
\end{array}$ & $\begin{array}{c}\text { selected items } \\
\text { limited options } \\
? \\
\end{array}$ \\
\hline $\begin{array}{l}\text { Program General: } \\
\text { Units Operations } \\
\text { User-defined Unit } \\
\text { Operations } \\
\text { Convergence } \\
\text { Optimization } \\
\text { Economics } \\
\end{array}$ & $\begin{array}{c}\text { see list } \\
\text { no } \\
\text { yes } \\
\text { cost } \\
5 \text { options } \\
\end{array}$ & $\begin{array}{c}\text { see list } \\
\text { yes } \\
\text { variety of algorithms } \\
\text { any variable } \\
?\end{array}$ & $\begin{array}{c}\text { see list } \\
\text { no } \\
\text { Bounded Wegstein } \\
\text { none } \\
\text { yes, options? } \\
\end{array}$ \\
\hline $\begin{array}{l}\text { Studies: } \\
\text { Sensitivity } \\
\text { Case } \\
\end{array}$ & $\begin{array}{l}\text { no } \\
\text { no }\end{array}$ & $\begin{array}{l}\text { yes } \\
\text { yes }\end{array}$ & $\begin{array}{l}\text { yes } \\
\text { no } \\
\end{array}$ \\
\hline $\begin{array}{l}\text { Help: } \\
\text { Unit Operations } \\
\text { Description } \\
\text { On-line } \\
\end{array}$ & $\begin{array}{l}\text { no } \\
\text { no }\end{array}$ & $\begin{array}{l}\text { yes } \\
\text { yes }\end{array}$ & $\begin{array}{c}\text { yes; editable } \\
\text { yes } \\
\end{array}$ \\
\hline $\begin{array}{l}\text { Error Detection: } \\
\text { Flow check } \\
\text { History file } \\
\end{array}$ & $\begin{array}{l}\text { no } \\
\text { no } \\
\end{array}$ & $\begin{array}{l}\text { yes } \\
\text { yes } \\
\end{array}$ & $\begin{array}{l}\text { yes } \\
\text { no }\end{array}$ \\
\hline
\end{tabular}


Table 2. Unit operation options included in each computer-aided design package.

\begin{tabular}{|c|c|c|}
\hline FOODS & ASPEN PLUS & BIOPRO \\
\hline Mixer & Mixer & \\
\hline $\begin{array}{l}\text { Splitters: } \\
\text { Flow }\end{array}$ & $\begin{array}{l}\text { Flow } \\
\text { Component (2) }\end{array}$ & $\begin{array}{l}\text { Flow } \\
\text { Component }\end{array}$ \\
\hline $\begin{array}{l}\text { Heat Exchangers: } \\
\text { Plate }\end{array}$ & $\begin{array}{l}\text { Heater/Cooler ( } 1 \text { side) } \\
\text { Co- \& Counter }(2 \text { side) } \\
\text { Multistream }\end{array}$ & $\begin{array}{l}\text { Plate and Frame } \\
\text { Spiral } \\
\text { Shell and Tube }\end{array}$ \\
\hline $\begin{array}{l}\text { Filters: } \\
\text { Ultrafiltration } \\
\text { Reverse Osmosis }\end{array}$ & & $\begin{array}{l}\text { Ultrafiltration } \\
\text { Reverse Osmosis } \\
\text { Membrane } \\
\text { Diafilter } \\
\text { Rotary Vacuum } \\
\text { Plate and Frame } \\
\text { Dead End } \\
\text { Air Filter } \\
\end{array}$ \\
\hline $\begin{array}{l}\text { Pumps \& Compressors: } \\
\text { Centrifugal } \\
\text { Positive Displacement } \\
\text { Mech. Vapor Recompression }\end{array}$ & $\begin{array}{l}\text { Pump/Hydraulic Turbine } \\
\text { Compressor/Turbine } \\
\text { Multistage } \\
\text { Compressor/Turbine } \\
\end{array}$ & $\begin{array}{l}\text { Centrifugal } \\
\text { Compressor - Centrifugal }\end{array}$ \\
\hline $\begin{array}{l}\text { Separations: } \\
\text { Absorber } \\
\text { Adsorber } \\
\text { Adsorption-Desorption } \\
\text { Distillation }\end{array}$ & $\begin{array}{l}\text { Absorber/Stripper } \\
\text { Short Cut Distillation } \\
\text { Short Cut Rating Dist. } \\
\text { S.C. for Complex Columns } \\
\text { Flash - single stage sep. } \\
\text { Rigorous Fractionation } \\
\end{array}$ & $\begin{array}{l}\text { Absorber \& Stripper } \\
\text { Short Cut Distillation }\end{array}$ \\
\hline Multiple Effect Evaporator & & Multiple Effect Evaporator \\
\hline $\begin{array}{l}\text { Dryers: } \\
\text { Spray Dryer }\end{array}$ & & $\begin{array}{l}\text { Flash Drum } \\
\text { Fluid Bed Dryer }\end{array}$ \\
\hline $\begin{array}{l}\text { Centrifuges: } \\
\text { Centrifuge }\end{array}$ & & \begin{tabular}{|l} 
Disk-Stack \\
Basket \\
Centrifuge Extractor
\end{tabular} \\
\hline
\end{tabular}


Table 2. (continued).

\begin{tabular}{|c|c|c|}
\hline FOODS & ASPEN PLUS & BIOPRO \\
\hline $\begin{array}{l}\text { Reactors: } \\
\text { Fermenter }\end{array}$ & $\begin{array}{l}\text { Continuous Stirred } \\
\text { Plug Flow } \\
\text { Batch } \\
\text { Stoichiometric } \\
\text { Yield } \\
\text { Equilibrium } \\
\end{array}$ & $\begin{array}{l}\text { Continuous Stirred } \\
\text { Well Mired } \\
\text { Air Lift } \\
\text { Plug Flow }\end{array}$ \\
\hline Crystallizer & & Crystallizer \\
\hline \multicolumn{3}{|l|}{$\begin{array}{l}\text { Crystallizer } \\
\text { Humidification }\end{array}$} \\
\hline \multicolumn{3}{|c|}{ Rectification-Condensation } \\
\hline Cell Disruptors: & & $\begin{array}{l}\text { High Pressure } \\
\text { Homogenization } \\
\text { Bead Mill } \\
\end{array}$ \\
\hline $\begin{array}{l}\text { Chromatography: } \\
\text { Ion Exchanger }\end{array}$ & & $\begin{array}{l}\text { Gel Filtration } \\
\text { Ion Exchanger } \\
\text { Affinity Chromatography }\end{array}$ \\
\hline Tanks: & & $\begin{array}{l}\text { Blending } \\
\text { Storage }(V, H) ; \text { Receiver } \\
\text { Decanter } \\
\end{array}$ \\
\hline Cyclones: & & $\begin{array}{l}\text { Cyclone } \\
\text { Hydrocyclone } \\
\end{array}$ \\
\hline
\end{tabular}




\section{Appendix A - enthc.f in Authorware}

--This subroutine calculates the enthalpies of a water, etoh, co2 system.

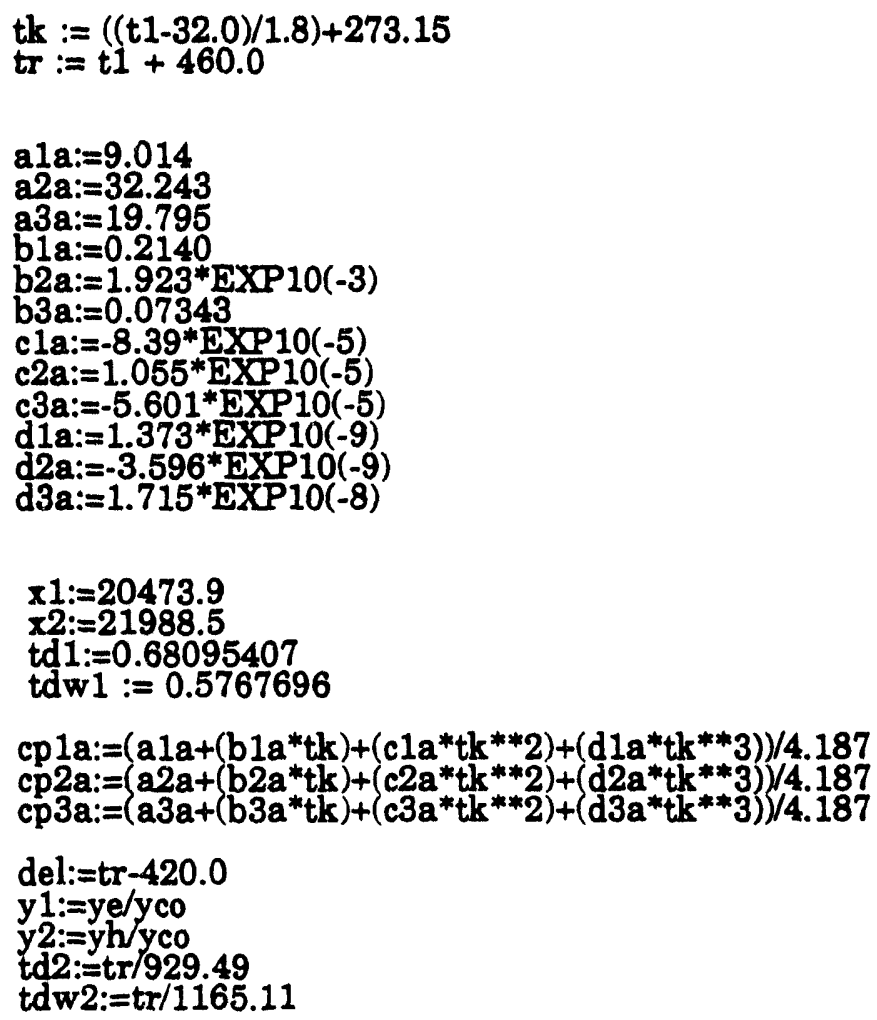

IF $\left(j=1, h 1:=\operatorname{cp} 3 a^{*} \operatorname{del}+\left(y 1 *\left(\operatorname{cp} 1 a^{*} \operatorname{del}+x 1\right)\right)+(y 2 *(\operatorname{cp} 2 a * \operatorname{del}+x 2))\right)$ IF ( $=1$, hvapla1: $=16668.099^{*}(((1.0$-td2)/(1.0-td1) **0.38))

IF $\left(j=1\right.$, hvap $\left.1 \mathrm{a} 2:=17481.465 *((1.0-\mathrm{tdw} 2) /(1.0-\mathrm{tdw} 1))^{* * 0.38)}\right)$

$\operatorname{IF}(j=2, h 2:=c p 3 a * \operatorname{del}+(y 1 *(c p 1 a * \operatorname{del}+x 1))+(y 2 *(c p 2 a * d e l+x 2)))$ IF $\mathrm{J}=2$, hvap2a1: $=16668.099^{*}(((1.0$-td2)/(1.0-td1) $* * 0.38))$ IF $\mathrm{J}=2$, hvap2a2 $\left.\left.:=17481.465 *((1.0-\mathrm{tdw} 2) /(1.0-\mathrm{tdw} 1))^{* *} 0.38\right)\right)$

IF $\left(j=3,1,3:=\operatorname{cp} 3 a^{*} \operatorname{del}+\left(y 1 *\left(\operatorname{cp} 1 a^{*} \operatorname{del}+x 1\right)\right)+(y 2 *(\operatorname{cp} 2 a * \operatorname{del}+x 2))\right)$ IF $\left(\mathrm{J}=3\right.$, hvap3a1: $=16668.099^{*}(((1.0$-td2)/(1.0-td1) $* * 0.38))$ IF $\mathrm{J}=3$, hvap $\left.\left.3 \mathrm{a}^{2}:=17481.465 *((1.0-\mathrm{tdw} 2) /(1.0-\mathrm{tdw} 1)) * 0.38\right)\right)$

IF $\left(j=4, h 4:=c p 3 a * d e l+(y 1 *(c p 1 a * d e l+x 1))+\left(y 2 *\left(c p 2 a^{*} d e l+x 2\right)\right)\right)$ IF $\mathrm{J}=4$, hvap4a1: $\left.=16668.099^{*}\left(((1.0-\mathrm{td2}) /(1.0 \text {-td1 }))^{* *} 0.38\right)\right)$ IF $\left(=4\right.$, hvap4a2: $=17481.465 *((1.0-t d w 2) /(1.0-t d w 1))^{* * 0.38))}$

IF $\left(j=5, h 5:=c p 3 a * \operatorname{del}+\left(y 1 *\left(c p 1 a^{*} \operatorname{del}+x 1\right)\right)+(y 2 *(c p 2 a * \operatorname{del}+x 2))\right)$ IF $(=5$, hvap5a1: $=16668.099 *(((1.0-\operatorname{td} 2) /(1.0-\operatorname{td} 1) * * 0.38))$ IF $\left(\mathrm{j}=5\right.$, hvap5a2: $=17481.465 *\left(((1.0-\mathrm{tdw}) /(1.0-\mathrm{tdw2}))^{* * 0.38))}\right.$

IF $\left(j=6, h 6:=c p 3 a * \operatorname{del}+\left(y 1 *\left(\operatorname{cp} 1 a^{*} \operatorname{del}+x 1\right)\right)+(y 2 *(\operatorname{cp} 2 a * \operatorname{del}+x 2))\right)$ IF $\left(\mathrm{l}=6\right.$, hvap6a1 $:=16668.099^{*}\left(\left((1.0\right.\right.$-td2 $\left.) /(1.0 \text {-td1) })^{* * 0.38)}\right)$ IF $(j=6, h$ vap6a2 $:=17481.465 *(((1.0-t d w 2) /(1.0-t d w 1) * * 0.38))$

IF $(\mathrm{j}=7, \mathrm{~h} 7:=\mathrm{cp} 3 \mathrm{a} *$ del $+(\mathrm{y} 1 *(\mathrm{cp} 1 \mathrm{a} *$ del $+\mathrm{x} 1))+(\mathrm{y} 2 *(\mathrm{cp} 2 \mathrm{a} *$ del $+\mathrm{x} 2)))$ IF $\mathrm{G}=7$, hvap7a1: $\left.=16668.099^{*}\left(((1.0-\mathrm{td} 2) /(1.0-\mathrm{td} 1))^{* * 0} 0.38\right)\right)$ IF $\mathrm{g}=7$, hvap7a2: $=17481.465 *\left(((1.0-\mathrm{tdw} 2) /(1.0-\mathrm{tdw} 1))^{* * 0.38))}\right.$

IF $\left(j=8, h 8:=c p 3 a * d e l+\left(y 1 *\left(\operatorname{cp} 1 a^{*} \operatorname{del}+x 1\right)\right)+(y 2 *(\operatorname{cp} 2 a * \operatorname{del}+x 2))\right)$ IF $(\mathrm{j}=8$, hvap8a1 $:=16668.099 *((1.0$-td2) $/(1.0$-td1) $) * 0.38))$

IF $\mathrm{J}=8$, hvap8a2: $=17481.465 *\left(((1.0-\mathrm{tdw}) /(1.0-\mathrm{tdw} 1))^{* * 0.38)}\right)$

IF $\left(j=9, h 9:=\operatorname{cp} 3 a^{*} \operatorname{del}+\left(y 1 *\left(\operatorname{cp} 1 a^{*} \operatorname{del}+x 1\right)\right)+(y 2 *(\operatorname{cp} 2 a * \operatorname{del}+x 2))\right)$ 


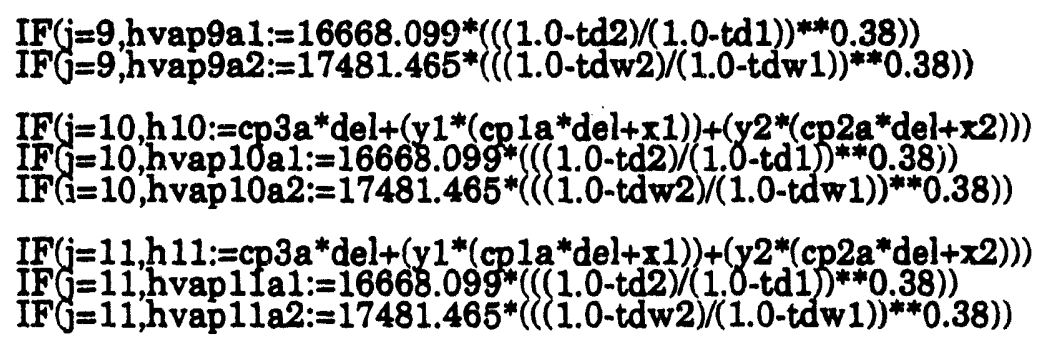




\section{Appendix A - enthc. in FORTRAN}

subroutine enthc(t1,ye, yco,yh, j, h, hvap)

c program to calculate the enthalpies of a water etoh co2 system

s. Havlik 7-26-88 updated: $7-27-88$

$\mathrm{t} 1=$ Deg. $\mathrm{F}$

yeth = ethanol vapor conc. molar

$\mathrm{yh}=$ water vapor conc. molar

yco $=$ co2 vapor conc. molar

$j=$ position

$h=$ vapor enthalpy

hvap = enthalpy of vaporization of liquid

implicit double precision (a-h, $0-\mathbf{z}$ )

dimension $\mathrm{a}(3), \mathrm{b}(3), \mathrm{c}(3), \mathrm{d}(3)$

dimension $h(11)$, hvap (11,2), $\mathrm{cp}(3)$

real t1,tk,tr

C

$t k=((t 1-32.0) / 1.8)+273.15$

$\mathrm{tr}=\mathrm{t} 1+460.0$

c write $(6,122)$ tk, tr,t1

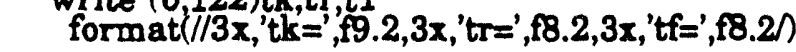

ethanol $=1$

water $=2$

$\mathrm{CO} 2=3$

constants for the heat capacity equations

$a(1)=9.014$

$\mathrm{a}(2)=32.243$

$\mathrm{a}(3)=19.795$

$\mathrm{b}(1)=.2140$

$\mathrm{b}(2)=1.923 \mathrm{e}-3$

$b(3)=.07343$

$c(1)=-8.39 \mathrm{e}-5$

$c(2)=1.055 \mathrm{e}-5$

$c(3)=-5.601 e-5$

$\mathrm{d}(1)=1.373 \mathrm{e}-9$

$d(2)=-3.596 e-9$

$\mathrm{d}(3)=1.715 \mathrm{e}-8$

c

$\mathrm{j}=$ position in condenser

$i=$ component number

determine the average heat capacity of each component at the vapor temperature do $110 \mathrm{i}=1,3$

$c p(i)=\left(a(i)+(b(i) * t k)+\left(c(i) * t k^{* * 2}\right)+\left(d(i) * t k^{* *} 3\right)\right) / 4.187$

110

continue

$x 1=20473.9$

$\times 2=21988.5$

c $\quad h=$ gas stream enthalpy component $j$

del $=\operatorname{tr}-420.0$

y $1=$ ye/yco

y $2=y h / y c 0$

$h(j)=\operatorname{cp}(3)^{*} \operatorname{del}+\left(y 1^{*}(\operatorname{cp}(1) * \operatorname{del}+x 1)\right)+\left(y 2 *\left(\operatorname{cp}(2)^{*} \operatorname{del}+x 2\right)\right)$

c output values for individual component enthalpies

td $1=.68095407$

$\operatorname{td} 2=\operatorname{tr} / 929.49$

$h \operatorname{vap}(j, 1)=16668.099 *\left(((1.0-\operatorname{td} 2) /(1.0-\operatorname{td} 1))^{* *} .38\right)$

tow $1=.5767696$

$\mathrm{tdw2}=\mathrm{tr} / 1165.11$

hvap $(j, 2)=17481.465^{*}\left(((1.0-t d w 2) /(1.0-t d w 1))^{* *} .38\right)$

return

end 


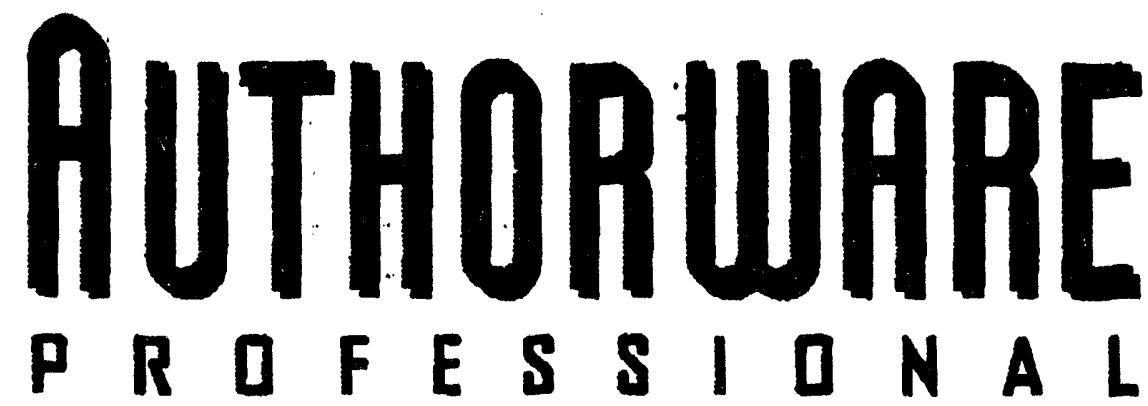

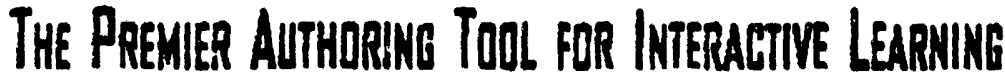

Authorware Professional is the premier multimadia authoring tool for interactive learning. Its objact-oriented interface gives non-programmers the power to create, deliver and maintain applications on either Macintosh or Windows platforms. Authorware's built-in intersctivity, data Teasurement functions and media integration controls bring powerful functionality to its aasyto-usá interface.

Five unique advantages make

Authorware Profusaional the standard cholce for intoracsive ieaming applications:

Dajett Authoring"

Allowe the usar to easily expariment with intaractive dosign rather then focusing solaly on modia content. An ologent and intuitivo iconic imerfoce controls the logic, making complax appllcations seav to author.

\section{MULTIPLATFORM ARCHITECTURE}

Makas Austionwere Proftessional the only authoring tool that supports nearly id entcal authoring anviron. ments on both the Mecintosh and Windows platforms.

Superian Destax

Provides authors of imterectivo loarning applleations with the brondest range of interactivity. Exronsive variables and functions provide the basis for collecting. storing and analyzing dera; and

buitt-in Computor Maneged

Instruction variables help

monsure users' performancs.

Mutimsoula Toats

Give authors the power to incorpopate tex, graphics, sounds, animation, and dlgltal video into highly offective imernetive leaming spplications.
Meoun Mavaben

Assists authors in afficiently managing media by storing the modia in libraries that are separate from the host application. This increases the productivity of the author and reduces the size of the application file.

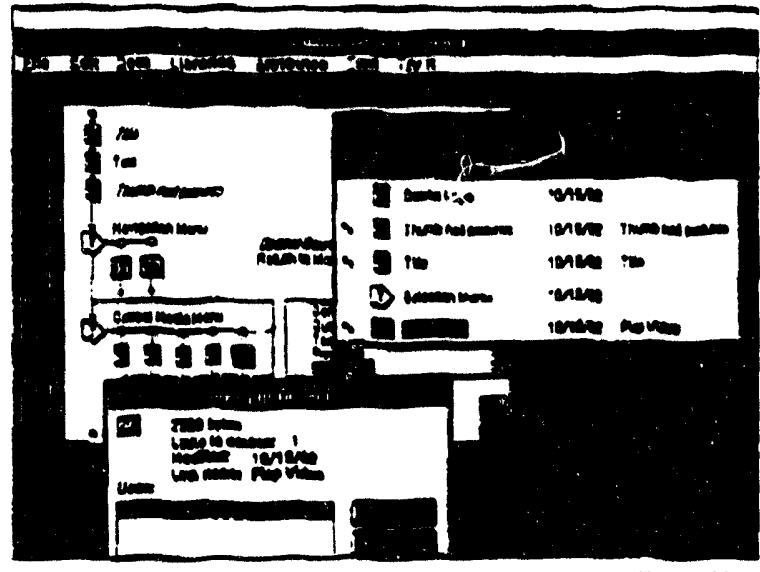

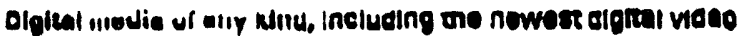
formex, can be stored in examel llbraries tor raforence in one or more applleatons 


\section{Key Features in Authorware Professional 2.I for Wimoows}

\section{Medlo Managor}

Uniqua to Authorwara, Medla Manager seres graphics, sounds, enimations, and other digital

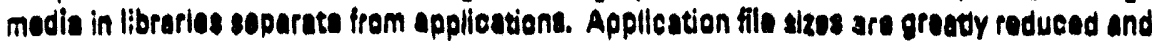
enanges in stored madia ara immediotaly roflocted in the applicationg-spoeding the authoring process significenty.

\section{Support for Macromodla Dirooror}

Lots users sfeste or repurpose groductient sfeatad with Mecromedia Director - the ofamiof

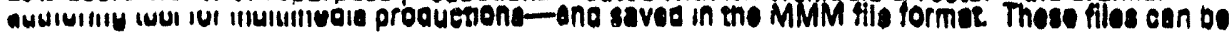
valled uliesuy via tise Movie icon.

\section{ClipModle and Examples}

Includes slip madia for animationa, gadgots, graphics, movies and sound. Contains comtentindepandent logic structures for filo operations, pull-down munus, noses, quentions, parformance

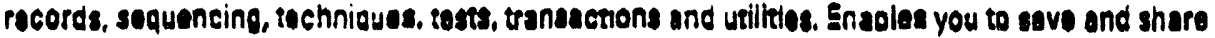
slio medie and custom icon modela. Modals are logic atructures that san bo peuted into an appll. cation, onabling you to ro-use previous work.

\section{Vartables and funotions}

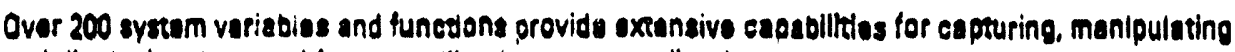
and dispinying dase, and for controlling now your application oporates.

\section{Automatic Documentation}

Annotared application index with of without icons. Print design and presententinn windowe. Cross-pafarence table of variables.

\section{Toxt:}

Mix fonts, solor, sizas, modes, and colors. Supports screlling text windows. Supports Windowe 3.1 Scroen fonts and TrueTypo fome. Standard intornetional cheractors.

\section{Grephice}

Stundare drawing tools. inelueting polygen, oval, ractangle. roundad rectangle. and lino are provisod within o familiar intartacs. Supports BMP, OIB, PCX, IIF, IPS, and RLE: Macintosh PICT and Paint and Windowe Motafile formats.

\section{Sound}

Control rapotition, star and stop. Impors PSM or WAV filos. Supports MIOI flles and CD.Augio through Microsotr's Multimodia Extensions, and imports sounds digizized with Mactomedia'c Machecordore Sound System Pro.

\section{Animation}

Control path, time, and apead, as woll as zars and and frames, plovbecx spaed, and repetition of movies. Multiple layering option controls which animated objecs overiaps another. Impors $\mathrm{FLI}$, FLC, CEL files. Playback Macremedie Director (MMM) filos.

\section{Digleal video}

Stll or motion video from one icon. Reskzeable, moveable video windowa. Playback of Microsoft Video fop Windowa, Apple QuickTima for Windowe and Indoo (DVI). Control seart and and treezeframes, playbeck spoed and rapretition of movies.

\section{Analog video}

Built-in video overiay suppor. Control start, ond and fraezo frames, playonek apeod and repottion of movies. Suppons two audio channols soparate from video channal.

\section{Extonaible environment}

Extenalblo through calls to OLLs and UCDe. Jump to and ioturn from omer applieations or files to

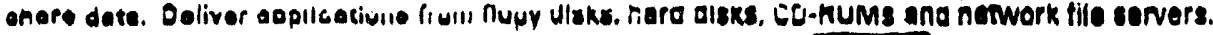
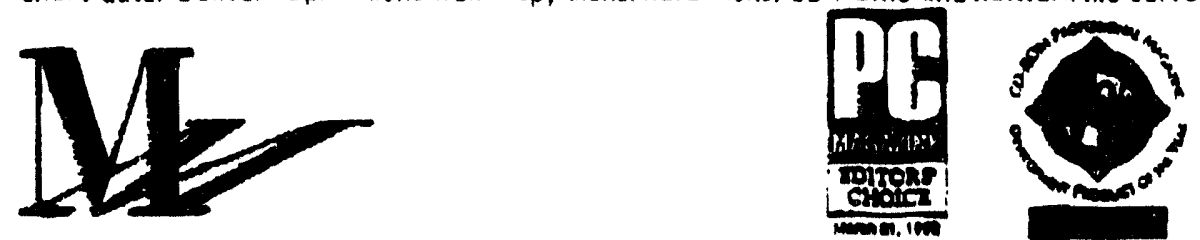

MUCROMEDLA

\section{file Formats}

Graphics: Supports BMP, DIB, PCX, TIF, EPS, RLE, Macintosh PICT \& Paint, Windows Metafiles

Sound: Imports PCM or WAV. MIDI and CD-Audlo supported through Microsott's Multimadia Extensions. Imports SoundEd Pro sound files.

Animotinat Impono FLI, rLe, CEL and Direeter MMM files.

Digital Vid oo: Playbaek for Video for Windows, QuickTime for Windows, and Indoo OVI.

\section{SYSTEM REQUIREMENTS}

IBM PS/2 and Uttimodie machines ano 80288, 388, and 486 processors running DOS 3.3 and Windowe 3.0 or latar.

Authoring minimum: $20 \mathrm{MHz} 386$ with 4M AAM, 18-colJr VGA, 40Mb hara disk, and mouse. Recommendod: $33+$ MHz 388 witi BMb AAM, 18-color VGA 1285-color with VGA+ card). Delivery minimum: $20 \mathrm{Mltz}$ 386 with 4Mb RAM, 18-color VEA, 20MB hard diak, and a mouse.

\section{Oroering information}

For the name of a Macromedia authorized reseller in your aras, call 1-800-288-4797. Informetion on Mecromodie training, developer and priority technical support services, is alao available.

For the name of an authorizad resellei outside of North Amarica, call the following Macromedia rogional sales offices:

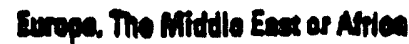

Macromedia Europo

Tol: (44) 344-78-1111 Fax: (44) 344-76-1149

\section{Jepen or Latin Amerted}

Mecromodie

Tal: (418) 252-2000 Fax (415) 626.0534

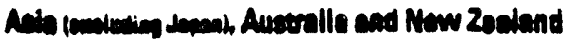
Macromedia Pacific

Tol: (81) 2.906-3283 Fax: (81) 2.908-6324

Pless Maseremedta, Ine. Authorwere Proteccional and

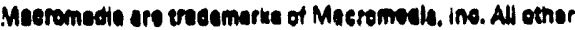

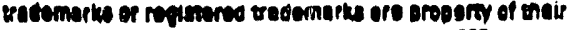

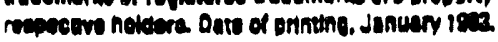




\section{PAopuct Gatenoniss: Authoring Toois, Multimedia, Windows}

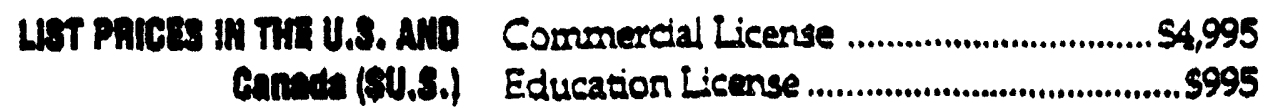

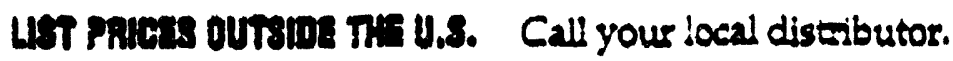
An andena

Gument Yeratam Authorware Professional for Windowg, Version 2.0

$$
\text { AvanuanTr: January, } 3993
$$

Upequass an min U.3. Ald Reglatered users of APW 1.1 can upgrade to APW 2.0 CaMana (EN.8.) for 5693. Education users of APW 1.1 can upgrade to APW 2.0 for 5395. Registered users of APW 1.0 or earlier can upgrade to APW 2.0 for 5995 . Education users of APW 1.0 or enrlies an upgrade to APW 2.0 for $\$ 495$.

Call 1-800-945-4061.

UPenunss orrere The U.s. Call your local distributos. An connan

SYSTEM REQuphemants: IBM PS/2 and Ultieredia machines and 80286, 386 and 486 processors running DOS 3.3 and Windows 3.0 or later.

Authoting mininum: $20 \mathrm{MR} 2386$ with $4 \mathrm{MBB}$ RAM, 16-color VGA, 40MB hard disk, and a mouse. Recommended 33 MH2 386 with 8MB RAM, 16color VGA (263-color with VGAt card)

Dellvery minimum: 20MIiz 386 with 4MB RAM, 16-color VGA, 20 MB hard diak, and a mouse. 


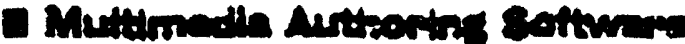

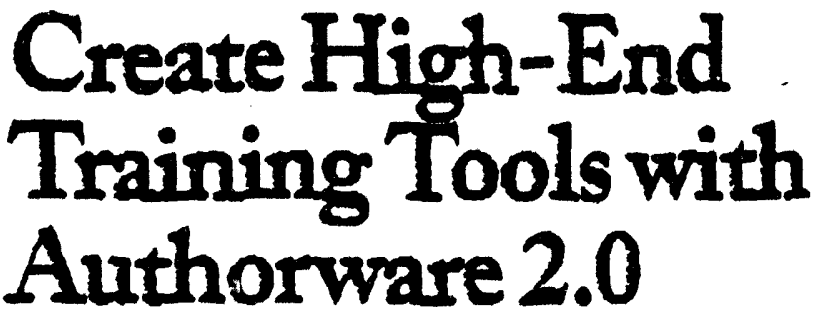

\section{ST nipho reor}

Whet we selested Authorwn Protessenci tor Wiadows. Varnios 1.0. As tho Editors' Choice ia ous Mares 31.1992. evaintion of muleimedis antwering cottwert. we poised out its iadustral -streagth los. ore sel ase said that mastorag the grogram would iaise a siz. sbie isrestuent of ttome asd effort. Vormos 2.0 des ovea more tearures, sus tortunately. the pasxage has become a bit comer so leare and ues.

Auscorware is a bigh-eed.

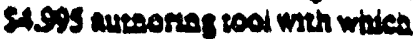

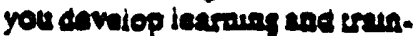
ing uppientiona using Whadom murreadis fearures (ineludios

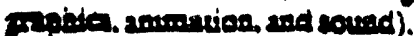
If hus boes uend to create ewry. thiag tron K.12 math and read. ing prograns to iratatne pro. grame for MeDonald's om. ployees to trunses simulations for girline seourity pernonsel.

\section{4t:}

This Windows propmen sulim on a vour slowethar molaphor for onam sppitenuom. There are

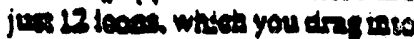

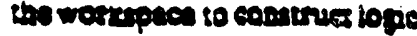
cernerming

After intortias an icen into

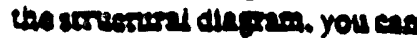
cotit it arserberee The prop cleo isedudes drawias soala 10 you sas Ereate or unsornte an imge (SMP. DL . BPS. PCX. PICT. 2LF and WMA sorman aro sceupred). You cas siso daflac the solors tor objecen ine apecial effeess used to make chose appose (aad disappens). and evea their dippley rodes. which deperrase wan portoes of brekpersed will show tarough
Joous tor breaching ather as a reault of calsulations. uner inpue or jut radora selection. are artilabla. A calcunneron icon san to und to trinet unes seores. brom evesta or une any one of

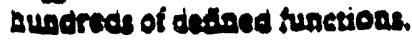
A "was". leas cas be used to paus sbe apelleation ustil the uece responcs of unsul a carsais amount of thm has elapue.

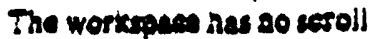
bars, 20 if your logic struesure sets 100 bis. if won's llt on. sereen. This oaly exsourages you to use the Aushorware "map" jeons, whiea serve so pises bolden for a collection of lecas Ints focturs is somowhas savlosous io subroutine in propremming. When you dou.

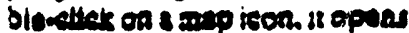
asochor wotkepaes whare you can edit its cemponeats. Map

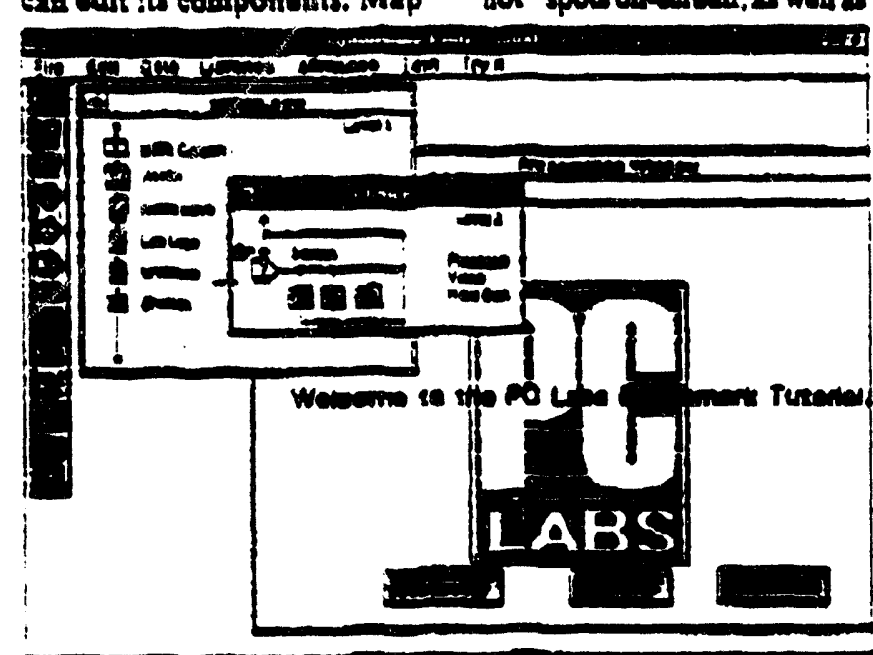

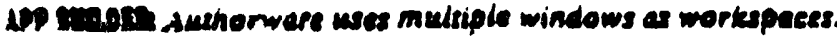

icom eas be ached. 50 you oun ceep your applination sepments senell and mann mble

Ro procras also hes jeons cop Dempinum frowion iselud. ing ceund antmend ooving and Varriea 2.0 adds atupors lop Meresedis Diswer siles in the MMM bormen It alno adda sup. pon for Microsolt Video for Whadow and Quiek Jime for Wradows (.MOV) files. Trese last two lorman gre secess to rull-mover. dixitend video imsers for youp applientioas. Dos proform suppers stere-andstop tranch. as wall as piavback nes. Taen ape ales fonures the suppor uxterend video playbonk dovieas such as iner dictse.

Aurborware sow includes more sophintiented text-han. dilng and lareseretive-seaponse centures. Is Verrioa 1.0. you could get uex rempenes ensough itcons tuen as punt burtoss and treform tess enwere. Verion 2.0 adds sophistiented optioss can inelude ineguinety shaped "bot" spore conerme, as wall y

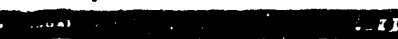

a series of sywaten rertablen tor

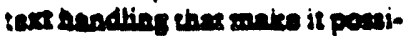
bo to erence byperex lines

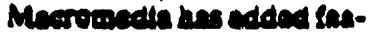
nure to Verven 20 enst enen it sanier to creste and mangets

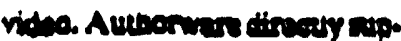
ports boll .PCM and .WAV cond-Els formate sed bus ane

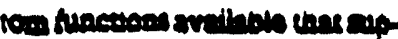

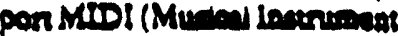
Diten lacuthes) ble and audio Co throupt the Wiadom MC

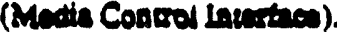

The procten supports a lane aumber of movis ale tor. muth iacludins Autodsek AniEneror, FLC. FLL, and .CLI. 20 nemeneprense is. in

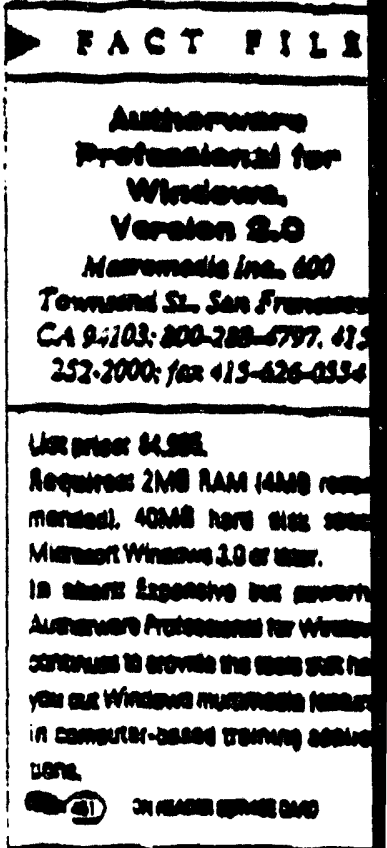

compies projoces. For arnor you eas predefian ieca tibrers? and that anan you eas and colleetios of atres-und ite? such as a display isea for yo eorrpasy's loso or a map is thes pariorms a vem log-oes

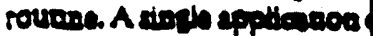
extl on alementes trom wore 4 one librery. which ens red devetopeneat tine.

Thase ars ovea asw fart bat dovalopas eas un to zo.

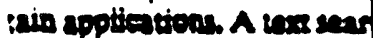
and-ropines fanurs on quie

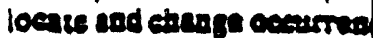

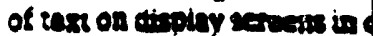
stop-a big tomenver.

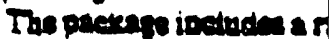
time versuen of the propr The standard lieanes pera

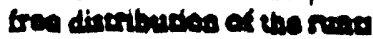
aikner witht the couparys pureheses the foll pectery ouraide. as long as the appij cos is dinortemed tor.

Texich the pive of Vea

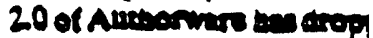
conaidarably (to su.ses a 58.000). it's still sot enoor does indleasel bownwes, thes pro rem init wellod - Pros jional" for aothine. Il yor loortas to areate birh-10= compunarband tretrines on

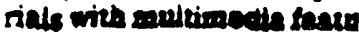

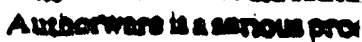
bas gees the job dowe 

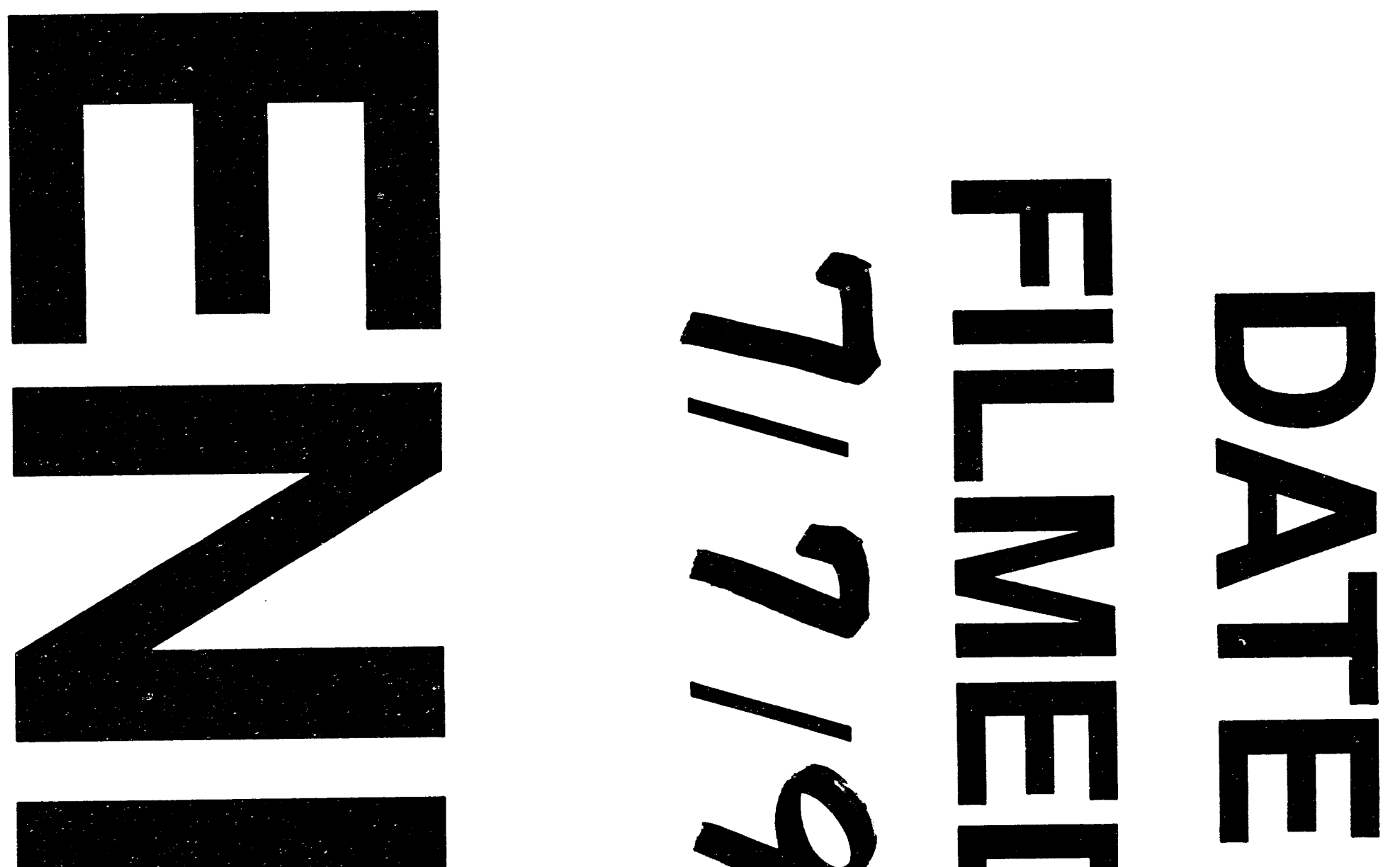

1
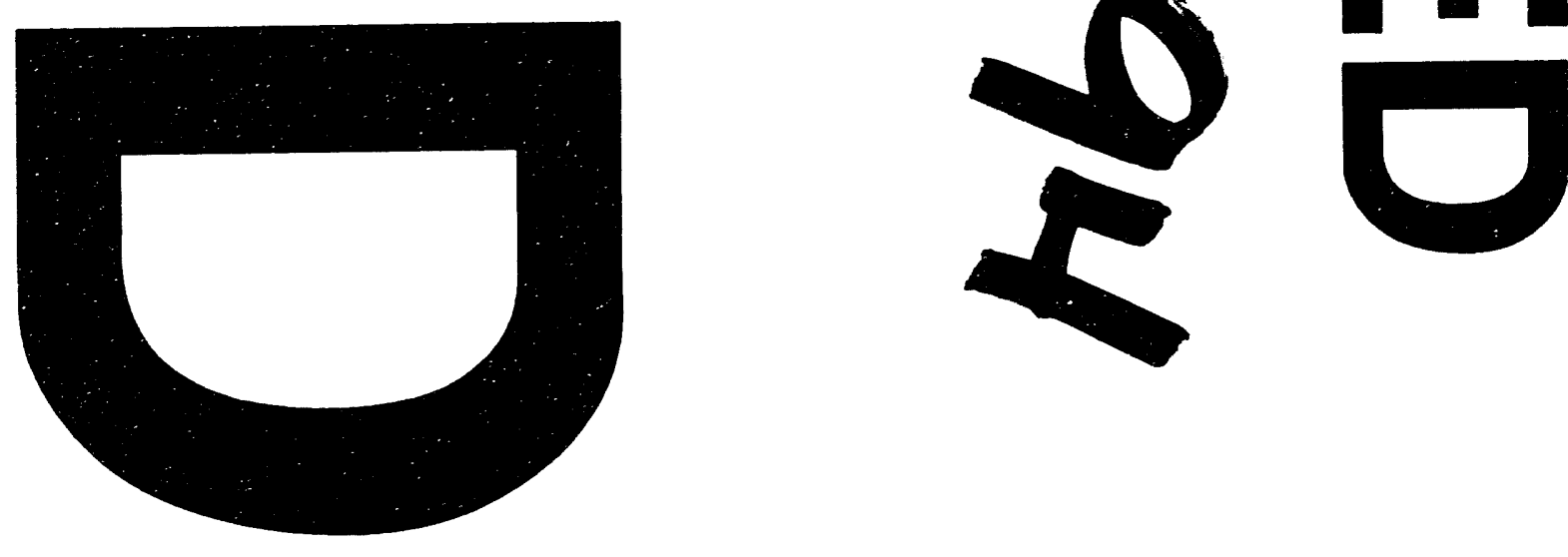


$$
\text { س.m. }
$$

